\title{
THE POLITICAL ATTITUDES OF DIVIDED EUROPEAN CITIZENS
} PUBLIC OPINION AND SOCIAL INEQUALITIES IN COMPARATIVE AND RELATIONAL PERSPECTIVE

Christian Lahusen 


\section{The Political Attitudes of Divided European Citizens}

This book unveils the significant impact of the European integration process on the political thinking of European citizens. With close attention to the interrelation between social and political divisions, it shows that an integrated Europe promotes consensus but also propagates growing dissent among its citizens, with both objective inequalities and the subjective perception of these inequalities fuelling political dissent. Based on original data sets developed from two EU-funded projects across eight and nine European countries, the volume demonstrates the important role played by the social structure of European social space in conditioning political attitudes and preferences. It shows, in particular, that Europeans are highly sensitive to unequal living conditions between European countries, thus affecting their political support of national politics and the European Union. As such, it will appeal to scholars of sociology and politics with interests in Europe and the European Union, European integration and political sociology.

Christian Lahusen is Professor of Sociology at the University of Siegen, Germany. His research interests include the sociology of European societies and European integration, social problems and social exclusion, social theory, political sociology, in particular movements, political conflicts and transformations of the state. 


\title{
Routledge Studies in Political Sociology
}

\section{Performance Action}

The Politics of Art Activism

Paula Serafini

\author{
Agonistic Articulations in the 'Creative' City \\ On New Actors and Activism in Berlin's Cultural Politics \\ Friederike Landau
}

\section{Talking Collective Action}

A Sequential Analysis of Strategic Planning in Anti-Nuclear Groups

Ole Pütz

\section{Brains, Media and Politics}

Generating Neoliberal Subjects

Rodolfo Leyva

\section{The New Demagogues}

Religion, Masculinity and the Populist Epoch

Joshua Roose

\section{The Political Attitudes of Divided European Citizens}

Public Opinion and Social Inequalities in Comparative and Relational Perspective Christian Lahusen

For a full list of titles in this series, please visit: https://www.routledge.com/ sociology/series/RSPS 


\section{The Political Attitudes of Divided European Citizens}

Public Opinion and Social Inequalities in Comparative and Relational Perspective

\section{Christian Lahusen}


First published 2021

by Routledge

2 Park Square, Milton Park, Abingdon, Oxon OX14 4RN

and by Routledge

52 Vanderbilt Avenue, New York, NY 10017

Routledge is an imprint of the Taylor \& Francis Group, an informa business

(C) 2021 Christian Lahusen

The right of Christian Lahusen to be identified as author of this work has been asserted by him in accordance with sections 77 and 78 of the Copyright, Designs and Patents Act 1988.

The Open Access version of this book, available at www.taylorfrancis.com, has been made available under a Creative Commons Attribution-Non Commercial-No Derivatives 4.0 license.

This book draws upon material originally published in German in Das gespaltene Europa: Eine politische Soziologie der Europäischen Union, Campus Verlag, 2019. Translated and published with permission.

Trademark notice: Product or corporate names may be trademarks or registered trademarks, and are used only for identification and explanation without intent to infringe.

British Library Cataloguing-in-Publication Data

A catalogue record for this book is available from the British Library

Library of Congress Cataloging-in-Publication Data

Names: Lahusen, Christian, author.

Title: The political attitudes of divided European citizens: public opinion and social inequalities in comparative and relational perspective / Christian Lahusen.

Description: 1 Edition. | New York: Routledge, 2020. |

Series: Routledge studies in political sociology | Includes

bibliographical references and index.

Identifiers: LCCN 2020032296 (print) | LCCN 2020032297 (ebook)

ISBN 9780367495671 (hardback) | ISBN 9781003046653 (ebook)

Subjects: LCSH: Public opinion-European Union countries. | Social stratification-European Union countries. | Political sociology-European Union countries.

Classification: LCC HM1236 .L34 2020 (print) | LCC HM1236 (ebook) |

DDC 306.2094-dc23

LC record available at https://lccn.loc.gov/2020032296

LC ebook record available at https://lccn.loc.gov/2020032297

ISBN: 9780367495671 (hbk)

ISBN: 9781003046653 (ebk)

Typeset in Times New Roman

by Deanta Global Publishing Services, Chennai, India 


\section{Contents}

1 Introduction 1

2 Towards a political sociology of Europe:

Theoretical localisations

3 Constructing a social space in troubled times:

Public spheres and cross-border debates

4 A European compass: Citizens' perceptions of European living conditions

5 Social divisions and perceptions of national politics:

The hidden European compass

6 Social divisions and perceptions of the European Union:

Local and European landmarks

7 The political (dis)integration of Europe 



\section{Introduction}

The European integration process introduced many changes that were intended to bring peace, prosperity and freedom of movement to a growing number of member states and their inhabitants. The Schengen Agreement led to the abolition of border controls, the internal market stimulated the trade of goods within Europe and the single currency unified and simplified capital and payments for businesses and individuals, both within and between countries. Touted as blessings of the European Union, these changes have increasingly become the subject of massive public criticism in the wake of the European economic and financial crisis and the high level of flight migration in the course of the 2010s. The Schengen Area is blamed for problems of uncontrolled immigration and public security, the internal market and the euro for cut-throat competition at the expense of weaker economies, for rising national debt and for reforms leading to social cutbacks. Now more than ever there is a dispute about the future shape of the EU because parties and groups critical of Europe are mobilising very successfully against the EU and against pro-European governments in the various member states.

This book is devoted to an analysis of this increased contentiousness. It wishes to add insights to the debate about the constant "politicisation" of the European citizenry (Hooghe and Marks 2009; de Wilde and Zürn 2012; Kriesi 2016b). Its main aim is to engage in a systematic analysis of the relationship between social inequalities and political attitudes, making use of datasets from 2015 to 2016 that mirror the aftermath of the economic and financial crisis. The objective is to take European integration seriously by highlighting that this process is not only affecting the political opinions citizens have about the European Union but also the way they perceive and assess the social and political reality in their own country. The focus is on social inequalities within and between countries, which are known to be a driver of political contentions about the EU, but also about national politics. In fact, research has already provided insights into the gradual politicisation of the EU, which nurtures political cleavages between pro-Europeans and a growing share of Eurosceptics (e.g., Krouwel and Abts 2007; Lubbers and Scheepers 2005; Treib 2014; Hernández and Kriesi 2016; Baute, Abts and Meuleman 2019). Many studies have shown, in particular, that social inequalities both within and between countries matter when understanding pro-European and Eurosceptic attitudes (e.g., Kuhn, van Elsas, Hakhverdian and van der Brug 2016; Ritzen, 


\section{Introduction}

Wehner and Zimmermann 2016; Kriesi and Pappas 2015; Dotti Sani and Magistro 2016; Schaff 2019; Lauterbach and de Vries 2020). Additionally, scholars tend to converge in the conviction that the various crises and the growing divisions between privileged and non-privileged countries and citizens are contributing to the emergence of a new political cleavage that runs across the EU's member states, even though this cleavage might not be the only one with which the EU is confronted (Kriesi 2016b; Hooghe and Marks 2018; Zeitlin, Nicoli and Laffan 2019). Findings, however, are incomplete and inconclusive and do not take into account the Europe-wide disparities and related perceptions among the citizenry that have a direct bearing on the degree of support for national government politics.

In the following chapters, I wish to provide a more systematic account of the effect of social inequalities on political attitudes towards the EU and its member states by addressing different dimensions of social inequalities. On the one hand, I wish to assess the relevance of "objective" social inequalities by dealing with both social stratifications and spatial disparities. This differentiation is necessary to better understand political divisions within the European citizenry because political attitudes can often differ among citizens with diverging social backgrounds (e.g., in terms of education, income, occupational status or social class affiliation) and thus along different positions within the hierarchical system of social stratification. At the same time, they could also be influenced by the socio-economic situation of the country and region they live in, given that citizens live in a more or less favourable social context (Lubbers and Scheepers 2005; Schraff 2019; Lauterbach and de Vries 2020). On the other hand, I will focus on the "subjective" dimension of social inequalities because research has convincingly demonstrated that political attitudes are also determined by the way citizens perceive social inequalities (Mause and Schlipphak 2016; Ritzen et al. 2016; Simpson 2019). In this regard, it will be necessary to differentiate between the perceptions of the citizens' own household situations and their stratificational position. It is to be expected that citizens who see themselves in an inferior position might be less satisfied with the current political situation. At the same time, however, we also have to deal with the subjective perception of spatial disparities. In this regard, it is very likely that citizens who perceive unequal living conditions between European countries, and who see themselves worse off when compared to other Europeans, will be more critical of the social and political conditions they live in.

The analyses follow the assumption that the European integration process should have influenced the political attitudes of European citizens by forming and consolidating a shared social and political reality for the European population. Following a sociological approach indebted to the analysis of social spaces and fields (Bourdieu 1985; 1996; 1998), it seems plausible to assume that the political attitudes of European citizens not only reflect their personal situation within a nationally contained system of inequalities but also their position within the larger European social space in its objective and subjective dimensions. In regard to the objective dimension, I will demonstrate that social inequalities affect supportive and critical attitudes toward national and European politics across countries in a similar way and that the relations of inequality between less and more 
privileged social strata do translate into a political cleavage between supporters and opponents of the EU. Irrespective of persistent national divisions, crossnational cleavages seem to be a relevant driving force in public opinion-shaping. In terms of subjective inequalities, I will show that European citizens assess living conditions (both their own and the ones in other countries) within a shared European frame of reference. "Europe" provides Europeans with a social map or compass that allows them to identify the position various peoples occupy in Europe, as well as their own specific reference point within the larger framework. These cognitive maps have significant effects on political attitudes, particularly in the way Europeans perceive and assess national politics and the extent to which they support the EU.

The findings of this book aim to contribute to a research debate within the social sciences that stresses the specificity of the European Union as a multilevel governance system within a multiscalar social space. The European Union consists of supranational, national and sub-national institutions and arenas of policymaking, and this multilevel structure is mirrored in the individual opinions and political attitudes European citizens hold. Surveys accurately testify that citizens have opinions about political institutions, policies and politicians at the local, national and European level. Yet more revealing is the fact that these attitudes are mutually interrelated. European citizens, for instance, perceive and assess the EU very often from their own country's perspective (Hobolt and de Vries 2016; Ares, Ceka and Kriesi 2017). The support of the EU depends, for instance, on levels of national prosperity and the evaluation of this prosperity (e.g., Rohrschneider and Loveless 2010; Ritzen et al. 2016), as well as on how citizens evaluate the institutional performance of national governments (e.g., Sánchez-Cuenca 2000; Kritzinger 2003; Boomgaarden, Schuck, Elenbaas and de Vreese 2011; de Vries 2018).

This book seeks to give insight into this relational perspective by introducing a sociological element to it that focuses more systematically on unequal living conditions and perceptions of inequality across Europe. Moreover, while research has tended to centre on the importance of national proxies, yardsticks, cues or benchmarks to form and voice political opinions about the EU (Anderson 1998; Muñoz, Torcal and Bonet 2011; Armingeon and Ceka 2014; Guinjoan and Rico 2018), I wish to highlight that the inverse effect is very likely, given that citizens are apt to apply a European yardstick when assessing national politics. In relational terms, the analysis is not only devoted to examining whether pro-European and Eurosceptic attitudes reflect the respondents' specific living conditions and the way they perceive their social position within a system of social stratification, it will also focus on whether political attitudes towards the nation state mirror the respondents' perceptions of social inequalities, in particular, unequal living conditions across Europe. In this sense, we might expect that the perception of social conditions in a country and the degree of public support of national governments depends on how citizens perceive and assess European living conditions and whether they develop a sense of relative deprivation. 


\section{The (partial) relevance of the European Union as opinion shaper: available knowledge}

Research has provided ample evidence of the fact that European integration is fuelling the contentiousness of European and national politics. Particular emphasis has been placed on the growing contentiousness of European and national politics. Particular emphasis has been placed on the constant "politicisation" of European integration and the EU itself (Hooghe and Marks 2009; de Wilde and Zürn 2012; Kriesi 2016b). The EU is being politicised because of diverging national interests and growing public concerns about threats to national cultures and identities (Fligstein, Polyakova and Sandholtz 2012; Kuhn and Stoeckel 2014; Hutter and Grande 2014; Hobolt and de Vries 2016; Otjes and Katsanidou 2017). The contentiousness is also attributed to an expanding social cleavage that confronts the winners and losers of societal developments that are believed to be rooted in the European integration process and/or globalisation. In particular, the Great Recession has deepened these cleavages, thus fuelling populist sentiment and in part the rise of anti-European groups and parties (Kriesi and Pappas 2015; Hutter 2014; Kriesi 2016b; Treib 2020). The dividing line has also been drawn between the privileged and non-privileged, between the elites and the socially disadvantaged population groups (Hooghe 2003; Fligstein 2008; Haller 2008).

The strengthening of Eurosceptic positions is also viewed against this backdrop (Kriesi, Grande, Lachat, Dolezal, Bornschier and Frey 2006; Kuhn et al. 2016). Analyses show that these populist views do not necessarily need to mirror objective vulnerabilities and economic hardships, but very often imply perceptions and feelings of deprivation and exposure to collective grievances (Rico and Anduiza 2016; Ritzen et al. 2016). Euroscepticism is becoming increasingly populist and thus takes on an anti-elitist orientation that merges two lines of conflict. The populist mobilisation against the political establishment is also increasingly becoming a Europe-critical mobilisation against Brussels' rule (Stockemer and Barisione 2016).

These research findings sensitise us to the fact that the politicisation of the EU is driven by societal developments that increase inequalities and cleavages and thus lead citizens to voice pro-European or Eurosceptic opinions that largely mirror social privileges and vulnerabilities. This argument is qualified, however, by references to the national "filter" that seems to mediate the political attitudes citizens have towards the European Union. Assuming that citizens might have less knowledge about the EU and might feel less comfortable in developing sound judgements, they seem to use national politics as a proxy, yardstick or benchmark for the formation of EU-related opinions (Anderson 1998; Kritzinger 2003; de Vries 2018). Additionally, it has been shown that citizens tend to "queue" behind national elites in their support or criticism of the EU when public debates are controversial (Hooghe and Marks 2005; Ares, Ceka and Kriesi 2017) and when right-wing populist parties influence public perceptions (Armingeon and Ceka 2014; Kuhn and Stoeckel 2014). Furthermore, public opinion within the various member states affects political attitudes towards the EU, thus hinting at the 
important mediating role of the mass media in the formation of individual perceptions and assessments (de Vreese and Boomgaarden 2006; Maier and Rittberger 2008; Conti and Memoli 2017). Finally, support for the European Union is also mediated by the strength of European and/or national identities (Fligstein 2008; Fligstein et al. 2012; Kuhn and Stoeckel 2014).

Overall, there is large consensus about the fact that European citizens perceive and assess the EU through the lens of their countries and their specific socio-economic, political and cultural reality. Citizens' support of the EU seems to depend, for instance, on how they evaluate the economic performance of their country (van Erkel and van der Meer 2016; Rohrschneider and Loveless 2010; Ritzen et al. 2016) and the political performance of their governments (e.g., Hobolt and de Vries 2016; Sánchez-Cuenca 2000; Desmet, van Spanje and de Vreese 2012). Trust in political institutions, to add a further example, is also strongly interrelated when comparing national and European levels, given that citizens tend to use national institutions as a yardstick to develop more or less confidence in European institutions (Muñoz et al. 2011; Armingeon and Ceka 2014). Finally, support for the EU also mirrors the extent by which citizens perceive the EU, the euro or the European market as a threat to their national economy or cultural identity (Kuhn and Stoeckel 2014; Braun and Tausendpfund 2014; Fligstein et al. 2012).

In sum, there is strong agreement about the priority of the national over the European, and the prevalence of national proxies, benchmarks or cues (Anderson 1998; Desmet et al. 2012; Hooghe and Marks 2005; de Vries 2018). In the formation of public opinions about the EU, the national level seems to be the first frame of reference, and political institutions are primarily conceived of as second-order institutions. This conclusion is echoed by research that deals with other areas of study. We find similar references to the importance of the "national" in studies examining the participation of the population in the European elections (Reiff and Schmitt 1980: Hix and Marsh 2007; Hobolt and Wittrock 2011; Boomgaarden, Johann and Kritzinger 2016) and the participation of the population in protests oriented towards European policy (Imig and Tarrow 2001; della Porta and Mattoni 2014). It is present in studies analysing the field of civic organisations and volunteer organisations (Ruzza and Bozzini 2008; Kohler-Koch and Quittkat 2013; Sanchez Salgado 2017), in research about public debates and mass media coverage of European issues (Boomgaarden et al. 2013; Statham and Trenz 2013; Caiani and Guerra 2017; Galpin and Trenz 2019; Adam et al. 2019) and scholarly writing on European feelings of belonging (Green 2000; Fligstein 2008; Risse 2010; Fuchs and Klingemann 2011).

These findings are puzzling if we consider the considerable impact of the EU on national politics. Social science research has provided ample evidence that the EU is a politically relevant community in legal, political and administrative terms, but findings suggest that the EU is not an active opinion former on its own that influences and moulds political attitudes down to the level of the citizen. From a legal point of view, it is known that the European treaties have become a constitutive reference point for national legal systems, that the total number of legal texts (laws, regulations and directives, decrees, etc.) has created a dense regulatory 


\section{Introduction}

carpet in a variety of policy domains and that the case law of the European Courts influences legal reality in the member states (Burley and Mattli 1993; Münch 2008; Augenstein 2012). From a political point of view, it is known that a large proportion of the legislative projects in national ministries and parliaments is based on European initiatives or decisions and that European negotiation and discussion forums also shape the decision-making process in the member states with regard to the ideas discussed during the identification and evaluation of the problems at hand and the proposed solutions (Kohler-Koch 2003; Featherstone and Radaelli 2003; Knill and Lehmkuhl 2002). From an administrative point of view, it is known that the EU invests a great deal of energy in the establishment of European administrative agencies, staff and networks, and supports administrative cooperation by promoting corresponding measures (exchange of experience, training programmes, mutual administrative assistance, etc.) and the establishment of cross-border procedures, databases and communication platforms to adapt and harmonise local administrative practice across countries (Siedentopf and Speer 2003; Hofmann 2008). Finally, it is known that interest groups and protest groups have become pan-European in most subject areas, joining associations, networks and platforms active in Brussels, forming lobbying alliances or organising transnational information and protest campaigns (Balme and Chabanet 2008; Monforte 2014; della Porta 2015; Lahusen, Zschache and Kousis 2020).

Against this backdrop, it is highly probable that the EU will have influenced the political opinions and practices of European citizens, but scholars disagree about the extent by which this will occur. There is some evidence of European influences on national politics. Citizens might have national agendas in mind when participating in European elections (Reiff and Schmitt 1980; Heath, McLean, Taylor and Curtice 1999; Boomgaarden et al. 2016), but European agendas and representational questions influence electoral choices in their own right, too (Clark and Rohrschneider 2009; Hobolt and Wittrock 2011). Additionally, the institutional and political context of the EU has had an impact on voter turnout and party choice within member states (van der Eijk, Franklin and Marsh 1996), and European politics seem to shape citizens' voting decisions in national election campaigns, for instance by providing smaller, populist and Eurosceptic parties with contentious issues aimed at mobilising voters and coordinating electoral campaigning cross-nationally (Krouwel and Abts 2007; Kriesi and Pappas 2015; Hong 2015; Kneuer 2019). Also in regard to unconventional political participation, studies witness the establishment of a European field of civil society organisations and citizens' initiatives (della Porta and Caiani 2009; Kohler-Koch and Quittkat 2013). People might continue to be primarily active in their local and national environment (e.g., Imig and Tarrow 1999; Roose, Kanellopoulos and Sommer 2017) but the European field of organised civil society is enmeshing local activities into transnational waves of protest (Ruzza and Bozzini 2008; della Porta and Mattoni 2014; Lahusen, Kousis, Zschache and Loukakis 2018). Finally, while public discourses in the media might be segmented into different language areas, nation states and mass media systems (Gerhards 2001; Brüggemann and Schulz-Forberg 2009; Schulz-Forberg and Stråth 2010), this does not rule out 
pan-European debates. EU institutions and policies provide repeated occasions for public discussions in the various countries, and this alters public debates by either increasing their contentiousness or leading to complementary or interlocked discourses (Pfetsch, Adam and Berkel 2006; Lahusen 2009; Statham and Trenz 2013; Segesten and Bossetta 2019).

If we look at these observations as a whole, the EU's political relevance to the European population is probable, but not obvious. Research findings urge us to be cautious in not overemphasising the role of the EU. At the same time, however, studies encourage us not to overlook the potential influences of the European Union on citizens' opinions and views. European integration might be responsible for converging public agendas, concerns and ideas, but it might also fed public contentions and political conflicts (Eder and Giessen 2001; de Wilde and Zürn 2012; Heidenreich, Rice and Zimmermann 2015).

\section{Europe as a shared space of political experiences: the research agenda}

The analyses and reflections of this book build on this extensive knowledge and aim to advance evidence in two areas. On the one hand, social inequalities are known to be important determinants of political opinions about the EU, which means that closer inspection is warranted. As elicited above, "social inequalities" need to be disaggregated into their different components, the vertical and horizontal dimensions (social stratifications and spatial inequalities) and the objective and subjective dimensions (the socio-economic resources and individual perceptions and evaluations). Following a research agenda committed to a sociological framework of analysis, I aim to identify those inequalities and divisions within the European social space that impact on the political opinion citizens have about national and European politics. On the other hand, it is well known that political attitudes within Europe diverge considerably depending on which perspective citizens view the European Union. In this regard, it is well known that the European population perceives and assesses the EU through their national lenses, and this means that pro-European and Eurosceptic opinions often mirror national susceptibilities (e.g., citizens' satisfaction with economic and institutional performance, trust or distrust). However, more care needs to be given to the inverse perspective, namely to the question of whether Europeans also perceive and assess national politics through a European lens, in particular through the way citizens perceive and assess Europe in terms of social inequalities. Following the sociological research agenda proposed above, I am particularly interested in validating whether Europeans are aware of unequal living conditions across European member states and whether they perceive Europe as a clearly patterned space of social inequalities. Moreover, I will try to validate whether this European map fuels perceptions of potential deprivations that might impact on the way citizens perceive and judge political institutions and policies in their own country.

These research aims and assumptions require systematic examination and validation. For this purpose, the book is organised into different chapters that deal 


\section{Introduction}

with distinct conceptual and empirical tasks. In the second chapter, I will present a theoretical framework of analysis that is indebted to a field-theoretical approach (Bourdieu 1985; 1996; Cohen 2011; Georgakakis and Rowell 2013; Fligstein and McAdam 2012). This approach seems well equipped to unravel the potential interrelations between social inequalities in Europe (the social space) and political attitudes within the multilevel system of European governance (the political field). The advantage of a field-theoretical anchoring is that it makes it possible to conceptualise "Europe" as a field of power in which not only governments, parties or associations, but also its people, with their specific social and political positions, are involved. Understanding Europe as a political field thus means putting the relativity and relationality of people's social and political positions at the centre of the investigation.

The guiding assumption of this book is that the political field is nested within the social space, which means that political cleavages should be embedded - and thus influenced by - social divisions. In positional terms, it is assumed that people's political attitudes are shaped by their social positions within the European social space, i.e., their political views should reflect where and how they live. In "relational" terms, it is expected that divergent political attitudes also mirror social relations of inequality. Field theory assumes that social inequalities entail "objective" relations of advantages and disadvantages when considering the unequal access to social resources (e.g., income, education, contacts). These "objective" relations translate into "subjectively" perceived relations of superiority and inferiority, given that people tend to perceive and evaluate social positions of the self and others in relation to each other. In the field-theoretic vein, it makes a big difference whether Europeans perceive and evaluate social inequalities only within a national frame of reference or whether they consider Europe as a shared social space with relations of superiority and inferiority. Citizens who consider themselves as less privileged, when compared to other Europeans, might be inclined to develop political opinions that are more critical of the social situation in their country and the political work of their governments. In the perception and evaluation of "local" politics, it should, therefore, make a big difference in how people perceive the social conditions in Europe and how they assess their own situation within these.

The aim of this book is to provide empirical evidence about "public opinion" that substantiates these assumptions. For this purpose, I will devote myself (Chapter 3) to an analysis of public debates with the mass media in a number of European countries in order to corroborate the assumption that publicised "public opinion" is transcending national borders and becoming part of a panEuropean sphere of communication, thus providing an extended frame of reference for the formation of "public opinions" by the citizenry. The analysis will be devoted to public discourses about the European financial and economic crisis in the mass media of nine countries (Germany, France, Greece, Italy, Poland, Spain, Sweden, Switzerland and the United Kingdom). The chapter builds on a wellestablished field of research that has corroborated the ability of the EU to furnish (national) mass media and public debates with recurrent topics, events and mutual 
interventions that affect the formation of public opinion (Eder 2004; 2014; Trenz 2004; Pfetsch et al. 2006; de Vreese and Boomgaarden 2006; Boomgaarden et al. 2013; Caiani and Guerra 2017). Even though these public debates are nationally segmented, we seem to witness common debates in which actors from different countries refer to each other (in positive or critical terms), thus consolidating horizontal, cross-national references that position nation states within a common cognitive and evaluative framework, with considerable implications for the political opinions and preferences that European citizens voice. This chapter relies on a dataset of public claims extracted through standardised media content analysis in the context of an EU-funded project (Livewhat ${ }^{1}$ ), as explained in more detail in Chapter 3 (see also Cinalli and Giugni 2016).

Chapter 4 moves from public debates about the economic crisis and takes a closer look at the perceptions and opinions of European citizens. Its aim is to validate whether citizens have internalised an extended cognitive and evaluative frame of reference that transcends national borders and takes the situation in other European countries into consideration when forming political opinions and attitudes, as mass-mediated "publicised" debates and opinions have done. In particular, I wish to corroborate whether citizens are used to assessing European living conditions, spotting social inequalities and identifying their own place within this cognitive map of Europe. The implications of these findings will be the central theme of Chapters 5 and 6. Here, I will determine the extent to which the perceptions of social inequalities have an effect on the way citizens view and assess politics at the national and European levels. Making use of survey data from nine countries (Germany, France, Greece, Italy, Poland, Spain, Sweden, Switzerland and the United Kingdom), I will look at the way people perceived and assessed the social and political reality in their own country in the year 2015 (Chapter 5). In particular, I will deal with the citizens' perceptions of the economic crisis, their satisfaction with their national governments, their likelihood of sharing populist attitudes and their readiness to participate in political protest actions and test whether objective exposure to social inequalities and their subjective perceptions have an impact on crisis sensitivity, political dissatisfaction, populist orientations and protest participation. In particular, I am interested in validating the extent to which the perception of unequal living conditions in Europe increases dissatisfaction and alienation.

In Chapter 6, I will move on to the European Union as a target of political attitudes, asking the same questions in regard to the readiness of Europeans to support the membership of their country in the EU. The effect of objective and subjective vulnerabilities on the readiness to support the EU membership will be central when analysing survey data from eight European countries (Denmark, Germany,

1 The project has the title "Living With Hard Times: How Citizens React to Economic Crises and Their Social and Political Consequences" and was funded by the EU Commission in the seventh research framework programme (contract number: 613237). Sourced materials and reports of the survey data used here can be found on the project's homepage: http://www.livewhat.unige.ch/ 
France, Greece, Italy, Poland, Switzerland and the United Kingdom) for the year 2016, gathered by the EU-funded TransSOL-project. ${ }^{2}$ A major objective will be to ask whether the perception of divergent living standards in Europe has an impact on EU-related attitudes. As the survey data used by this chapter is restricted to eight countries, I will widen the focus of analysis (latter part of Chapter 6) to the EU of 28 member states, making use of Eurobarometer data for the same year. The objective is, on the one hand, to check whether findings from eight countries can be generalised to the full EU 28 and, on the other hand, to differentiate the analysis, taking into consideration that the socio-economic situation in countries diverges strongly between regions. A multilevel analysis will help to understand the impact of individual, regional and national factors on the formation of EU-related attitudes. In particular, it will help to better understand the relationship between spatial and stratificational inequalities and their additive effect on the respondents' readiness to express Eurosceptic views. The analysis will show that support of the EU depends on social divides that are placed at the individual, regional and national levels alike. The social divisions between privileged and disadvantaged citizens and regions translate into a political conflict between pro-Europeans and Eurosceptics, hinting at homologies or congruencies between social and political positions, between the social space and Europe's political field.

The empirical analyses of these two chapters make use of survey data from three sources. I rely on survey data collected by two EU-funded research projects that followed a very similar methodology and used a similar questionnaire, bar its diverging foci of attention. The first survey, from the Livewhat project, was conducted in nine countries (Germany, France, Greece, Italy, Poland, Spain, Sweden, Switzerland and the United Kingdom). It will be used for the analysis in Chapter 5 because its focal point was on people's attitudes about national politics. The second survey comes from a different project (TransSOL) but provides data for a similar sample of countries (Denmark, France, Germany, Greece, Italy, Poland, Switzerland, United Kingdom). Given that its questionnaire placed more attention on the EU, it will be used to answer the empirical questions posed in Chapter 6. Both questionnaires employed similar items to measure social structural traits and political orientations, and both included a battery of questions measuring perceptions of living conditions in other countries. In terms of methodology, each national sample contained about 2,000 respondents. Sampling used quotas to ensure that data is representative of adults in terms of age, gender, education and social class, and thus matches Eurostat population statistics for these countries (see Livewhat 2016; TransSOL 2018). Data retrieval used the computer-assisted web-interviewing (CAWI) method.

2 This project was devoted to the analysis of "European Paths to Transnational Solidarity at Times of Crisis: Conditions, Forms, Role-models and Policy Responses" (TransSOL) and was funded by the EU Commission in the Horizon2020 research and innovation programme (contract number: 649435). Sourced materials and reports of the survey data used here can be found on the project homepage: https://transsol.eu/ 
Chapter 6 additionally relies on data from a Eurobarometer survey from late 2016 (ZA6697, Eurobarometer 86.1). The use of this data requires caution, given that the Eurobarometer has been justifiably criticised, from the outset, both for being instrumentalised by the EU and methodological flaws, among them the untransparent methodological documentation, low response rates and simple operationalisations (Katz 1985; Schmitt 2003; Nissen 2014; Höpner and Jurczyk 2015). In spite of these limitations, it has been widely used, albeit with prudence, largely because it offers systematic data that other surveys do not provide. For my purposes, I rely on this dataset because other standard surveys (e.g., European Value Study or the World Values Survey, the European Social Survey, the European Elections Study or EU-Silc) do not fulfil the necessary criteria defined by the research objectives of this book; for instance, they fail to provide data for the years 2015-2017, comprise the full set of member states, ask pertinent questions about the support of EU membership and/or ensure better response rates for some countries. As will be discussed, Eurobarometer data paint a more positive picture about the support of EU membership when compared to other opinion polls (e.g., Pew Research Centre 2012; YouGov 2016) and the TransSOL data used as a main source of information. However, Eurobarometer data provide an important added value to my analysis, as it allows us to look at the EU 28 and disaggregate the findings by countries and regions. Its use is justified because the aim is not to paint an accurate picture of the exact level of public support of the EU membership but to engage in an additional explanatory analysis of correlates and predictors of EU-related attitudes that allow us to check the validity of the findings generated on the basis of the TransSOL data in regard to the full EU 28. As will be seen, the findings are quite robust.

Chapter 7 will summarise and discuss the main findings presented in this book by highlighting a number of implications and conclusions. In particular, I will argue that the process of European integration makes people consider "society" and "politics" in European dimensions. It establishes a European frame of reference - the European Union or simply "Europe" - which provides a new horizon for the perception and assessment of social reality and political conditions. This assumption does not entail more political agreement and consensus among European citizens. On the contrary, I propose that the political integration of Europe will have integrative and disintegrative effects on the European population. In fact, the political integration of the EU has intensified public debates within and across nation states in regard to shared occasions, issues or demands, which will impact on political debates, public opinions, individual preferences and attitudes within each country. This political integration seems to unleash disintegrative forces because joint public debates do not necessarily translate into political agreement; more often than not, it triggers social dissent and conflict. In this regard, special attention needs to be given to the sociologists' concern for social inequalities because societal cleavages within the EU - between citizens and regions - translate into political conflicts about established politics, both at EU and national levels. The European Union has institutionalised a European political field that, as a political community, has become a reference point for people's 


\section{Introduction}

political thinking. The EU has also fundamentally politicised the European social space by giving it a political contour and structure. The EU seems to "politicise" social cleavages along social class stratifications and regional disparities. In fact, the aim of the European integration process may well have been to develop comparable living conditions in Europe and also to defuse potential lines of conflict in order to assure both social cohesion and political consensus. But since the economic and financial crisis that ensued after 2008, it is not only the inequalities of living conditions in Europe that have increased. The EU's crisis of acceptance has also shifted the lines of conflict between supporters and opponents at the centre of public life throughout Europe, also affecting the support or criticism citizens address to their national governments. Under these circumstances, it is highly probable that the homologies between social divisions and political cleavages will continue to feed political contentions and conflicts at the national and European levels. 


\section{Towards a political sociology of Europe Theoretical localisations}

The discussion about the European integration process with its political and social implications is not short of diagnoses, interpretations and explanations. It is largely undisputed that the integration process has shaped and changed the social and political situation in all member states. However, opinions differ on the question of how noticeable these changes are and what forces are behind them. Put simply, the debate revolves around the question of whether European integration is forming a European society or whether it is merely changing coexisting national societies. On the one side, there are those who expect a higher degree of European integration and a structural change in societal reality. According to this perspective, the development is heading towards a European society (Outhwaite 2008; Beck and Grande 2007), even if its structure cannot be compared with its national predecessors (Delanty 1998; Trenz 2008). The constitutive conditions of such a European society are clearly thought of politically because the European integration process is a political unification project that establishes pan-European fields of power that have an effect on social reality and influence the choices of citizens (Fligstein 2008; Vobruba 2012; Eder 2014). On the other side, there are those who affirm the continuing relevance of the national element, the continuity of nationally segmented societies and the need to analyse them in comparative terms (Therborn 1995; Crouch 1999). Even if they identify significant changes and assume an increasing Europeanisation and transnationalisation of European societies, the social structures and contours remain strongly shaped by a national framework. Here, too, the relevance of a nationally segmented social space is thought of politically, as it is the nation state that asserts itself against the political union of Europe and thus leaves societal living conditions, solidarities and identities within the national framework of social order (Fossum and Schlesinger 2007; Crouch 2016: 1-28).

This fundamental debate is of decisive relevance for the objective of this book because it wants to establish whether Europe has also taken root in people's minds as a reference for their perceptions and opinions. The fact that citizens comprehend social reality and political matters in national categories is beyond doubt, but citizens are also inclined to grasp Europe as a social and political reality and thus as a social space with diverse living conditions and as an institutionalised field of contentious politics. This implies that European citizens will be able to 
form and voice opinions about national and European politics at the same time. Additionally, it is to be expected that these opinions will reflect not only national concerns and orientations but also European viewpoints and evaluations that help to identify, for instance, where the public's own country stands within the social reality and political fabric of the EU. The political dissent between pro-Europeans and Eurosceptics might thus reflect not only objective social cleavages within Europe but also the way citizens perceive and assess living conditions within this European social space.

These research objectives require conceptual and theoretical clarifications. In analytic terms, it is necessary to disentangle the conceptual and theoretical debate introduced before in order to ascertain whether social reality in its objective and subjective dimensions is transcending national borders and is merging into a fairly integrated European social space. The available diagnoses and interpretations are based on different notions of the nature of Europe's societal reality, which is why it is not always clear where there is a contradiction and where there is consensus.

\section{Antipodes and correlates: the European and the national sphere}

The social science debate can be differentiated along two dimensions or axes. On the one hand, opinions differ as soon as the relevance of the European integration process is assessed. As already described, there is as much convincing evidence and explanation for the path-breaking force of the European integration process as for the continued effectiveness of the nation state. However, the dissent sparked by this question is not the only relevant difference of opinion. On the other hand, the debate is also structured along disciplinary perspectives and priorities. European research in political science and sociology has always led independent research debates. While one debate was more interested in the political-institutional aspects of the European integration project, the other focused its attention on the social and cultural dimensions of the integration process. Both research perspectives are important for the present study because an analysis of people's political thinking and actions must take into account the institutional opportunities and constraints of the political structure as well as the social structures of societal reality. If these two axes are followed, European social science research can be divided into four sub-debates, which will be presented in the following.

Firstly, European studies research has been interested in the impressive progress of the European integration process. While it is true that the long history of this integration project was and remains marked by stagnation and ruptures, many authors were however of the opinion that the establishment of the EC and EU went hand in hand with such far-reaching changes in political and societal reality in Europe that suitable explanations had to be found for precisely this extraordinary change (Favell and Guiraudon 2009; Outhwaite 2008). Institutions play a very important role in these explanations. According to this interpretation, the European integration process was so momentous because it established new supranational and intergovernmental institutions (Schmitter 1969; 2009; Hooghe and Marks 2008). Institutions lay down norms, rules and 
missions, with which they also have a transformative character because they introduce new incentives and constraints, expose actors to new orders of interaction and negotiation, channel common socialisation processes and promote discourse and learning processes (Christiansen, Jorgensen and Wiener 2001). Once this process of institutionalisation is underway, it develops a momentum of its own because the establishment of the EU not only creates new actors (the EU institutions, European associations, the political groups in the European Parliament, etc.) but also forces national and sub-national actors (governments, private companies, interest groups, political parties, etc.) to reposition their problem perceptions and interpretations, interests and strategies of action within a European framework (Eder 2004; Trenz and Eder 2004), thus generating new conflict lines (Fligstein 2008; Vobruba 2014). Even in areas where the EU does not have its own legislative powers with "hard" rights of intervention, the expansion logic is not invalidated, as research on Europe has indicated that the EU has developed "soft" management and coordination instruments to achieve unification and harmonisation goals also in these fields (Hodson and Maher 2001; Mosher and Trubek 2003; Jessoula 2015). In this context, it was noted that the EU is very successful in the diffusion and creeping convergence of political problem diagnoses, proposed solutions and regulatory ideas (Featherstone and Radaelli 2003).

Secondly, research has provided ample evidence on considerable transformations of European societies, which have been noted, for example, in regard to demographic structures (birth rates, ageing), labour markets (tertiarisation, knowledge base and digitisation), education systems (expansion of education, participation of women) or social values (de-traditionalisation, individualisation and pluralisation). These changes are understood not only as separate developments but as elements of a common process of modernisation (Eisenstadt 1964; Therborn 1995; Münch 1996; Beck 2000; Beck and Grande 2007) that is partly enforced by the European integration process (Favell and Guiraudon 2011) due to the modernisation script promoted by the EU in many areas (for example, work, education and private life). However, these transformations are driven by endogenous forces that tend to overcome national divisions. As modernity prevails, societal reality increasingly detaches itself - in particular through its functional systems from the national "container" in order to become increasingly Europeanised and globalised (Luhmann 1977; Münch 2008). Modernisation is described as a twofold process: it releases people from traditional models of social order, and it implements new forms of social differentiation (Beck, Giddens and Lash 1994; Beck and Beck-Gernsheim 2002). Individual life chances and lifestyles become individualised out of necessity since individuals must find and consolidate their societal position in a more competitive (European and global) social space, which is less cushioned by social rights and redistribution measures fixed by the nation state (Münch 2012; van Gerven and Ossewaarde 2012). In this respect, societal living conditions can be expected to converge and drift apart at the same time; life opportunities and lifestyles are likely to converge across Europe, but at the same time inequalities between people are expected to increase. Political opinions and 
orientations would become clearly individualised or might follow cross-border milieus with similar living conditions and preferences.

These diagnoses and explanations have not gone unchallenged (Pollack 2001). According to a third strand of research, nation states have in no way lost relevance, meaning that the process of European integration continues to be mediated and ruptured by them (Moravcsik 1998). On the one hand, steps towards European integration always require approval and therefore remain open-ended. On the other hand, transformations unleashed by the European integration process are always mediated or filtered by the nation states. Political and social changes at the local level are path-dependent, which is why European directives or recommendations are "processed" at the national level along historically grown structures, customs and priorities, i.e., either slowed down, diluted or adapted (Pierson 2000). Processes of "vertical Europeanisation", based on a mutual transfer of political ideas or measures between the national and European levels, can therefore succeed only if the institutional, legal or political conditions at both levels are compatible (Börzel 1999; Knill and Lehmkuhl 2002). According to this interpretation, a de facto convergence of political conditions is to be questioned; rather, the focus is on "differential" forms of integration and convergence (Héritier et al. 2001; Leruth and Lord 2016). This research direction thus highlights the continuity of political differences between the member states. It is no coincidence that this approach is committed to country comparison as a methodological perspective because, in this manner, it is necessary to show that political systems make a difference. It is also argued with regard to the political attitudes and behaviour of the population that the nation state continues to be the primary "container" of political life insofar as it offers the central opportunities, procedures, resources and identifications of political participation, which is why the political attitudes of the citizens are ultimately always shaped and communicated with a national bias (Hobolt and de Vries 2016).

Such a position is also adopted within the sociological debate, our final strand of research relevant to this study. Sociology, since its beginnings, has considered societal reality from a national perspective, which is why societies are equated with countries. This position has been criticised as "methodological nationalism" (Beck 2003; Beck and Grande 2007), but the self-image of this sociological analysis has not necessarily suffered. A study of national societies continues to be advocated as a legitimate and empirically validated option. Research interests in the welfare state also contribute to this, as the latter is ascribed an important role in the constitution of societal orders in many areas of society (EspingAnderson 1990; Castles and Mitchell 1992). Societal transformations relating to the European integration process are not ignored but qualified with reference to the inertia of grown structures of everyday life. This position essentially uses the conceptual distinction between systemic and social integration (Lockwood 1964; Archer 1996). In this reading, the European integration process can be presented as a two-track development that changes much and little at the same time. On the one hand, the European integration project establishes systemic functional spheres in the form of state bodies and economic markets that essentially act through law, 
power and money (Münch 2008; Streeck 2012; 2017). The spatial expansion of these functional systems changes people's everyday social reality only peripherally, as it remains tied to local lifeworlds and national communities (Berezin and Díez-Medrano 2008; Fligstein et al. 2012). Europeanised "systems" and local living environments not only stand side by side as "parallel worlds". Rather, it is assumed that the systemic integration project establishes a "Europe" that is managed without "society" (Sissenich 2007; Bach 2006). According to this diagnosis, the dual logic of European integration must necessarily lead to an alienation of people from the European project. Such alienation is likely to increase particularly in times of economic and political crises because the European economic and financial crisis of the years after 2008 and the political crisis of European asylum and immigration policy since 2015 have grown into a far-reaching crisis of acceptance for the EU. It seems to combine both a critique of Europe's "systemic" integration project and a return to national societies and ideologies (Braun and Tausendpfund 2014; Polyakova and Fligstein 2016).

The research debates discussed here provide a number of assumptions that help us to better understand the forces impinging on people's perceptions and attitudes. Paying heed to those who stress the deep transformations induced by European integration, it is to be expected that political attitudes and preferences are "disembedded" from the national container. While local and national politics might continue to be decisive for the people, the fact that Europe is providing an additional point of reference for political attitudes cannot be ignored. This interpretation implies, in the first instance, an "additive expansion" of the political horizon. According to this assumption, people no longer see themselves merely as members of a local and national community, but as part of a pan-European political association. In a more far-reaching way, this process might contribute to "disembedding" public opinion from the national "container". One would assume that the European population either develops highly individualised attitudes or produces cross-border opinion profiles along with common characteristics (generation, social strata or milieus).

The sceptical voices would contradict the previous assumptions since they postulate the undiminished importance of national frames of reference for people's political thinking. These approaches would concede that the establishment of the EU has introduced a new arena of political decision-making and participation that has expanded people's thinking and actions towards the European arena of policy-making. However, since the nation state is still the central arena for political decision-making and identification, the likelihood of the EU being regarded as second tier cannot be excluded. According to this view, citizens essentially remain embedded within a societal reality shaped by the nation state. It may well be that the European integration process is changing the living conditions of people in Europe in view of liberalised markets, common legal systems and bureaucratic regulatory structures. However, people's circumstances still differ considerably between the EU member states. In addition, people's everyday lives are still clearly marked by local group ties and national affiliations. These ties and affiliations are likely to be much more decisive for the formation of political 
opinions and political attitudes than the integration of markets, legal and administrative systems. When analysing political attitudes towards the EU, it should, therefore, be expected that approval and rejection rates will vary primarily among member states.

The discussion of opposing assumptions should not stop at this point because the contraposition of the two perspectives outlined before overstretches the dissent within scholarly debates. In fact, research on public opinion has been interested in analysing the European and national levels in a more integrated way because the social and political reality formed in the process of European integration and institutionally constituted by the European Union has both national and European components. People are not only part of a national and European polity through citizenship and residence; their perceptions and assessments of the political communities are likely to be intertwined. It can be assumed that people always perceive and evaluate the EU from the local and national perspectives of their environment, but at the same time, it is likely that they also observe and assess the political situation in their country from a pan-European perspective. This has to do with the fact that the European Union is an institutionalised multilevel system consisting of local, national and European arenas for political decision-making. Politics is pursued at the local, regional, national, European or global level, which is why there are also multiple arenas for political decision-making and participation (Marks, Hooghe and Blank 1996; Scharpf 1997; Bache and Flinders 2004) and thus also various frames of reference for shaping political attitudes (Hobolt and Tilley 2014). As already demonstrated, there is less agreement on which of these multiple arenas and frames of reference is the most relevant. For some, politics is shaped to a growing degree by the EU; for others, it is still subordinate to the national level.

The relational approach has been applied extensively to the study of political attitudes because there is ample evidence that the political thinking of European citizens is patterned by national and European references and orientations alike. Particularly telling are findings from research devoted to the public support for the EU and the growing importance of Euroscepticism (e.g., Hooghe and Marks 2007; Krouwel and Abts 2007; McLaren 2007; Boomgaarden et al. 2011; Braun and Tausendpfund 2014; de Vries 2018). Political opinions and attitudes towards the EU not only deviate between the different member states (Lubbers and Scheepers 2005; 2010). Citizens also tend to perceive and assess the EU, its institutions and policies from the national perspective. The support is thus determined by the perceived performance of the national economy and the satisfaction with national politics (Kitzinger 2003; Rohrschneider and Loveless 2010; Hobolt and de Vries 2016), the established political party system, the prevailing political ideologies and the attachment to national identities (Anderson 1998; Hooghe and Marks 2005; Armingeon and Ceka 2014; Ares et al. 2017). It could be shown that the primacy of the "national" element is much stronger in times of crisis, as dissatisfaction with the EU increases and at the same time leads to a renationalisation of people's political orientations (Fligstein et al. 2012; Polyakova and Fligstein 2016; Ritzen et al. 2016). 
Much less attention was granted to the "inverse" interaction between the European and national frame of reference, given that the main objective was to explain diverging rates of public support for the EU. However, there is evidence suggesting that citizens also have formed an opinion about the EU and that these views have an influence on how they perceive and assess political and social conditions in their own country or their own surroundings. Studies show, for instance, that well-informed people have their own opinions about Europe and develop EU-specific confidence or mistrust (Karp, Banducci and Bowler 2003; Clark and Rohrschneider 2009; Armingeon and Ceka 2014). In terms of electoral behaviour at the national level, it has been shown that the political context of the EU affects voter turnout and party choice within member states (van der Eijk et al. 1996). Moreover, there is ample evidence about the indirect effect of European politics on citizens' voting behaviour. The electoral success of populist and Eurosceptic parties shows that the EU is contributing to altering the citizens' party preferences and affiliation within their own countries (Krouwel and Abts 2007; Kriesi and Pappas 2015; Hong 2015; Kneuer 2019).

In regard to the analysis of collective identities, a relational element is present as well, given that most studies refer to the multiple identities most European citizens share (Green 2000; Risse, Herrmann and Brewer 2004; Fuchs and Klingemann 2011). While most studies highlight that European identifications are a secondary source of collective identities, when compared to the nation state or the region, there are also indications that the European integration process is having an impact on national identities (Eder and Giesen 2001; Risse 2001). The majority of Europeans feel attached to their own country and Europe, which means that many share multiple identities that will infuse national identities with a sense of "Europeanness". However, the European integration process will not only promote shared feelings of belonging to Europe, but also the inverse effect is very likely. In fact, even in the event of a renaissance of national sentiments, it must be assumed that the European integration process is involved (Polyakova and Fligstein 2016) since the European Union institutionalised the idea of "unity in diversity" and thus of cultural (national or regional) differences (D'haen and Goerlandt 2009; Karaca 2010). The reawakening of nationalism and anti-European parties and groups is thus also a reflection of the contentious politics of identity within the EU and the growing cultural cleavages it mobilises (Fligstein et al. 2012; Kriesi 2016b; Otjes and Katsanidou 2017). The production or reproduction of a national collective seems, therefore, to be a necessary consequence of the efforts of the member states to position and assert themselves as an independent economic, political or cultural force in the pan-European fabric of the EU. The Europeanisation and the renationalisation of European policy might thus be correlates of the same development.

Less evidence is available on the relation between European living conditions, the perception of inequalities and deprivations and political attitudes. There are indications that confidence or mistrust in the EU influences how satisfied people are with their lives (Hudson 2006). Moreover, the comparison of living conditions between countries also influences life satisfaction, i.e., feelings of relative 
deprivation are associated with lower levels of satisfaction (Delhey, Böhnke, Habich and Zapf 2002; Delhey and Dragolov 2014; Lahusen and Kiess 2019). It is also suspected that social inequalities are now perceived and assessed within a pan-European framework, with potential effects on the satisfaction with one's own situation (Heidenreich 2016c). This could have political consequences because the residents of the member states may experience the unequal living conditions in Europe as unfair. Furthermore, the European economic and financial crisis has led to an increase in the proportion of people who are dissatisfied with politics as a whole. This may be evidence that the European acceptance crisis is also having an impact on national politics.

\section{The political Europe: field-theoretical adjustments}

Previous research teaches that political attitudes involve national and European references and orientations at the same time. Citizens perceive and evaluate the EU from the angle of their political and social reality, meaning that their political attitudes are localised. At the same time, however, we should expect that European integration has had an impact on the living conditions of European citizens and the way they look at them. Additionally, it is to be expected that they should have developed a sense of what Europe (as a social space) and the EU (as a political field) is about. In particular, citizens should be able to assess comparatively the living conditions in Europe, and they should be inclined to localise and conceptualise themselves and their country as part of this cognitive map. Their ability to situate themselves within this larger map thus involves relational considerations that might impact on their perceptions and evaluations of national and European politics.

The sociological research agenda followed in this book is interested in validating both assumptions. On the one hand, it wishes to corroborate whether European citizens have altered the perceptions of social inequalities by expanding the implicit frame of reference from the national to the European. On the other hand, it strives to ascertain whether social cleavages translate into political divisions or conflicts and whether the Europeanised perception of social inequalities is thus translating into political divisions that transcend national borders. In particular, it aims to unveil whether social divisions between vulnerable and privileged strata of the population are cutting across countries and are thus nurturing political antagonisms cross-nationally in scope, e.g., in terms of political divisions between pro-European and Eurosceptic citizens and between proponents and opponents of the political establishment at the national level.

These assumptions build on field theory, as was developed in continuation of Pierre Bourdieu's social theory (1990 and 1998) and his analysis of power (Bourdieu 1987; 1996). Its advantage resides in the conceptual differentiation between spaces and fields. This distinction allows us to conceptualise the relation between social living conditions (social space) and political attitudes (political field) by ascertaining a relation of congruity or homology, for instance, between structures of social inequality (social space) and structures of political conflicts 
(political fields). This theoretical approach needs to be described and developed in more detail, particularly in regard to the concepts of social space and social field, in order to delineate more clearly the assumptions driving the empirical analyses.

The concept of "space" has been introduced to demarcate people's situatedness in society. In the first instance, people's places are defined in terms of their resources, activities, contacts or cognitions, and these positions will diverge, given that individuals have different types and amounts of resources, engage in different activities, maintain diverging contacts and voice diverse beliefs. According to this conceptualisation, societal reality is a "space" of diverging positions marked by inequalities of resources, activities, contacts and beliefs. The concept of "space" highlights that these positions are related to one another when considering the distribution of scarce resources, social relations and perceptions. The internal structure has to do with the fact that "spaces" are, to some extent, bounded. In this regard, institutions play a decisive role, given that they intervene by providing resources, directing activities, moulding contacts and shaping beliefs. We might, for instance, consider the role of the nation state in providing civic, political and social rights to their citizens, affecting their resources, activities, contacts and beliefs and setting them apart from other "nationals". However, national borders do not terminate social spaces, given that people can exchange resources, engage in activities and maintain contacts across borders, thus expanding the social space beyond the institutional borders of the nation state. Opportunities for engaging in cross-border relations should have increased during the course of European integration because the $\mathrm{EC} / \mathrm{EU}$ has been actively committed to disembedding the social space from its national borders. However, the EU is also impacting on the spatial contours of the social space, given that it assigns rights to its citizens while dissociating them from third country members. In this sense, it seems appropriate to speak about a "European social space" comprising myriad social positions taken by its "members".

The notion of a "European social space" assumes that the resources, activities, contacts and beliefs of people have gained a European scope. And it presupposes that the people are situated - and situate themselves - within this wider social space, with considerable consequences for their living conditions. In fact, the wider space should alter (e.g., limit or expand) the type and range of resources, activities, contacts or beliefs people have. Citizens living in a transnationallyknit space should thus be exposed to different structures of inequality, and these structures should be formative for the living conditions of people, the experiences they have and the opinions they form. In this regard, three factors or mechanisms have to be highlighted as they are constitutive for the formation of social spaces: interdependencies, interactions and shared perceptions.

Firstly, social spaces are formed on the basis of objective interdependencies between positions. The internal market is regarded as a prime example here, as economies and economic actors compete with each other, which is why growth and unemployment rates, income and consumption levels in the various countries depend on each other. Profits on one side easily turn into losses on the other. These (macrosocial) interdependencies have a direct impact on the reality of people's 
lives, for instance, in terms of income or educational inequalities (Beckfield 2006; Streeck 2012; Petmesidou and Guillén 2015; Gerhards, Hans and Carlson 2017). They change people's opportunity structures, scopes of action and the way people perceive and evaluate their situation (Heidenreich 2016b). A Europe of open borders and integrated markets, for example, means that people might see their own opportunities on the labour market in relation to the opportunities of others who now also directly or indirectly belong to or have access to this labour market. This will have an impact on people's actions and attitudes, for example, on the educational decisions of families, the mobility of workers or political demands for the protection of national labour markets.

Secondly, Europe is a shared social space because of the scope and structure of interactions when looking at cross-border relationships and practices (Favell 2008; Kuhn 2011; Delhey, Deutschmann, Graf and Richter 2014). The contours of this space cannot be delimited precisely because space is constituted on the basis of people's social relations and social networks, meaning that the breadth and structure of social spaces are determined by the patterns and scopes of real interactions. The social interactions are more often than not supra-local and are also very often cross-border. People not only have contacts with "locals" but also with people from other regions or countries (Mau 2009). Additionally, it has been shown that people build spatially extended spaces also on the basis of their everyday practices. People are mobile or migrate; they consume products from different countries of origin or are networked through the media (Delhey et al. 2014; Deutschman and Delhey 2015). The data show that people travel within Europe, have family members in other European countries or buy products from these countries. These practices are not always accompanied by cross-border attitudes and identities, but the frame of reference for many of these people is extended transnationally (Kuhn 2011). The geographical structure of these practices and attitudes thus paints the picture of a "horizontally" open European social space (Beck and Grande 2007). It should be added, however, that the geographical boundaries of these "lived-in" social spaces are variable. They are smaller than the EU because contacts and practices are limited to certain member states or groups of countries; they are larger than the EU because they also include non-European countries and continents. In this respect, authors prefer to speak of transnationalisation processes, which are not necessarily processes of Europeanisation (Mau 2009; Gerhards and Hans 2013; Deutschmann and Delhey 2015).

Thirdly, social spaces are constituted not only on the basis of interdependencies and interactions but also through subjective perceptions, ideas and beliefs. The European social space may already be "real" due to objective interdependencies, cross-border networks and practices. But the European social space only becomes directly relevant once people recognise it as a meaningful frame of reference and thus as an implicit or explicit point of reference for their thoughts and actions, regardless of whether they have a good or bad impression of "Europe" or whether they regard the EU as a useful or reprehensible institution. In addition to an "objective construction" of Europe, a "subjective construction" of the European social space is essential to justify it as a socially relevant reality. This 
proposition is subscribed by previous studies that centred on the perceptions, attitudes and identifications of European citizens. Political sciences, for instance, have collected data to determine whether people take note of the EU, European policy and Europe at all, have the necessary knowledge, show interest in these topics and share them in their environment (Faas 2007; Hobolt and Tilley 2014). The findings show that the EU has stepped out of the slipstream of the nation state. People form their own opinions about the EU and develop their own type of trust and distrust, which do not have to be congruent with attitudes towards the country (Karp et al. 2003; Armingeon and Ceka 2014). And these attitudes also seem to have consequences for people's satisfaction with their lives and politics (Hudson 2006). Additionally, Europeans have developed a shared sense of European solidarity that involves common norms of mutual responsibility, cooperation and wealth distribution (Gerhards, Lengfeld, Ignácz, Kley and Priem 2019; Lahusen 2020). Finally, the subjective relevance of Europe is apparent when focusing on identities and identifications. Europeans have developed a sense of belonging and associate this group membership with expectations about their own behaviour (Green 2000; Fuchs and Klingemann 2011). While national and local identities are more widely diffused, it is well-known that Europeans share a sense of multiple identities (Risse et al. 2004; Hooghe and Marks 2005). These collective identities do not require "identical" identifications because Europeans will have a different vision and understanding of what "Europe" and "European identity" means. However, subscribing to a European identity should also impact on the meaning of national identities, once individuals define them as part of a shared European identity.

In sum, there are strong arguments justifying the idea of a "European social space", even though it is necessary to highlight that this space is not simply given but constructed and reshaped constantly. This is not only the case because interdependencies and interactions change constantly and will most probably not be identical to what we conceive of being "European". Ultimately, Europe is an "imagined community", and even if it shares this fate with all other collective identities, such as the national one (Anderson 1991), it is a particularly diffuse and complex "imagined community". The "European social space" is not a given objective social reality but a contested construct. These lessons are drawn from the theoretical arguments developed by spatial and boundary-sociological research in regard to the European experience (Berezin and Schain 2003; Rumford 2006). Here too, it is argued that the EU has created arenas of communication and conflict in which "Europe" is symbolically constructed through narratives, myths, images and identities. This symbolically constructed "Europe" becomes socially relevant only because it is institutionalised within the architecture of the EU (e.g., the European treaties, institutions and policy domains) and reasserted by the dominant discourse of European politics (Eder and Giesen 2001; Eder 2004; 2014; Vobruba 2012; Trenz 2016).

The "reality" of the European social space is thus the product of endogenous and exogenous forces. In regard to internal processes, Europe is a social space only in relative terms. It is a densely populated area that gradually stands out from 
the wider "environment" through a substantially higher number of trade flows and economic dependencies, personal contacts and spatial practices, communication flows and identifications. The contours of the European social space are thus the product of internal compression, but also of external closure (Münch 1996; 2006). And in this sense, social fields play a particularly important role.

Conceptually, it is thus necessary to take up the conceptual dyad of spaces and fields introduced before. A social field is a societal sphere of action formalised and institutionalised along specific missions, rules and discourses (Bourdieu 1987; 1990; Cohen 2011). In regard to the constitution of a European social field, this conceptualisation would thus highlight that the building of the EC/EU has involved the formation of joint institutions that created a "joint situation" for a defined "membership" by introducing binding problem definitions and purposes, rules and principles. European integration is a process of institutionalisation, which is in itself highly differentiated into different spheres (markets, legal or political systems, science, etc.). If one, therefore, wants to comprehend Europe as a social space, one cannot avoid the concept of social fields, because the contours and the structure of the European social space are shaped primarily by the institutionalisation of (diverse) social fields. Sociological theories of societal differentiation (Parsons 1964; Eisenstadt 1964; Luhmann 1977; Münch 2012; Lepsius 2017) sensitise us to the fact that the European integration project has created a social space that not only generates internally different, sector-specific "concentrations" of economic, political, cultural, educational or scientific activities involved, but also establishes a variable geometry with different expansions and boundaries (Beck and Grande 2007; Outhwaite 2008: 95; Heidenreich 2019). The "situation" (economic, political, cultural, educational, etc.) in which people live is not the same for everyone. Rather, it depends on where they reside, work or live. Indeed, EU citizens live in the same and different social reality because they are exposed to shared issues and problems, opportunities and constraints. But their living conditions are not identical because their countries are not all members of all social fields (e.g., the euro, Schengen, the European Economic Community, higher education area) and are not situated necessarily in a homologous position across them.

Field theory has proven beneficial for sociological research on Europe (Georgakakis and Weisbein 2010; Cohen 2011; Kauppi and Madsen 2013), and it is also of great advantage for the present study with its much more specific objective, for two reasons. On the one hand, this book is intended to examine people's political attitudes towards politics in Europe. According to the sociological agenda, it is interested in unravelling the relationship between the population's living conditions (the social space) and institutionalised politics (the social field). Here, a specifically sociological explanation strategy resonates because it follows the sociological suspicion that political attitudes are pre-formed by society and must, therefore, be explained with reference to precisely this social space and the location of the individual within. By establishing a field of institutionalised politics, the EU has not only incorporated different societies into a new political order, 
but it has also given an integrated social space a political contour and structure, meaning that social divisions will most probably be translated into political divisions. The sociological approach proposed here thus assumes that people's political attitudes towards the EU and national governments can only be understood under consideration of the positions these people occupy in a pan-European social space with its respective differentiations and divisional structures. As citizens, they are socially located in the political field, and this should influence the experiences and perspectives from which they perceive and assess political conditions and events in their immediate environment and Europe.

On the other hand, field theory is also crucial in order to sufficiently sensitise the sociological analysis of politics to the dynamics of the European integration process, as previous theoretical premises can easily be misunderstood as static definitions. The establishment of the EU does not necessarily impose a binding "situation" that structures and determines the actions of its "members" (governments, parties, interest groups but also the individual citizens). This deterministic formulation contradicts the basic field-theoretical premise because according to Bourdieu's theory, these fields are arenas of social negotiations and disputes (Bourdieu 1996; 1998). In fact, the EU cannot determine or remotely control the thinking and actions of its "members". What the establishment of the EU has done is to institutionalise fields in which the actors vie to shape societal and political conditions (Cohen 2011; Georgakakis and Rowell 2013).

Fields are sector-specific arenas in which the production and distribution of scarce goods (e.g., money, profits, prosperity, power, binding decisions, political order) are at stake and in which actors fight over the production and distribution of scarce goods (Bourdieu 1987; 1996). There is no doubt that the establishment of the EU has institutionalised such a field, particularly in the area of politics, and that this field has also changed the political reality for the actors. At least it can be said that social science research shows little difference of opinion with regard to these two general observations. Disagreement arises more on the question of whether the EU is transferring political powers from the national to the European arena, or whether the nation state ultimately remains the linchpin of European politics. The field-theoretical approach suggests overcoming the assumed opposition of European and national politics and understanding them as part of a shared field. According to this approach, the EU can be understood as a communitised field of national fields. This interpretation is close to the concept of the EU as a "multilevel system" (Marks et al., 1996; Bache and Flinders 2004). The field-theoretical approach goes beyond the concept of the multilevel system because it argues that political deliberations, negotiations and conflicts become part of a common European field. The EU not only "vertically" adds a new political entity that transfers powers to the supranational level and enmeshes nation states into panEuropean politics. Sociological field theory argues that the EU has established a political field that incorporates European and national actors indirectly or directly into common deliberations, negotiations and conflicts and thus opens national arenas "horizontally" (Georgakakis and Weisbein 2010; Cohen 2011; Kauppi and 
Madsen 2013). National actors carefully monitor legislative processes within the EU institutions because they will be affected by these decisions directly. And this means that they vie with each other over the outcome of European legislative procedures because the preferences and positions of other national governments will have an impact on the joint decisions taken jointly. The European political field, therefore, intertwines political disputes across national borders and arenas. This implies that the European political field will have an influence on the political positions of nation state actors, for instance, when the latter start to define their "national" interests in view of EU-specific policy debates and decisions and with reference to the interests of other actors from other member states.

Political science research offers vivid accounts of this system of interlocked competences and provides rich material for the interdependent processes of political decision-making and implementation (Scharpf 1997; Kohler-Koch 2005). Many scholars have provided ample evidence that speaks to the fact that European issues and disputes have had a strong impact on the public opinion and the electoral behaviour in European member states (de Vries and Edwards 2009; Hutter and Grande 2014; Armingeon and Guthmann 2014; Sommer, Roose, Scholl and Papanikopoulos 2016). The same is true for research about public discourses within the mass media, which have provided insights that are particularly important when analysing "public opinion". These studies have been interested in identifying the extent to which the public spheres at the national level have been "Europeanised" in regard to actors, issues and events linked to the EU (Gerhards 2001; Trenz 2004; Machill, Beiler and Fischer 2006; Brüggemann and SchulzForberg 2009; Eisele 2017; Caiani and Guerra 2017; Segesten and Bossetta 2019). The focus was primarily the question of whether the discussions reproduced in the national mass media are at all European and thus open across borders. Scepticism was appropriate because public discourses are conveyed linguistically and by the mass media, which means that even shared European events or topics are translated into the national language and dealt with according to the working routines and preference structures of the national media systems. Research has primarily concerned with the "degree of Europeanisation" of national discourses, which was determined, for example, by the proportion of contributions with a European reference (for example, with regard to EU-specific actors or topics) and thus ultimately took into account the "vertical" relationship of the national and European arenas of political communication. Less attention was paid to "horizontal" relationships, which are just as important for a field-theoretical view (Eder 2004; Trenz and Eder 2004). This concerned the assumption that national discourses, even if they have to be conveyed through a national "filter" in terms of language and mass media, can nevertheless be "horizontally" interwoven or "synchronised". These debates would provide an indication of a European field of politics in which political actors from different member states vie for interpretations, solutions and loyalties, even beyond the borders of their own audience.

An analysis of European "public opinion" must take these findings seriously for two different reasons. On the one hand, evidence suggests that public opinions within European countries need to be analysed comparatively and cross-nationally 
because political opinions seem to be formed within and beyond national arenas. Public spheres are still segmented along national divisions when considering mass media systems, political institutions or language areas. But these public spheres are nested within a broader, European arena that facilitates the flow of communication across borders. On the other hand, previous reflections consider the fact that "public opinions" are formed within specific fields (in particular, the political system, the mass media) and this means that the analysis of individual citizens' opinions and attitudes has to take the field-specific contexts into account when engaging in data analysis. This warning is relevant for the purposes of this book, which is mainly interested in addressing the political attitudes of European citizens. This study follows familiar conceptualisations, as it defines political attitudes as beliefs, preferences and orientations of people towards a political issue, a political person or institution that unite emotional and cognitive elements (Easton 1975; Dalton 1999). This understanding is shared by research on EU-related attitudes, which has been interested in determining whether or not citizens support the European integration process and the institutions and persons entrusted with it (Hooghe 2003; Eichenberg and Dalton 2007; Fuchs and Schneider 2011; Hobolt and de Vries 2016). My own research agenda conforms to this understanding, given that I wish to empirically delineate the perceptions and opinions European citizens have formed in regard to European and national politics. The field-theoretical agenda adds an empirical objective because I wish to validate the role of an expanded arena of public opinion formation. In particular, the aim is to identify the extent to which citizens form their opinions within a spatially expanded arena that transcends national borders "horizontally", takes the situation in other European countries into consideration and thus makes implicit use of a European frame of reference.

In order to do justice to the complexity of "European public opinion", I thus see the need to embark on an analysis that takes into consideration the political positions of policy actors before addressing the people's political opinions and attitudes. Both sides are involved in the formation of "public opinion", the political elites through public statements published in the mass media and the people through recurrently published opinion polls. This extended analysis is required because the analysis of "public opinion" demands cautious interpretation to avoid reification. According to Bourdieu, there is no "public opinion" out there (Bourdieu 1979), which means that public opinion research is wrong to affirm that it is able to objectively determine the opinion of the population. Opinion research presupposes "opinions" among people, although it is to be expected that social inequalities and existing power relations in the field of politics produce both mobilising and de-mobilising effects. Bourdieu (1979) argues that there is a systematic exclusion of those who do not have a firm opinion, which is why the relationship of opinions and omitted statements ("don't know" or missing values) must remain in the focus of the analysis. At the same time, public opinion is a "mobilised" and thus highly selective social opinion (Bourdieu 1991). This applies particularly to "publicised public opinion", i.e., public discourses conveyed by the mass media, which serves as a public sounding board 
for institutionalised politics (Luhmann 1996). As the relevant research has shown, this mass-mediated "public sphere" consists essentially of representatives of politically influential organisations and thus ultimately of members of the political elite. Weak or unorganised interests of the population hardly appear in these discourses (Bennett 1990; Koopmans 2007).

These reflections show that an analysis of "public opinion" is an insightful venture if adequately conducted. The inquiry into the political attitudes of the people has to consider the footprint of social positions, inequalities and cleavages in order to get a sense of how "public opinion" is mobilised and formed. It also has to consider that opinion formation at the level of citizens is situated within a public sphere strongly shaped by political actors providing "political opinions" and the mass media placing and interrelating these "publicised opinions" both within and across countries. Against this backdrop, the following analyses will need to embark, in the first instance, on the analysis of mass-mediated public discourses in order to uncover the national and cross-national constellations guiding the formation of publicised "public opinion". For one thing, the analysis can disclose the internal structure of "publicised public opinion" and thus reach a better understanding of the role of political elites in the constitution of public debates and opinions. Within this context, the inquiry should be able to explore the "European dimension" of this political field, particularly by identifying the extent to which public statements transcend national borders and contribute to the formation of pan-European public debates.

The analysis will then move to the citizen level and take a look at their political perceptions and opinions, with back-references to the role of mass media consumption and use. With the findings of the cross-nationally expanded public debates in mind, it will be our mission to validate whether European citizens' perceptions and opinions are embedded in a pan-European frame of reference. In field theoretic terms, I assume that European citizens are used to situating themselves in a European social space, that they are also ready to identify the positions of other fellow Europeans within it and that they consider this expanded European cognitive map as a highly relevant proxy, yardstick or benchmark to form opinions about the social and political reality around them.

These assumptions will require validation. In the first step, the investigation will centre on the way people perceive and assess national politics. People should perceive and assess national politics in accordance with the way they place themselves and others within this cognitive map of European living conditions. People who feel less well-positioned when they compare themselves with other Europeans, for instance, should also perceive grievances and problems much more frequently than people who see their own social situation more positively. People who feel less well-positioned when they compare themselves with other Europeans should be more critical of their own government and more involved in political protests than people who see their own social situation more positively. In the second step, I will examine the attitudes of citizens towards the EU. The 
aim is to validate field theory in its assumption that the structure of the European social space, in terms of stratificational and spatial as well as objective and subjective inequality structures, strongly shapes and forms public opinion about the EU. In particular, I will be interested in identifying the extent to which citizens have formed opinions about the EU that mirror their situatedness in the European social space and the way they perceive their own situation in relation to other Europeans. 


\title{
3 Constructing a social space in troubled times
}

\author{
Public spheres and cross-border debates
}

The European institutions and the Council of Europe have for many years stressed that the European integration process must combat and reduce economic development disparities and social inequalities within Europe (EU Commission 2009; Council of Europe 2000; 2004; 2010). This challenge is directed in part against spatial inequalities (EU Commission 2008) and focuses on support programmes for the improvement of infrastructure (transport routes, telecommunications), rural development and the creation of jobs in structurally weak regions. Furthermore, it aims to tackle social inequalities within the member states and regions, primarily by improving the situation of marginalised groups (e.g., the unemployed, migrants, single parents, the elderly). In these areas, the EU is mainly active through the establishment of fundamental rights (e.g., the European Convention on Human Rights or the European Social Charter) and the financing of support programmes (e.g., the European Social Fund). Additionally, there are soft regulatory instruments, because in the absence of independent legislative powers in the field of labour market policy and social policy, the EU has been relying for decades on coordination instruments (e.g., the Open Method of Coordination or the European Semester of the Europe 2020 Strategy). These efforts are also aimed at improving and harmonising working and living conditions in the member states. Member states are included in many regulatory areas in a continuous process of measurement, benchmarking and evaluation of existing national action plans (Hodson and Maher 2001; Heidenreich and Zeitlin 2009; Jessoula 2015; Copeland and Daly 2018). This process is organised as a continuous learning process because this method conceives Europe as an integrated social space that makes it possible to compare people, regions and nations. More than that, with the goal of a convergence of social living conditions, these people, regions and countries must be systematically compared with one another in order to identify and initiate recommendations for action.

The European Union thus specifically promotes political debates across national borders. Political decisions and legal provisions in individual countries are to be compared with others and evaluated with a view to the common objectives. In this sense, the EU establishes a pan-European communication area that provokes debates in the individual countries with a view to the political "performance record" of the EU and its member states. This does not mean that the 
European integration process is gradually transforming the national media and audiences into a pan-European public sphere, for Europe is too clearly divided into different language areas and media systems. However, this does not rule out talking about each other within the EU, setting common topics, discussing similar problems and potential solutions. National public spheres are not dismissed but mutually intertwined since socio-economic developments and political decisions from the member states are observed, reflected upon and evaluated in the other states (Eder 2004; Eriksen 2005; Trenz and Eder 2004). The EU has established arenas and procedures for political opinion-forming and decision-making that create a sufficiently integrated space for communication and discourse to relate national audiences to each other. In such a framework of discourse, the member state actors not only perceive each other but also assign positions to each other. Actual or supposed similarities and differences between the populations and the countries of Europe thus become more virulent. They give rise to interwoven debates that can generate consensus or dissent - and thus also shape public opinion.

In this chapter, I wish to empirically validate whether such transnational debates have emerged, given that they have the potential to "Europeanise" public opinion not only about the European Union but also about national governments and domestic politics. Previous research has already dealt intensively with the European public sphere, and the guiding question here has been whether and to what extent (national) media audiences have been penetrated by Europe. This "degree of Europeanisation" was determined by establishing the extent to which actors, topics and statements belonging to the EU (EU institutions and other member states) are heard in national media. The findings vary. A sceptical position prevailed for the 1990s because scholars argued that public debates imparted by the mass media only had a weak European focus (Gerhards 2001; Machill et al., 2006; Fossum and Schlesinger 2007). The presence of EU-specific actors and issues within national reporting barely kept pace with the growing scope of political decisions within the EU and the actual deepening and expansion of the European integration process. This weak Europeanisation was generally explained by the lack of a strong political governing body at European level, the multitude of languages and media systems, the relevance of national politics and the observable alienation of the EU from its citizens (Bijsmans and Altides 2007; Brüggemann and Schulz-Forberg 2009; Schulz-Forberg and Stråth 2010; Zschache 2016). Another interpretation saw a greater scope for opening up national media coverage in Europe. These scholars stressed that the Europeanisation of national debates is not dependent on a pan-European public sphere (Eder 2014; Trenz 2016). Massmediated public debates might be linked to linguistic regions and national media systems, but cross-border communication, even pan-European debates, can also take place even within spatially segmented public spheres (Eriksen 2005; Pfetsch et al. 2006; de Vreese 2007; Lahusen 2009). Such cross-border discourses can emerge on the basis of common events and occasions, shared topics and interrelated interventions. Spatially divided but interconnected debates will arise in such a communication space, leading both to consensus and dissent (Trenz 2004; 
Statham 2007; Boomgaarden et al. 2013; Galpin and Trenz 2019; Segesten and Bossetta 2019).

The fact that cross-border, discursively interlinked debate takes place has already been shown at key milestones in the European integration process (Statham and Trenz 2013; de Wilde, Michailidou and Trenz 2013; Zschache 2016). However, the importance of cross-border debates has been, above all, confirmed since the outbreak of the European economic and financial crisis in 2008, as national mass media reported quite intensively on relevant events and information. Although the situation at home was the first priority (Monza and Anduiza 2016), European actors and issues were also discussed. Reports on other countries increased in particular, especially Greece. They provided an opportunity to publicly address the European dimension of the crisis (Mylonas 2012; Papathanassopoulos 2015). These debates show astonishing parallels, although this did not necessarily benefit the EU and the member states concerned, as a tone critical of Europe and Greece dominated the climate of opinion (Statham and Trenz 2013; Papathanassopoulos 2015).

The following will build on these findings. The aim is to clarify whether the debate conveyed by the mass media in the countries - under the impression of the crisis - was actually "opened up" in European terms. The aim is also to identify how these national debates are interlinked. In particular, the focus is on whether Europeanisation follows a vertical penetration of national media reporting (e.g., through the inclusion of EU institutions or other international and global actors) and/ or a horizontal intertwining of debates across national borders (e.g., by opening up to actors from other member states). The analyses will be particularly interested in the actors involved in such a discursive Europeanisation. According to the tenor of previous media and European studies research, media coverage is clearly determined by social elites, especially the political and state elites (Bennett 1990; Skogerbo, Bruns, Quodling and Ingebretsen 2016). With regard to the European communication space, it is also assumed that the "public opinion" on Europe, which is circulated and mobilised in the mass media of the various member states, is primarily shaped by these elites (Eder and Giesen 2001; Koopmans 2007). This will also apply to horizontally intertwined debates because national elites of the different countries will most probably perceive and observe each other, talk about each other and refer to each other. This way they contribute to stimulating transnational debates, which should have an opinion-forming effect on the populations of the countries.

This Europeanisation of public discourses will be empirically examined on the basis of data from a European project (Livewhat) that focused on media reporting in nine countries: Germany, France, Greece, the UK, Italy, Poland, Sweden, Switzerland and Spain. Five newspapers per country were selected as the data source ${ }^{1}$ care was taken to include at least one tabloid in addition to the quality

1 Germany (Bild, Die Welt, Frankfurter Allgemeine Zeitung, Frankfurter Rundschau, Süddeutsche Zeitung), France (Le Figaro, La Tribune, Le Monde, Le Parisien, Libération), Greece (Eleytherotypia, Kathimerini, Rizospastis, Ta Nea, To Vima), the UK (Daily Mail, Daily Mirror, The Guardian, 
press. The special feature of this data set is that it did not use the article as an investigation unit but the claims identifiable in the articles. The newspapers were therefore used as an "archive" of public claims and positions of social actors (Franzosi 1987). The interest was not directed primarily at the journalists themselves, although they also had a say in the articles. Rather, statements and actions of the quoted actors (governments, parties, associations, experts, non-governmental organisations, individuals, etc.) were extracted in order to reconstruct the public debates on the crisis. Following the guidelines of this "claims-making" approach (Koopmans and Statham 1999; Giugni and Statham 2002; Cinalli and Giugni 2016), a data set was generated from these newspapers consisting of 9,000 claims for the period between 2008 and 2014. ${ }^{2}$

\section{Debates on the economic and financial crisis: national and European issues}

The global economic and financial crisis, which began in 2007, had a noticeable impact on the European Economic Area from 2008 onwards, as it resulted in massive economic slumps, growing indebtedness of banks and public budgets, rising unemployment figures and increasing poverty. The public reacted to these developments with concern, as the mass media reported more and more on the crisis, its causes and consequences. The following graphs illustrate the course of the debate for the nine countries examined (Figure 3.1). As a similar number of claims were evaluated in the nine countries, it is not possible to say in which countries the public discourses were more intensive and in which they were less developed. What the data show, however, is the intensity of the public debate over time, which varies from country to country. In one group of countries (Germany, Sweden, Switzerland and Poland), public attention very quickly increased to over 300 claims a year, only to gradually lose momentum. Another slight increase in 2014 was only observed in Poland. In the other countries (UK, Greece, Italy and Spain), public interest in the economic crisis after 2008 remains fairly constant until 2013 and only dropped noticeably afterwards.

The Sun, The Times), Italy (Corriere della Sera, La Stampa, Repubblica, Secolo XIX, Sole 24 Ore), Poland (Dziennik Gazeta Prawna, Super Express, Gazeta Polska Codziennie, Gazeta Wyborcza, Rzeczpospolita), Spain (ABC, El País, El Peridico de Catalunya, La Vanguardia, El Mundo), Sweden (Aftonbladet, Dagen Nyheter, Göterborgs Posten, Norbottens Kuriren, Svenska Dagbladet) and Switzerland (Blick, Le Matin, Le Temps, Neue Zürcher Zeitung, Tages Anzeiger)

2 The extraction of claims from the articles of these national newspapers followed a three-step procedure. In the first step, the research teams used the electronic archives of the newspapers mentioned to identify all articles in the period in question that belonged to the subject matter of the study. Following the objectives of the project, media coverage of the (European) economic and financial crisis was to be examined, which is why all articles were identified that contained the keywords "crisis", "recession" or "austerity" in the full text search. From this (adjusted) total number, articles were then taken at random step by step from the total population until the desired number of 1,000 claims per country had been determined. These claims were analysed and coded on the basis of a common codebook. 

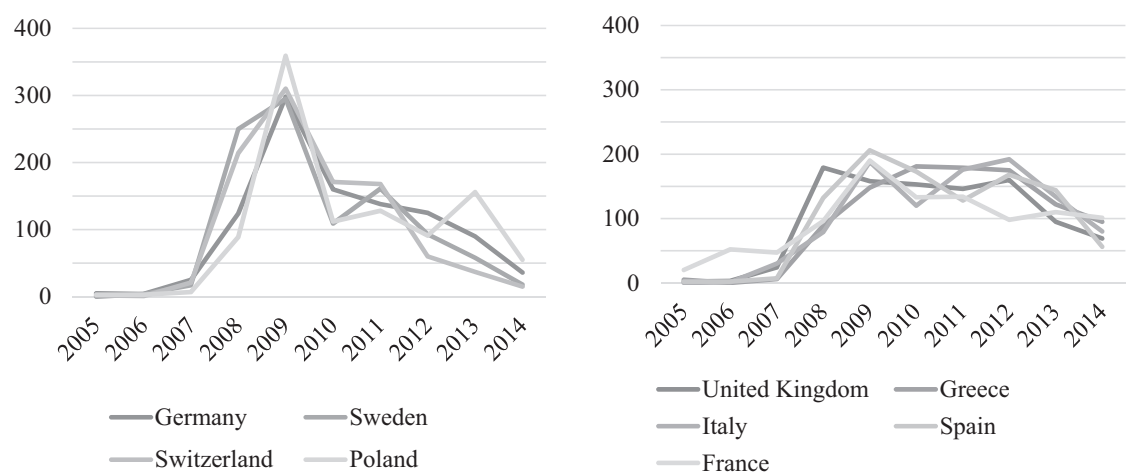

Figure 3.1 Public claims on the crisis (absolute figures). Source: Livewhat WP3 political claims dataset.

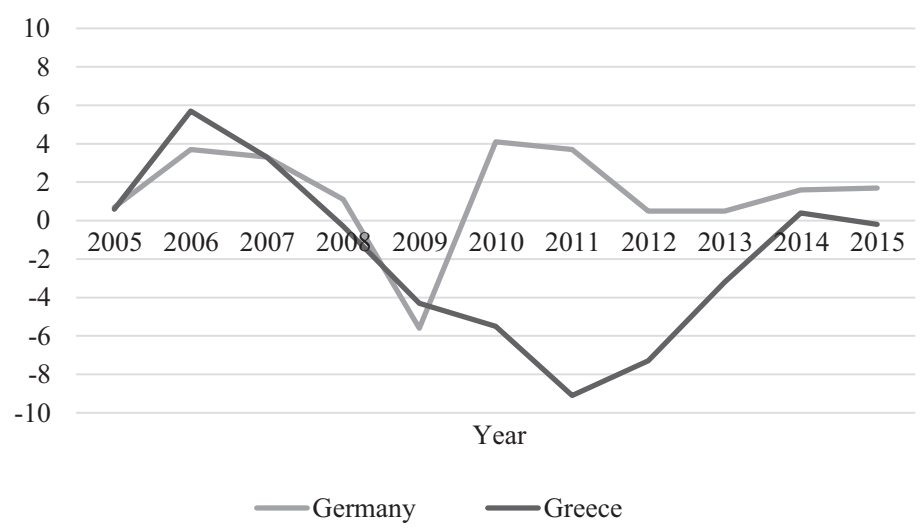

Figure 3.2 Real GDP growth rate - change compared to the previous year (\%). Source: Eurostat.

If this is compared with economic developments - for the sake of clarity only for Germany and Greece - it can be seen from Figure 3.2 that these discourses follow actual economic developments. Measured in terms of the development of gross domestic product compared to the respective previous year, economic growth in Germany slumped by $5.9 \%$ in 2009 . The economy had already calmed down again in the following year. In Greece, however, the low point was not reached until 2011 - and was a full 9.1\%. It was not until 2013 that the Greek government emerged from the recession.

As shown in Table 3.1, public claims covered a variety of topics. However, economic issues were at the centre of public discourses. Half of all the statements were about the overall economic situation, and one in five discussed trade 
Table 3.1 Main topics of the debates (multiple answers, number of cases: 9,000)

\begin{tabular}{lrr}
\hline & $N$ & $\%$ \\
\hline Economics & 4499 & 49.99 \\
Trade and finance & 1917 & 21.30 \\
Work and employment & 1723 & 19.14 \\
State, public service and administration & 589 & 6.54 \\
Environment, energy, transport & 550 & 6.11 \\
Health and social affairs & 441 & 4.90 \\
Education and science & 358 & 3.98 \\
Home affairs, immigration & 331 & 3.68 \\
International relations & 346 & 3.84 \\
Urban and regional policy & 331 & 3.68 \\
Other & 1121 & 12.46 \\
Total no. of answers & 12206 & \\
\hline
\end{tabular}

Source: Livewhat WP3 political claims dataset.

Note: The percentages result in more than $100 \%$ as multiple answers can be given.

and financial issues. Immediately following is the area of work and employment, with almost every fifth statement. Several other topics only emerge at a greater distance; these include the role of the state, administration and public services, health and social policy issues and aspects such as the environment, energy and natural resources, transport and public transport. The list of topics shows that hardly any policy area was left out because in all these areas the causes, effects or implications of the economic and financial crisis were identified and discussed. On balance, however, public discourses remained committed to an economic and fiscal agenda.

As can be seen from Table 3.2, the focal topics vary only slightly between countries. For each of the nine countries, the discourses were also dominated by economic issues, while health and social issues played a subordinate role. Differences occurred in the relative weighting. The economic situation was the focus of particular attention in the UK, Sweden and Germany, while trade and finance were of particular importance in Switzerland and Germany. Labour and employment were more important in France, Poland and Italy than in other countries, and in Poland, Greece and Spain this was the case for the topics of health and social affairs.

The debates on these topics have barely changed over time, which is why they are not presented in graphical or tabular form here. Indeed, these thematic debates followed the pattern identified above for the overall debate (Figure 3.1). For those countries less affected by the economic and financial crisis, the intensity of the debates after 2010 levelled off considerably. In Greece, public discourses on the economic situation gathered momentum until 2012, and in Italy, work and employment also became the focus of the debate in that year. But beyond these striking features, the topic-specific course of the debate corresponded to the general trend already described. 
Table 3.2 Topics by country (selection, multiple answers, number of cases: 8960)

\begin{tabular}{|c|c|c|c|c|c|c|c|c|}
\hline & \multicolumn{2}{|c|}{ Economy } & \multicolumn{2}{|c|}{ Trade/finance } & \multicolumn{2}{|c|}{ Work/ employment } & \multicolumn{2}{|c|}{ Health/social affairs } \\
\hline & $N$ & $\%$ & $N$ & $\%$ & $N$ & $\%$ & $N$ & $\%$ \\
\hline France & 415 & 42.3 & 184 & 18.8 & 253 & 25.8 & 60 & 6.1 \\
\hline Germany & 528 & 52.5 & 298 & 29.7 & 146 & 14.5 & 26 & 2.6 \\
\hline Greece & 516 & 51.6 & 179 & 17.9 & 195 & 19.5 & 65 & 6.5 \\
\hline Italy & 418 & 41.8 & 168 & 16.8 & 202 & 20.2 & 52 & 5.2 \\
\hline Poland & 464 & 46.3 & 192 & 19.1 & 224 & 22.3 & 70 & 7.0 \\
\hline Spain & 394 & 38.7 & 168 & 16.5 & 143 & 14.1 & 61 & 6.0 \\
\hline Sweden & 583 & 58.0 & 197 & 19.6 & 199 & 19.8 & 39 & 3.9 \\
\hline Switzerland & 467 & 46.8 & 350 & 35.0 & 194 & 19.4 & 46 & 4.6 \\
\hline UK & 714 & 72.2 & 181 & 18.3 & 167 & 16.9 & 22 & 2.2 \\
\hline $\begin{array}{l}\text { Total no. of } \\
\text { answers }\end{array}$ & 4499 & 50.0 & 1917 & 21.3 & 1723 & 19.1 & 441 & 4.9 \\
\hline
\end{tabular}

Source: Livewhat WP3 political claims dataset.

Note: The percentages result in more than $100 \%$ as multiple answers can be given.

However, these representations leave us in the dark as to whether the public discourses on the crisis contain a European component at all. Was the crisis addressed as a "European" issue, or did a primarily national reference horizon dominate? Following the assumption expressed at the start of this chapter, public debates in Europe are likely to remain structured in segments along national discourse spaces (languages, media systems, political arenas, etc.). However, it can be assumed that these national discourses are embedded in a pan-European frame of reference that should be empirically comprehensible through common events, topics and mutual interventions between the actors themselves. The course of the public discourse on the crisis has already provided us with such an indication. The debates began in all nine countries with the economic slump, the imminent bankruptcy of banks and the rise in unemployment in 2008. It is also significant that the debates have not only remained lively for years in those countries most affected by the global economic and financial crisis but have also continued in those states that announced a lessening or even end of the crisis in their own countries.

The economic and financial crisis was thus a common cause for debate. However, this is only a weak indication of a pan-European discourse space, as the figures only show that the countries were affected (indirectly or directly) by the crisis at the same time. It is unclear as to whether the crisis was also perceived as a common topic or whether the actors rather referred to "own" (national or local) crisis problems. After all, the economic and financial crisis was multifaceted; it had global repercussions, which is why it was also addressed as a global economic crisis; it affected the European economic and monetary area as a whole, but ultimately it also affected the countries (and different regions within them) to varying degrees. This raises the question of how the crisis was perceived and addressed in the scrutinised public debates. Is the crisis "framed" and defined more as a global 
or a European, national or local issue? This question can be clarified on the basis of the discourse data used because during the evaluation of the reporting of the national print media, care was taken to also include these spatial "frameworks" and problem horizons.

Table 3.3 shows the spatial problem horizon of the crisis debates for the nine countries. The national frame of reference dominates for most of the claims, i.e., the crisis-relevant issues were addressed by the claimants as topics and problems linked to the own country. Only one in ten claims discussed the issues in a European framework, i.e., referred to the EU as a whole or to the situation in other European countries. This is followed by the global, regional and local levels. However, the differences between the countries are particularly striking. The European dimension was more in the focus of debate in Germany, Greece and Italy, while it played a lesser role in the other countries. Compared to the European dimension, the global thematic horizon was particularly dominant in Switzerland, but the situation was similar in Sweden and the UK. In contrast, the national frame of reference was particularly decisive in the UK and Greece.

The development of the debates reveals that the European problem horizon was addressed more frequently by the actors involved as time progressed. Figure 3.3 compiles the changes between 2006 and 2014, although for simplicity's sake a distinction is only made between three reference areas; in addition to the global and European problem horizon, the national, regional and local references have been combined. The figure contains two diagrams, one showing the evolution of the debates in absolute terms and the other in percentage terms. The top diagram reflects the already familiar picture, as the vast majority of claims on the crisis were made in the years between 2008 and 2009, while the intensity of the debates gradually decreased after 2010. The "hot phase" was determined by a nationally framed crisis discourse, which is why the global and European reference point remained subordinate in this period. However, the relationship between the debates changes when moving towards 2010. The focus on the national reference horizon is continuously decreasing; the global perspective is being replaced by the European perspective. This observation is underpinned as soon as one looks at percentage shares. Over the period, the share of national framing of the discourse remained quite stable at a high level, while the subordinate spatial references changed. A global problem horizon became a European one.

This moderate reorientation is confirmed as soon as the changes are broken down by country. Figure 3.4 only shows the development in absolute figures, as this breakdown takes the intensity of the debates into account more reliably. The figure initially underpins the observation that public discourses in all countries placed the crisis in a dominant, national problem horizon. This does not mean that these debates were completely devoid of European or global references. It will become evident that national discourses are implicitly interwoven into such a framework. However, explicit references to the European and global problem dimension remained marginal.

Differences between countries should be taken into account when looking at these developments. For Switzerland, in particular, the global reference area 


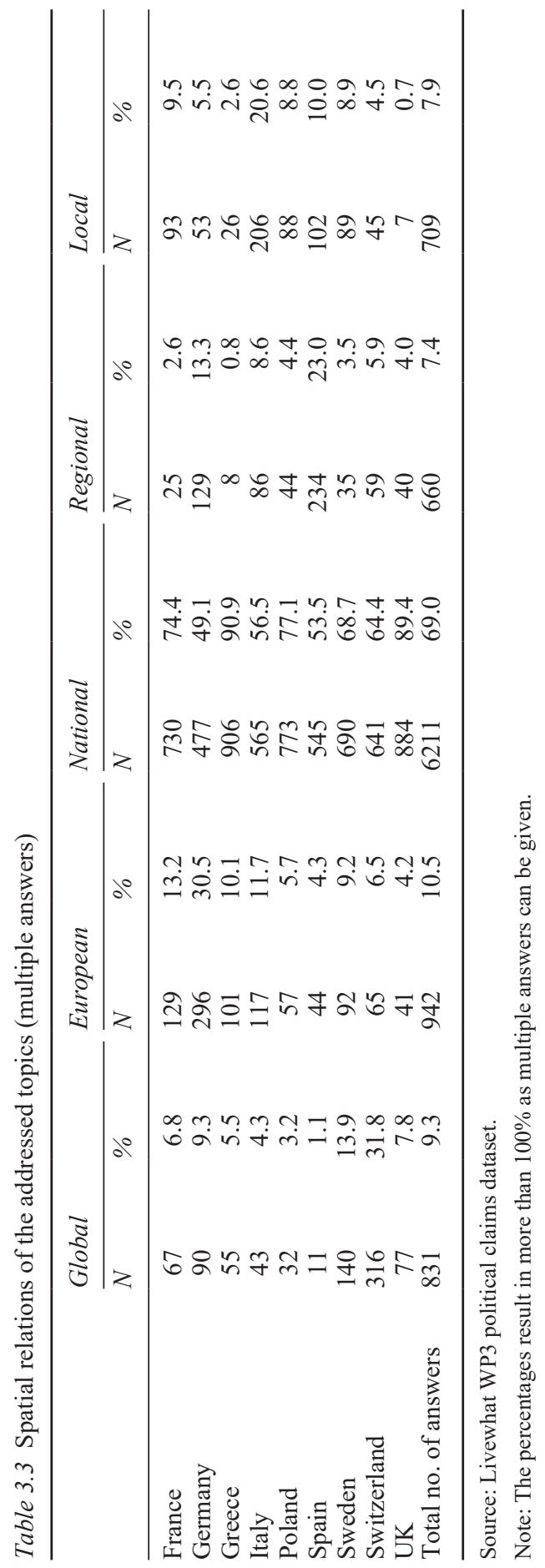




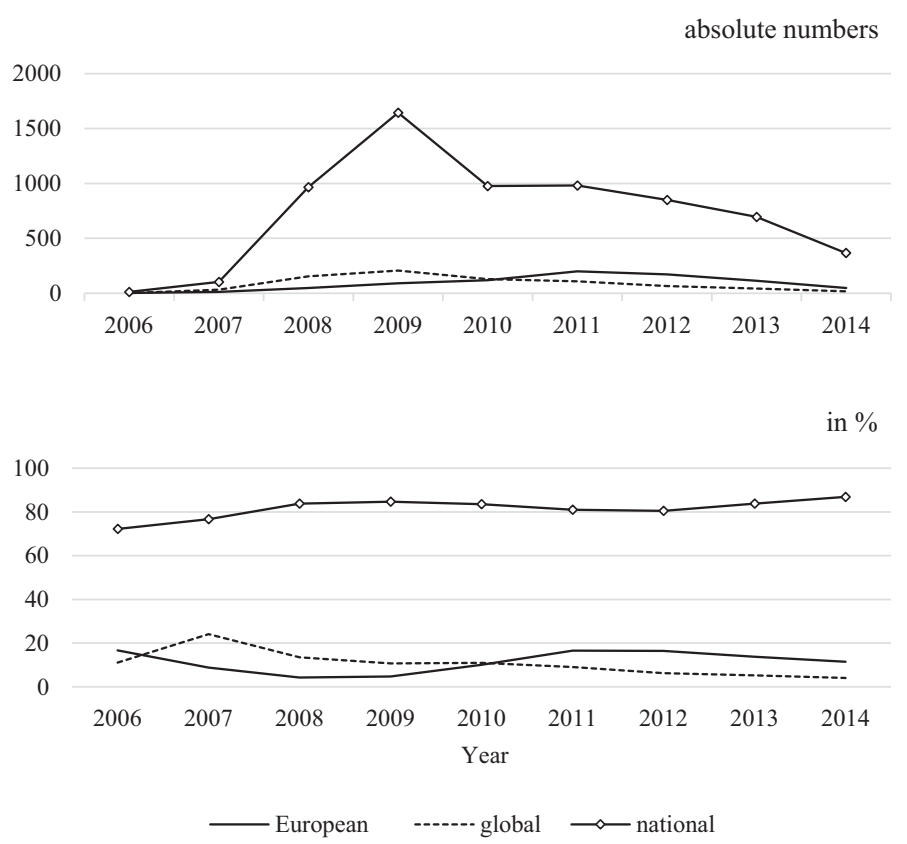

Figure 3.3 Problem horizon of the debates (multiple answers). Source: Livewhat WP3 political claims dataset.

was consistently more important than the European one. Everywhere else, however, the global frame of reference was overlaid by a European one during the course of our investigation period. This is particularly true for Germany because the European dimension has been decisive from 2010. With the exception of Switzerland, the same applies to all other countries, as between 2010 and 2012 the primarily national debates were supplemented by a European dimension.

This part of the discourse is connected to the contents of the debate. Table 3.4 shows that the debates with a national or European problem horizon had different thematic priorities. Economic, monetary, financial and external relations issues were clearly more often defined as European issues, while the areas of labour and employment, health and social affairs were primarily discussed at the national level. Monetary policy in particular was one of the most prominent European issues as one in three statements dealing with the European problem horizon dealt with this issue. In this way, public debates reflect actual political realities because the European Union has a clear mandate in the field of monetary policy, while it lacks such competences in the fields of labour and employment, social affairs and health. It is the nation state that continues to take the lead in these policy areas. It is not surprising, therefore, that actors primarily focus on a national problem horizon as soon as they deal with these issues. 

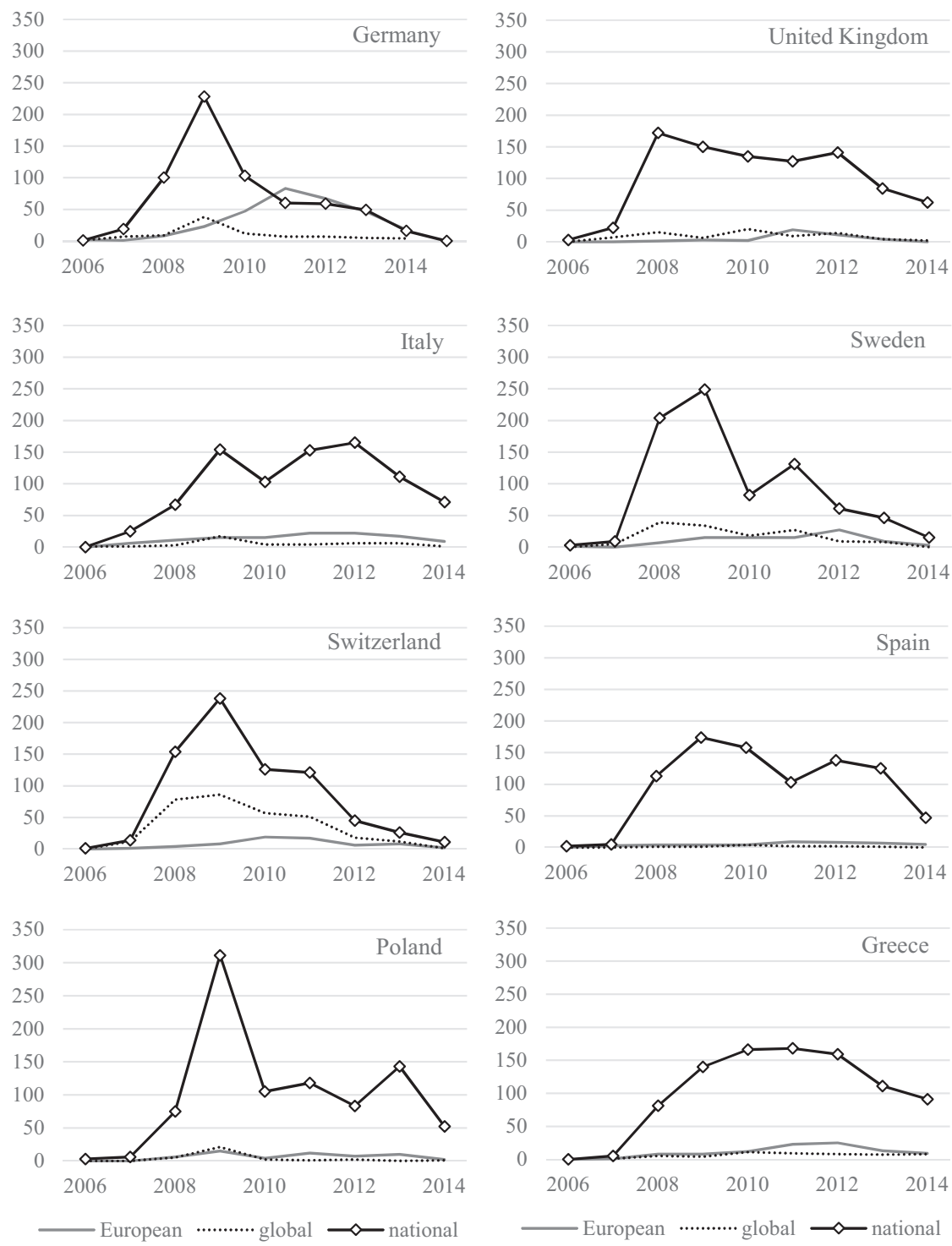

Figure 3.4 Problem horizon of the debates by country (multiple answers). Source: Livewhat WP3 political claims dataset.

In the overall picture, this results in a crisis discourse, which was divided into several partial debates. The monetary and financial policy implications of the crisis and the corresponding measures to overcome them were discussed primarily as a European issue, while the "clean-up" in the field of labour and social policy was seen as a topic for the member states. However, the two partial debates were 
Table 3.4 Problem horizons by topic (multiple answers)

\begin{tabular}{lrrrrr}
\hline & \multicolumn{3}{c}{ National } & & \multicolumn{2}{c}{ European } \\
\cline { 2 - 3 } \cline { 5 - 6 }$N$ & $N$ & $\%$ & & \multicolumn{1}{c}{$N$} \\
\hline Economic and monetary affairs & 3714 & $49.7 \%$ & 633 & $67.2 \%$ \\
Work and employment & 1610 & $21.5 \%$ & 73 & $7.8 \%$ \\
Trade and finance & 1434 & $19.2 \%$ & 238 & $25.3 \%$ \\
Urban and regional policy & 889 & $11.9 \%$ & 113 & $12.0 \%$ \\
Health and social affairs & 510 & $6.8 \%$ & 19 & $2.0 \%$ \\
Education and science & 430 & $5.8 \%$ & 57 & $6.1 \%$ \\
Home affairs, immigration & 404 & $5.4 \%$ & 29 & $3.1 \%$ \\
State and administration & 385 & $5.2 \%$ & 12 & $1.3 \%$ \\
Environment, energy and transport & 368 & $4.9 \%$ & 29 & $3.1 \%$ \\
International relations & 307 & $4.1 \%$ & 132 & $14.0 \%$ \\
Other & 174 & $2.3 \%$ & 16 & $1.7 \%$ \\
Total no. of cases & 7478 & & 942 & \\
Total no. of answers & 10225 & & 1351 & \\
\hline
\end{tabular}

Source: Livewhat WP3 political claims dataset.

interrelated insofar as labour market policy and social policy were embedded in European economic, financial and monetary policy and therefore also had to be subordinately aligned with it.

The interweaving of these partial debates becomes even more tangible as soon as a closer look at the content of the debates is taken and the issues expressed by the actors in the print media over the years are examined. Despite the multitude of topics, arguments and demands, it is possible to reconstruct and paraphrase certain threads of the debates. ${ }^{3}$ For instance, at the beginning of the economic and financial crisis, the focus of public statements was still almost entirely on one's own country. In Germany, for example, there was intensive discussion in 2008 and 2009 about short-time working, the prevention of mass redundancies and high unemployment. The discussion focused on government economic stimulus programmes propagated at the federal and state level to overcome the economic crisis, on new national debts and the sense or nonsense of tax relief for private individuals and companies. There was also controversy about rescuing ailing banks (BayernLB, IIKB Deutsche Industriebank, HSH Nordbank, Hypo Real Estate, WestLB) and corporations (e.g., Adam Opel Werke, Arcandor/ Karstadt). The focus was also on wage policy, as employers and unions had different opinions as to whether wage increases were justified in times of crisis. In

3 Following the codebook of the "claims-making" analysis, the teams were instructed to summarise the contents for each identified statement. The paraphrasing is done in English, which allowed comparative evaluations. For the purposes presented here, the most frequent claims per country were identified and paraphrased. These evaluations therefore primarily serve to illustrate dominant debates. 
Greece, there were more reports of corporate insolvencies, collective redundancies and salary cuts. The discussions in Greece were about measures to make the labour market more flexible, but also about the Greek state's debt, and here specifically about tax increases, restrictions on welfare benefits, the fight against tax evasion and the privatisation of public enterprises. Demands for a reduction in municipal taxes and duties were also discussed in order to relieve the tourism industry and agriculture. Several speakers called for strikes or street protests against the government's austerity and reform policies. Here and elsewhere, the situation in one's own country was at the focus of interest, as the vast majority of statements dealt with the claimants' own economy and financial sector, labour market and social system. And everywhere, the political measures that should be taken in the country to get a grip on the consequences of the crisis were discussed.

Although the global and European problem horizon was implicitly or indirectly addressed in most of these statements, the proportion of claims that explicitly referred to this problem horizon, which goes beyond one's own country, was still quite low in the early days of the crisis. In 2008, only 62 statements referred to a European problem horizon out of a total of 1,246 (i.e., 5\%). And while this figure rose to 108 in 2009, this partial debate remained subordinate. Additionally, these claims were devoted to a wide range of topics. Companies that had instigated redundancies in several European countries at the same time came forward. National governments presented their national policies as a response to the common European crisis. Representatives of the member states and the European institutions (Commission, Economic and Financial Affairs Council, etc.) highlighted the need for a coordinated economic, monetary and financial policy but without being able to report consensus. At the same time, criticism was also voiced in the individual countries. On the German side, French demands for a European economic government were discussed just as critically as the European Central Bank's policy of cheap money. In Poland, a more consistent distribution of European subsidies for the eastern European member states was demanded and proposals to make the labour market more flexible were criticised. And in Sweden, for example, there was a call for a clearer EU commitment to fighting unemployment and regulating the financial markets. At the same time, these actors stressed that they did not consider economic policy coordination to be very useful.

From 2010, the number of statements with European references increased. By 2011 , the number of such claims had doubled to $234(17.3 \%)$, gradually falling to $65(12.4 \%)$ by 2014 . The thematic priorities are particularly important since in 2010 every other of these statements concerned issues of (European) monetary, budgetary and financial policy. In 2011 and 2012, this proportion even increased to two-thirds of these statements. The background to the change in the debate was the dramatic worsening of the economic and financial crisis in some member states. Several countries had to contend with rising public debt, declining growth prospects and hard-to-predict risks from bad loans from national and private banks (including Ireland, Portugal, Italy, Spain, Greece). This weakened 
the single currency and dampened confidence in the stability of the euro and the European banking and financial system. Work on a coordinated monetary and financial policy gathered considerable momentum in the wake of Greece's imminent national bankruptcy in spring 2010. As is well known, this led to the creation of a "euro rescue package" consisting of several programmes and institutions: bilateral loans and intergovernmental financing programmes such as the European Financial Stabilisation Mechanism (EFSM), the European Financial Stability Facility (EFSF) or the European Stability Mechanism (ESM). All of them were looking to secure the solvency of individual member states. Essentially, the policy consisted of granting loans, all of which had to be repaid. Disbursement was subject to strict reform conditions negotiated and monitored by a troika of lenders: the European Central Bank (ECB), the International Monetary Fund (IMF) and the European Commission (EC).

The course of the debate strikingly reflects these events. For example, a large proportion of the Europe-related statements made in 2010 dealt with the European rescue package, the necessity of which was largely accepted. Greece appeared as an addressed country in a whole series of claims, with the leading commentators originating mainly from France, Germany, Sweden and Switzerland. In the following years, the European rescue package with its central instruments (EFSF and EFSM) left the focus somewhat. However, actors who were concerned that Greece's excessive debt entailed incalculable risks continued to speak up. Demands were therefore made for a consistent policy of stability and reform. Actors repeatedly discussed Greece's possible withdrawal from the eurozone. In addition, there was demand for a stronger recapitalisation of banks and a stronger regulation of the banking sector. This "banking union" has been discussed since 2012 and was commented on until its implementation in 2014. Since 2013, more and more voices were talking about an imminent end to the economic and financial crisis and there was light at the end of the tunnel even for Greece. Demands for growth-promoting economic, industrial, tax and financial policies now moved more into the spotlight. Actors opposed the primacy of an austerity policy and called for greater flexibility on the subject of public debt and public investment programmes. The common fight against unemployment was discussed only marginally in this context but now started to gain prominence.

The debates thus had common points of reference. The same events and issues were mentioned in all of the countries: the Greek sovereign debt crisis, the ECB's decisions on interest rates or the purchase of government bonds, the summits of heads of government or ministers, economic development and mass unemployment. And similar assessments or demands were made everywhere: the stabilisation of the euro, the budgetary discipline of the member states, the recapitalisation of banks, etc. Despite wide agreement on the issues and the general tenor of the demands, public debates were not without dissent. Critical voices were heard either branding the agreed measures as too timid or protesting against the austerity policy of the EU and its spokespersons. These statements were mainly made in those countries where the European problem horizon was much more significant for public debates; this is particularly true of Germany and Greece. 
Weightings, assessments and demands differed considerably between the countries. For instance, public debates in the euro countries tended to differ from those in countries that were not members of the eurozone or the EU. In the euro countries, the common monetary and financial policy was a very decisive subject. This was easy to understand for Greece, as the solvency of the Greek state was largely dependent on decisions taken within the EU with regard to contingency plans, euro rescue packages, loans and purchases of government bonds. At the same time, however, there was also vehement criticism of EU policy, as numerous Greek statements focused on the social consequences of austerity policy and the promised reforms. The monetary and financial policy was also of great importance in Germany, as the German government played a leading role in the development of the publicly discussed measures. Most spokespersons agreed that the EU should not become a transfer union because this would mean that taxpayers in one country would have to answer for the sins (past and future) of others. They argued that EU policies should be based on loans and encourage governments to undertake serious reforms in order to protect German taxpayers. In France and Italy too, statements related to Europe focused on the common monetary and financial policy. Greece remained a cause for concern and an incentive for a policy of sound public finances in these countries. In Italy, actors who criticised the primacy of austerity policy and wanted to generate more growth spoke out from 2012 onwards. A more active industrial policy and more state investments were called for, as was a more flexible approach to public debt. Spain's overall picture is out of the ordinary in that the number of public claims with a European dimension was very small. But here too, most of the statements related to the EU's monetary and financial policy.

In comparison, public debates in countries that had not adopted the euro as their common currency diverged somewhat from the picture drawn so far in terms of subject matter and tenor. The few voices that welcomed their country's entry into the eurozone at the beginning of the crisis quickly became silent, and there was concern that developments within Europe could be economically damaging to one's own country. This not only referred to the recession in the entire domestic market in the years 2008 to 2010 and the weak overall economy after 2011. Above all, the crisis of the euro and its fiscal policy causes (high indebtedness of states and banks) were criticised as they also harmed the country's own economic development. This argument was put forward repeatedly, particularly in Sweden and the UK. In the UK, concerns were expressed in 2011 that the problems in the eurozone could undermine the tentative recovery of the British economy and plunge it into a new recession. In both countries, reference was made to the remaining risks in countries such as Greece, Spain, Italy and France. Many commentators felt that it was important for the countries of the eurozone to do their homework, with the support of the British and Swedish governments. Similar voices were also found in Switzerland. The relatively high proportion of Europe-related statements for a non-EU country can be explained by the fact that the weakness of the euro had simultaneously led to a strong Swiss franc, which proved to be harmful for many companies in the long term. The debate on the 
European sovereign debt crisis and the envisaged banking regulation also played an equally important role in Switzerland.

Finally, European monetary and financial policy remained a marginal topic in Poland. Here the European debates were dominated more by policy-specific topics, such as whether the European climate protection targets could harm Polish coal. Concerns about the European Structural and Social Funds were voiced repeatedly. After all, the desire of many EU and euro countries to use part of these funds for stimulus programmes and the fight against mass unemployment could be to the detriment of eastern and central European countries and damage European cohesion policy.

Overall, the evaluations to date show that public debates on the crisis in all countries were primarily committed to a national agenda. This does not contradict the fact that the economic and financial crisis of the years after 2008, objectively speaking, affected several countries at once and should therefore be understood as a global and European crisis in its causes, manifestations and consequences. For public debates, however, it remained central that the crisis was discussed primarily with a view to the concrete situation locally. The discussion focused on layoffs, short-time work or wage cuts, ailing banks and public finances, investment programmes, social benefits and austerity measures at home. Public debates rarely dealt explicitly with the European and global dimensions of the crisis, and in this respect a monetary and fiscal agenda prevailed. From a topical point of view, the public discourses on the crisis were therefore divided into different partial debates. The situation in one's own country was the subject of debates that mainly concerned the banking and financial system, the economic situation and the situation of private and public budgets. There were also statements on unemployment and employment, social affairs and health. The statements related to Europe followed a much more limited agenda. They very rarely dealt with the specific situation in individual countries. Instead, they were about the weak euro, risks to the stability of the currency resulting from ailing banks and bankrupt states and measures to support the euro, stabilise public finances and recapitalise banks. These European-related debates were not free from dissent and reflected the particular situation of the countries within the EU and the monetary union. However, the pronounced consistency of events, topics and demands across national borders is surprising.

\section{Actors and discourse arenas: multi-level reciprocity}

The global economic and financial crisis has sparked a public debate in all the countries studied. As has been shown, the vast majority of the public statements remained committed to a national problem horizon, as they dealt with countryspecific consequences, countermeasures and problem solutions. This national segmentation of public discourse has been repeatedly confirmed by previous research (Gerhards 2001; Machill et al. 2006; Zschache 2016). The fact that a global economic crisis that spread across national borders and continents is discussed and addressed at a small scale may be surprising but can be explained by 
the unbroken importance of language and cultural regions on the one hand, and nation states and nationally segmented public spheres on the other. However, this national segmentation in no way prevents cross-border debates because the same events, topics and demands were discussed in the respective countries. There were also mutual references to the situation in other European countries.

This observation will be pursued in the following. These findings could indicate that the European Union - despite country-specific debates - has created a cross-border communication space in which the participating actors not only share common topics but also talk to and about each other. It has not yet been possible to answer this question clearly on the basis of the previous analyses. It was only possible to demonstrate that in addition to the debates on the economic and financial crisis with a national problem horizon, there was an additional discourse devoted to pan-European issues. This may be an indication that there are two separate partial debates. In fact, it is possible that national actors were concerned with the causes, manifestations and consequences of the crisis in their country, while the EU institutions held a discourse on the accompanying monetary, economic and financial policy measures to contain the crisis. These would be findings that would speak against a pan-European communication space in the proposed sense; they would rather support the hypothesis of a separate and supranational arena of public interventions with EU-specific topics and actors that would leave the segmental character of national public spheres untouched. Horizontally interlinked, pan-European debates in our sense would only exist if national actors got involved in the debates with a European dimension and if EU institutions and actors from other member states were present in the debates of the individual countries. Only in this sense would the public discourses be mutually interlinked.

The empirical claims-making data provides answers to the question as to which of these two scenarios is the right one. To this end, it is helpful to give an overview of the group of actors involved. As Table 3.5 shows, state actors dominated public debates with over $50 \%$ of the statements. It was mainly representatives of governments, parties and state authorities or agencies who spoke up. Other speakers included banks, companies, employers, economic research institutes and experts, including trade unions. Each of these actors highlighted different dimensions of the crisis: banks and companies discussed the economic implications (e.g., order situation, short-time work or redundancies, insolvencies, investments, capitalisation); the trade unions identified the problems specific to the labour market (wage development, rising insecurity and unemployment, socially acceptable countermeasures by employers and the state); state actors discussed appropriate political solutions (investment programmes, tax increases, savings measures, social policy reforms, etc.).

All in all, it can be seen that the public debates on the crisis were essentially conducted by political and economic elites. This is not unusual for media reporting, since it is mainly representatives from the state, politics, business and science who have their say in newspapers (Bennett 1990; Koopmans 2007), which also seems to apply to the debates on the economic and financial crisis. Additionally, public discussions were dominated by conventional forms of public debate 
Table 3.5 Actors who had their say (multiple answers)

\begin{tabular}{lrr}
\hline & $N$ & $\%$ \\
\hline State actors & & \\
Governments, executive & 2140 & 23.8 \\
Parliaments & 517 & 5.7 \\
Parties & 1038 & 11.5 \\
Courts & 44 & 0.5 \\
Governmental agencies & 876 & 9.7 \\
Economy and finance & & \\
Banks & 1021 & 11.3 \\
Companies and employers & 1498 & 16.6 \\
Employees and civil society & & \\
Trade unions & 751 & 8.3 \\
Civil society actors & 451 & 5.0 \\
Other actors & & \\
Media & 140 & 1.6 \\
Think tanks, experts & 624 & 6.9 \\
Other & 240 & 2.7 \\
Unknown & 22 & 0.2 \\
Total no. of cases & 9000 & \\
Total number of answers & 9362 & \\
\hline
\end{tabular}

Source: Livewhat WP3 political claims dataset.

because in the vast majority of cases they consist of verbal announcements and claims (press releases and conferences, resolutions, position papers and reports, etc.) or the announcement of political decisions or enforcement measures (legislative initiatives, party programmes, administrative decisions, etc.). This share of $94.5 \%$ of all statements is contrasted by a small number of cases involving the political participation of civic groups or individuals (court actions, lobbying, petitions from citizens, participation in consultation procedures or committees, etc.), street protests (demonstrative, confrontational or violent forms of protest) or self-help initiatives (barter exchanges, soup kitchens, cooperatives, counselling centres, etc.). Only $3 \%$ of the statements are from street protests. In some countries, the share is more elevated - with 7.9\% in Italy, 5.5\% in France and 3.9\% in Greece - but also in these cases they were unable to change the tenor of the debates. In fact, the few public protests reported in the media were eclipsed by a flood of conventional interventions, announcements and claims. The latter were not free from dissent but were nevertheless part of a surprisingly integrated and moderate discourse arena. This might be due to the content because as was shown, public debates on the crisis were dominated by an economic and financial agenda that ensured leadership for certain actors. However, this does not apply without restriction; one only needs to consider the greater diversity of topics in debates with a primarily national problem horizon. These debates also covered labour market and employment policy, social and health policy, education and regional 
development. The fact that protesters and more confrontational objections hardly played a role despite this diversity of debates suggests that public discourse about the crisis was ultimately contained and controlled by well-established discourse communities (Singer 1990; Hajer 1993; Bislev, Salskov-Iversen and Hansen 2002), and these discourse communities consisted primarily of representatives of political and economic elites who cultivated a rather conventional culture of communication.

These observations can be confirmed as soon as the participants are broken down by country, and it is determined which actors were heard, and how frequently, in the print media of the nine countries (Table 3.6). State actors were omnipresent, particularly in Germany, Greece and Spain, while banks, companies and employers, trade unions and organised civil society played a role in the rest of the debate. In the UK, Switzerland, France and Italy, the state actors were somewhat less prominent, with almost $50 \%$ of all speeches. However, banks, companies and employers were in the media much more frequently in the UK and Switzerland than trade unions and organised civil society, with almost one in three claims. In France and Italy, capital and labour were present with roughly equal shares. Finally, the debates in Poland and Sweden are striking in that state actors shaped the debates much less than banks, companies and employers, which is why the workforce and civil society ended up as a side note.

The findings show that state actors and interest groups shape public debates about the crisis everywhere, but they do not disclose yet whether public discourses about the crisis transcended a purely national arena. An initial answer is provided as soon as it is determined whether the actors who spoke were representatives of local, national, European or global organisations or groups. In this regard, the data assembles public statements by myriad different actors, among them local and global companies, national governments, EU institutions or international organisations (e.g., the World Bank or the IMF). Table 3.7 shows the proportions of claims. The results essentially confirm the findings already determined for the problem horizon of the topics discussed. Almost two-thirds of all claims were made by actors based in the country concerned; only one in ten statements came from a representative of a global organisation (mostly companies, the World Bank or the IMF). European actors only had a say in every 14th case, with the share of the EU institutions being significantly higher than the number of actors from other EU member states.

If the circle of participants is subdivided by type (Table 3.8), it can be seen that European actors came mainly from the executive, political and administrative sectors - in the majority representatives of the European Commission, national governments of other countries or national delegates within the Council of Ministers. Interestingly, European companies or employers' organisations, trade unions and non-governmental organisations did not play a significant role. The picture changes in relation to global actors as global banks, financial service providers, rating agencies and private companies dominate in particular. Trade unions and civil society organisations were again mainly active at the national and localregional level. 


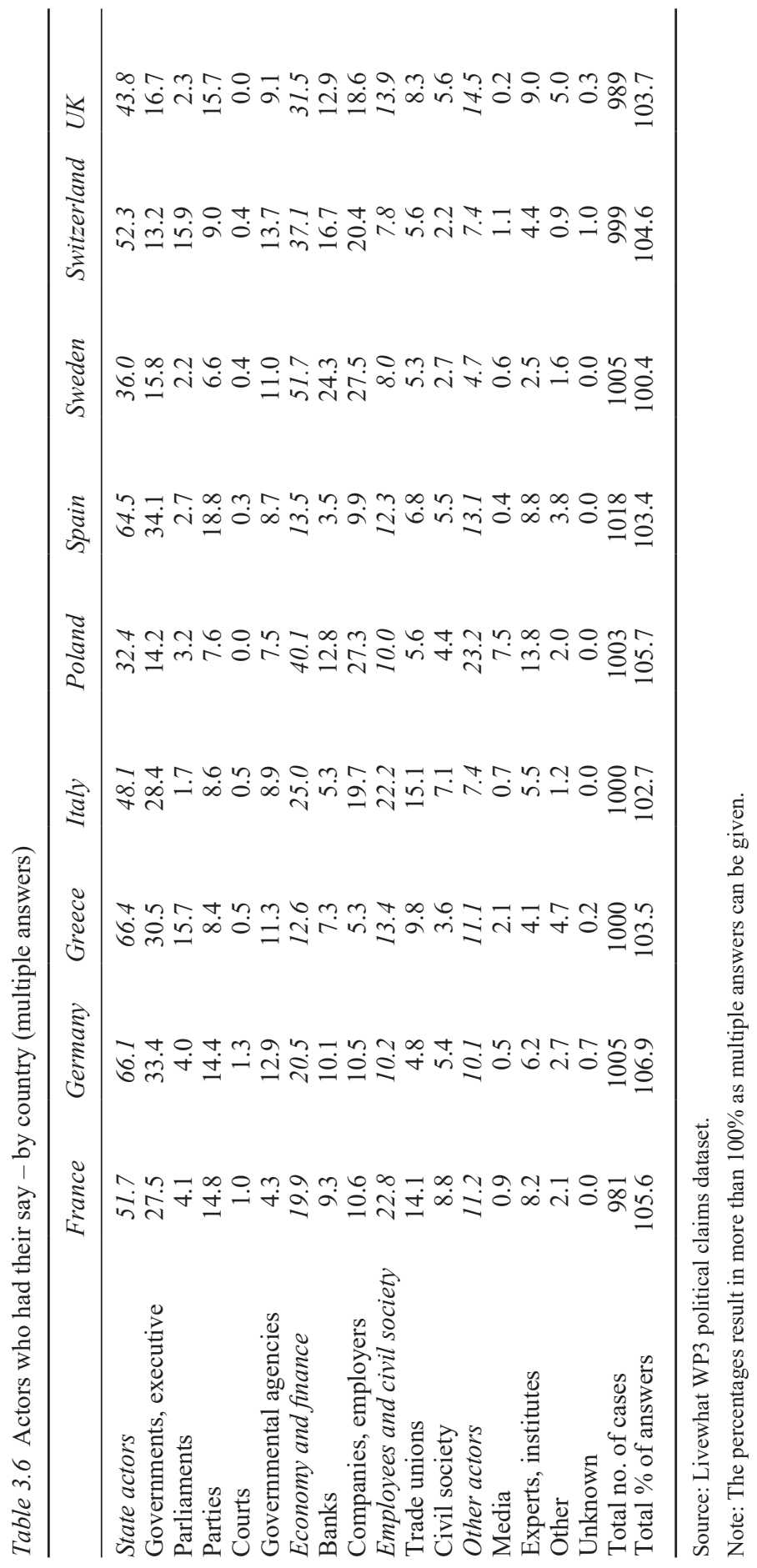


Table 3.7 Actors by action level (multiple answers)

\begin{tabular}{llrr}
\hline & \multicolumn{1}{c}{$N$} & $\%$ \\
\hline Global & & 825 & 9.2 \\
European & EU level & 490 & 5.5 \\
& other member states & 158 & 1.8 \\
Multilateral & & 73 & 0.8 \\
National & 5689 & 63.2 \\
Regional & 786 & 8.7 \\
Local & 826 & 9.2 \\
Unknown & 1512 & 16.8 \\
Total no. of cases & 8999 & \\
Total no. of answers & 10359 & \\
\hline
\end{tabular}

Source: Livewhat WP3 political claims dataset.

The findings demonstrate that public debates were restricted to a national arena in all countries. The majority of the actors who have their say in the national media debates come from the respective country. However, one should not be blinded too much by this impression. This tabular overview simplifies the picture and thus also exaggerates the national isolation of public debates. It is true that only $10 \%$ of all the issues raised in the claims were identified as "European" (see Table 3.3 above), and it is true that only $7 \%$ of the actors who spoke are either from the EU institutions or from another member state (see Table 3.8). This does not necessarily mean, however, that the debates on the crisis fall into two separate arenas: the few European actors would therefore only talk about European issues, the many national actors only about national ones. This is not the case, however, because European actors also spoke with regard to national issues and national actors took part in debates with a pan-European topical horizon.

In order to support this finding with data, the spatial problem horizons of the topics dealt with and the action horizons of the actors involved have been put in relation to each other. Table 3.9 provides a summary of the results, with all national, regional and local issues and actors summarised in the category "national" for the sake of clarity. The "European" categories contain statements by EU institutions and actors from other member states who comment on events in the respective country. The figures clearly show that the actors took a stand on issues at their respective action levels. This applies in particular to national actors who spoke almost exclusively on national issues, while in almost two-thirds of the cases, European actors also expressed their views on European issues.

However, in more than half of the cases, global and European actors also comment on national issues - in many cases they refer to multiple levels. The global actors with national issues include, for example, the rating agency Moody, which spoke in November 2007 to announce that French banks should emerge unscathed from the global financial crisis. These cases also include an announcement by eBay in October 2008 of the intention to lay off 100 employees in Germany in response to 


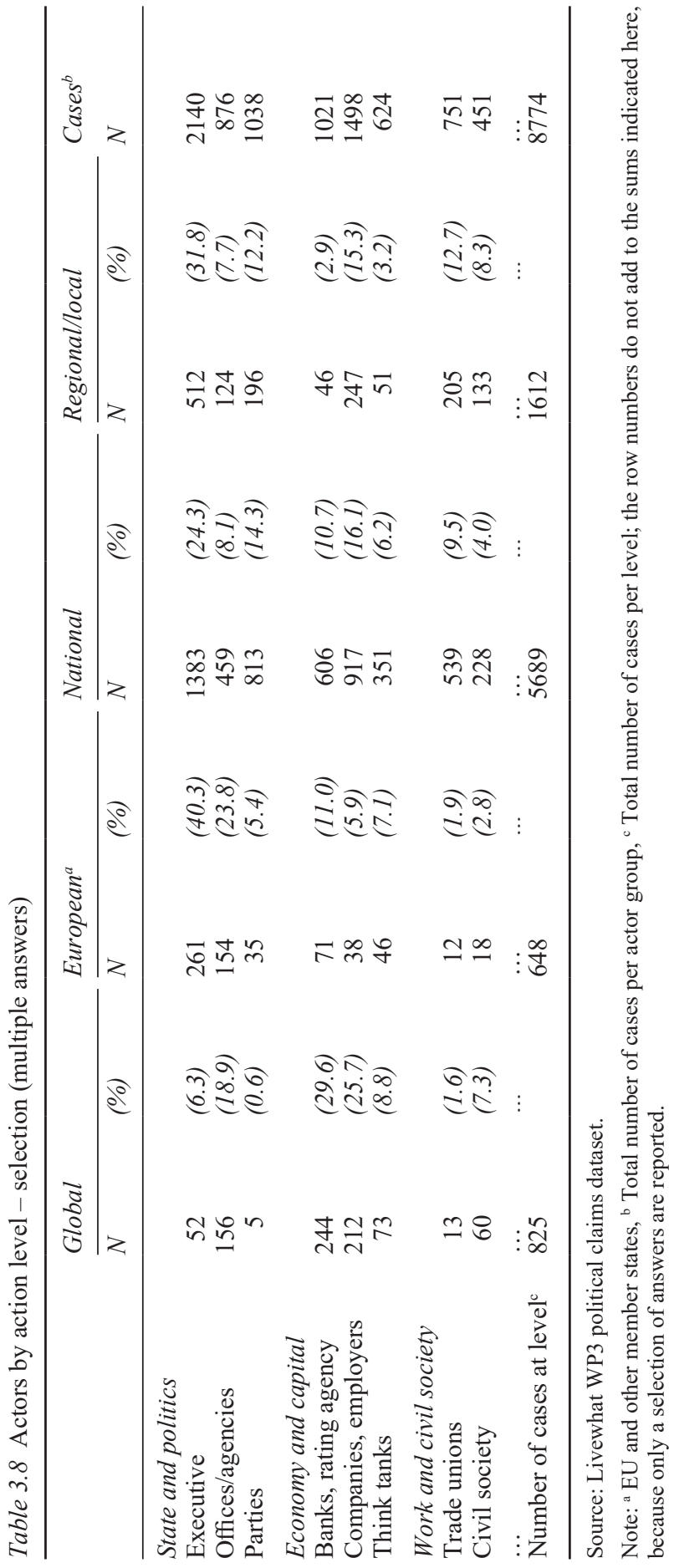


Table 3.9 Actors and topics by level (multiple answers)

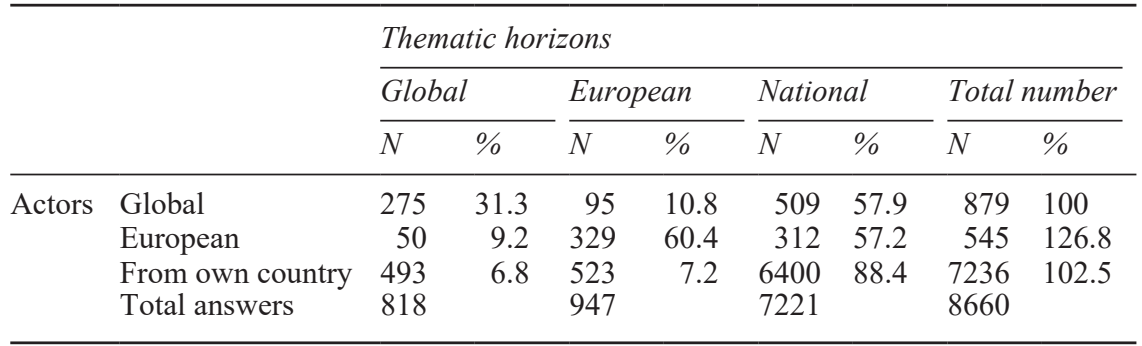

Source: Livewhat WP3 political claims dataset.

Note: $\%$ sums above 100 due to multiple answers.

the crisis. Another example is the IMF's demand for a deferral of Greek loan repayments in December 2010. European actors who spoke on country-specific topics included primarily claims by European institutions and other member states, such as the European Central Bank's demand on the French government in December 2009 to secure the liquidity of the French central bank. Another example is provided by the rejection of state support by the EU Commission for the ailing Arcandor Group in June 2009. A statement by the President of the Commission, José Manuel Barroso, in January 2014 can also be added to this group; during a meeting in Brussels with the Greek Prime Minister, Andonis Samaras, he expressed his hope that the Greek government would implement the negotiated reform package and that the Greek economy would overcome the crisis.

This finding provides us with the first indication that the public debates about the crisis were vertically as well as horizontally interwoven, even though the national focus remained. However, these results must be broken down by country, because, as has already been shown, the public debates in the various countries also differ in the extent to which they are open to non-domestic actors. This applies particularly to the question of how often global and European actors have their say on national issues. The following table summarises the figures for this part of the debate (Table 3.10) because, as shown, speeches on national issues account for the lion's share of the debates on the crisis circulated in the media. The last column lists the total number of claims on national issues; the two previous columns list the shares of European and global actors who spoke on these national issues.

The results show that global actors only make up a considerable proportion in Switzerland and the UK, while European actors play no role. The high presence of multinational corporations and globally active banks and financial service providers in the media coverage of these countries reflects the global orientation of the Swiss and British economies and financial world, and thus also the special sensitivity of these countries in their involvement in the global economic and financial crisis. European actors play a particularly prominent role in public debates in Germany and Greece. A closer look at the data shows that the European 
Table 3.10 Claims on national issues by country (multiple answers)

\begin{tabular}{|c|c|c|c|c|c|}
\hline & \multicolumn{2}{|c|}{ Global actors } & \multicolumn{2}{|c|}{ European actors } & \multirow[t]{2}{*}{ Total } \\
\hline & $N$ & $\%$ & $N$ & $\%$ & \\
\hline France & 34 & 4.1 & 28 & 3.3 & 839 \\
\hline Germany & 35 & 5.5 & 63 & 9.8 & 641 \\
\hline Greece & 77 & 8.3 & 109 & 11.7 & 930 \\
\hline Italy & 32 & 3.8 & 22 & 2.6 & 849 \\
\hline Poland & 56 & 6.2 & 33 & 3.7 & 903 \\
\hline Spain & 30 & 3.5 & 35 & 4.0 & 867 \\
\hline Sweden & 4 & 0.5 & 8 & 1.0 & 800 \\
\hline Switzerland & 99 & 13.5 & 5 & 0.7 & 735 \\
\hline UK & 142 & 15.6 & 9 & 1.0 & 913 \\
\hline
\end{tabular}

Source: Livewhat WP3 political claims dataset.

institutions often had their say in the German newspapers in order to comment on and evaluate national measures for overcoming the crisis. In Greek newspapers, however, EU institutions and representatives of governments, industry or associations from other member states were very strongly represented. This reflects the Greek government's clear dependence on international lenders and the high degree of sensitivity to the role of European policy in the Greek national situation.

Further evidence of the interrelatedness of European and national debates can be provided when looking at who the actors involved turn to in their claims. Not all claims mentioned an addressee, as this only applied to over 7,800 of the 9,000 statements evaluated. Nor was it possible to identify in each of these claims the level of action at which these addressees are located because in many cases the actors addressed politics, the economy or society in general. Overall, it was possible to assign the addressees to a specific level of action in $73 \%$ of all statements. For this section, the same image that was identified in the topics can be traced (see Table 3.11). First of all, the data highlights the importance of the national level, as almost two-thirds of the statements were addressed to actors from the respective country. Global addressees were addressed in only every 20th claim, European addressees in every 12 th statement. The vast majority of these statements were addressed to the EU, while other member states were rarely addressed.

When relating the actors to the addressees, it can be seen from Table 3.12 that national actors primarily address other organisations from their country; the proportion of global or European actors addressing their peers is also high. However, it can be noted that global and European actors very often addressed national organisations, as half of the statements by global actors and $43.2 \%$ of the European ones were addressed to national addressees. National actors also turned to the EU institutions or other governments in a considerable number of cases, but the relative figures are small. Since national actors dominated public debates on the crisis, our data set contains 330 statements addressed to EU institutions or other member states but this represents only a share of $7.2 \%$ of their public interventions. 
Table 3.11 Addressees by level of action (single answers)

\begin{tabular}{|c|c|c|c|}
\hline & & $N$ & $\%$ \\
\hline Global & & 359 & 4.6 \\
\hline \multirow[t]{2}{*}{ European } & EU level & 557 & 7.1 \\
\hline & other member states & 83 & 1.1 \\
\hline Multilateral & & 16 & 0.2 \\
\hline National & & 4736 & 60.1 \\
\hline Unknown & & 2124 & 27.0 \\
\hline Total & & 7875 & 100.00 \\
\hline
\end{tabular}

Source: Livewhat WP3 political claims dataset

Table 3.12 Actors and addressees by action level

\begin{tabular}{|c|c|c|c|c|c|c|c|c|c|}
\hline & & \multicolumn{8}{|c|}{ Addressees } \\
\hline & & \multicolumn{2}{|c|}{ Global } & \multicolumn{2}{|c|}{ European } & \multicolumn{2}{|c|}{ National } & \multicolumn{2}{|l|}{ Total } \\
\hline & & $\bar{N}$ & $\%$ & $\bar{N}$ & $\%$ & $\bar{N}$ & $\%$ & $\bar{N}$ & $\%$ \\
\hline \multirow[t]{4}{*}{ Actors } & Global & 158 & 35.2 & 61 & 13.6 & 230 & 51.2 & 449 & 100 \\
\hline & European & 37 & 7.3 & 250 & 49.5 & 218 & 43.2 & 505 & 100.0 \\
\hline & National & 169 & 3,7 & 330 & 7.2 & 4096 & 89.1 & 4595 & 100.0 \\
\hline & total & 364 & & 641 & & 4544 & & 5549 & \\
\hline
\end{tabular}

Source: Livewhat WP3 political claims dataset.

The intertwining of the debates on the crisis varies from country to country, also in terms of the addressees. When looking at the claims relating to national addressees, the following table shows that global actors in the UK were more relevant, as in one in ten cases these organisations were aimed at British addressees (Table 3.13). In Greece, European actors played a greater role, as more than one in ten statements was from EU institutions or organisations from other member states and addressed to Greek actors. In 1 in 17 and 19 statements, respectively, these institutions addressed German or Spanish actors, and in 1 in 30 cases they did so with France, Spain and Italy in mind.

In terms of numbers, these mutual references are a small part of the overall debate. Nevertheless, they show that the public debates in the various countries and on the various political stages were interrelated. This is most evident in Greece, where the economic and financial crisis made Greece an important point of reference for public debate and discourse. European and international actors were an integral part of the reporting in the Greek press. In our data set, there are 19 statements or announcements from these actors in 2009, and in the years between 2010 and 2012, this figure rose to 40 to 53 per year, only to fall again in 2013 . However, it must be emphasised that our data set only collected public claims on a random basis, which is why the absolute number of statements was likely to 
Table 3.13 Global and European actors speak to addressees of the countries

\begin{tabular}{|c|c|c|c|c|c|}
\hline & \multicolumn{2}{|c|}{ Global actors } & \multicolumn{2}{|c|}{ European actors } & \multirow{2}{*}{$\begin{array}{l}\text { Total number of } \\
\text { addressees }\end{array}$} \\
\hline & $\bar{N}$ & $\%$ & $\bar{N}$ & $\%$ & \\
\hline France & 21 & 4.0 & 23 & 4.3 & 531 \\
\hline Germany & 27 & 5.1 & 31 & 5.9 & 527 \\
\hline Greece & 42 & 6.0 & 79 & 11.2 & 704 \\
\hline Italy & 28 & 3.8 & 25 & 3.4 & 737 \\
\hline Poland & 35 & 4.7 & 24 & 3.2 & 742 \\
\hline Spain & 20 & 3.8 & 27 & 5.2 & 520 \\
\hline Sweden & 0 & 0.0 & 2 & 1.0 & 209 \\
\hline Switzerland & 20 & 5.3 & 3 & 0.8 & 375 \\
\hline UK & 37 & 9.5 & 4 & 1.0 & 391 \\
\hline
\end{tabular}

Source: Livewhat WP3 political claims dataset.

Note: Total number of addressees outnumbers the sum of columns because only two categories of actors are listed.

be many times higher. It can therefore be assumed that "European" actors were heard in the Greek media at least once a week, certainly more often in the heated phase. These organisations included international organisations such as the IMF, the World Bank or the Organisation for Economic Cooperation and Development (OCED), the rating agencies (Fitch, Moody, Standard \& Poor's) and multinational banks and financial service providers such as Deutsche Bank or Commerzbank. Representatives of European institutions, such as the European Commission, the European Parliament, the Council of Ministers or the ECB, also contributed. Also present were the Spanish, Italian or French Prime Minister, the German Chancellor, the German Minister of Finance and the German Minister of Foreign Affairs.

These actors were quoted with their assessments of the economic situation in Greece. The statements included claims announcing a sharp rise in unemployment in 2010 (OECD, 7 July 2010), describing the situation of the Greek financial sector as disastrous (Goldman Sachs, 14 April 2010) and denouncing public debt (Bloomberg, 18 August 2010; IMF, 8 July 2013). Greek newspapers reported that rating agencies downgraded Greece's creditworthiness (Fitch, 12 December 2008; Standard \& Poor's, 9 May 2011) or warned investors not to invest in Greece (rating agencies 14 April 2010 and 4 December 2011). The EU institutions (Commission, ECB, Eurogroup) and leading member states were very frequently quoted with assurances that Greece would remain part of the euro (European Head of State, 5 December 2009; Olli Rehn, Commissioner for Economic and Monetary Affairs, 30 January 2010; Jean-Claude Trichet, ECB, 8 April 2010). Reference was repeatedly made to negotiations on the granting and extension of loans from European rescue packages (Commission President Jean-Claude Juncker, 13 December 2012; Poul Thomsen, Deputy Director of the IMF, 2 November 2013). At the same time, however, the demands of international lenders, the Eurogroup and important member states who linked a commitment of 
funds to structural reforms, became public. These actors were repeatedly quoted with their concrete demands. They dealt with the reduction of public debt (Angela Merkel, German Chancellor, 26 April 2010) and the strengthening of Greek competitiveness (IMF, 12 April 2010). To this end, European actors called for wage cuts and redundancies in the public sector (Troika, 5 October 2011), cuts in social benefits (IMF, 21 August 2009), tax increases and a reduction in tax relief (Troika, 10 July 2014), the privatisation of public enterprises (German federal government, 22 July 2011) or increased flexibility of labour markets (Troika, 10 September 2012). Dissent was only mentioned in passing, for example, when members of the European Parliament criticised the Troika's austerity policy and called for a change of course (14 January 2011). Differences between international lenders on the issue of Greek debt relief and restructuring also became apparent, as the IMF (13 November 2012), the European institutions (ECB, 26 April 2011) or the German government (Wolfgang Schäuble, Minister of Finance, 31 January 2011) took different positions on this issue. In general, however, the tenor of the objections and demands of international and foreign actors can be clearly heard. The objective was in line with a neo-liberal programme aimed at consolidating public budgets, deregulating markets, creating investment incentives and increasing competitiveness.

However, the interest of international organisations and European governments in Greece, which is reflected in Greek reporting, also implied that the "causa Greece" was also negotiated in the public debates of the other member states. This is particularly true for the years from 2010 to 2012 when the threat of national bankruptcy was tangible and calls for political action became unmistakable. This issue repeatedly attracted attention in Germany, which is also related to the fact that the German government claimed political opinion leadership at the European level. The handling of the financial and currency crisis was negotiated in the German newspapers between 2010 and 2012 as an explosive topic in European and domestic policy and was high on the minds of parties, associations and think tanks. This can also be illustrated with reference to our data. Even before the law on German participation in the first bailout package for Greece was passed, there were voices against the communitarisation of Greek debt (the liberal party FDP, 1 February 2010; the Chamber of Commerce Deutscher Industrie- und Handelskammertag President Martin Wansleben, 15 February 2010). This debate continued until the decision of the German Federal Constitutional Court, which declared Germany's participation in the EFSM constitutional (7 September 2011) (Peter Gauweiler, ChristlichSoziale Union member of the German parliament, 8 September 2011), although the opinion prevailed that the Greek sovereign debt crisis could create a domino effect, which is why it needed urgent resolution (Josef Ackermann, Deutsche Bank, 29 June 2011; Olli Rehn, Economic and Monetary Commissioner, 29 June 2011; Angela Merkel, German Chancellor, 28 September 2011). The position of the German federal government was repeated endlessly. Loans were linked to the fulfilment of strict reforms, debt relief with reference to the role of private investors and creditors excluded (Angela Merkel, 17 June 2011; 
Wolfgang Schäuble, Minister of Finance, 13 November 2012 and 9 April 2013; Jens Weidmann, President of the German Federal Bank, 20 May 2011). After all, Germans should not have to pay for the rescue of Greece (Angela Merkel, 12 August 2013).

The criticism was directed primarily at the Greek government. Some actors claimed that it had been a mistake to integrate the country into the eurozone (Kai Wegner, Christlich Demokratische Union, and Marco Buschmann, Freie Demokratische Partei, 11 May 2010; Helmut Kohl, former German Chancellor, 18 July 2011); others stated that Greece may have to be excluded from the monetary union again if reforms are not implemented (Philipp Rösler, German Minister of Economic Affairs, 7 November 2011). The opposition parties repeatedly attacked this strict position of the federal government and the international lenders, and they also spoke out against the disproportionate criticism of Greece (Sigmar Gabriel, Sozialdemokratische Partei Deutschland, 27 April 2010; Jürgen Trittin, Green Party, and Carsten Schneider, SPD, 12 August 2013). At the same time, it was stated that German aid should also be given out of self-interest (Peer Steinbrück, SPD, 22 June 2011 and 7 February 2013; Martin Schulz, President of the European Parliament, 17 November 2012). There are virtually no public protests in our data, with the exception of a call to demonstrations by the trade unions and other groups against the eurozone crisis policy (7 January 2012).

In other countries, the causa Greece is negotiated much less publicly. This applies to France, Sweden and Switzerland, but particularly to the UK, Italy and Spain, where our data set contains few public statements on this matter. In these few cases, it was primarily governments, banks or economic research institutes that commented on the economic and monetary consequences of Greece's sovereign debt crisis and addressed the possible implications for their own economies or currencies. Very rarely, trade unions spoke out against the EU's austerity policy towards Greece and raised concerns that this could also affect their own country. With these statements, the perspective also remained inward, because these references to the EU and other EU member states were ultimately about the position and role of one's own country in the European economic, monetary and/ or solidarity community.

\section{Public debates on the crisis: interlocked segmentation}

Since its beginnings in 2008, the European economic and financial crisis has also left its mark on the public discourses in the mass media. Many actors spoke up to discuss the causes and consequences of the crisis and to propose possible solutions. In the nine countries studied, for which newspaper data was collected and analysed (Germany, France, Greece, the UK, Italy, Poland, Sweden, Switzerland and Spain), it quickly became apparent that mass-mediated public discourses are conducted by political and economic elites. The vast majority of public statements about the economic and financial crisis can be attributed to governments, state agencies or political parties, banks and rating agencies, companies, employers' associations or economic research institutes, and to a certain extent also trade 
unions and organised civil society. Confrontational objections and protest activities were very rare. Debates on the crisis conveyed by the mass media thus mobilised only a very specific section of "public opinion" because here the voice of the social elites clearly dominates.

Additionally, the analyses have substantiated the fact that public debates about the crisis unfold in a partially open discursive space. On the one hand, they remained committed to a national arena and agenda; on the other hand, they were permeated with public statements from EU institutions and claimants from other member states. National and European debates about the crisis were not separate and secluded discourses but interwoven and interrelated discussions. Public discourses are thus nationally segmented, but horizontally and vertically interconnected.

This observation is in line with the findings of previous studies, which have shown that public debates in the mass media remain bound to a national frame of reference. They have provided evidence corroborating that countries have their own agendas and deal with common European topics in quite different ways (Gerhards 2001; Machill et al. 2006; Zschache 2016). The results of our own analyses emphatically confirm this picture because national discourses addressed the economic and financial crisis from different angles and stressed country-specific circumstances and consequences. However, our findings have also shown that this picture is too one-sided because national debates are not closed entities. Particularly within the EU, public interventions by the EU institutions and other member state actors are relevant news that have to be taken into consideration and will provoke comments or reactions. Public debates about the crisis might gravitate around one's own country, but the various national debates are embedded into a field of mutual influences and interrelations. This means that pan-European discourses can unfold within nationally segmented public spheres (Eder 2004; Trenz 2004; Pfetsch et al. 2006).

The empirical data presented in this chapter evidences that pan-European discourses developed in response to the economic and financial crisis but that these discourses remained committed to a national agenda. These pan-European discourses thus challenge simplistic assumption, given that they are European and national at the same time. In the first instance, pan-European discourses are patterned along national segmentations. The financial and economic crisis might have been a joint problem, but countries were affected differently, which means that the crisis remained much more in the public consciousness in the southern European countries, while the discussions in the northern member states reached a peak in 2008 and 2009 and levelled off afterwards. Additionally, issue agendas differed as well, because public statements centred on economic developments in Germany or Sweden, ailing banks in France or Switzerland, redundancies and the unemployed in Spain or Poland and public debt in Greece or Italy, to name but a few examples. The focus was on country-specific causes and consequences of the crisis and country-specific measures taken to overcome them.

These issues were discussed time and again in their global and European dimensions since one out of ten claims opened up a global problem horizon and 
just as many statements were made in European categories when they referred to the situation in other member states and/or looked at the European Union as a whole. However, there are also differences between countries in this respect. In Germany, Italy and Greece, the debates were the most enriched with European references when asking about the importance of the European problem horizon of the topics in question. In contrast, the debates in the UK, Sweden and Switzerland were the least open towards Europe; i.e., EU institutions and actors from other member states hardly ever got a chance to speak there, and the topics dealt with were hardly ever discussed in their European dimension. The fact that Switzerland is not a member of the EU and that the UK and Sweden are not members of the eurozone undoubtedly plays a role here. For these countries, the financial and economic crisis was only defined as an indirectly common problem, as it was seen as an external risk to the economic recovery of the British and Swedish economies. In the UK and Switzerland, the global dimension was much more important than the European dimension, as documented by the presence of global actors and global problem attributions in the media of these countries. This global dimension is due to the fact that the banking and financial sectors in both countries are particularly active outside of Europe.

This national "bias" of public debates on the "common" economic and financial crisis is to be explained by the fact that the investigation focused on public statements conveyed by the mass media. The primacy of the national element is linked to the structure of mass media systems (Machill et al. 2006; Brüggemann and Schulz-Forberg 2009; Zschache 2016; Segesten and Bossetta 2019). In fact, mass media are still primarily nationally organised and oriented, which means that public debates reported by the mass media continue to be linked to linguistic areas and national markets, especially when asking about the audience of these media, the readership of newspapers and the listeners of radio broadcasts. The news value of the reports depends on the perceived relevance of the contributions to the specific audience, which is why it can be assumed that global and European reports are "nationalised" to become more palatable. Reports on the global financial crisis and the risks to the single European currency, for example, will ask what this means for each country, which actors are affected, what consequences can be expected and what measures should be taken.

It can be assumed that such a national "filter" exists for the selection and presentation of public statements on the economic and financial crisis (Zamponi and Bosi 2016; Sommer et al. 2016) and that such a national filter is linked to the functioning and orientation patterns of mass media (Bijsmans and Altides 2007; Boomgaarden et al. 2013; Adam et al. 2019). However, this is not the only reason, because if the media were the central driving force behind this national bias, this would be reflected in our data set. Journalists and media representatives who speak up themselves in our data set should become spokespersons for such a national agenda. This assumption cannot be confirmed because journalists and publicists did not privilege a national agenda but spoke as often about a global or European problem horizon as the other actors did. 
It is plausible to assume that the national "bias" of public discourses about the crisis is determined by the dominant role of political elites within the public sphere (Bennett 1990; Boomgaarden et al. 2013; Skogerbo et al. 2016). In fact, the empirical evidence presented in this chapter shows that mass-mediated public discourses are dominated by actors with a national mandate. They are representatives of national governments, administrations or agencies, spokespersons of national employers' associations, often also members of national banks or companies, and also representatives of national trade unions and non-governmental organisations. Even if they operate on the international stage, their claims will very often be linked to their mandate and thus primarily addressed to a nationally defined audience.

Public debates about the crisis are thus divided or segmented nationally for understandable reasons. However, this national element does not rule out the possibility of these debates having cross-border structures. As has been shown, the same events and topics are being discussed, common partial discourses are also unfolding, and there is also talk about each other. Although national segmentation is the dominant feature, the interconnections between national debates within a pan-European area of communication is a secondary but not insignificant feature (Trenz and Eder 2004; Pfetsch et al. 2006; Caiani and Guerra 2017; Segesten and Bossetta 2019). In this sense, public discourses unfold as a network of segmented debates.

According to our findings, this interweaving of national debates takes place along the aforementioned elements. First of all, common events and issues were discussed in all countries. This might seem trivial because it is the function of the mass media to report about news. However, mass media do not fulfil this function in the sense of a mirror image since the actors involved and the mass media that circulate these claims interpret, construe and translate these events. This applies in particular to the public debates on the economic and financial crisis, since the current situation had to be initially considered to be "crisis-like", and actors had to agree on such an assessment if crisis perception was to establish itself as "public opinion" (Bohmann and Vobruba 1992; Stråth and Wodak 2009; Coleman 2013; Lahusen Kousis, Kiess and Paschou 2016). The interpretation of a situation as a crisis is necessarily linked to public debate because such interpretations must be negotiated, recognised and shared. At the same time, this discursive construction remains fundamentally conflictual because the assessment of a situation as critical releases criticism of existing conditions and implies the need for action. Thus, crisis discourses are always controversial discourses on the correct diagnosis and the appropriate remedies (Fairclough 1993; Hay 1996; 2002; Kiess 2019).

With regard to the crisis discourses in the nine countries examined, the debates were dominated by an economic, monetary and financial policy agenda, with two-thirds of all public claims relating to these fields. The areas of work and employment fell sharply, with a greater focus on high unemployment and job security, especially in the first year of the 2009 crisis. Social and health policy issues played an even more marginal role, and this also affected those countries that were hit hardest by the recession, high mass unemployment and the 
impoverishment of entire sections of the population (especially Greece, but also Italy and Spain). The unison between the countries is surprising and speaks for a pan-European basic consensus shared by the actors raising their voices within the media. They saw the primary objective in stabilising the banking and financial sectors, improving the competitiveness of the economy, reducing public debt burdens and strengthening the single currency. Social policy measures played an accompanying role in alleviating the social consequences of the economic and financial crisis. However, they ultimately had to comply with a supply-oriented policy approach that focused on economic growth by improving corporate investment decisions, bank liquidity and currency stability. Criticism of this dominant agenda was expressed as well, in the newspapers examined, but this was only a very small minority of statements.

A second striking element of these crisis debates, which points to a pan-European crisis discourse, can be found in the claims that advocated a pan-European solution to the problem. This debate gained momentum in 2010 when it became clear to governments that the crisis had caused massive distortions in the member states and could therefore entail incalculable risks for the internal market and the single currency. Although the debate was sparked by Greece's looming national bankruptcy, it also pointed to the problem of the high national debt of several member states (Ireland, Portugal, Spain or Italy). The fact that this partial debate placed a clear emphasis on monetary, financial and competition policy certainly has something to do with the competences of the European Union because in these areas the EU institutions are much more active than in the areas of labour market and employment, social and health policy. However, it also seemed decisive that the group of actors involved was quite small, as it consisted of the EU Commission, the European Central Bank, the Council of Ministers, and the International Monetary Fund. Apparently these actors were able to agree quite quickly on a general approach. At the European level, it can be stated without reservation that the battle to interpret the crisis, especially with regard to the causes and the steps derived from these, can be regarded as concluded as of 2010. The participants generally agreed that the crisis had a strong financial and fiscal policy component, which was largely attributed to the high level of debt of the states and banks and the imminent dangers for the common currency. The measures negotiated primarily concerned the member states that were part of the common currency (e.g., the euro rescue package and the various aid packages for Greece). However, our evaluations have shown that there was also a view in the other countries that there was no alternative to such a policy in order to get the European Economic Area off the ground again as a whole.

There is also a third indication of a European interlinking of public debates in the individual countries among the actors involved. Public debates about the economic and financial crisis centred mainly on national issues and agendas and mainly involved actors from the respective countries. However, the European institutions and some member states (in particular the German government) repeatedly appeared in the newspaper reports of other countries with their assessments and demands, particularly frequently in Greece, but again and again also 
in Poland, Italy and Spain. At the same time, the situation in other countries was repeatedly the subject of country-specific debates, because the causa Greece, for example, was often discussed by the German government, the German economic institutes or associations. Particularly with regard to Greece and Germany, the public debates were interlinked on a transnational basis, as they were always talked about and both referred to one another. In quantitative terms, these crossborder claims are only a small proportion of all statements printed in the newspapers of the countries. But our data are based on a representative sample from a much larger overall population of public claims, which is why it can be assumed that such articles are likely to have appeared regularly (sometimes weekly) in the press.

The public debates about the crisis thus reveal the existence of a common political field in which the right way of dealing with the economic and financial crisis, including before the eyes of the mass media, was discussed. With regard to the field-theoretical frame of reference and the objectives pursued here, the question of whether this also constitutes a "European public sphere" does not appear to be the relevant one. The mass media continues to be primarily nationally structured, which is why debates mediated by the mass media also remain a national issue. This also applies to the debates on the economic and financial crisis. However, the field-theoretical frame of reference on which this study was based sensitises us to the fact that "published opinions" within the EU are pulled out of a purely national discourse space and are drawn into a common field of political will formation and decision-making. What European and national actors say about the crisis also becomes politically relevant for other countries in a common Europe. European and national actors therefore not only struggle within the EU institutions for binding decisions on how to deal properly with the crisis but also wrangle within the public space for the valid interpretation of the crisis and the justification of political decisions.

These observations are of particular importance for an analysis of people's political attitudes because they show that public opinions are expressed and formed within a pan-European field of debate and contestation. Controversies about the economic and financial crisis are not settled within a purely national arena of public debate, given that views from "outside" have an effect on the formation of "public opinions" about the extent to which the economy and society in the various member states were affected by the crisis and how well the crisis and its consequences were handled. Although the focus of the debates was primarily national, the severity of the crisis, the extent of the social upheavals and the appropriateness of the countermeasures in the respective countries were ultimately "comparatively" determined within a pan-European frame of reference. This is an indication of European standards of perception and assessment. The national frame of reference is obviously not dissolved but apparently embedded in a pan-European reference horizon. 


\section{A European compass \\ Citizens' perceptions of European living conditions}

European integration is having an impact on everyday life in various ways. Europeans have stepped up their mobility in recent decades when considering educational pathways, professional work and career development. They have developed informal contact networks, consumption habits and leisure time activities that frequently transcend national borders (Mau 2009; Kuhn 2011; 2012; Delhey et al. 2014). All this allows them to extend the range of their experience and knowledge beyond national borders within their personal life. Additionally, citizens make use of mass media and are thus enmeshed in public debates that recurrently address news from other European countries. In the face of various crises, there has been increasing attention focused on living conditions in other European countries and the interdependence of economic and political conditions (Vobruba 2012), as evidenced in the previous chapter. It is thus very likely that Europeans directly or indirectly relate the situation in other European countries to their own living conditions, thus encouraging people to place themselves on a European cognitive map.

The European Union is nurturing this European frame of reference explicitly (Beck and Grande 2007). Social cohesion and equal living conditions are among the EU's key objectives (EU Commission 2009; Council of Europe 2000; 2004; 2010), and instruments to measure and assess the performance of member states and their regions are at the very centre of European institutions and policies. In fact, the EU sees Europe as a common social space that must be integrated and harmonised legally through binding fundamental rights, politically through joint decisions and financially through structural funds worth billions (Kangas and Ritakallio 2007; Lahusen 2013). The implementation of European policy is accompanied by more or less binding processes of evaluation, control and sanctions (Hodson and Maher 2001; Heidenreich and Zeitlin, 2009; Jessoula 2015; Copeland and Daly 2018). Although these efforts in no way reduce economic and social inequalities between countries, regions and people to the desired extent, the EU is at least establishing a cognitive map of Europe, institutionalised in the form of databases and expert bodies, regular evaluations and decision-making processes. In this way, the EU urges political actors and the public to compare countries, regions and people. 
European integration should have thus shaped the way European citizens perceive and assess their own situation by animating them to compare themselves with other Europeans. This expanded frame of reference might have a significant impact on their perceptions and assessments of the social and political reality in which they live. This is to be expected if research on reference groups is taken into consideration. Many of these studies showed early on that people frequently compare their social situation with that of other groups (Merton and Kitt 1950; Kapteyn, van Praag and van Herwaarden 1978). People judge their own situation as good or bad not only in absolute categories but also relative to that of others, as better or worse. For this reason, the feeling of social disadvantage is very often a relational feeling, i.e., one of relative disadvantage or deprivation compared to other people (Walker and Smith 2010). In the search for relevant reference groups, research has identified a large number of real or imaginary reference groups, e.g., friends, neighbours or colleagues, professional groups, social classes or generations (van Praag 2011; Luttmer 2005; Goerke and Pannenberg 2015). Countries can also become points of reference for comparison because people compare their social situation with the perceived living conditions in other countries with demonstrable consequences for their own life satisfaction (Delhey and Kohler 2006; Lahusen and Kiess 2019).

The analyses of this chapter are guided by these insights and wish to assess the extent to which and how citizens perceive and assess differences between living conditions of various reference groups, among their friends, their neighbourhood, their country and most importantly, other European countries. This inquiry will prepare the ground for the subsequent chapters, which will be interested in the potential effect of perceived living conditions abroad on the political attitudes and evaluations of European citizens. Before embarking on this task, however, a number of questions have to be answered. Are Europeans able and ready to assess living conditions between European countries? To what degree do these perceptions deviate from the assessment of more immediate reference groups, such as friends or neighbourhoods? Do Europeans from different countries agree in regard to their perception of living conditions in other European countries? And how do they see their own situation, when compared to these assessments of living conditions abroad?

Data collected by Livewhat, an EU-funded research project (see Chapter 1), on the basis of an online population survey (CAWI) conducted in 2015, can be examined to answer these questions. The representative samples consist of at least 2,000 respondents from each of the participating countries (Germany, France, Greece, the UK, Italy, Poland, Sweden, Switzerland and Spain). Although this data set does not provide a complete picture of the EU with its former 28 member states, the country selection gives us a varied insight into the topic because these countries represent very different social realities, as will be shown. Data comes from old and new member states, as well as from a non-member country (Switzerland). There are economically strong and weak countries that were hit more or less severely by the economic and financial crisis, and levels and forms of social inequalities and societal divisions also diverge significantly. Additionally, this data set is well equipped to provide the 
necessary insights because it was built on a questionnaire that was explicitly interested in a comparison of living conditions, using different reference groups for this purpose. On this basis, it is possible to paint a nuanced picture of the divergent living conditions in a diversity of European countries and the specific ways European citizens perceive and evaluate them.

\section{Social divisions and perceptions of divergent living conditions}

Living conditions are, indeed, very different when comparing European countries. Scholarly writing explains these differences with reference to a number of factors, among them the strength of the national economy, the inclusiveness of the labour market, the magnitude of the welfare state and its measures of social redistribution (Beckfield 2006; Barbieri and Cutuli 2016; Heidenreich 2016a; Saltkjel 2018; Verbunt and Guio 2019). In more specific monetary terms, living conditions are determined by access to paid work, labour-market-specific wage levels and welfare-related social benefits on the one hand, and by the accessibility of goods and services within market economies on the other. These differences materialise in social inequalities, given that households have dissimilar levels of monetary income and consumption of goods. Commonly, these social inequalities are measured in terms of income differentials, risk of poverty rates and/or levels of material deprivation (Fusco, Guio and Marlier 2010; Guio 2018).

The available data paint a clear picture of diverging living conditions in European societies, as visualised in the following two graphs (Figure 4.1). The left figure plots the strength of the national economy (measured in gross domestic product per capita in purchase parity standards (PPS) in euro) against the percentage of households being materially deprived when considering economic
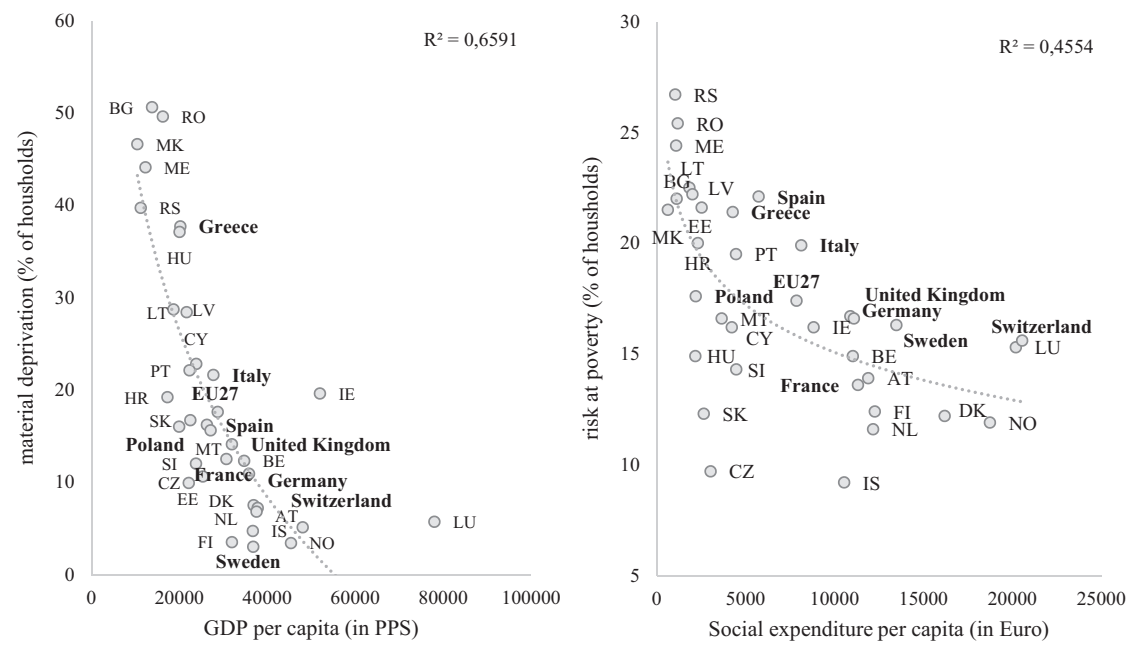

Figure 4.1 Living conditions - selected indicators (2015). 
strain, the availability of durables, housing deprivation and the environment of the dwelling. The right side graph plots levels of social expenditure per capita against the rate of households that are at risk of poverty, as they only earn less than $60 \%$ of the national median equivalised disposable income. The eight countries in the centre of attention are highlighted in order to show that they represent, by and large, the range of disparate living conditions in Europe.

The data show that European countries with a lower level of economic wealth per capita are also those with higher rates of households living in conditions of material deprivation. The fact that material deprivation is less extensive in Sweden, even though the GDP per capita is lower than the one of Switzerland, shows that economic development is not the only contextual condition impacting on material deprivation but also the generosity of the welfare state (Saltkjel 2018; Verbunt and Guio 2019). As indicated in the graph on the right, the percentage of households that are at risk of poverty, when considering their disposable income, is lower in countries with higher rates of social expenditure.

More information about the living conditions of households is provided in Table 4.1, which summarises available data on a number of socio-economic indicators for our nine countries. The rate of households suffering material deprivations while very low in Sweden and Switzerland is elevated in Greece, Italy and Spain. This has to do with the higher shares of households living under the statistical poverty line in regard to their income situation. These higher rates have to do, in the first instance, with higher unemployment rates, in particular, long-term unemployment, as joblessness deprives household members of earnings. However, unequal wages within the labour market also contribute to poverty rates, given that countries with higher levels of income inequalities are among those with a greater number of households living at risk of poverty. Finally, the generosity of the welfare state makes a considerable difference, given that the risk of belonging to a poor household is lower in countries with a welfare state investing higher sums of public funds into redistribution, and thus contributing to the household income through social benefits. However, there is also an indirect effect of the performance of the national economy, given that countries with a higher GDP per capita (and a higher growth rate) are also among those with a more proactive welfare state. The financial and economic crisis of 2008 has had a considerable impact on the economic development of the European Union, albeit with big differences between its member states. Switzerland, Germany and Sweden experienced only a short-term economic recession (Poland was marginally affected), while the Mediterranean countries - Spain, Italy and most notably Greece - were exposed to a longstanding economic crisis that has had considerable effects on living conditions.

Macro-economic development has had a clear impact on European citizens, given that a considerable share of the respondents participating in the Livewhat survey in 2015 reported less favourable socio-economic situations. Tables 4.2 and 4.3 summarise the finding of questions that tried to grasp the subjective perception of economic aggravations at the household and national levels. In the first instance, respondents were asked to assess the economic situation of their household compared 


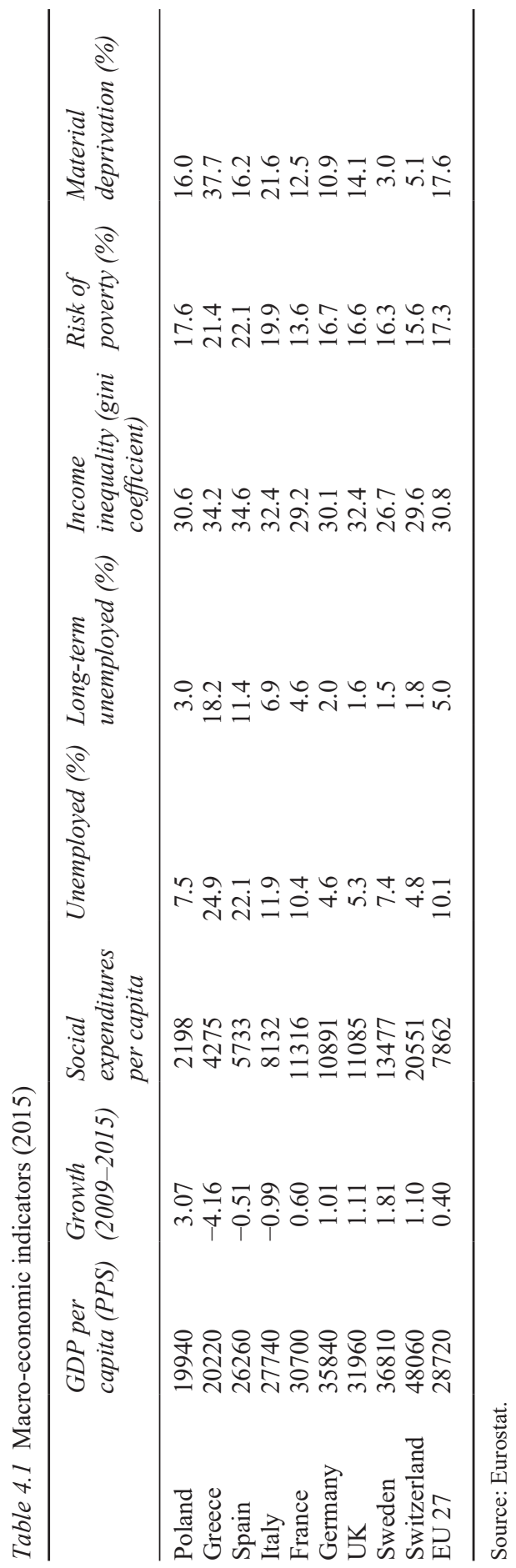


Table 4.2 Subjective perception of the household situation compared to earlier times (means, 1="much better" - 10="much worse")

\begin{tabular}{|c|c|c|c|c|c|c|c|}
\hline & \multicolumn{6}{|c|}{ Compared to } & \multirow{3}{*}{ Differences } \\
\hline & \multicolumn{3}{|c|}{5 years ago } & \multicolumn{3}{|c|}{12 months ago } & \\
\hline & Mean & $S D$ & $N$ & Mean & $S D$ & $N$ & \\
\hline Sweden & 4.88 & 2.64 & 1947 & 5.43 & 2.25 & 1920 & 0.54 \\
\hline Germany & 5.54 & 2.22 & 1988 & 5.68 & 1.82 & 1991 & 0.14 \\
\hline Switzerland & 5.77 & 2.33 & 1992 & 5.90 & 1.92 & 1967 & 0.14 \\
\hline United Kingdom & 5.84 & 2.47 & 1959 & 5.92 & 2.06 & 1965 & 0.08 \\
\hline Poland & 6.15 & 2.86 & 1979 & 6.16 & 2.53 & 1966 & 0.02 \\
\hline All & 6.48 & 2.71 & 17864 & 6.29 & 2.26 & 17761 & -0.19 \\
\hline France & 6.89 & 2.40 & 1952 & 6.69 & 2.11 & 1946 & -0.20 \\
\hline Spain & 7.05 & 2.51 & 2006 & 6.34 & 2.14 & 1992 & -0.70 \\
\hline Italy & 7.17 & 2.45 & 2001 & 6.71 & 2.20 & 1983 & -0.47 \\
\hline Greece & 8.89 & 2.21 & 2040 & 7.73 & 2.31 & 2031 & -1.16 \\
\hline
\end{tabular}

Source: Livewhat WP4 population survey.

to five years and twelve months ago, using in both cases a ten-point scale that has been recoded to run from one, "much better", to ten, "much worse", for the purpose of analysis. In the northern European countries, citizens tended to opt for the intermediary categories, indicating that respondents perceive their household situation to be neither better nor worse, that is, ultimately unchanged or stable. Answers vary around this opinion, on average two and a half points, but this shows that there is largely agreement among the vast majority of the surveyed population. Polish respondents marginally lean towards the negative assessment, but it is particularly the French, Spanish and Italian, who converge on the opinion that their households' living conditions have deteriorated. In the Greek case, it has become much worse. When taking a closer look at the assessment of the developments during the last 12 months, we see that the differences between countries shrink, given that the northern countries see, on average, a slight deterioration, while the Mediterranean countries report minor improvements. Greek respondents assess their household's situation more than one point less precarious, when comparing the last 12 months with five years ago, as the last column of Table 4.2 shows.

Respondents were also asked to assess the development of the national economy. The findings do not markedly diverge when compared to the evaluation of the household situation. British, German and Swedish respondents report a minor downturn, while the Italian, French and Greek respondents indicate substantial degradations. Overall, respondents paint a gloomier picture of the national economy (see the last column of Table 4.3) - with the exception of the British, who testified that the national economy is in a slightly better condition than their own households. However, the assessment of the personal and the national situation is very similar, thus reaffirming the ranking between the nine countries. In countries with a weaker performance of the national economy, the situation of 
Table 4.3 Subjective perception of the national economy - compared (means, 1="much better" $-10=$ "much worse")

\begin{tabular}{lllll}
\hline & \multicolumn{3}{l}{ Compared to 12 months ago } & $\begin{array}{l}\text { Difference to the } \\
\text { household situation 12 } \\
\text { months }\end{array}$ \\
\cline { 2 - 4 } & Mean & $S D$ & $N$ & -0.28 \\
United Kingdom & 5.64 & 2.16 & 1918 & 0.03 \\
Germany & 5.71 & 1.62 & 1916 & 0.40 \\
Sweden & 5.83 & 2.17 & 1862 & 0.39 \\
Switzerland & 6.29 & 1.63 & 1874 & 0.25 \\
Spain & 6.59 & 2.34 & 1987 & 0.45 \\
Poland & 6.61 & 2.39 & 1882 & 0.52 \\
All & 6.81 & 2.37 & 17346 & 0.97 \\
Italy & 7.68 & 2.31 & 1982 & 1.00 \\
France & 7.69 & 2.16 & 1909 & 1.31 \\
Greece & 9.04 & 2.06 & 2016 & \\
\hline
\end{tabular}

Source: Livewhat WP4 population survey.

the respondents' own household has also deteriorated; in those countries with a more stable economy, the personal living conditions remain largely unaltered. It would appear that the citizenry has a tendency to rank the living conditions of their household and their social environment in a highly congruous manner.

This general observation disregards the potential variations that might prevail within each of the nine countries. In fact, the economic situation of households differs considerably within each nation state, mirroring the social inequalities depicted above. Following these observations, it is to be assumed that the assessment of the economic situation and the potential aggravations reported by citizens will differ significantly between households in weak and strong economic conditions. Additionally, it is very likely that the different sensitivity towards past economic aggravations might be patterned by both the specific position of households in the stratification system of each country and by the joint experiences of citizens of the same country. This assumption requires validation, particularly because the ambition of this chapter is to highlight whether respondents assess their living conditions with "countries" as contextual frameworks.

In order to account for the internal variation of perceptions between and within countries, a linear regression analysis was calculated with the assessment of the household situation, compared to the living conditions five years ago, as the dependent variable. The two other items (i.e., the perceived economic development of the household and national economy in the last 12 months) generated similar findings, albeit with slightly lower effects. The analysis includes two sets of explanatory factors: the various countries of residence and a number of standard indicators of the respondents' social structural position (age, gender, migration background, education, income, occupational status). In regard to countries, we assume that residents will share a similar assessment of the economic situation of their household with countries in a better socio-economic situation (see 
Table 4.1 above) encouraging more positive assessments, while nation states with worse living conditions encourage feelings of economic deterioration. The fact that countries mirror specific socio-economic, institutional or cultural contexts will be disregarded for the moment and taken up in Chapter 6 because at this point of the analysis, it is important to unveil whether countries are a relevant reference point affecting the assessment of living conditions, as confirmed in general terms by previous studies (Kapteyn et al. 1978; Frey and Stutzer 2000; Böhnke 2008). In regard to the social structural position of respondents, we assume that vulnerability determines the perception of economic degradation, in the sense that households with a weak socio-economic condition (i.e., in terms of income, educational attainment, social class affiliation, occupational group) might experience social degradation much more directly than households with a stronger position.

Table 4.4 summarises the findings in two steps, focusing on country effects before and after including a number of social structural predictors. The findings show that the perception of economic deterioration is influenced by both the country of residence and the degree of social structural vulnerabilities, given that the overall explanatory power of the integrated model is higher than the one with country variables alone. That is, the effect of national contexts does decrease once the social divisions within countries are included in the model. However, the reduction is moderate and restricted to the German, Swedish, Polish and Italian respondents. Swedish respondents are among those who report less often about the degradation of their household situation when compared with the French; a similar observation applies to the German, Swiss, British and Polish respondents. In Spain and Greece, the likelihood of perceiving aggravations is much higher, particularly among Greek respondents who rank the economic situation of their households 2.1 points worse than those of the French. In terms of predictive margins, French respondents opted, on average, for a 6.8 on the 10-point scale, while Greek respondents chose an 8.9. In regard to individual vulnerabilities, households with the poorest income situation assess their living conditions more than one point worse than five years ago, when compared with households with the best income situation. The same is true for the unemployed or chronically ill respondents and those affiliating themselves with the lower middle or lowest social classes.

The two factors, national contexts and internal vulnerability, are interrelated, which means that the perception of deteriorating living conditions diverges considerably between poor and rich households of economically strong and weak countries. If we estimate the average assessments of different occupational groups (predictive margins) on the basis of the regression model above, we see how far apart the households from different countries are. Unemployed Greek respondents with a low household income will assess their household's situation as much worse than it was five years ago (9.94 points on the 10-point scale), while Swedish respondents in the same situation indicate a modest decrease only (an estimated average of 6.4). Fully employed Swedish citizens with high incomes report a slight improvement (an average of 4.4), while the same respondents in Greece argue that they are confronted with a considerable degradation of their 
Table 4.4 Perception of the household's living conditions (OLS regression, marginal effects)

\begin{tabular}{|c|c|c|}
\hline \multicolumn{3}{|l|}{ Country (France) } \\
\hline Sweden & $-1.994 * * *$ & $-1.545 * * *$ \\
\hline Germany & $-1.316^{* * *}$ & $-0.854 * * *$ \\
\hline Switzerland & $-1.080 * * *$ & $-0.809 * * *$ \\
\hline United Kingdom & $-1.000 * * *$ & $-0.906 * * *$ \\
\hline Poland & $-0.689 * * *$ & $-0.319 * * *$ \\
\hline Italy & $0.251 * * *$ & 0.007 \\
\hline Spain & $0.231 * * *$ & $0.353 * * *$ \\
\hline Greece & $2.082 * * *$ & $2.089 * * *$ \\
\hline Age (std.) & & $0.430 * * *$ \\
\hline Gender (male) & & $0.087 * *$ \\
\hline Born in country (yes) & & $-0.210 * * *$ \\
\hline \multicolumn{3}{|c|}{ Educational attainment (university) } \\
\hline Secondary & & -0.055 \\
\hline Less than secondary & & $-0.140 * *$ \\
\hline \multicolumn{3}{|l|}{ Income (highest tercile) } \\
\hline Middle tercile & & $0.432 * * *$ \\
\hline Lowest tercile & & $1.106^{* * *}$ \\
\hline \multicolumn{3}{|c|}{ Subjective social class (upper) } \\
\hline Middle & & $0.393 * * *$ \\
\hline Lower middle & & $0.864 * * *$ \\
\hline Lower & & $1.425 * * *$ \\
\hline \multicolumn{3}{|l|}{ Main activity (full time) } \\
\hline Part-time employment & & $0.111^{*}$ \\
\hline In education & & $0.416 * * *$ \\
\hline Unemployed & & $0.904 * * *$ \\
\hline Chronically ill & & $0.934 * * *$ \\
\hline Retired & & $-0.153 * *$ \\
\hline Housework, care & & 0.146 \\
\hline Observations & 14523 & 14523 \\
\hline Pseudo $\mathrm{R}^{2}$ & 0.178 & 0.292 \\
\hline
\end{tabular}

Significance level: $* P<0.1 ; * * P<0.05 ; * * * P<0.01$.

Data Source: Livewhat WP4 population survey.

living conditions (an average of 7.9). It is noteworthy that unemployed Swedish respondents report a less drastic deterioration in their living conditions when compared to the employed Greek respondents.

Obviously, this peculiar ranking does not entail that the two groups have similar living conditions because our dependent variable measures perceived changes across time. In regard to objective indicators, we can expect that the poorest Swedish households will be exposed to stronger vulnerabilities than Greek households with a very good income situation. However, what these comparisons show is that the perception of relative deprivation is strongly dependent on the country of residence. Respondents from the same country share similar experiences, albeit 
on different levels of personal wealth. These findings indicate that respondents share an understanding of how their countries are doing, what the standard of living conditions is, with which they compare themselves and how they have generally developed across time. This consensus hints at comparative assessments between countries. The fact that Greek respondents agree on the weakness of their economy and household situation, while Swedish respondents discard significant deteriorations of their economy and personal living standards does not seem to be determined only by their being asked to compare today's situation with the situation in previous times. It seems as though respondents share a feeling of where they are placed in comparison with other countries and citizens.

\section{The relevance of European living conditions for people}

These preliminary findings raise the question of whether "countries" are relevant reference groups with which individual respondents compare themselves when assessing their living conditions and forming political perceptions and opinions. Earlier studies have provided evidence supporting the assumption that countries are relevant reference groups (Kapteyn et al. 1978). This applies for one thing to one's own country because it has been shown that the perception of economic, social and political conditions in one's own country has a discernible influence on personal life satisfaction (Frey and Stutzer 2000; Böhnke 2008). But a comparison with living conditions in other countries has also proved to be an equally reliable factor. This insight was gained from studies by Jan Delhey and his research team because survey data from 1999 and 2002 enabled them to determine the influence of the perceived living conditions of a number of reference groups, such as friends, neighbours, fellow citizens of the country, and also other countries, on personal life satisfaction. The comparison with other countries was validated as an influential factor in these studies (Delhey et al. 2002; Delhey and Dragolov 2014; Lahusen and Kiess 2019).

However, until now, research has not been interested in whether such comparisons also shape people's political attitudes. These questions will be addressed in this and the next chapters on the basis of the data presented above. It is necessary to remember that this survey was conducted in 2015, i.e., during the European economic and financial crisis. Disparities and inequalities between countries are expected to be more virulent and prominent in such times. Macro-economic indicators (e.g., economic performance and growth, employment and unemployment, salaries and income) confirm that national differences have widened since 2008 (Barbieri and Cutuli 2016; Heidenreich 2016a). And as was shown in the previous chapter, the living conditions in the member states and the political measures to overcome the crisis were discussed intensively in the countries (Kutter and Jessop 2015; Monza and Anduiza 2016; Sommer et al. 2016). It can be assumed that there is also likely to be heightened public awareness of differences in national living conditions in times of crisis and that people are also likely to be able to compare themselves with other Europeans in these circumstances. 
Data collected in the Livewhat project is used to examine countries as reference groups. In this investigation, people were asked to place other countries on an 11-point scale, after placing their own country. The list included the nine countries that were part of this project, which makes it possible to provide data on eight benchmarks. For each country, respondents made their assessments using a scale ranging from 1 ("very bad living conditions") to 11 ("very good living conditions"); "don't know" was also a possible answer. In addition to these questions, the participants were asked about their own current living conditions as well as the conditions in the neighbourhood and among friends, each along the same scale. In addition, there were questions about assessing the living conditions in one's own country.

Looking at the results, the first thing of interest is whether respondents have the confidence to assess living conditions in other countries. For this purpose, Table 4.5 shows the percentage of respondents who selected "don't know" for each of these questions. In the italic parentheses, the proportions of respondents who do not know the living conditions in their own country are added.

It can be seen that only a very small minority is not able to estimate how good or bad the living conditions in other European countries are. The proportion of people who feel unable to rate their own country is even lower, which indicates that they are even more familiar with their own country's conditions. In regard to the assessment of other countries, the differences are rather small. British citizens are consistently more often unable to evaluate the living conditions abroad because the proportion of "don't know" ranges between $11.6 \%$ (in regard to Greece) and $13.7 \%$ (Italy). The readiness to assess living conditions abroad also varies very little for the other respondents because the shares of "don't knows" are either 4\% (Italy), 7.5\% (Greece) or $11.4 \%$ (Poland) apart.

On closer inspection, respondents particularly believe they can make an assessment with regard to living conditions in Greece and Germany. People are the least likely to assess the situation in Poland. The attention that Greece and Germany have received in public debates on the EU's economic and financial crisis may explain this noticeable accumulation. The fact that many people feel more familiar with living conditions in Switzerland than with those in Poland may have something to do with cultural proximity and the historical heritage of the division of Europe. However, this cannot be fully clarified.

The socio-structural profile of those who do not believe they can answer the question of living conditions in other countries can be determined more clearly. For this purpose, a binary logistic regression analysis was performed, which tries to determine whether the people who ticked "don't know" differ from those who provided an answer (no matter which one). It is to be assumed that those respondents who do not feel confident in their assessment are among the more disadvantaged in terms of social structure, are less frequently informed via the mass media and also have less social capital in the form of personal contacts and organisational memberships. They are likely to be less well-connected and less informed. To check whether these effects are not caused by socio-demographic factors, such as age, gender or migration background and differences between countries, these factors were also included in the calculations. 


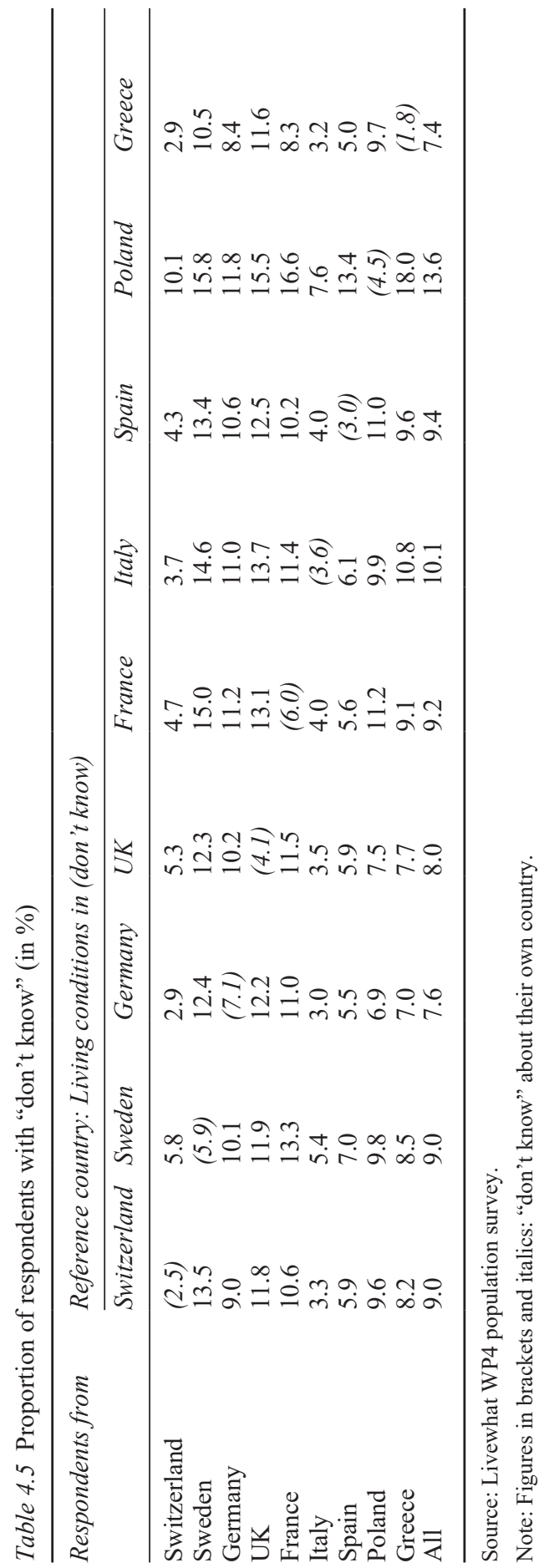


The results in Table 4.6 largely confirm these assumptions. As can be seen, this table has refrained from extending the evaluations to all nine reference countries. Instead, only the results of the two countries that cover the spectrum of response behaviour have been determined. These are the countries with the lowest (Greece) and highest (Poland) shares of "don't know" answers. As will be shown, the explanations for the response behaviour are similar in both cases. Finally, it should also be noted that the total number of cases taken into account varies, as respondents from Greece and Poland were asked to assess the living conditions in the other countries and are not taken into account in regard to their own country.

Overall, the explanatory power of the model with its various influencing factors is not very high. In the Greek case, the $r^{2}$ coefficient is higher than in the Polish case. This may be due to the fact that the number of people who did not want to respond varied between the two countries. In the Greek case, there were fewer respondents, increasing the likelihood that they are people with a similar social profile. In the case of Poland, the group was larger and possibly also more socially heterogenous. Despite the generally low explanatory content, however, the findings still give us information about the social profile of people who do not believe themselves capable of making an assessment.

Educational attainment is one of the more important determinants, as people with lower educational attainment tend more often not to give an answer to the question of living conditions in Poland. The relative probability of not answering the question is $3.7 \%$ higher among respondents with the lowest educational attainment level when compared with those with university degrees. It is possible to identify the expected shares predicting probabilities on this basis. Only $9.2 \%$ of people with a university degree do not provide an answer; this proportion increases by $2 \%$ and $3.7 \%$ to $11.2 \%$ and $12.9 \%$ for those with secondary education and those without a school-leaving qualification, respectively. For Greece, the relative difference is estimated to be $3.3 \%$, which means that the predictive probability increases from $3.6 \%$ to $6.9 \%$ when comparing the group with the lowest and highest level of education. It is also remarkable that the budgetary situation has an influence on response behaviour. More often than not, people do not respond if they live in a household that is economically worse off than before. It can be assumed that this is an effect of social disadvantage. The fact that the subjective stratification assessment has a similar effect also fits this assumption. People locating themselves at the lower end of the stratification structure more often state that they do not know the conditions in other countries - even if this effect is statistically significant only for Poland.

In addition to these socio-structural characteristics, it was shown that media consumption makes a difference. People who do not regularly inform themselves via the mass media also frequently do not provide an answer. Social capital also plays a role because people who meet with friends more often and are also members of one or more (volunteer) organisations put a "don't know" on record less often. In addition to the mass media, friends and organisations seem to offer a means of finding out about living conditions in other countries. Finally, the results show that women fail to respond more often than men. The youngest and older 
Table 4.6 Social profile of respondents with "don't know" (logistic regression, average marginal effects)

\begin{tabular}{|c|c|c|}
\hline Don't know living conditions in & Greece & Poland \\
\hline \multicolumn{3}{|l|}{ Socio-structural position } \\
\hline \multicolumn{3}{|l|}{ Education level (ref: university degree and above) } \\
\hline Secondary education & $0.013 * * *$ & $0.020 * * *$ \\
\hline Lower than secondary education & $0.033 * * *$ & $0.037 * * *$ \\
\hline \multicolumn{3}{|l|}{ Household situation (ref: better than before) } \\
\hline About the same & 0.007 & 0.005 \\
\hline Worse & $0.025 * * *$ & $0.026 * * *$ \\
\hline \multicolumn{3}{|l|}{ Subjective class assignment (ref: upper classes) } \\
\hline Middle class & 0.008 & 0.018 \\
\hline Lower middle class & 0.005 & 0.005 \\
\hline Working class and lower class & $0.017 * *$ & $0.038 * * *$ \\
\hline \multicolumn{3}{|l|}{ Informedness and social capital } \\
\hline Regular newspaper reader (ref: min. 3 days/week) & $0.022 * * *$ & $0.041 * * *$ \\
\hline \multicolumn{3}{|l|}{ Meeting friends (ref: less than once a week) } \\
\hline $1-2$ times a week & $-0.014 * * *$ & $-0.025 * * *$ \\
\hline Every week and more & $-0.016^{* * *}$ & $-0.024 * * *$ \\
\hline \multicolumn{3}{|l|}{ Member in organisations (ref: no) } \\
\hline In one & $-0.022 * * *$ & $-0.035^{* * *}$ \\
\hline In two & $-0.028 * * *$ & $-0.036^{* * *}$ \\
\hline In three and more & $-0.043 * * *$ & $-0.064 * * *$ \\
\hline \multicolumn{3}{|l|}{ Socio-demographic factors } \\
\hline Gender (ref: male) & $0.025 * * *$ & $0.051 * * *$ \\
\hline \multicolumn{3}{|l|}{ Age (Ref: $25-44$ years) } \\
\hline $18-24$ & -0.006 & 0.003 \\
\hline $45-64$ & $-0.023 * * *$ & $-0.030 * * *$ \\
\hline $65+$ & $-0.029 * * *$ & $-0.020 * *$ \\
\hline Migration background (ref: no) & -0.006 & 0.003 \\
\hline \multicolumn{3}{|l|}{ Place of residence (ref: city and surroundings) } \\
\hline (Small) town & -0.001 & -0.002 \\
\hline Village and countryside & 0.005 & 0.002 \\
\hline \multicolumn{3}{|l|}{ Country (ref: United Kingdom) } \\
\hline France & $-0.050 * * *$ & $-0.020 * *$ \\
\hline Germany & $-0.045^{* * *}$ & $-0.047 * *$ \\
\hline Sweden & 0.009 & $0.026^{* *}$ \\
\hline Poland & $-0.029 * * *$ & - \\
\hline Italy & $-0.078 * * *$ & $-0.075^{* * *}$ \\
\hline Spain & $-0.059 * * *$ & -0.006 \\
\hline Switzerland & $-0.073 * * *$ & $-0.033 * * *$ \\
\hline Greece & - & $0.022 *$ \\
\hline Observations & 14.459 & 14.591 \\
\hline Pseudo $\mathrm{R}^{2}$ & 0.103 & 0.0663 \\
\hline
\end{tabular}

Source: Livewhat WP4 population survey.

Note: Significance levels: $* P<0.1, * * P<0.05$, *** $P<0.01$. 
respondents are significantly more likely to evaluate living conditions elsewhere compared to those in the middle of their careers and family life. The place of residence has no discernible influence, which means that it is also possible to rule out an urban-rural divide.

These findings show that people in socially disadvantaged situations abstain somewhat more frequently from providing an answer. Conversely, this means that the group of respondents who assess living conditions elsewhere have a slight middle- and upper-class bias. This can be seen not only in the higher level of education and the better economic situation of households. The greater availability of social capital also fits this stratification component because previous research has shown that the middle and upper classes have larger contact networks and increased organisational memberships (van Oorschot, Arts, Gelissen 2006; Warr 2006; Deutschmann and Delhey 2015).

Overall, it can be stated that people in the investigated countries are familiar with living conditions in other European countries. At least, they are so familiar with them that they are confident enough to make an assessment along a scale. Only a very small minority of respondents stated that they were unable to answer this question. It is remarkable that the proportion of respondents who are unable or unwilling to assess the situation in their own country is similar. These initial observations are important for further analyses. First of all, it can be seen that people are sufficiently informed about living conditions in other European countries as they are about those in their own country or at least that they are supported in their assessment by the media, friends or organisations. It can therefore also be assumed that people are so familiar with living conditions in other countries that they are likely to compare themselves with other Europeans. This would mean that other countries play a role for people as relevant reference groups. Later analyses will look at the consequences of these comparisons for people's political thinking.

\section{One's own place within a European space of unequal living conditions}

When looking at the vast majority of those who feel confident to assess the living conditions in other European countries, the answers are quite striking. Figure 4.2 summarises the results by showing how respondents assess living conditions in nine European countries. The scale ranges from 1 (very bad) to 11 (very good). The bars reflect the data of all respondents, with the exception of the inhabitants of the country, as only the living conditions outside their own country were assessed. It can be seen that the respondents assess the living conditions in Switzerland as very good because the median value is 10 , which means $50 \%$ of the respondents describe the Swiss conditions with an 11 as very good and $50 \%$ of responses are below. The grey bar shows that half of the respondents assess life in Switzerland between 9 and 11. The spike on the left side of the grey box indicates the assessments given by a further quarter of the respondents, in this case, a mediocre to good value (6 to 9 ). There are outliers, but the answers are scattered much less compared with answers for the other countries. 


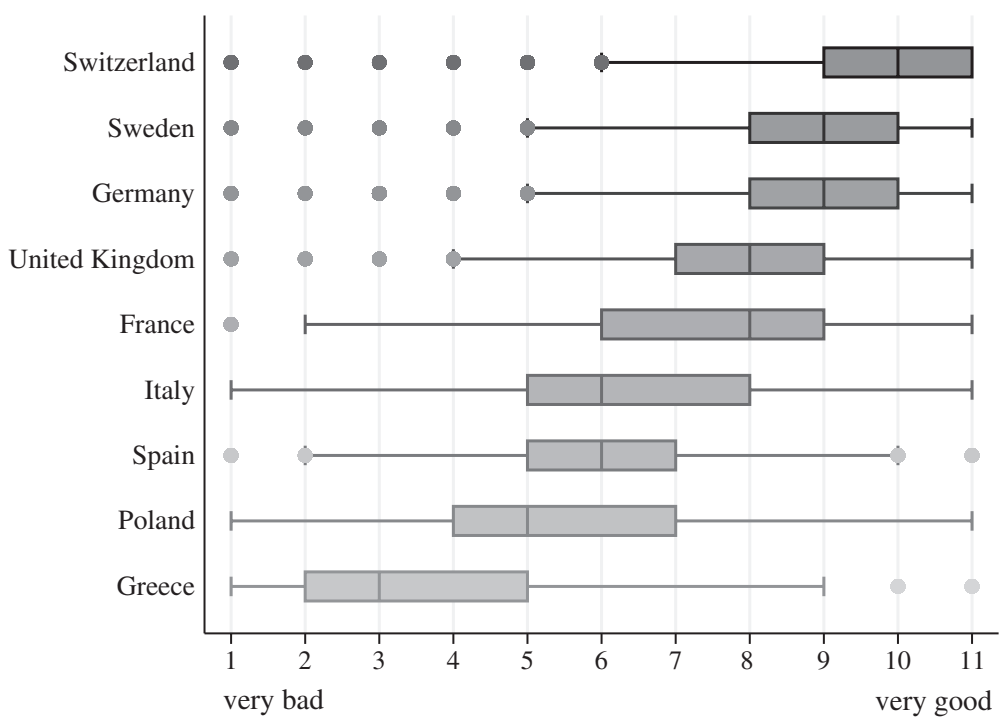

Figure 4.2 Living conditions in other countries (boxplot). Source: Livewhat WP4 population survey.

Sweden and Germany are placed behind Switzerland. Living conditions are also rated as good here as the median value is 9 ; the median $50 \%$ of respondents state between 8 and 10 . While the lower quarter rates the situation as less than good (5 to 8), the top quarter assesses the situation as excellent. The ratings for the UK, France and Italy dropped again by a few points on the scale, as did those for Spain and Poland. Additionally, respondents do not agree as much, as the range of the responses increases not only in the median $50 \%$ but also in the lower and upper quarters. For Poland, respondents use the entire range of values. The trend is for living conditions to be considered rather mediocre. Greece comes off worst in this assessment, even if the values are also scattered here.

The subjective assessments correspond to the picture that would be expected when consulting available indicators for country-specific living conditions. For example, following the OECD's Better Life Index, which includes a number of indicators such as housing, income and employment, education, environment, health, life satisfaction and security in the country comparison, an almost identical order for our countries in 2015 can be seen, with only Italy and Spain changing places. When looking at individual OECD indicators separately, there are some shifts. In the subjective assessment of their own health, Switzerland and Sweden are once again in the lead with a high number of satisfied people $(81 \%$ and $80 \%$ of respondents respectively). The UK and Greece are equal (74\%), followed by Spain (72\%), France (67\%), Germany (65\%) and Poland (58\%). Similar rankings are also repeated with regard to many other indicators, such as disposable 
Table 4.7 Assessment of the living conditions in the nine countries (mean values)

\begin{tabular}{|c|c|c|c|c|c|c|c|}
\hline & \multicolumn{3}{|c|}{ Self-assessment } & \multicolumn{3}{|c|}{ External assessment } & \multirow[t]{2}{*}{ Deviation } \\
\hline & Average & $S D$ & $N$ & Average & $S D$ & $N$ & \\
\hline Switzerland & 8.27 & 2.15 & 1994 & 9.50 & 1.63 & 14859 & 1.23 \\
\hline Sweden & 8.24 & 2.06 & 1900 & 9.09 & 1.73 & 14884 & 0.85 \\
\hline Germany & 7.97 & 2.00 & 1958 & 8.66 & 1.83 & 15023 & 0.69 \\
\hline UK & 7.61 & 1.95 & 1940 & 7.97 & 1.89 & 15039 & 0.36 \\
\hline France & 6.22 & 2.10 & 1905 & 7.61 & 1.83 & 14834 & 1.39 \\
\hline Italy & 4.86 & 2.10 & 1967 & 6.19 & 1.96 & 14672 & 1.33 \\
\hline Spain & 5.69 & 2.03 & 1975 & 6.09 & 1.93 & 14793 & 0.40 \\
\hline Poland & 5.25 & 2.19 & 1933 & 5.38 & 1.88 & 14125 & 0.13 \\
\hline Greece & 4.12 & 2.01 & 2011 & 3.76 & 2.15 & 15105 & -0.35 \\
\hline
\end{tabular}

Source: Livewhat WP4 population survey.

household income, where Switzerland, Germany and Sweden are at the top of the list with US\$ 33,491, US\$ 31,252 and US\$ 29,185, respectively. They are followed by France (US\$ 28,799), the UK (US\$ 27,029), Italy (US\$ 25,166), Spain (US\$ 22,477) and Greece (US\$ 18,575), which is why Poland (US\$ 17,852) drops to the end (OECD, 2014). ${ }^{1}$

Overall, the findings show that respondents in the nine countries are generally in agreement as to which countries have the best and worst living conditions. The ranking that people make is also confirmed when looking at how respondents view living conditions in their own country. As can be seen in Table 4.7, the Swiss and Swedish respondents also believe that conditions in their country are very good, while those from Greece consider the conditions to be rather mediocre. Only the Italians are changing the order because they evaluate the conditions in their own country to be almost the same as those in Greece.

What is interesting about the findings is the difference between the external assessment and the self-assessment because the conditions in one's own country are assessed more negatively almost everywhere than they are from outside. This is shown by the mean values of the respective estimates and the deviation between the two values, which are listed separately in the last columns. The deviation is particularly pronounced for France, as self-perception is at a moderate 6.22, while the external assessment of French living conditions has turned out better at 7.61. The same applies to the Swiss, as they consider the living conditions in their country to be quite good with an average of 8.27; however, the respondents from all other countries rate the situation in Switzerland 1.23 points better. This picture is repeated in most countries, albeit at a lower level. In Spain, the UK and Poland, the differences are smaller but point in a similar direction. The opposite is 
the case only with Greece because although the Greeks consider the situation in their own country to be rather poor, respondents from the other countries assume an even more negative situation. Media coverage of the economic crisis and its disastrous consequences for life in Greece has obviously had a very clear impact on people's perception.

Finally, it is striking that all respondents rate living conditions in other countries quite similarly. In fact, Table 4.7 shows that external assessments are less scattered than self-perceptions, as can be seen from the standard deviation. In terms of self-perception, respondents' assessments vary by two points around the mean value, while this value drops noticeably for the external assessment, especially for the two top-ranked countries. It is only with regard to Greece that opinions differ somewhat more. This unanimity is remarkable inasmuch as the respondents from all other countries were taken into account in the external assessment, which means that more than seven times as many opinions were included than for the assessment of living conditions in respondents' own countries. The circle of participants is therefore much larger, and yet the assessments are much closer together.

Especially with regard to the best-placed countries (Switzerland and Sweden), there is a great deal of consensus about the living conditions there, while the opinions among the countries in the lower ranks vary more significantly. This may be because respondents are less certain with regard to the less well-off countries but more confident in agreeing about the good situation in the best-ranked countries. Additionally, it is very likely that the respondents have assessed living conditions in a comparative manner. Spanish respondents, for instance, will agree that the situation in Switzerland is likely to be very good, while opinions differ more strongly when it comes to assessing the situation in France, Poland or Greece, which are perceived to be closer to the Spanish living standards. The assumption that the assessments always contain a comparative component is reasonable because the questionnaire design suggested this comparison. The respondents always assessed the living conditions in the nine countries as an overall package, i.e., they had to tick the boxes for all countries one after the other. The respondents may have therefore followed an implicit ranking in the individual assessments.

This comparative and relational assessment of living conditions in Europe can be empirically verified when comparing the average assessments per country and checking whether the deviations between the mean values are also statistically significant. In other words, it can be assumed that the respondents differ in their assessment of living conditions in other countries because they always judge the situation from the perspective of their own situation. It is therefore conceivable that the Swedish respondents do not portray Swiss living conditions as good as the Greeks because the Swedish respondents are likely to judge Switzerland from a much higher standard than the Greeks.

A multivariate analysis of variance (ANOVA) is recommended to verify this assumption. The respondents from France were used as a reference group for this purpose. This enables us to clarify to what extent the average ratings of respondents from the other eight countries differ from those of the French sample. For example, it will be determined whether people from Switzerland or Sweden assess 
the situation in other countries worse on average than those from France, since the former look at all other countries from a higher reference value than the latter, and whether the respondents from Greece or Poland assess living conditions better elsewhere than the people from France, since the situation in their own country is perceived as less good. As can be seen from Table 4.8, this is indeed the case. The Swiss, for example, assess the situation in other countries almost consistently worse than the French, which makes it clear that they do this assessment from a higher perceived standard of living than the French. With regard to the UK, this deviation is more than half a point on a scale of 11 points. This assumption is also confirmed by respondents from Poland and Greece, where the assessment of living conditions in the other countries is much more positive than in the French sample. People from Poland rate the situation in Germany and the UK more than one and a half points better than the French group, and in relation to Italy even more than two points.

The picture is less clear with the other survey groups because people from Sweden, Germany and the UK also assess the situation in other countries almost consistently better than those from France. Conversely, this means that respondents from France see living conditions in Italy or Germany in a worse light than those from the UK by more than one point. But this is also due to the fact that the social situation in France is viewed more negatively by the locals as a whole. This was already shown in Table 4.7 above. Respondents from France also consistently rate other countries worse when their assessments are compared with those by the other samples. Separate calculations show that people in France rate living conditions in Sweden at 8.6 points, at least half a point worse than all other respondents, with the exception of people from Switzerland. The same applies to the assessment of the other countries.

When summarising the results so far, it can be seen that the people of all the countries investigated live and think in a European reference area. They are in a position to assess social conditions in other countries, and they largely agree in their assessments of the countries in which social conditions are good, mediocre or bad. The assessments differ from one another to some extent because people judge the situation elsewhere from their (national) perspective. Respondents from countries with poorer living conditions tend to assess the situation in other countries to be better compared to people living in countries with good living conditions because the latter always gives the situation in the same countries a slightly worse rating. But the consensus about the quality of life in different European countries is remarkable. Europe is therefore perceived as a social space with unequal living conditions. And one's own country is located within this hierarchically ordered space, with a generally agreed-upon position. Citizens tend to view the living conditions in their own country as somewhat worse when self-perception is compared with external assessments, but this changes little in the ranking.

These findings raise the follow-up question on where the respondents situate their personal situation in this social space. How do people assess their current living conditions? Do the people of the different countries also differ from one another in this respect? And what is the relationship between one's own living 


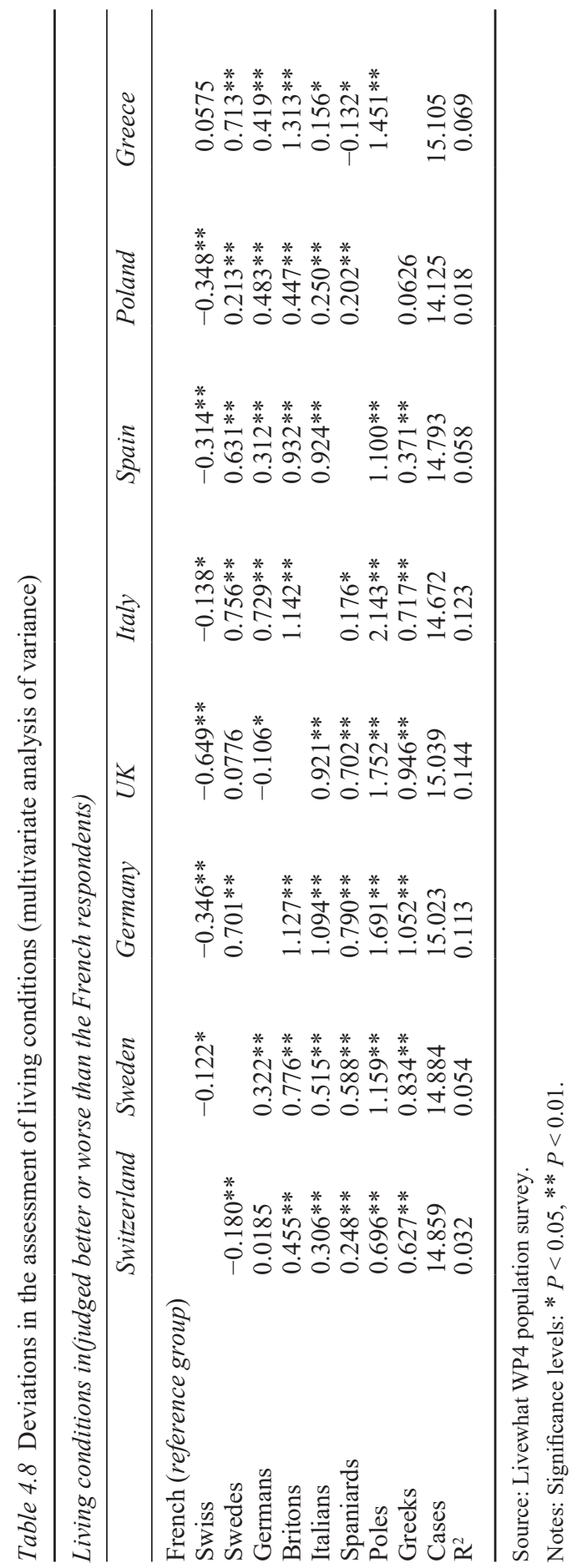


conditions and the perceived situation of other groups or countries? In order to answer these questions, I will add another variable to the analyses. In the questionnaire, people were also asked to assess their own current living conditions. The 11-point scale marked the differences even more clearly since it compared the "worst imaginable" and the "best imaginable living conditions".

A look at the frequency distributions on this scale shows that the assessments of people follow a similar pattern (see Figure 4.3). The majority of people position themselves more in the middle of the scale. The figures drop towards the margins as fewer respondents say they live in particularly bad or good conditions. However, the majority of respondents tend to describe their personal situation as good, and this is especially true for people from Switzerland, Sweden, Germany and the UK. But in the other countries, the assessment also tends to be rather positive, which is why an accumulation of negative assessments can only be found in Greece. Here the proportion of people who describe their position as the "worst imaginable" (9.4\%) or as rather poor (18.8\% at scale point 4$)$ is increasing.

The statistical measures confirm the visual impression of the bar graphs shown, as demonstrated in Table 4.9. However, they indicate even more clearly
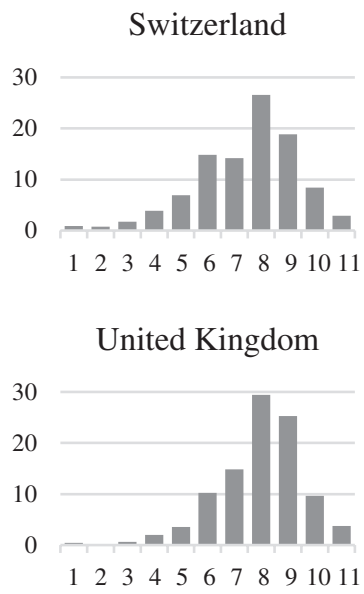

Spain

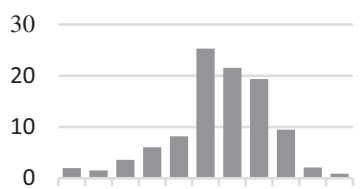

$\begin{array}{llllllllll}1 & 2 & 3 & 4 & 5 & 6 & 7 & 8 & 9 & 1011\end{array}$ worst
Sweden

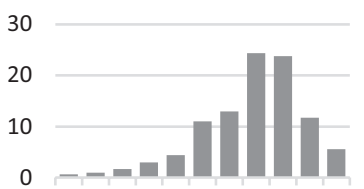

$122 \quad 3 \quad 4 \quad 5 \quad 6 \quad 7 \quad 8 \quad 91011$

France

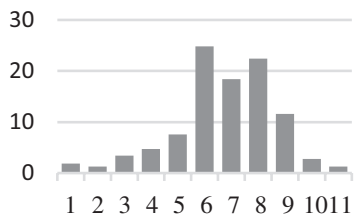

Poland

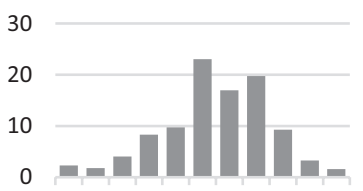

1234567891011 worst best living conditions
Germany

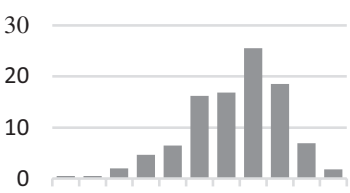

$\begin{array}{llllllllll}1 & 2 & 3 & 4 & 5 & 6 & 7 & 8 & 9 & 1011\end{array}$

Italy

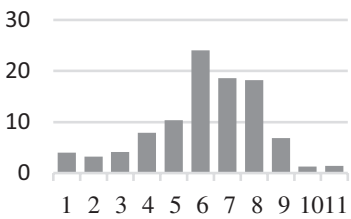

Greece

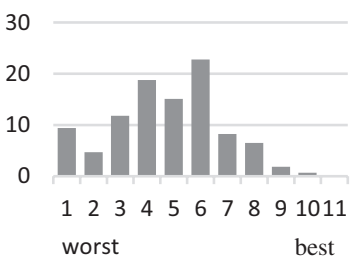

Figure 4.3 Assessment of own living conditions per country (in \%). Source: Livewhat WP4 population survey. 
Table 4.9 Assessment of own, current living conditions, per country

\begin{tabular}{llllll}
\hline & Mean value & $S D$ & Skewness & Kurtosis & $N$ \\
\hline Switzerland & 7.45 & 1.90 & -0.70 & 3.61 & 1998 \\
Sweden & 7.85 & 1.92 & -0.86 & 3.92 & 1951 \\
Germany & 7.34 & 1.81 & -0.60 & 3.37 & 1949 \\
UK & 7.94 & 1.62 & -0.83 & 4.54 & 1964 \\
France & 6.74 & 1.89 & -0.65 & 3.72 & 1920 \\
Italy & 6.16 & 2.09 & -0.55 & 3.21 & 1983 \\
Spain & 6.55 & 1.87 & -0.62 & 3.67 & 1969 \\
Poland & 6.48 & 2.03 & -0.43 & 3.16 & 1986 \\
Greece & 4.77 & 2.06 & -0.03 & 2.65 & 2019 \\
\hline
\end{tabular}

Source: Livewhat WP4 population survey.

that these self-assessments have certain peculiarities. British respondents are now among those who, on average, rate their own living conditions to be best. The people from Sweden, Switzerland and Germany only follow after. Respondents in Greece and Italy consider their own situation to be rather poor. The frequency distribution has a tendency to more positive assessments everywhere (a skewness to the right). From the curvature, it can be seen that the answers pile up more strongly in a smaller (here, the middle) scale range, while the people in Greece are more clearly distributed across the width of the scale, especially in the lower range.

Furthermore, the assessments of the personal life situation do not differ as much as expected on the basis of the results to date. For example, the differences between the top group (Switzerland and Sweden) and the worst performer (Greece) with regard to the assessed living conditions at home were much greater, as seen in Table 4.7. A reminder, external assessments were 9.5 for Switzerland and 3.8 for Greece. This is a difference of 5.7 points, while the values differ by only 3.2 points with regard to the respondents' own living conditions. People, therefore, tend to make more drastic appraisals when assessing another country's general living conditions than when assessing their own circumstances.

However, personal living conditions do deviate to a considerable degree. And it is remarkable that respondents agree about how they rank their personal living conditions: Swiss and Swedish citizens see themselves on average at the top of the social ladder and the Greek respondents at the bottom. Responses deviate from the average scores in all countries (i.e., 1.6 to 2.1 points), but the deviation is not very large. This finding is noteworthy because it indicates that European citizens have a similar compass to identify one's own position within a stratified social space. It could be that European citizens have a common anchor point from which to assess their personal living conditions. This interpretation is not fully convincing because it is highly improbable that all respondents have internalised an identical reference point, an absolute shared value of good life. More convincing is the assumption that the similarities in the assessment of respondents' own living 
conditions are a consequence of ongoing comparisons. People assess the situation in their own country in relation to the conditions in other countries, and they assess their own situation in relation to others, whether these others are tangible reference groups (friends, family, neighbours, colleagues, etc.) or abstract units such as their own country or other states. Europe would, therefore, be a common social space that enables people to comparatively construct a social hierarchy of living conditions and thus determine common standard values that serve as points of reference or yardsticks for assessing their own living conditions. Europeans seem to have internalised a mental map of social living standards, and this means that this map is a collectively shared compass. Europeans should know from each other that they take up different positions in a consistently unequal habitat. The less well-placed know that there are others who are better placed and the same applies to those who see themselves as better placed because they have others in mind that they consider to be worse off. The fact that this relational map extends beyond the borders of one's own environment, even of one's own country, would be the special thing about Europe.

Before looking at these assumptions to determine the degree of consensus, however, it must be recognised that there are differences in the assessments of social conditions between countries. It was shown that people in France tend to view living conditions at home and in other countries more negatively than other respondents, and the same applies to respondents from Italy. In the UK, people's own circumstances (and the situation in their own country) tend to be rated more positively than those of other countries. These deviations are a sign of a more pessimistic or optimistic attitude among those surveyed in the countries. In any case, they show that it could be problematic for our further analyses to directly compare the assessments of the respondents across national borders and possibly treat them as equivalent. People in France, Italy and the UK may, to stay with the examples, assess the social situation to be worse or better per se, which is why any attempt to compare them directly across countries would mean engaging in systematic distortions.

For this reason, I abstained from using the absolute assessments, i.e., those of the living conditions of the individual, the country or other countries. Instead, I will only apply relative assessments. The question to be asked in the following is how the assessments of other countries fare in relation to the perception of one's own living conditions and vice versa. To this end, it is useful that the survey encouraged respondents to assess the living conditions of a whole range of reference groups such as those of friends and neighbours in their own country and those in the other eight countries that were part of the survey. If these questions are related to each other, it is possible to determine what the assessment of personal living conditions is in relation to that of others. Are people in their personal situation doing worse or better than their friends and neighbours, their compatriots or the inhabitants of other European countries? A separate variable was calculated for each of these reference groups, which puts the ratings in relation to each other on the 11-point scale. Each of these relational variables ranges from -10 (one's own living conditions are 10 points worse than those of the other 
reference groups) to +10 (one's own living conditions are 10 points better than those of the reference groups). A zero would indicate that the respondent sees no differences between their own living conditions and the ones of the reference group under consideration.

In Figure 4.4, these relational assessments were compiled for three reference groups: friends, neighbourhood and one's own country. The figure shows the frequency distribution in per cent. Since a single chart would be too confusing for all nine countries, the focus is initially only on respondents from Switzerland, France and Greece, which provides a good picture of the country spectrum. The results show that the vast majority of respondents consider the living conditions of their friends and neighbours to be identical to their own. For friends, the proportion of those for whom the value zero has been determined is almost $60 \%$, for neighbours, approximately $50 \%$. The proportion of those who assess their own circumstances to be somewhat worse is slightly higher than those who assess their

... that of friends

Switzerland

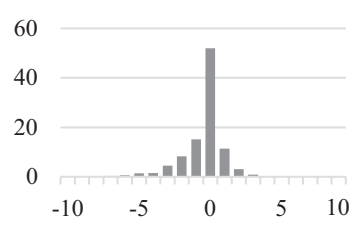

France

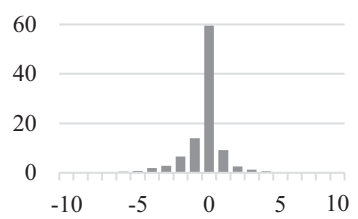

Greece

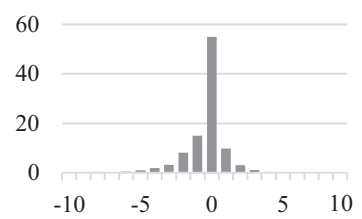

\section{... those in the neighbourhood}

Switzerland

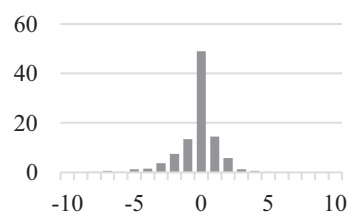

... those in my country

Switzerland

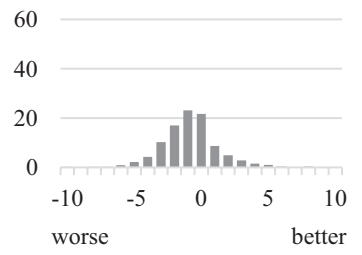

France

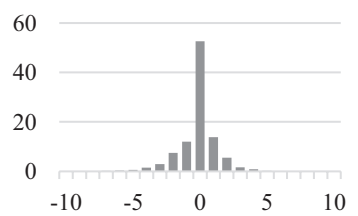

Greece

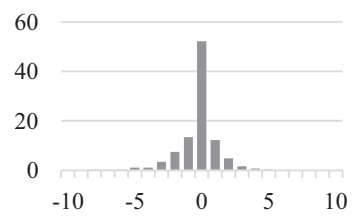

Figure 4.4 Own living conditions better or worse than (in \%) - only for respondents from Switzerland, France and Greece. Source: Livewhat WP4 population survey. 
own situation to be better. Overall, it can be seen that the living conditions are perceived very homogenously in the immediate environment of the respondents.

A greater scatter only occurs at the country level, where the proportion of those who find no difference between their own living conditions and those of the country falls below 30\%. More people, therefore, see a difference between the perceived standard of living in the country and their own situation. In Switzerland, respondents tend to think that their living conditions are slightly worse than those in the rest of the country, while the Greeks tend to think that they are somewhat better off than their compatriots in general.

These observations are confirmed when the statistical measures for all countries are collected in relation to all three reference groups (see Table 4.10). On average, people in all countries assess their own living conditions as only slightly worse than those in the neighbourhood and among friends. This results in a clearly

Table 4.10 Own living conditions better/worse than

\begin{tabular}{|c|c|c|c|c|c|}
\hline & Mean value & $S D$ & Skewness & Kurtosis & $N$ \\
\hline \multicolumn{6}{|c|}{ In the neighbourhood } \\
\hline Switzerland & -0.27 & 1.60 & -1.25 & 8.02 & 1934 \\
\hline Sweden & -0.65 & 1.73 & -0.48 & 6.77 & 1943 \\
\hline Germany & -0.17 & 1.55 & -0.69 & 6.46 & 1877 \\
\hline UK & 0.02 & 1.08 & -0.12 & 10.82 & 1934 \\
\hline France & -0.14 & 1.44 & -0.87 & 7.80 & 1800 \\
\hline Italy & -0.25 & 1.49 & -0.97 & 8.54 & 1937 \\
\hline Spain & 0.09 & 1.55 & -0.49 & 7.01 & 1922 \\
\hline Poland & -0.22 & 1.65 & -0.54 & 6.64 & 1846 \\
\hline Greece & -0.23 & 1.58 & -0.79 & 9.15 & 1949 \\
\hline \multicolumn{6}{|l|}{ Of friends } \\
\hline Switzerland & -0.44 & 1.55 & -1.21 & 8.67 & 1972 \\
\hline Sweden & -0.42 & 1.65 & -0.92 & 6.33 & 1827 \\
\hline Germany & -0.30 & 1.42 & -1.12 & 8.32 & 1899 \\
\hline UK & -0.18 & 1.10 & -1.03 & 9.13 & 1926 \\
\hline France & -0.32 & 1.36 & -1.24 & 8.29 & 1850 \\
\hline Italy & -0.56 & 1.63 & -1.45 & 8.47 & 1954 \\
\hline Spain & -0.26 & 1.53 & -0.96 & 7.21 & 1935 \\
\hline Poland & -0.56 & 1.65 & -0.72 & 7.02 & 1927 \\
\hline Greece & -0.39 & 1.50 & -1.21 & 9.16 & 2002 \\
\hline \multicolumn{6}{|c|}{ In own country } \\
\hline Switzerland & -0.82 & 2.17 & 0.30 & 5.45 & 1968 \\
\hline Sweden & -0.36 & 2.11 & 0.19 & 4.48 & 1880 \\
\hline Germany & -0.64 & 2.03 & 0.12 & 4.40 & 1899 \\
\hline UK & 0.33 & 1.89 & 0.50 & 5.29 & 1912 \\
\hline France & 0.49 & 2.01 & 0.23 & 5.14 & 1847 \\
\hline Italy & 1.30 & 2.21 & 0.11 & 4.22 & 1940 \\
\hline Spain & 0.85 & 2.04 & 0.22 & 4.63 & 1944 \\
\hline Poland & 1.24 & 2.20 & -0.05 & 4.29 & 1918 \\
\hline Greece & 0.68 & 2.22 & -0.21 & 5.23 & 1988 \\
\hline
\end{tabular}

Source: Livewhat WP4 population survey. 
peaked frequency distribution (kurtosis), and only a very slight, right-heavy skewness. The assessments also scatter only very weakly because the assessments of having better or worse living conditions than friends or neighbours scatter only around the mean value by $1-1.7$ points.

The assessments regarding the situation in the respondents' own country differ considerably. In the countries that were among the leaders in living conditions (Switzerland, Sweden and Germany), people tend to think that they are personally a little worse off. This is reversed in the other countries. Here, the respondents' personal situation is judged somewhat more favourably than that of the country overall. As expected, opinions scatter more strongly around the mean value (i.e., up to two points), which also means that the frequency distribution does not run so sharply, but has a flatter curvature.

Leaving the immediate environment of the respondents and looking at the other countries, there are remarkable differences to be seen. People's own living conditions are assessed significantly differently from the situation in other countries. It is enough to concentrate on two countries - Switzerland and Greece to document these striking discrepancies because the living conditions there were rated best and worst, relatively, by those surveyed. In the other six countries, differences are also apparent when comparing the well-placed countries (Sweden and Germany) and the worst-placed countries (Poland and Spain). The identified patterns remain similar, which is why these results are not graphically represented here.

Table 4.11 summarises the results of the relational assessments. With regard to Switzerland, the respondents from other countries consider their personal living conditions to be worse. For instance, people in Sweden rate their personal situation on average one point worse than living conditions in Switzerland. This figure rises to up to five points among Greek respondents. This means that in this country, the subjective situation differs the most from Swiss living conditions.

The relative assessments reported in Table 4.11 are averages, and it is important to keep in mind that these relational assessments deviate around the mean by more than two points of scale almost everywhere. Hence, respondents do not fully agree regarding how they relate their own situation with that in other European countries, that is, some highlight bigger differences, others less marked ones. This variance will be the result of different living conditions among residents within each of our nine countries. In Sweden, for example, the worse-off may perceive a greater contrast between their own situation and Swiss living standards than their well-off compatriots. The picture is mirrored when looking at Greece as a point of reference. For all other countries, respondents assess their own living conditions as more favourable than those of Greece. The difference for respondents from Poland is 1.7 points, and this difference grows in the other survey groups. In Switzerland, the estimation of the Swiss' own personal situation is four points better than the living conditions in Greece. Here, too, the values scatter, generally even more strongly. 
Table 4.11 Own living conditions better/worse than

\begin{tabular}{|c|c|c|c|c|c|}
\hline & Mean value & $S D$ & Skewness & Kurtosis & $N$ \\
\hline \multicolumn{6}{|l|}{ In Switzerland } \\
\hline Respondents from & - & - & - & - & - \\
\hline $\begin{array}{l}\text { Switzerland } \\
\text { Sweden }\end{array}$ & -1.13 & \multicolumn{4}{|c|}{ Switzerland } \\
\hline $\begin{array}{l}\text { Sweden } \\
\text { Germany }\end{array}$ & $\begin{array}{l}-1.15 \\
-1.88\end{array}$ & 2.21 & -0.30 & 4.18 & 1738 \\
\hline Germany & -1.88 & & -0.36 & 3.81 & 1877 \\
\hline UK & -1.73 & 1.86 & -0.43 & 4.51 & 1772 \\
\hline France & -2.46 & 2.33 & -0.19 & 3.85 & 1785 \\
\hline Italy & -3.36 & 2.59 & -0.25 & 3.22 & 1948 \\
\hline Spain & -2.90 & 2.37 & -0.26 & 3.80 & 1900 \\
\hline Poland & -3.43 & 2.38 & -0.11 & 3.32 & 1823 \\
\hline Greece & -5.07 & 2.63 & 0.36 & 3.65 & 1875 \\
\hline \multicolumn{6}{|l|}{ In Greece } \\
\hline Switzerland & 4.12 & 2.51 & -0.48 & 3.71 & 1959 \\
\hline Sweden & 3.91 & 2.60 & -0.40 & 3.39 & 1796 \\
\hline Germany & 3.66 & 2.52 & -0.45 & 3.92 & 1887 \\
\hline UK & 3.35 & 2.33 & -0.16 & 3.26 & 1777 \\
\hline France & 3.46 & 2.54 & -0.58 & 3.84 & 1826 \\
\hline Italy & 2.72 & 2.63 & -0.50 & 4.04 & 1948 \\
\hline Spain & 3.41 & 2.44 & -0.51 & 4.00 & 1916 \\
\hline Poland & 1.76 & 3.08 & -0.40 & 3.65 & 1823 \\
\hline Greece & - & - & - & - & - \\
\hline
\end{tabular}

Source: Livewhat WP4 population survey.

\section{A cognitive map of the European social space}

European citizens do not hesitate to assess and rank the living conditions in their environment. The share of respondents claiming to be unable or unwilling to make a guess is very small and even corresponds with the share of people that refrain from making judgements about other groups as well. Respondents in all countries agree that the living conditions of their friends and neighbours come very close, if not identical, to their personal living conditions. Major differences arise as soon as the subjective perception of the respondents' own situation is compared with the assessment of national living conditions. But even these differences are relatively minor. Much larger deviations only occur when looking at other countries. Respondents consistently agree that while living conditions are very good in Sweden, Switzerland and Germany, they are poor in Greece. They also agree in relative terms on the divergences between their own situation and the living standards in countries in the top and bottom positions. Respondents in most countries find themselves in a disadvantaged or privileged situation when comparing themselves either with Swiss or Greek citizens.

The analysis of these relative assessments has two implications that are of crucial importance for the subsequent analyses in the next chapters. First, and 
following the subjective perception of the living conditions of all reference groups, it is possible to trace the picture of a gradual increase in social differences from the closest area to one that is further removed. It is the comparison with other societies, and thus the European frame of reference, that makes social differences for people more marked. Put another way, on a European scale, the homogeneity of living conditions within one's environment is eclipsed by the perception of a clear social heterogeneity of personal situations within Europe. Secondly, there is impressive agreement among European citizens in their perception of living conditions abroad. Europeans from different countries are not only capable of placing each other on a map of European living conditions, they also agree about which countries should be placed where. This shows that across countries, people have internalised a similar scale and ranking of living standards. Europeans claim to know where living standards are very high, moderate and low, and even if there is variation, due to the diverging perspectives from which they report about "high", "moderate" and "low" standards, this ranking corresponds largely to the picture painted by macro-economic indicators.

European citizens thus seem to perceive and assess living conditions in European categories. The uniformity with which they identify positions and place countries shows that they are following an implicit yardstick that allows them to identify comparable living standards and that enables them to specify which countries perform better or worse. These findings suggest that European citizens have internalised a cognitive map of a European social space that is made up of different living conditions that are related to each another in a hierarchical manner, e.g., in terms of inferior and superior positions. This cognitive map, which is not necessarily restricted to the European continent, nor the EU, allows citizens to place themselves and their countries in reference to other Europeans and countries. Citizens, for instance, had no problem placing Switzerland into the larger landscape of European living conditions, even though this country is not a formal nor full member of the European Union. We would assume that citizens would also add further, non-European countries onto the list of countries with superior or inferior living conditions. This has to do with the fact, discussed in Chapter 2, that social spaces are in themselves not strictly contained by political borders. However, the openness of social spaces does not limit the relevance of the related cognitive maps; even "open" cognitive maps can provide citizens with an orientation and yardstick to perceive and assess living conditions in specific places. The social division enshrined in these maps might have an impact on the assessment of the political field with its internal cleavages, as proposed before.

The findings of this chapter suggest that Europe and the European Union increase the salience and relevance of some countries, to the detriment of others. Our data, for instance, shows that respondents exhibited a lower inclination to assess the living conditions in Poland, while they had the least problems in doing so for Germany and Greece. Both countries were at the centre of public debates about the European financial and economic crisis in 2009 (see Chapter 3) and were thus more salient for our respondents when fieldwork was conducted in 2015. Additionally, it is plausible to assume that these countries will be more 
relevant as reference groups when focusing on the potential impact of the cognitive map on the political views and attitudes of European citizens. Citizens that highlight divergent living conditions within Europe might be more dissatisfied with politics. These comparisons might nurture feelings of relative deprivation, particularly when citizens compare themselves with better-off Europeans. These assessments might have the potential to become social dynamite if the citizens assume that the national governments and EU institutions do not consistently pursue the promise of comparable living conditions for all countries, regions and people. 


\title{
5 Social divisions and perceptions of national politics
}

\author{
The hidden European compass
}

Public opinion is strongly focused on national politics, even if European issues are at stake. This is true when looking at citizens' political knowledge, their policy priorities and political behaviour. It is also true when considering how citizens think about the European Union because their perceptions and assessments are strongly mediated and directed by the nation state to which they belong, with its political institutions, party allegiances and political cleavages (Hooghe and Marks 2005; Desmet et al. 2012; de Vries, 2018). The European Union might have become an important arena for political decision-making, but this political weight does not seem to have translated into an ability to shape public opinion in the member states unmediated by the arena of national politics itself. Indeed, national governments, parties, associations or experts are all likely to have formed an opinion about the EU, implying that public opinion about the EU reflects the agendas and cleavages of the national arenas.

Public debates in the mass media mirror this situation quite clearly, as highlighted in Chapter 3. The 2009 economic and financial crisis was experienced as a common, European crisis. However, public debates within the different member states were devoted primarily to discussing the implications of the economic and financial crisis for their own country. The European Union has not been successful in shifting public interest more strongly from the national onto the European level. However, this does not segregate public opinion into closed national containers. Public debates and perceptions transcend national borders horizontally through interrelating events and claims from different countries. Public debates do not shift the focus of attention from the national to the European arena but expand public awareness beyond national borders, thus nurturing cross-national debates. Governments, associations and parties observe the positions of other actors in other countries; they take a public position on them and react with agreement or criticism. The public opinion thus seems to maintain its primary focus on the nation state without fencing itself off. It does gravitate around the nation state but expands the range of potentially relevant actors, issues and claims (Trenz 2004; Pfersch et al. 2006; Caiani and Guerra 2017; Segesten and Bossetta 2019).

These observations suggest that it is advisable to reach beyond the nation state when analysing political perceptions and attitudes. While public opinion about national and European politics appears to be strongly shaped by the 
socio-economic, political and cultural situations within the respective countries, it is also true that these national "containers" are not secluded and disjointed but strongly interrelated points of reference for public opinion formation. Citizens' judgements about national and European politics might not be grounded in their position only (i.e., their residence, social-structural situation), but in a relational assessment that takes the situation in other countries into account, thus expanding their frame of reference to include national and European politics. The findings of the previous chapter evidence that citizens tend to do so when asked to assess the living conditions in their immediate environment and that of other European countries.

The analyses of this chapter wishes to validate the relevance of this cognitive map as a factor influencing political perceptions and attitudes. This general aim translates into general and more specific objectives. In the first instance, it is necessary to examine whether cross-national perceptions have an impact on the assessment of national politics. In particular, the aim is to validate whether the perception of social divisions within and between countries is having an effect on the way citizens perceive and assess the social and political reality in their own country. Three main topic areas are addressed here. Firstly, the question of whether the comparison of living conditions goes hand in hand with increased crisis sensitivity, and thus with feelings of both personal and collective concern about economic distortions and social decline. Secondly, it must be clarified whether country comparisons and crisis sensitivity also affect political attitudes. It is conceivable that people's perceptions and feelings of relative deprivation result in more forceful distancing from political institutions, developing a greater dissatisfaction with governments and orienting themselves much more frequently towards a populist criticism of the political establishment. Finally, it must be asked whether the cognitive map of the European social space also influences political participation, for example, in terms of protest mobilisation. The empirical analyses will make use of the Livewhat survey conducted in 2015, presented in the previous chapter.

\section{Perception of the economic crisis in a European comparative horizon}

The global economic crisis, which began at the end of 2008 with the insolvency of the private bank Lehman Brothers in the USA, led to massive economic slumps in Europe, rocked the banking systems and exacerbated the over-indebtedness of public budgets in many member states. Economic output for the EU as a whole fell by $6.1 \%$ (in market prices per capita) between 2008 and 2009. The economic downturn was of a shorter duration for some countries (e.g., Germany, Austria, Sweden or Poland), but in many others, recovery was slow and arduous. Five years later, total economic output had fallen by $24.3 \%$ in Greece, $13.2 \%$ in Cyprus, $9.5 \%$ in Spain and $9 \%$ in Croatia. As a result, many people lost their jobs, and the unemployment rate within the EU rose from an average of $7 \%$ in 2008 to $10.9 \%$ in 2013. In Greece and Spain in particular, one in four citizens was unemployed (i.e., 
$27.5 \%$ and $26.1 \%$, respectively). But mass unemployment also affected countries such as Croatia, Portugal, Slovakia and Ireland, where unemployment rates were $13 \%-17 \%$ in 2013.

These figures conceal a massive deterioration in the personal situation of many people, especially in the countries hardest hit by the economic, financial and national debt crisis and austerity policy reforms, where disposable household income dropped in the face of unemployment, shrinking wages and social benefits and rising taxes and contributions (Hermann 2014; Petmesidou and Guillén 2015). The supply situation of the population with goods and services deteriorated noticeably, as did the infrastructure and the health and social system. Many, especially younger, better-educated people left their countries in search of work and better prospects elsewhere. In the crisis countries, homelessness and suicide rates increased markedly (Markantonatou 2013; Monastiriotis 2013).

Even if the economic and financial crisis had significant and sometimes dramatic consequences for the population, especially in the southern and eastern European countries, the economically more stable countries were not unaffected. This also applies, among others, to Germany, which is generally believed to have already overcome the crisis in 2010. At the height of the economic crisis, the number of employees in short-time work reached 1.5 million (May 2008), compared with 810,000 in December 2009 (Brenke, Rinne and Zimmerman 2011). Unemployment was a realistic threat for many Germans during these years. The number of atypical employment situations and precarious circumstances has increased significantly in the last two decades (Countouris 2007; Heidenreich 2016a). Insecure employment, periods of unemployment and low income were faced by an increasing number of people in the heart of society. The increasing polarisation of personal situations at the expense of the middle classes (Atkinson and Brandolini 2013) and the decline of the middle classes (Pressman 2007; Mau 2015) are also spoken about in this context. Concerns about a social decline seem to have firmly established themselves in the middle classes (Ehrenreich 1989; Bude and Spengler 2018).

The survey data used here were collected in 2015 , which is why it can be assumed that the economic and financial crisis was no longer the focus of public attention everywhere at the time of the survey. However, it can be assumed that the difficult economic and social upheavals had a strong influence on the mood of the European population. The fact that this is indeed the case is shown in Table 5.1, which lists how clearly the sense of crisis is prevalent among the populations of the countries surveyed. The table is based on a statement that was used to obtain the respondents' personal assessment of the economic situation at the time:

Some say that our country is suffering a very serious economic crisis, others say that we are suffering a crisis but it is not very serious, while others say that there isn't any economic crisis. What do you think?

Livewhat 2015: p. 48 
Table 5.1 Crisis perception ( $\mathrm{N}$ and \%)

\begin{tabular}{lllllll}
\hline & $\begin{array}{l}\text { Serious } \\
\text { crisis }\end{array}$ & $\begin{array}{l}\text { Crisis not } \\
\text { serious }\end{array}$ & No crisis & Other & $\begin{array}{l}\text { Don't } \\
\text { know }\end{array}$ & $N$ \\
\hline Switzerland & 313 & 1062 & 432 & 62 & 177 & 2046 \\
& $15.3 \%$ & $51.9 \%$ & $21.1 \%$ & $3.0 \%$ & $8.7 \%$ & $100 \%$ \\
Sweden & 327 & 844 & 492 & 32 & 323 & 2018 \\
& $16.2 \%$ & $41.8 \%$ & $24.4 \%$ & $1.6 \%$ & $16.0 \%$ & $100 \%$ \\
Germany & 353 & 679 & 744 & 53 & 279 & 2108 \\
& $16.8 \%$ & $32.2 \%$ & $35.3 \%$ & $2.5 \%$ & $13.2 \%$ & $100 \%$ \\
UK & 753 & 875 & 196 & 36 & 162 & 2022 \\
& $37.2 \%$ & $43.3 \%$ & $9.7 \%$ & $1.8 \%$ & $8.0 \%$ & $100 \%$ \\
France & 1357 & 341 & 70 & 60 & 199 & 2027 \\
& $67.0 \%$ & $16.8 \%$ & $3.5 \%$ & $3.0 \%$ & $9.8 \%$ & $100 \%$ \\
Italy & 1611 & 241 & 72 & 39 & 77 & 2040 \\
& $79.0 \%$ & $11.8 \%$ & $3.5 \%$ & $1.9 \%$ & $3.8 \%$ & $100 \%$ \\
Spain & 1497 & 355 & 50 & 77 & 56 & 2035 \\
& $73.6 \%$ & $17.4 \%$ & $2.5 \%$ & $3.8 \%$ & $2.8 \%$ & $100 \%$ \\
Poland & 477 & 843 & 464 & 35 & 205 & 2024 \\
& $23.6 \%$ & $41.7 \%$ & $22.9 \%$ & $1.7 \%$ & $10.1 \%$ & $100 \%$ \\
Greece & 1805 & 110 & 51 & 57 & 25 & 2048 \\
& $88.1 \%$ & $5.4 \%$ & $2.5 \%$ & $2.8 \%$ & $1.2 \%$ & $100 \%$ \\
Total & 8493 & 5350 & 2571 & 451 & 1503 & 18368 \\
& $46.2 \%$ & $29.1 \%$ & $14.0 \%$ & $2.5 \%$ & $8.2 \%$ & $100 \%$ \\
\hline
\end{tabular}

Source: Livewhat WP4 population survey.

The frequency distribution shows that at the time of the survey, almost all Greek respondents felt that their country was in a serious crisis. More than two-thirds of respondents from Spain, Italy and France took the situation equally seriously. This assessment was shared by one in three in the UK, one in four in Poland and one in six in the other countries. Even in those countries that respondents felt were less hard-hit, the view was that the country was indeed experiencing a crisis, even if it was not serious and therefore surmountable. This meant that only a quarter of all people were of the opinion that there was no crisis in 2015. While this share was highest in Germany with one-third, it nevertheless shows that the feeling of living in times of crisis was also widespread in this country.

But how can these quite different crisis perceptions be explained? This question seems unnecessary with regard to Greece, as the widespread sensitivity to the crisis is likely to be a direct response to the prolonged recession, austerity policies and serious social upheavals. A similar assumption can be made for Spain and Italy. However, this explanation is unsatisfactory because even in the crisis countries, there are people who do not speak of a crisis. At the same time, it must be clarified why so many respondents from the UK, Sweden, Germany and Switzerland assume that their country is going through a crisis when the socioeconomic core indicators seem to suggest a different conclusion. 
Social science research has shown that crises are, above all, interpretations of existing circumstances (Bohmann and Vobruba 1992; Hay 1996). There is no doubt that such interpretations respond to economic, political or social events and people's experiences with them. But a situation must first be defined as a crisis, which is why public discourses are an important arena for these - certainly contested - interpretations (Coleman 2013; Kiess 2019; Lahusen et al., 2016). It has also been confirmed at the level of individual crisis perception that external events and circumstances also need to be interpreted as "crises". Besides psychological factors such as self-confidence, life satisfaction and resilience, societal characteristics, such as gender, income and social situation, as well as political attitudes, such as trust in political institutions, also play a role (Zoll and Neumann 1986; Burns, Peters and Slovic 2011).

These assumptions will be pursued in the following. It is not only a question of determining the social factors influencing crisis perception. This book is also interested in the country comparisons discussed so far, which also raises the question of whether the perception of the crisis in the countries is also associated with the perception of living conditions in other countries. But these aspects will be addressed in a second step. First, three groups of possible explanatory variables are to be included in the analyses and only then are the country comparisons to be included in the evaluations.

The first step is to clarify which population groups are more sensitive to crises. The aim is, in particular, to determine whether the groups of people with high and low crisis sensitivity can be distinguished through identifiable characteristics. The focus here will be on three factors: socio-structural positions, political attitudes and socio-demographic profiles. First, it must be clarified whether the socio-structural situation of the respondents has an influence on their perception of the crisis. This is determined using the respondents' data on their educational attainment, subjective income situation (measured by the financial problems of their household) and their subjective affiliation with a social class. In addition, the perceived development of the economic situation of the respondent's household budget and that of the respondent's own country will be included; respondents were able to provide information on a ten-point scale ranging from "greatly deteriorated" to "greatly improved". Behind these factors is the assumption that respondents in a less privileged position develop a greater sensitivity to crises than people with better capital resources. A lower level of education, limited household income and negative development of one's household situation are likely to feed the opinion that the consequences of a crisis (job losses, wage cuts and the associated curtailment of one's lifestyle) have either already hit or are due to hit.

Secondly, the effect of trust in fellow human beings and political institutions is being examined. After all, to speak of a serious crisis is to assume serious disruptions or emergencies that can no longer be easily overcome and call into question the functioning of the existing system. People with greater confidence in their environment are less likely to experience a serious crisis. People should be more confident that serious crises cannot arise in the first place and/or can be effectively overcome if they have greater confidence in institutions. 
Thirdly, a number of control variables are to be introduced. It is conceivable that the perception of crises has to do with the socio-demographic characteristics of the interviewees, such as gender, age, migration background and residential perspective. Older men with a migration background living in urban contexts might be more vulnerable in regard to the effects of an economic crisis and thus more disposed to see their country in a crisis when compared with the younger respondents, women and residents of rural areas. In addition, there is the country in which the respondents live, as crisis sensitivity varies considerably between countries, as Table 5.1 shows.

Table 5.2 summarises the results of a regression analysis (ordered logit model). Two answer categories were excluded from the calculations, namely those respondents who indicated "don't know" and "other" in their answers. This reduces the number of cases by approximately 1,950 respondents. The people who assumed "no crisis" form the basis of this regression analysis as a reference group. The aim is to clarify whether the social background and political orientation of the crisis-sensitive respondents are noticeably different from that of those who do not perceive a crisis. The listed coefficients are average marginal effects and can be interpreted as percentages of higher or lower probabilities.

What is not surprising about the results is that the average probability of respondents in the crisis countries of southern Europe speaking of a serious crisis is much higher when compared with the people living in Switzerland (see bottom of the table). The probability is $58.2 \%$ higher in Greece when compared with responses from Swiss respondents. In Italy, Spain or France, on the one hand, the probability of seeing the country in a serious crisis is $51 \%, 48 \%$ and $46 \%$ higher, respectively. In Poland, Sweden and Germany, on the other hand, it is slightly lower. More interesting for the purposes pursued here are the findings for the other factors. First of all, it should be noted that the socio-structural position of the respondents plays a minor role. Low educational attainment and low income do not have a significant impact on crisis perception. It is surprising that people with the lowest household income are not more likely to perceive the existence of a crisis, while those having trouble paying their bills are more crisis sensitive. It may be that sporadic financial problems are more likely to be associated with a temporary crisis, while permanent financial problems are more likely to be associated with stable (but unfavourable) conditions. Those who do not know whether their household has financial problems are also more likely to deny that the country is in a serious crisis.

While the objective indicators of social situation (education and income) hardly contribute to the identification of the group of crisis-sensitive people, the subjective class affiliation is different. It can be seen that crisis sensitivity increases the more we move down from those who feel they belong to the upper class or the upper-middle class to the lower classes. For respondents who feel they belong to the lower class, the probability of assuming a serious crisis is $5.1 \%$ higher than among those who see themselves at the top of the pyramid. Conversely, these respondents also tend to be less likely to believe that their country is not in any crisis. However, the group that cannot or do not want to locate themselves is also 
Table 5.2 Crisis sensitivity and its determinants - a basic model (ordered logistic regression, average marginal effects)

\begin{tabular}{|c|c|c|c|}
\hline & Serious crisis & Crisis not serious & No crisis \\
\hline \multicolumn{4}{|l|}{ Educational attainment (university) } \\
\hline Secondary education & -0.009 & 0.003 & 0.006 \\
\hline Lower than secondary education & -0.009 & 0.003 & 0.006 \\
\hline \multicolumn{4}{|l|}{ Monthly household income (top third) } \\
\hline Middle third & -0.006 & 0.002 & 0.004 \\
\hline Lower third & -0.005 & 0.002 & 0.004 \\
\hline No details & $0.018 * *$ & $-0.006^{* *}$ & $-0.013 * *$ \\
\hline \multicolumn{4}{|l|}{$\begin{array}{l}\text { Financial household situation (no } \\
\text { problems) }\end{array}$} \\
\hline Manages with difficulty & $0.031 * * *$ & $-0.010^{* * *}$ & $-0.022 * * *$ \\
\hline Manages with problems & 0.013 & -0.004 & -0.009 \\
\hline Don’t know & -0.026 & 0.006 & 0.019 \\
\hline \multicolumn{4}{|l|}{$\begin{array}{l}\text { Subjective class affiliation (upper class, } \\
\text { upper-middle class) }\end{array}$} \\
\hline Middle class & 0.016 & -0.004 & -0.012 \\
\hline Lower middle class & $0.030 * *$ & $-0.008 * * *$ & $-0.022 * *$ \\
\hline Lower class & $0.051^{* * *}$ & $-0.015 * * *$ & $-0.036 * * *$ \\
\hline Other, don't know & $0.056^{* * *}$ & $-0.017 * * *$ & $-0.039 * * *$ \\
\hline \multicolumn{4}{|c|}{$\begin{array}{l}\text { Economic situation of the household over } \\
\text { the past five years (better) }\end{array}$} \\
\hline Similar & $0.036^{* * *}$ & $-0.010 * * *$ & $-0.026 * * *$ \\
\hline Worse & $0.138 * * *$ & $-0.052 * * *$ & $-0.086^{* * *}$ \\
\hline Don’t know & 0.013 & -0.003 & -0.009 \\
\hline \multicolumn{4}{|l|}{ Trust in fellow human beings (low) } \\
\hline Medium & $-0.030 * * *$ & $0.010 * * *$ & $0.021 * * *$ \\
\hline High & $-0.043 * * *$ & $0.013 * * *$ & $0.030 * * *$ \\
\hline Don’t know & 0.026 & -0.010 & -0.016 \\
\hline \multicolumn{4}{|l|}{ Trust in institutions (low) } \\
\hline Medium & $-0.103 * * *$ & $0.041 * * *$ & $0.062 * * *$ \\
\hline High & $-0.156^{* * *}$ & $0.053 * * *$ & $0.103 * * *$ \\
\hline Don't know & $-0.080^{* * *}$ & $0.033 * * *$ & $0.046^{* * *}$ \\
\hline Gender (male) & $0.037 * * *$ & $-0.011 * * *$ & $-0.026 * * *$ \\
\hline \multicolumn{4}{|l|}{ Age $(18-24)$} \\
\hline $25-44$ & -0.013 & 0.004 & 0.010 \\
\hline $45-64$ & $0.016^{*}$ & $-0.005^{*}$ & $-0.011 *$ \\
\hline $65+$ & -0.012 & 0.004 & 0.009 \\
\hline Migration background (no) & $-0.019 * * *$ & $0.006^{* * *}$ & $0.013 * * *$ \\
\hline \multicolumn{4}{|l|}{ Place of residence (city) } \\
\hline (Small) town & 0.007 & -0.002 & -0.005 \\
\hline Village and countryside & 0.001 & -0.000 & -0.001 \\
\hline \multicolumn{4}{|l|}{ Countries (Switzerland) } \\
\hline Sweden & -0.004 & 0.000 & 0.004 \\
\hline Germany & $-0.084 * * *$ & $-0.008 * * *$ & $0.092 * * *$ \\
\hline United Kingdom & $0.181 * * *$ & $-0.066^{* * *}$ & $-0.115^{* * *}$ \\
\hline France & $0.460 * * *$ & $-0.263 * * *$ & $-0.198 * * *$ \\
\hline Italy & $0.512 * * *$ & $-0.305^{* * *}$ & $-0.207 * * *$ \\
\hline Spain & $0.482 * * *$ & $-0.280^{* * *}$ & $\begin{array}{l}-0.202^{* * *} \\
(\text { Continued })\end{array}$ \\
\hline
\end{tabular}


Table 5.2 Continued

\begin{tabular}{clll}
\hline & Serious crisis & Crisis not serious & No crisis \\
\hline Poland & $-0.028^{* *}$ & 0.001 & $0.027^{* *}$ \\
Greece & $0.582^{* * *}$ & $-0.364^{* * *}$ & $-0.217^{* * *}$ \\
Cases & 16.413 & & \\
Pseudo $\mathrm{R}^{2}$ & 0.246 & & \\
\hline
\end{tabular}

Source: Livewhat WP4 population survey.

Note: Significance levels: $* P<0.1, * * P<0.05$, *** $P<0.01$.

much more sensitive to the crisis. In summary, the following can be stated: it is the people who consider themselves to belong to the middle and the upper classes who are less likely to perceive a crisis, all other locations on the social spectrum are more sensitive to crises.

The perceived deterioration of the economic situation significantly increases the perception of the crisis at $13.8 \%$ compared to those who do not perceive a deterioration. As far as trust is concerned, the assumption is confirmed. Trusting individuals perceive a serious crisis less often. Above all, however, confidence in political institutions makes a clear difference as it significantly reduces crisis sensitivity by $15.6 \%$ from a predicted $60.1 \%$ for those with low institutional confidence to $44.5 \%$ for those with high confidence. It is also remarkable that this effect only occurs during the perception of a serious crisis. Those surveyed who have great confidence in the institutions either assume that the crisis is moderate, i.e., not so serious, or completely deny that their country is in crisis. As suspected, institutional confidence does not seem to blind people to the effects of crises. However, it seems to take away their concern that crises are no longer controllable or manageable.

By summarising these interim results, it becomes clear that the perception of the crisis is noticeably linked to the relative position of the respondents in the social sphere. People who tend to rank lower in the stratification pyramid and who have seen their situation deteriorate over the last few years are also more sensitive to crises. The relational position of people in space and time is thus the factor that is linked to crisis perception. Objective and absolute positions in the social structure (e.g., determined by educational titles or income) play no discernible role. Finally, crisis sensitivity is also linked to greater distrust towards fellow human beings and institutions.

The factors discussed so far are related to the national frame of reference. This is explicitly the case with educational attainment, the assessment of the economic situation of one's own country or with regard to confidence in political institutions. But with the other factors, it is not clear per se whether the information provided by the respondents stops at national borders. This applies to subjective class affiliation because the possibility that respondents have also drawn comparisons with people in other countries when indicating a social class cannot be ruled out. The fact that migrants rarely perceive there to be a crisis may have something to 
do with the fact that they also take their home country into account when assessing the current economic situation. They may, therefore, come to the conclusion that the situation in their current country of residence is not so bad when compared with the situation in their home country. In this sense, people with a migration background would be less pessimistic than the local population because their frame of reference is an international one.

This raises the question as to whether people also assess the economic situation in their country within such an international frame of reference. The findings so far have at least shown that almost all respondents consider themselves able to assess living conditions in other European countries. And people manage to put the living conditions of different reference groups (their own situation, the living conditions of their friends, neighbours, their fellow citizens and people in other countries) into a logical and coherent order. On the basis of these insights, it can be concluded that the European citizens have a mental map of the European social space in mind, which they used to position themselves and others.

It, therefore, makes sense to presume that the perception of a crisis is also adapted to this mental map. Following plausibility considerations, it can be assumed that people who view living conditions elsewhere as better, and thus their own situation comparatively worse, are much more like to perceive there to be a crisis, especially a serious one. In order to check the validity of the assumed correlations, the variables measuring the relative assessments of living conditions in other countries have been included in the modelling. This study considers an extended regression model based on the basic model already described (see Table 5.2) to examine the significance of country comparisons in the perception of crises. Figure 5.1 summarises the results, listing only the effects of the comparing variables. The model is too extensive to be included here in its entirety. However, a breakdown would also not provide any new information, as the effects of the variables listed above remain largely the same. Generally, the extended model once again excludes respondents and thus reduces the number of cases. Firstly, people who did not answer the question about the crisis or provided other statements are not taken into account. Secondly, the question of living conditions in other countries was only answered by respondents from the other respective eight countries. Therefore, a regression analysis had to be carried out for each reference country without the participation of respondents from the respective country being assessed. These separate calculations also give us an idea of the extent to which the effects of the other factors change as soon as a group of respondents is excluded. As can be seen from the figures, the effects remain quite constant, making the results robust.

Figure 5.1 shows that crisis perception is associated with the comparative assessment of living conditions in other countries. People who perceive the existence of a crisis consider themselves to be worse off than their fellow Europeans when compared with those respondents who do not perceive there to be a crisis. The link is strongest with regard to Switzerland and Germany because here, the likelihood that respondents who consider their personal situation to be worse than those of the Swiss or German also speak of a serious 
country in a serious crisis

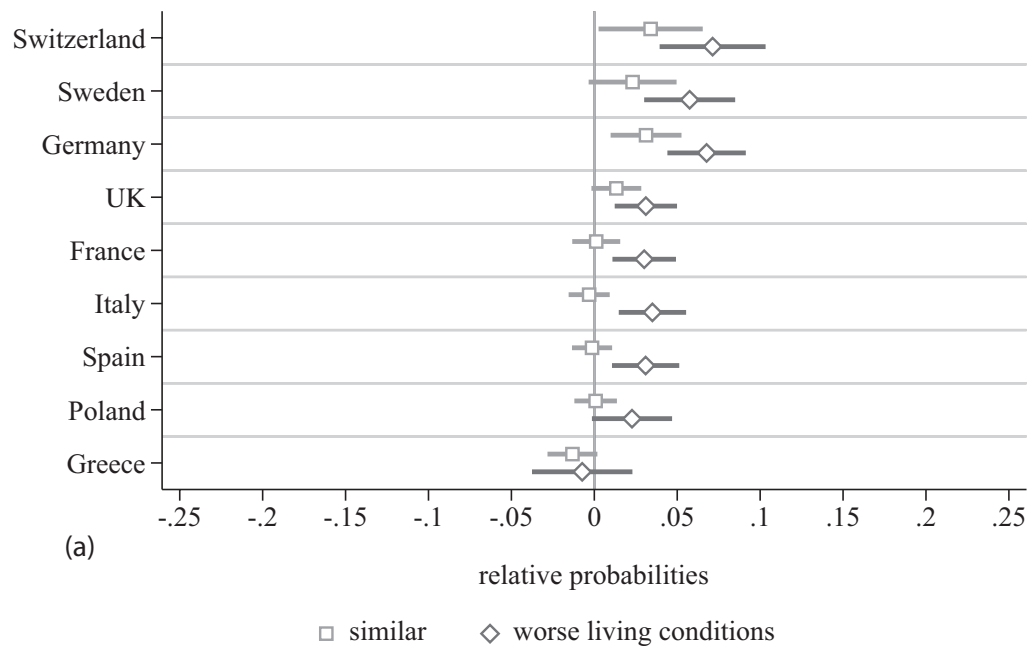

crisis, but not serious

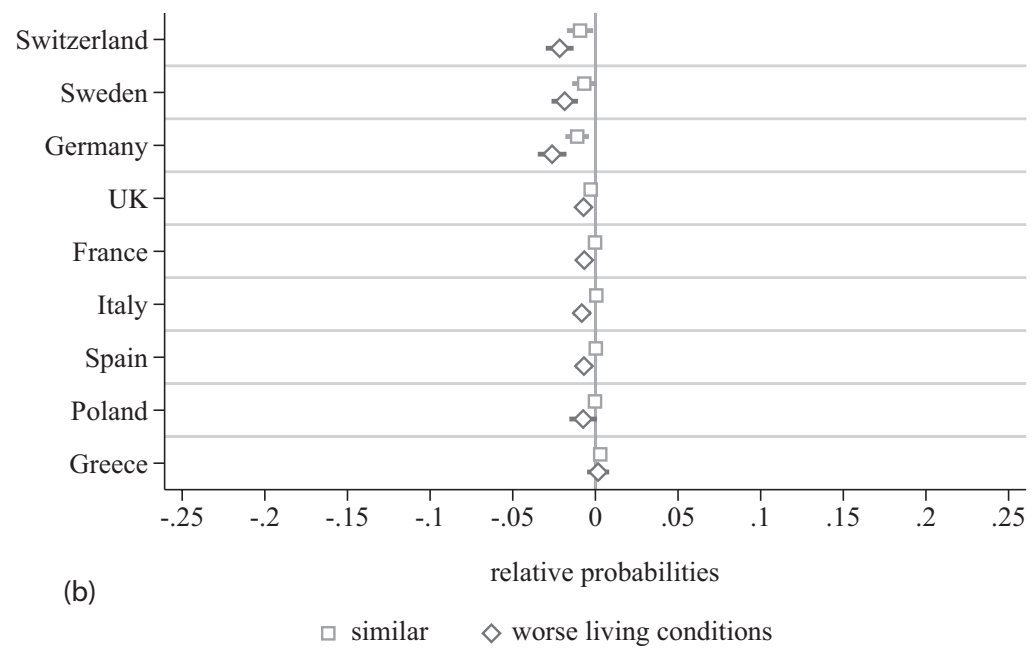

Figure 5.1 Crisis perception and assessment of own living conditions - extended model (ordered logistic regression, average marginal effects). Note: The findings shown in these tables are limited to the coefficients of the variables (country comparisons) additionally introduced in the extended model. The variables of the basic model (see Table 5.2) were included but effects are not displayed. Source: Livewhat WP4 population survey. 
crisis is approximately $7 \%$ higher than with those who consider their situation to be better. The predictive probability of seeing a serious crisis is $57.5 \%$ and $57.9 \%$ of those being worse off than people in Switzerland and Germany, while the share is lower for those judging their personal situation as being better $(50.4 \%$ and $51.1 \%)$. A comparison with Switzerland and Germany thus seems to increase the likelihood of a crisis being perceived. It is interesting to note that the effect for Germany is almost as high as for Switzerland, although Switzerland is still ahead of Germany in the ranking of living conditions; consequently, the group of people who locate their own living conditions below Swiss conditions is also the largest. Nevertheless, the comparison with Germany has just as recognisable an impact on people's perception of the crisis. This is likely to be due to the fact that Germany and the German government have been much more at the centre of public discussions about the crisis and the policies for dealing with it than other countries and national governments. This seems to have given special attention or saliency to German living conditions. Is it notable that respondents who report that their living conditions are comparable to those in other countries also tend to see a crisis slightly more often. In these cases, the general assessment of the citizens' country's situation might influence these assessments indirectly.

Furthermore, it is striking that the relevance of living conditions abroad steadily decreases when moving from the best-placed countries (Switzerland, Sweden and Germany) to the member states at the bottom of the scale. The effect decreases continuously and even reverses in the case of Greece. With regard to Greece, European citizens who feel that they are worse off than people in Greece (a total of nearly 800 respondents in all other countries), are less likely to perceive there to be a crisis in their own country, even a not very serious, temporary one. The comparison of one's living conditions with the conditions in Greece thus seems to even reduce crisis sensitivity, even though this effect is weaker than the one associated with comparisons with better-off countries. This finding proves that comparisons with those who are better off are more relevant and have more consequences for people than comparisons with those who are worse off. It corresponds with the findings of earlier studies, which have shown that an upwards comparison places a greater burden on life satisfaction than downwards comparisons (Delhey and Kohler 2006; Boyce, Brown and Moore 2010).

So far, it has been possible to confirm this correlation across all countries and samples. However, it cannot be ruled out that differences between countries may be overlooked; after all, Table 5.1 shows that the perception of the crisis varies considerably from country to country. It is necessary to differentiate the calculated effects by country. It must be clarified whether the probability of talking about a serious crisis is higher in all countries among those respondents who feel personally worse off compared with the well-placed countries. Figure 5.2 shows predictions of marginal effects for the two opposite response categories - for those who perceive a serious crisis and for those who do not see a crisis - broken down for 
the respondents of each country. This study is limited to the reference country that was identified in the extended regression model as a particularly influential comparison target, Germany.

The results confirm that the comparison of personal living conditions with those in Germany demonstrably influences the perception of the crisis in all other countries. It is true that the probability of the perception of a serious crisis is generally higher in the "crisis countries" of Greece, Italy, Spain and also in France than in the other four countries. However, one effect can be confirmed everywhere; the probability of crisis perception increases as soon as people have the impression that their life situation is worse than the perceived living conditions in Switzerland or Germany. The effect is not very great, especially in Greece, but this is probably also due to the fact that crisis perception is very widespread. In the reverse case - the respondents do not consider their country to be in any crisis - the effect is even clearer. Those respondents who assess their own living conditions as better than German living conditions are more likely not to perceive a crisis if compared with those who assess their situation as worse. In the crisis countries, this effect is smaller, but here the people seem to generally assume that the country is experiencing a crisis. In other countries, the crisis-sensitising effect of personal disadvantage is, however, clearly pronounced.

Overall, it can be seen that people in Europe not only assess the economic situation in their countries from a purely national perspective. Whether the situation has changed drastically, and whether we are therefore facing an economic crisis, is something that Europeans also assess within a pan-European frame of reference. For them, the living conditions in other countries are not unknown. Their own situation, as well as the conditions in their country, can place them at a recognisable relation to the living conditions in other countries. This creates a mental map of living conditions within Europe, and in this way, also, a mental representation of Europe as a common social area. People seem to see Europe as a common living space characterised by differences. This map allows people to define their own position, that of their own member state and that of other populations with a considerable agreement, as was made clear in previous remarks. What was added, however, as a result of the analysis of crisis perception, is the insight that this intellectual map is becoming a relevant point of reference for the evaluation of national conditions. The more the conditions in countries differ from those in other countries, the more significantly the crisis perception increases. Effects measure correlations, which means that responses are closely related to each other. People who are worse off than those in other countries see the national economy in a serious crisis, but this also means that people who perceive a serious crisis also describe the situation in other countries (especially the top-ranked member states) as better. What is important, however, is the clear link between the two assessments because, for Europeans, the mental map of living conditions in Europe is an inescapable part of their verdicts about the economic situation in their own country. 


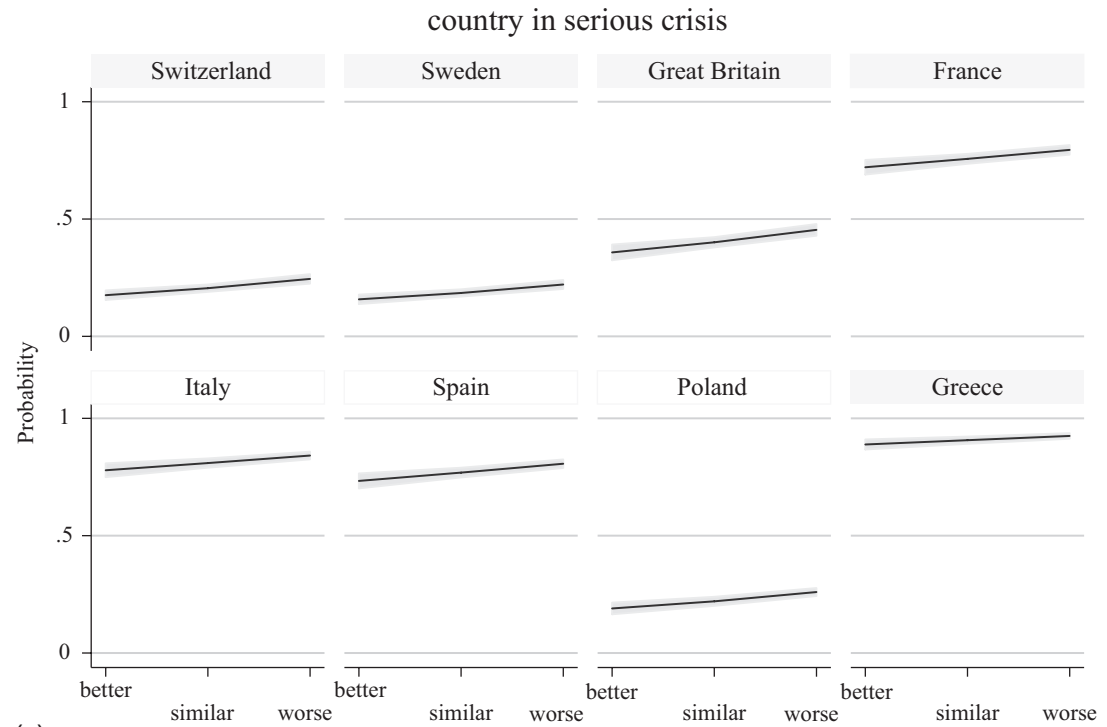

(a)

own living conditions compared to Germany

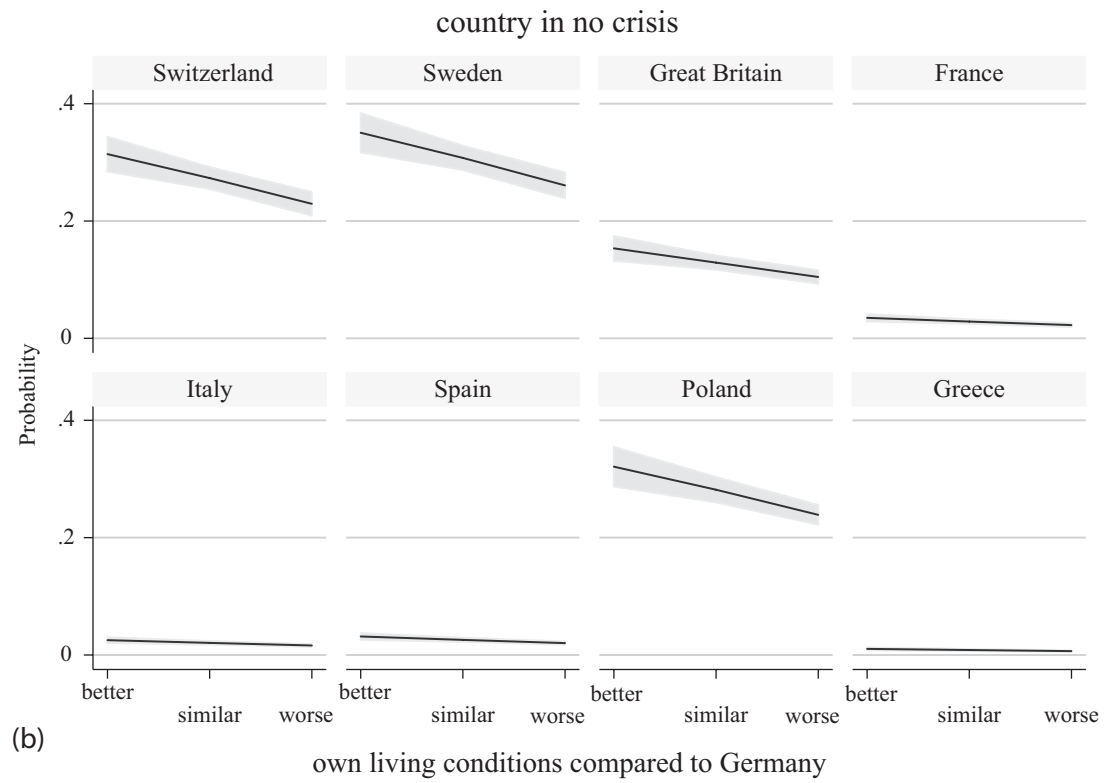

Figure 5.2 Influence of comparisons on crisis perception (predictive margins). Source: Livewhat WP4 population survey. 


\section{The assessment of national politics: a quiet benchmarking?}

With these findings in mind, we now turn to a politically explosive follow-up question. How satisfied are people with the work of their governments in the countries surveyed? What factors cause some respondents to be satisfied and others dissatisfied? Do the assessments of living conditions in other countries also play a role here? Is people's satisfaction with the government's work in their own country also influenced by how well or badly they assess their situation in life compared to that of other countries? And is the perception of divergent living conditions in Europe affecting the populist criticism citizens' voice in regard to national politics?

\section{Satisfaction with the respondents' government}

The following will first investigate the proposition that people blame their governments for life being better in other countries. This assumption fits into the research discussion because studies to date have shown that satisfaction with the work of the national government seems to depend on a whole series of factors. It would, therefore, come as no surprise that such a comparison leaves its mark across national borders. However, so far there have been no findings on this question, which is why barely anything can be said about whether the support of the national government now also depends on the assessment of life situations in other European countries.

In order to be able to measure the effect of perceived life situations in Europe on satisfaction with the government's work empirically, other accepted explanations must be taken on board. It may be the case that living conditions in other countries are only of secondary importance once more important factors are taken into account. Political science research has shown that satisfaction with the government's work is a specific form of support for political institutions (Easton 1975; Dalton 1999), which reacts sensitively to current events and developments. Compared with more general forms of political support, such as advocacy for democracy and confidence in existing political institutions, the assessment of government work is about what outputs day-to-day politics delivers. Even a population that is thoroughly satisfied with democracy can be rather dissatisfied with the work of the government currently in office. It can even be assumed that the higher the democratic demands of a population, the more the dissatisfaction will grow (Dalton 2005; 2008).

Among the most important factors influencing satisfaction are bundles of causes, some of which have already been outlined. Firstly, people evaluate the respective revenue of government work from their respective social situations. The socio-structural position within society, which is measured, for example, by educational attainment or income, should make a difference as much as the economic situation in a country (Newton 2006; Dotti and Magistro 2016). Secondly, general support for the political system (e.g., in the sense of fundamental trust in the institutions) should have an effect on satisfaction with the work of the 
government; those who generally do not trust the political institutions should also be much more dissatisfied with the work of those institutions (Hetherington 1998; Chanley, Rudolph and Rahn 2000). Thirdly, the assessment of the country's current situation is likely to play an important role (Armingeon and Guthmann 2014; Cordero and Simón 2016); in our context, this is the assessment of the economic situation as difficult or critical. Respondents who perceive a (serious) crisis may be more dissatisfied with the work of their own government if it is assumed that people feel that the governments are partly responsible for the course of the crisis. Fourthly, the influence of personal characteristics must be controlled. In addition to the socio-demographic factors considered so far (gender, age, migration background and place of residence), it must be clarified whether general life satisfaction also influences satisfaction with the work of the government.

Before looking at these explanatory factors, it is necessary first to describe how satisfied people in the countries surveyed were with their governments at the time of the survey. For this purpose, the answers to the following question are used: "How satisfied or dissatisfied are you with the way in which your country's government is dealing with the following?" Eight subject areas were available for selection: the economy, poverty, education, unemployment, healthcare, precarious employment, immigration and childcare. Respondents were able to give answers between 1 (extremely dissatisfied) and 11 (extremely satisfied), or tick “don't know". On average, childcare (mean 4.97), education policy (4.94) and healthcare (4.80) with a value in the middle of the scale got better scores, while immigration and poverty (3.87 and 3.96, respectively) were ranked last. Table 5.3 presents the results for four of these policy areas for all nine countries.

While respondents' answers show that people are more satisfied with certain policies than with others, it must be emphasised that satisfaction varies much more between countries. Respondents from Switzerland are most satisfied with

Table 5.3 Satisfaction with government policy (averages)

\begin{tabular}{|c|c|c|c|c|c|c|c|c|}
\hline & \multicolumn{2}{|c|}{ Economy } & \multicolumn{2}{|c|}{ Poverty } & \multicolumn{2}{|c|}{ Education } & \multicolumn{2}{|c|}{ Immigration } \\
\hline & $\begin{array}{l}\text { Mean } \\
\text { value }\end{array}$ & $S D$ & $\begin{array}{l}\text { Mean } \\
\text { value }\end{array}$ & $S D$ & $\begin{array}{l}\text { Mean } \\
\text { value }\end{array}$ & $S D$ & $\begin{array}{l}\text { Mean } \\
\text { value }\end{array}$ & $S D$ \\
\hline Switzerland & 6.97 & 2.19 & 5.44 & 2.57 & 7.21 & 2.37 & 4.82 & 2.59 \\
\hline Sweden & 5.12 & 2.56 & 4.68 & 2.43 & 5.37 & 2.52 & 3.79 & 2.65 \\
\hline Germany & 6.48 & 2.45 & 4.45 & 2.53 & 5.37 & 2.52 & 4.62 & 2.55 \\
\hline UK & 5.90 & 2.86 & 4.48 & 2.64 & 5.48 & 2.52 & 3.66 & 2.37 \\
\hline France & 3.95 & 2.54 & 3.73 & 2.48 & 4.65 & 2.73 & 3.60 & 2.62 \\
\hline Italy & 3.60 & 2.54 & 3.27 & 2.45 & 4.17 & 2.64 & 3.22 & 2.57 \\
\hline Spain & 3.89 & 2.67 & 3.22 & 2.33 & 3.84 & 2.56 & 3.81 & 2.42 \\
\hline Poland & 4.69 & 2.59 & 3.33 & 2.34 & 4.97 & 2.60 & 4.17 & 2.52 \\
\hline Greece & 3.24 & 2.42 & 3.15 & 2.32 & 3.50 & 2.32 & 3.17 & 2.33 \\
\hline All & 4.86 & 2.84 & 3.96 & 2.57 & 4.94 & 2.74 & 3.87 & 2.57 \\
\hline$N$ & 17609 & & 17499 & & 17567 & & 17551 & \\
\hline
\end{tabular}

Source: Livewhat WP4 population survey. 
the government's work in all policy areas, while those from Greece are most dissatisfied. The differences between these two countries are remarkable, as opinions differ by almost four points of scale. Behind the Swiss are respondents from the UK, who are among the most satisfied citizens, even ahead of those from Germany and Sweden. The people from Poland are close to this group and are still ahead of France in terms of their satisfaction values. In addition to the respondents from Greece, it is sometimes those from Italy or Spain who show very low satisfaction values.

However, the standard deviation shows that the respondents' answers clearly scatter around these mean values - by 2.5 to 3 points on both sides of the mean. This shows that opinions in the countries are clearly diverging. In the UK, for example, people are most divided when it comes to assessing economic and poverty policies, whereas the French and the Swedes disagree when it comes to immigration issues. These differences are mainly due to the high number of people who are extremely dissatisfied with their respective governments in the aforementioned policy areas. The individual evaluations have been combined into an index that shows how dissatisfied or satisfied the respondents are across all policy areas to illustrate this fact. The proportion of respondents who consistently provide the minimum value, 1 (extremely dissatisfied), is only $0.4 \%$ in Switzerland, but increases in Germany, Sweden and the UK (3.3\%, 5.2\% and 5.9\%, respectively). In France and Poland, already 1 in 10 respondents are extremely dissatisfied $(10.9 \%$ and $9.6 \%$, respectively), and in Italy, Spain and Greece even 1 in 7 (16.7\%, 15.4\% and 15.8\%).

Figure 5.3 summarises the frequency distribution of satisfaction values for a selection of countries to illustrate this. For Switzerland, a normal distribution with a slightly positive overall trend can be seen, as the values are accumulating in the middle range, while they are increasingly thinning out in the direction of high dissatisfaction or satisfaction. Even in Germany, the average satisfaction values are clearly increasing at the expense of the dissatisfied. In Poland and Greece, there is a one-sided tendency because the clearly dissatisfied dominate the picture; the more the focus moves to moderate and positive assessments, the fewer respondents can be found. The countries not shown here also match this picture because Spain and Italy follow the Greek pattern in surprising proximity, Sweden and the UK follow the German example and France follows Poland.

It can, therefore, be assumed that people's dissatisfaction with their governments is a reaction to the major crises in the European Union. The citizens of the countries most affected by the economic and financial crisis (Greece, Italy, Spain) are most dissatisfied with the work of their governments. However, this applies not only to politics with regard to the issues most closely linked to the crisis, such as the economy, unemployment, insecure employment and poverty, but also to other policy areas such as education, healthcare, family and immigration policy. In this respect, too, it was shown that dissatisfaction is extremely widespread in Greece, Italy and Spain. In these countries, the economic and financial crisis has apparently become a widespread acceptance crisis as a result of the prolonged recession and the strict conditions imposed by the European austerity policy. However, the number of extremely dissatisfied people in other European 

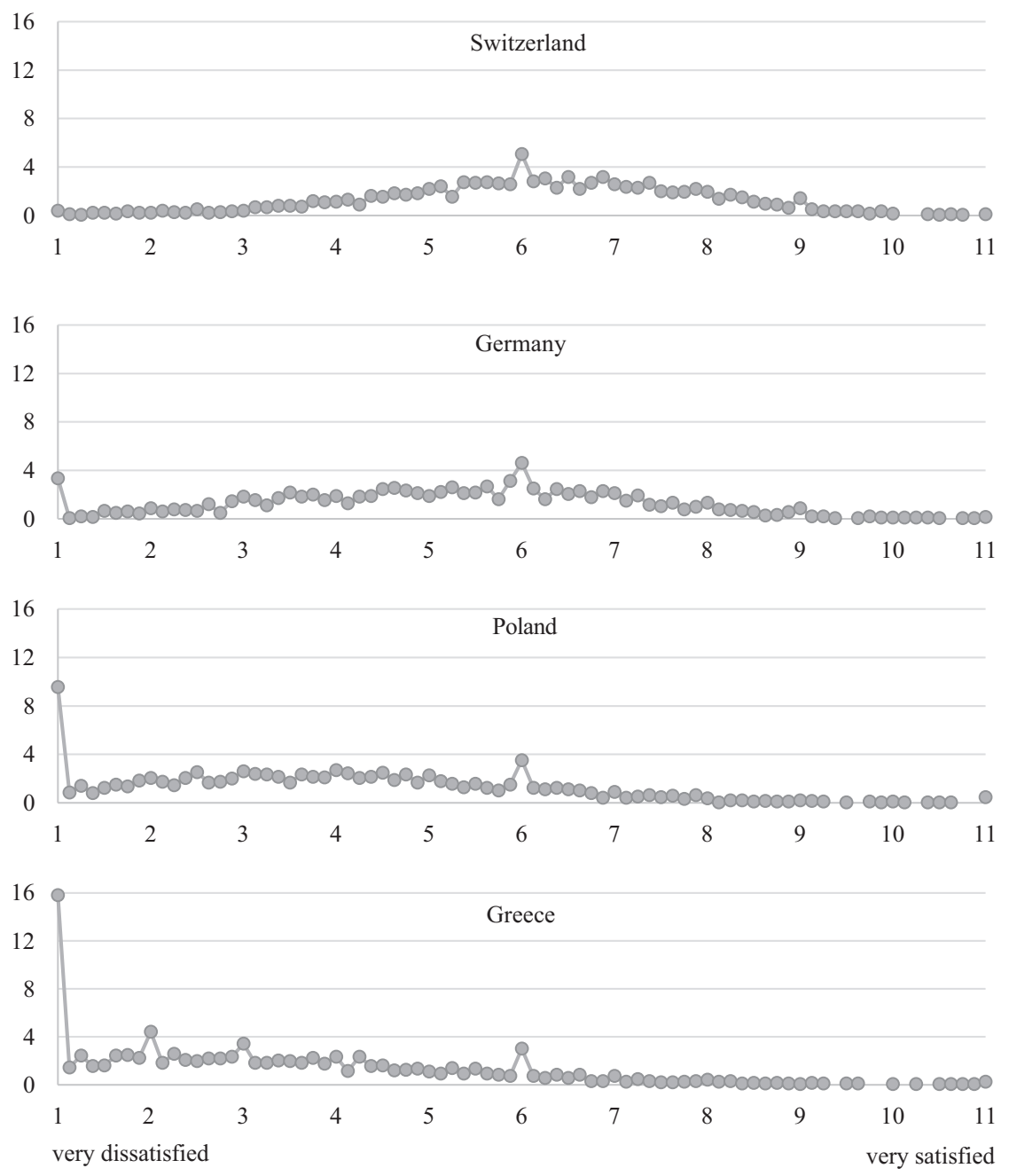

Figure 5.3 Satisfaction with the government (all fields, in \%). Source: Livewhat WP4 population survey.

countries, with the exception of Switzerland, has also reached a surprising level. This may be a sign that the European crises in these countries could also have had a lasting impact on the part of the population.

Against this background, it is now important to clarify which social and political factors guide people's assessments and which population groups belong to the dissatisfied ones. For this purpose, we would like to fall back on the explanatory factors introduced above and that have been bundled to form a basic model. The respondents were divided into three groups with regard to the dependent variable 
to verify these assumptions: the most satisfied, the dissatisfied, and the respondents with medium satisfaction values. This classification should make it possible to identify clear group differences. In this case, too, a regression analysis (ordered logit model) was carried out, which is appropriate for this group differentiation. A number of cases had to be excluded because they had not answered some of the questions about satisfaction with government work.

Table 5.4 shows that most of the research assumptions are correct, albeit with nuances. The income situation has little recognisable influence on satisfaction. Only people with low educational attainment have a slightly increased tendency to dissatisfaction. The respondents who feel they belong to the middle and lowermiddle classes are often moderately satisfied or dissatisfied compared with the greater satisfaction felt by the upper and upper-middle classes. Those who assign themselves to the lower class are more likely to be dissatisfied.

There are clearer differences in the assessment of the economic situation. For example, respondents complaining about the deterioration in the economic situation of their household and diagnosing a serious crisis are dissatisfied. In figures, this means that the predicted average likelihood of dissatisfaction with government work is $40.7 \%$ for households experiencing a financial decline, i.e., about $13.4 \%$ higher than for those who see their budgetary situation improving $(27.3 \%)$. However, the high levels of dissatisfaction among those surveyed who did not provide any information show that the dissatisfaction is a relative one. In particular, the better off, those who have improved their financial situation and are unable to discern a crisis, are comparatively more satisfied with the work of the government.

With regard to political factors, political confidence and political interest make a difference in the level of dissatisfaction with government policies. When it comes to institutional confidence, in particular, it is noticeable that people with a high level of confidence are much more satisfied with the government. Conversely, satisfaction with the work of the government decreases dramatically when people have less confidence in political institutions or do not provide any information. Among the personal attributes, it is noticeable that respondents with a generally higher level of life satisfaction are less often dissatisfied with government work. Women and all those over 25 tend to be slightly less satisfied than men and younger people. Respondents with a migration background are less critical. And with regard to the countries, it can be seen that in all countries there is a noticeably higher tendency to be dissatisfied with government work when the answers are compared with those of the Swiss respondents.

All in all, the social position of people in society plays a less visible role in determining whether citizens are satisfied with their government. Rather, it is the perceived deterioration of the personal economic situation and the increasing crisis sensitivity as well as the fundamental trust of the respondents in the political institutions that are closely related to satisfaction.

On the basis of these findings, the analysis can move to the question of whether the satisfaction with the work of the government may also be related to the assessment of living conditions in other countries. For this purpose, the 
Table 5.4 Satisfaction with government, basic model (ordered logistic regression, average marginal effects)

\begin{tabular}{|c|c|c|c|}
\hline & Mostly satisfied & Neither & Mostly dissatisfied \\
\hline \multicolumn{4}{|l|}{ Educational attainment (university) } \\
\hline Secondary education & -0.003 & -0.002 & 0.006 \\
\hline Less than secondary education & $-0.015^{* * *}$ & $-0.013 * * *$ & $0.028 * * *$ \\
\hline \multicolumn{4}{|l|}{$\begin{array}{l}\text { Monthly household income } \\
\text { (top third) }\end{array}$} \\
\hline Middle third & 0.002 & 0.002 & -0.004 \\
\hline Lower third & 0.004 & 0.003 & -0.007 \\
\hline No details & -0.002 & -0.002 & 0.004 \\
\hline \multicolumn{4}{|l|}{$\begin{array}{l}\text { Subjective class affiliation (upper } \\
\text { class, upper-middle class) }\end{array}$} \\
\hline Middle class & -0.002 & -0.002 & 0.004 \\
\hline Lower middle class & -0.003 & -0.002 & 0.006 \\
\hline Lower class & $-0.028 * * *$ & $-0.025^{* * *}$ & $0.054 * * *$ \\
\hline Other, don’t know & $-0.019 * *$ & $-0.015 * *$ & $0.034 * *$ \\
\hline \multicolumn{4}{|l|}{$\begin{array}{l}\text { Economic situation of the } \\
\text { household over the past five } \\
\text { years (better) }\end{array}$} \\
\hline Similar & $-0.020 * * *$ & $-0.013 * * *$ & $0.032 * * *$ \\
\hline Worse & $-0.066 * * *$ & $-0.068 * * *$ & $0.134 * * *$ \\
\hline Don’t know & $-0.041 * * *$ & $-0.032 *$ & $0.073 * *$ \\
\hline \multicolumn{4}{|l|}{ Crisis perception (no crisis) } \\
\hline Non-serious crisis & $-0.034 * * *$ & $-0.012 * * *$ & $0.046^{* * *}$ \\
\hline Serious crisis & $-0.096 * * *$ & $-0.079 * * *$ & $0.175 * * *$ \\
\hline No details & $-0.054 * * *$ & $-0.025 * * *$ & $0.079 * * *$ \\
\hline \multicolumn{4}{|l|}{ Trust in institutions (high) } \\
\hline Medium & $-0.168 * * *$ & 0.004 & $0.164 * * *$ \\
\hline Low & $-0.245 * * *$ & $-0.198 * * *$ & $0.444 * * *$ \\
\hline Don’t know & $-0.193 * * *$ & $-0.028 * * *$ & $0.221 * * *$ \\
\hline Political interest (mostly interested) & 0.003 & 0.002 & -0.005 \\
\hline \multicolumn{4}{|l|}{ Political orientation (right) } \\
\hline Centre & 0.004 & 0.003 & -0.007 \\
\hline Left wing & $-0.008 * *$ & $-0.007 * *$ & $0.015 * *$ \\
\hline Don’t know & $-0.018^{* * *}$ & $-0.016^{* * *}$ & $0.034 * * *$ \\
\hline $\begin{array}{l}\text { Life satisfaction (mostly } \\
\quad \text { dissatisfied) }\end{array}$ & $0.027 * * *$ & $0.027 * * *$ & $-0.054 * * *$ \\
\hline Gender (male) & $-0.010 * * *$ & $-0.008 * * *$ & $0.018 * * *$ \\
\hline \multicolumn{4}{|l|}{ Age } \\
\hline $25-44$ & $-0.031 * * *$ & $-0.020 * * *$ & $0.051 * * *$ \\
\hline $45-64$ & $-0.033 * * *$ & $-0.022 * * *$ & $0.055^{* * *}$ \\
\hline $65+$ & $-0.026 * * *$ & $-0.017 * * *$ & $0.043 * * *$ \\
\hline Migration background (no) & $0.012 * * *$ & $0.009^{* * *}$ & $-0.021 * * *$ \\
\hline \multicolumn{4}{|l|}{ Place of residence (city) } \\
\hline Town (small) & -0.003 & -0.002 & 0.005 \\
\hline Village and countryside & -0.006 & -0.005 & 0.012 \\
\hline \multicolumn{4}{|l|}{ Country (Switzerland) } \\
\hline Sweden & $-0.125^{* * *}$ & $-0.051 * * *$ & $0.176 * * *$ \\
\hline Germany & $-0.098 * * *$ & $-0.024 * * *$ & $0.123 * * *$ \\
\hline
\end{tabular}

(Continued) 
Table 5.4 Continued

\begin{tabular}{llll}
\hline & Mostly satisfied & Neither & Mostly dissatisfied \\
\hline United Kingdom & $-0.074^{* * *}$ & $-0.010^{* * *}$ & $0.084 * * *$ \\
France & $-0.098^{* * *}$ & $-0.024 * * *$ & $0.123^{* * *}$ \\
Italy & $-0.118^{* * *}$ & $-0.042^{* * *}$ & $0.160^{* * *}$ \\
Spain & $-0.130^{* * *}$ & $-0.057^{* * *}$ & $0.187 * * *$ \\
Poland & $-0.161^{* * *}$ & $-0.114^{* * *}$ & $0.275^{* * *}$ \\
Greece & $-0.127^{* * *}$ & $-0.053^{* * *}$ & $0.180^{* * *}$ \\
Cases & 15.330 & & \\
Pseudo R & 0.2349 & & \\
\hline
\end{tabular}

Source: Livewhat WP4 population survey.

Note: Significance levels: $* P<0.1, * * P<0.05$, $* * * P<0.01$.

regression analysis was recalculated, but now additionally with the respective reference countries. As in the previous sections, the analysis had to be calculated separately for each reference country, with the result that respondents from the respective reference country were not included in the calculations either. As the results table with all variables is too extensive to be presented here, merely a compilation of the correlation measures for the nine reference countries is presented here.

Figure 5.4 shows that satisfaction with government work is clearly related to the assessment of living conditions elsewhere; those who feel worse off are also less satisfied. Our findings, therefore, suggest that people measure their own government by whether living in other countries is better or worse. Here, too, the ranking between the best-placed and worst-placed countries can be seen. The highest probability of dissatisfaction with one's own government is among people who view their living conditions more negatively than Swiss living conditions. This effect is also repeated at a slightly lower level in the other well-placed countries (Sweden, Germany, UK, partly France). The correlation among the crisis countries (Spain, Italy and Greece) is much less pronounced. In the case of Greece, the influence of the poor living conditions on satisfaction largely evaporates; here, the comparison seems to be less disappointing. This confirms that comparisons with poorly placed countries have less impact on people's political judgements than comparisons upwards.

Figure 5.4 also breaks down whether people who assess their personal situation as similar to those in other countries are also more dissatisfied with their governments. This is evidently not the case. On the contrary, there are signs of the opposite effect: people who see similarities are less likely to be dissatisfied with their government. It seems that these people see less reason to criticise their politicians as their personal situation does not differ significantly from that of other Europeans. The effects vary only very slightly between the nine reference countries, indicating that the similarity of living conditions, in any case, has a moderating influence on the assessment of the government. People seem to have less cause for dissatisfaction as long as they are as well or as badly off as other Europeans. 


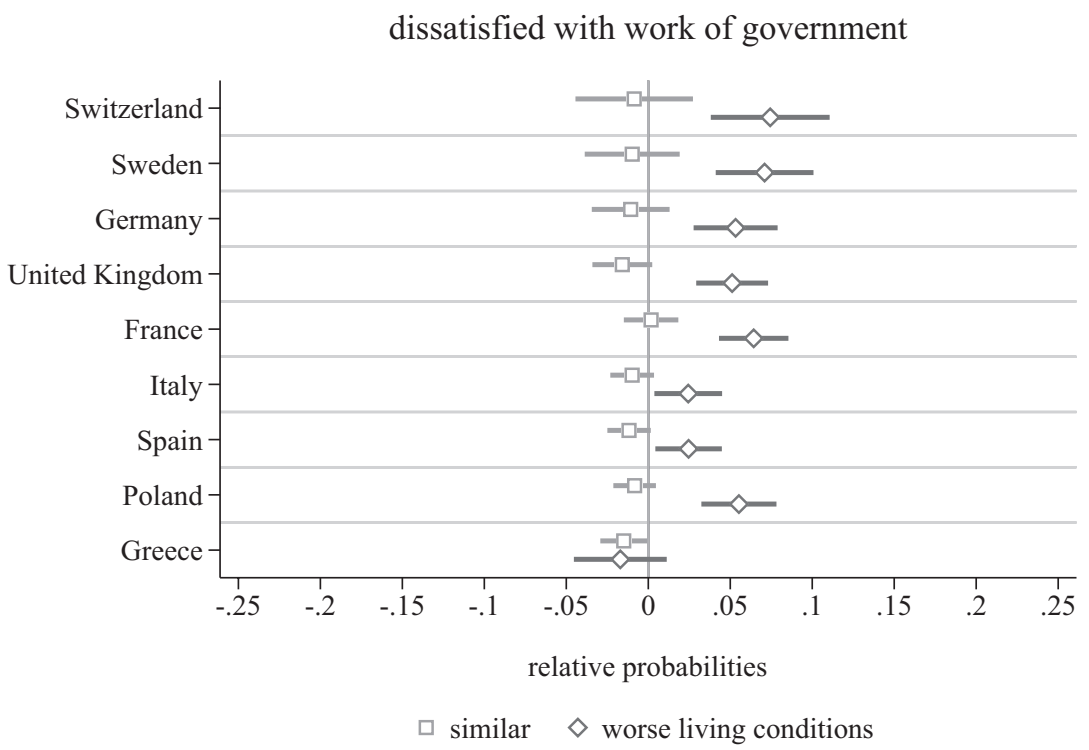

Figure 5.4 Satisfaction with government and living conditions - extended model (ordered logistic regression, average marginal effects). Source: Livewhat WP4 population survey.

The calculation of the predictive margins per country shows that these correlations follow the same pattern everywhere (see Figure 5.5). This time, the analysis is restricted to one reference country, namely Sweden. As in the previous section, it can be seen that the member states initially differ in the average probability of having dissatisfied or satisfied citizens. Figure 5.5a shows that dissatisfaction is generally highest in Italy, Spain and Greece, while it is lowest in Switzerland, Germany and the UK. Inversely, satisfaction is higher in the wealthier countries and lower in the crisis countries. In addition, however, the comparisons of living conditions have a clear influence on satisfaction with government work everywhere. Respondents from all countries have a clear tendency to be dissatisfied once they assess their personal situation more negatively than that in Sweden. The effect is weaker in the best-ranked countries, probably also because the countries receive similarly good marks as Sweden. The increase in dissatisfaction is remarkable in the less wellplaced member states. Finally, it is confirmed for each individual country that the perception of similar living standards has a tempering influence on political dissatisfaction. The group that considers itself on par with the Swedish population is not only as often satisfied with its own government as those who feel better off; figure $5.5 \mathrm{~b}$ shows that this group tends to be even more satisfied.

It can be concluded that similar standards of living reduce political dissatisfaction while unequal standards of living increase dissatisfaction with one's own government. The general insight behind this association is remarkable. On the 


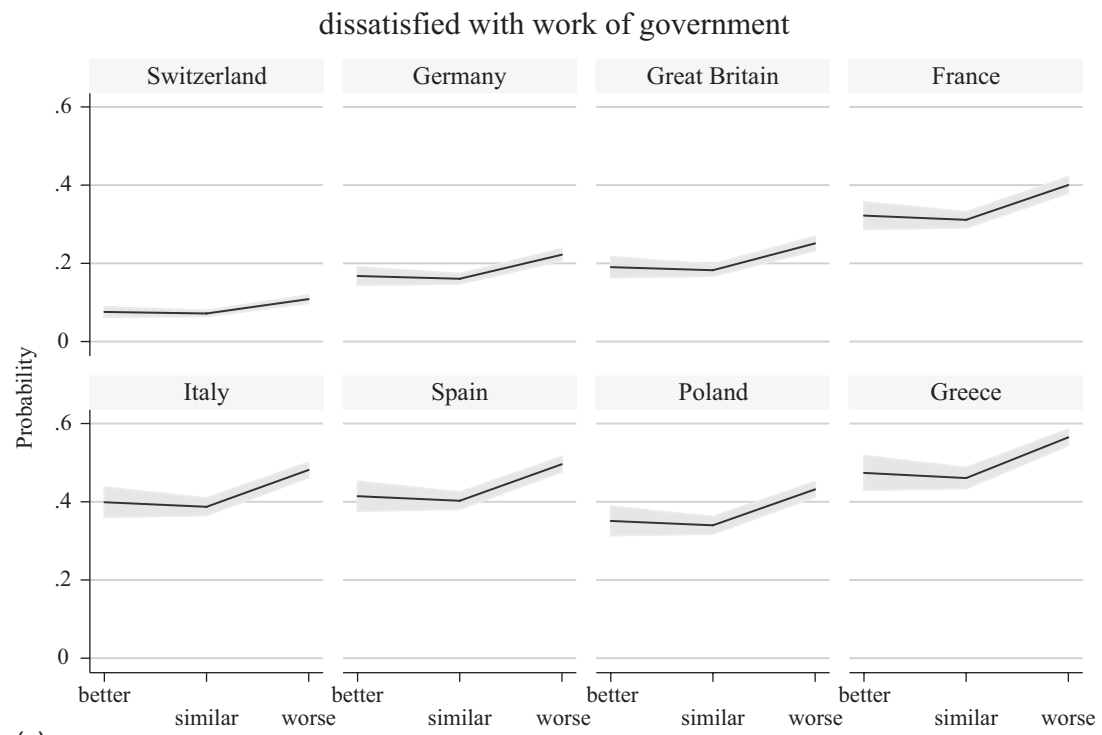

(a)

own living conditions compared to Sweden

satisfied with work of government

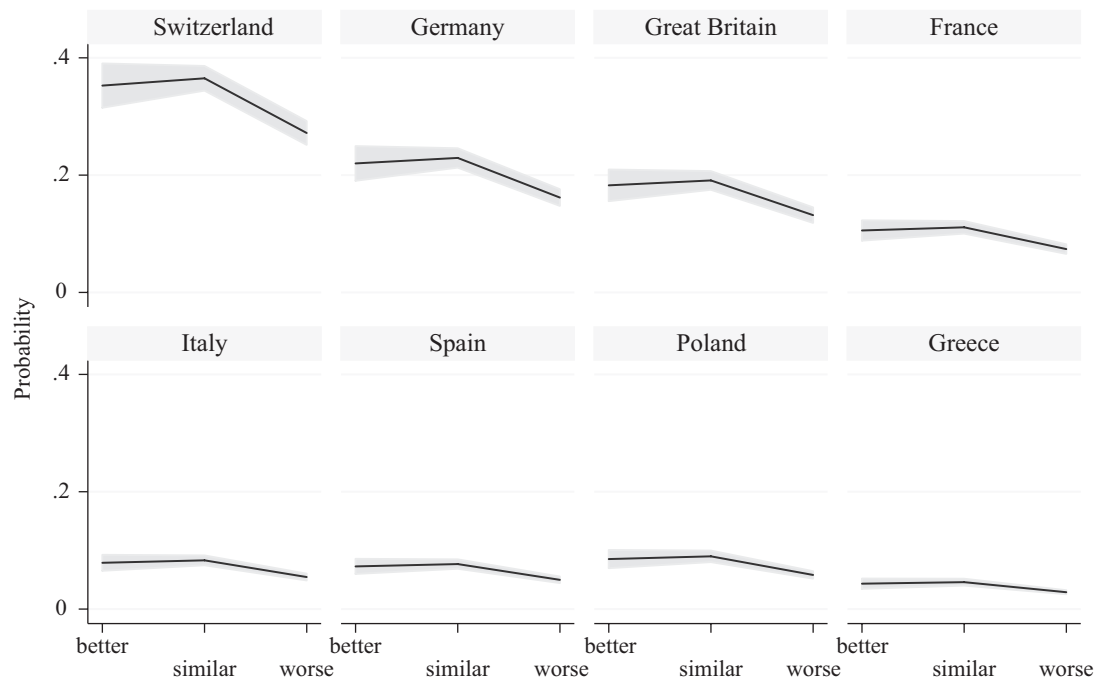

(b)

own living conditions compared to Sweden

Figure 5.5 Dissatisfaction with government work and country comparisons (predictive marginal effects). Source: Livewhat WP4 population survey. 
one hand, people assess their governments' performance within a pan-European frame of reference, which implies that people have ideas of a common European standard of living - otherwise the comparisons of social situations on both sides of the border would have no political relevance. On the other hand, it shows that the similarity of living conditions in Europe does not just have a neutral effect, but also diminishes political dissatisfaction and even supports satisfaction with one's own government. The similarity, therefore, seems to be people's compass for assessing political performance balances, and this aspect shows that people have indeed internalised the concept of a common European living standard. The European population is evidently a strong supporter of the EU's mission to create equal living conditions in Europe.

\section{Political disappointment with the political "establishment" on a European scale}

It has been shown that the dissatisfaction of citizens with the political work of their government is noticeably linked to the economic situation in the countries. Satisfaction levels are collapsing, especially in the crisis-stricken countries of southern Europe. But the poorer economic situation of the personal household also causes respondents to be dissatisfied with their governments, especially if they believe that life is better elsewhere. This dissatisfaction is part of political reality and thus also an incentive for democracy because it puts pressure on the governing parties to improve their performance balance, and it provides the political opposition with new opportunities to win elections. Satisfaction or dissatisfaction with the work of the government is regarded as specific support or criticism of the political system and is thus the fuel of a living democracy (Dalton 1999; 2008).

Nevertheless, the dissatisfaction of citizens with the work of the government may well lead to the alienation of citizens from the political system, provided that the criticism no longer only questions the work of the political personnel but, more fundamentally, also questions the political conditions or institutions as a whole. In the analyses above, for example, it was shown that satisfaction with government work very often goes hand in hand with fundamental trust in political institutions. Conversely, the dissatisfied much more often distrust political institutions. It seems that bridges have already been burned here.

This topic has been intensively researched for many decades, with the debate having been conducted under a variety of buzzwords. It was about political disinterest and non-participation (abstentionism or disengagement), disenchantment with politics and alienation from the political system, protest voters and angry citizens and, most recently, populism (Finifter 1970; Kleinhenz 1998; Amnå and Ekman 2014; Fieschi and Heywood 2004; Kneuer 2019). These debates unite a dual diagnosis because, on the one hand, it was found that people stay away from politics because they are simply not interested. It is not seen as part of their life, their priorities and desires. Very often, people around them share this view, which is why politics is experienced as a foreign body in their everyday life (Smith 
2011; Hobbins and Lahusen 2015). Disinterested people frequently lean towards political passivity out of ignorance, incapacity or apathy and, therefore, share a feeling of internal ineffectiveness (Bertelson 1974; Reichert 2016). On the other hand, it is noted that political abstinence can also be the result of political disenchantment and thus of active dislike. Here it is the disappointment and alienation from day-to-day political business and political institutions that drive people to turn away from politics. This alienation does not rule out political participation because disappointed voters can vote for parties outside the established party spectrum (Stockemer and Barisione 2016; Treib 2020). Behind this disappointment and alienation is very often the belief that one's political participation has little effect on politics (Ruxton and Saunders 2016) since the rulers have no ear for one's interests.

Populist parties and groups know how to play to this kind of audience and can successfully use the electoral potential of the politically disappointed for their own benefit. While dissatisfaction and disenchantment with politics are nothing new, the fact that political parties are being established that successfully call these people to the polls is a novel phenomenon. These groups address a somewhat diffuse general unease with established politics (Taggart 2004), but it should be noted that such parties can be found in all political leanings of the party spectrum (left and right, but also liberal, market-radical movements). They include, for instance, national right-wing parties such as the Rassemblement National in France, Austria's Freiheitliche Partei Österreichs or Germany's Alternative für Deutschland, but left-wing liberal groups such as the Spanish Podemos or the Greek Syriza should also be mentioned. These parties thus serve a worldview described as populist, which essentially consists of few convictions such as the belief in the people as a homogenous group, the opposition against a corrupt elite and the absolute desire to make the voice of the people heard. The criticism of the political system and the elite is often accompanied by the support of a charismatic leader who is seen as the direct representation of the people. After all, populism is considered a phenomenon of a crisis because it appeals to people who see themselves as losers of the social changes that they experience as rapid, and who consequently believe not only themselves but society and politics to be in a serious crisis (Mudde 2004; Rooduijn 2014; Kriesi and Pappas 2015; Kneuer 2019).

If these descriptions are correct, populist attitudes should be generally represented in the European population. After all, so far, it has been shown that a considerable proportion of respondents assume that we are living in times of a noticeable, even serious crisis. And many people are dissatisfied with the work of their governments in a whole range of policy areas. This seems to indicate that the long-standing economic and financial crisis has triggered a crisis of political acceptance and legitimacy of the existing representative democracy in parts of the citizenry. Populist beliefs would be a good indicator of this.

But how widespread are these ideas among the European population? Is it possible to determine an association with the perception of the crisis, i.e., are these convictions much more prevalent in the crisis countries of southern Europe than in the member states that are less noticeably and enduringly affected by the 
crisis? Can it also be said that populist beliefs are often shared by people living in disadvantaged circumstances who are at risk of social decline and more sensitive to crises? And does the comparison of living conditions within Europe fuel such populist convictions as soon as people assume that they are personally worse off than those living in other European countries?

In order to answer these questions, a battery of items from the survey evaluated so far will be used, which seeks to measure populist beliefs on the basis of proposals from previous studies (Akkerman, Mudde and Zaslove 2014; Stanley 2011; Elchardus and Spruyt 2016). The measuring instrument consists of eight statements that belong to the populist core convictions, namely the centring on the people, the anti-elitist orientation, the antagonism between people and political class and the primacy of popular sovereignty (Rico and Anduiza 2016). In detail, respondents were asked to comment on the following statements, with answers ranging from one (completely disagree) to five (completely agree):

- politicians in [the country's] parliament need to follow the will of the people

- the people, and not politicians, should make our most important political decisions

- the political differences between the elite and the people are larger than the differences among the people

- I would rather be represented by a citizen than by specialised politician

- elected officials talk too much and take too little action

- what people call "compromise" in politics is really just selling out on one's principles

- the particular interests of the political class negatively affect the welfare of the people

- politicians always end up agreeing when it comes to protecting their privileges

Table 5.5, with an integrated chart, gives an overview of the opinion climate in the countries by expressing the average agreement with the eight statements. The scatter of the answers was not included; however, with values around 0.8-1.0, the standard deviation with each statement is recognisable but moderate. It can be seen that not all statements meet equal approval. Respondents are less convinced that politicians betray their principles when they make compromises. And the desire that citizens and not professional politicians should direct the fate of the country also barely receives approval, as with 3.6 it is only slightly above a mediocre "neither". However, respondents broadly agree that parliament should follow the will of the people and that politicians talk too much and have their own privileges in mind.

With regard to the average opinion in the countries, it is obvious that the French, Italian and Greek respondents are more aligned with populist beliefs than the others. Particularly the criticism of the political class is very pronounced because, on average, respondents agree with the statement that the elites seek to protect their own privileges and harm the welfare of the people. In contrast, Switzerland, Sweden, Germany and the UK are among the countries with lower 
Table 5.5 Agreement with populist beliefs (averages)

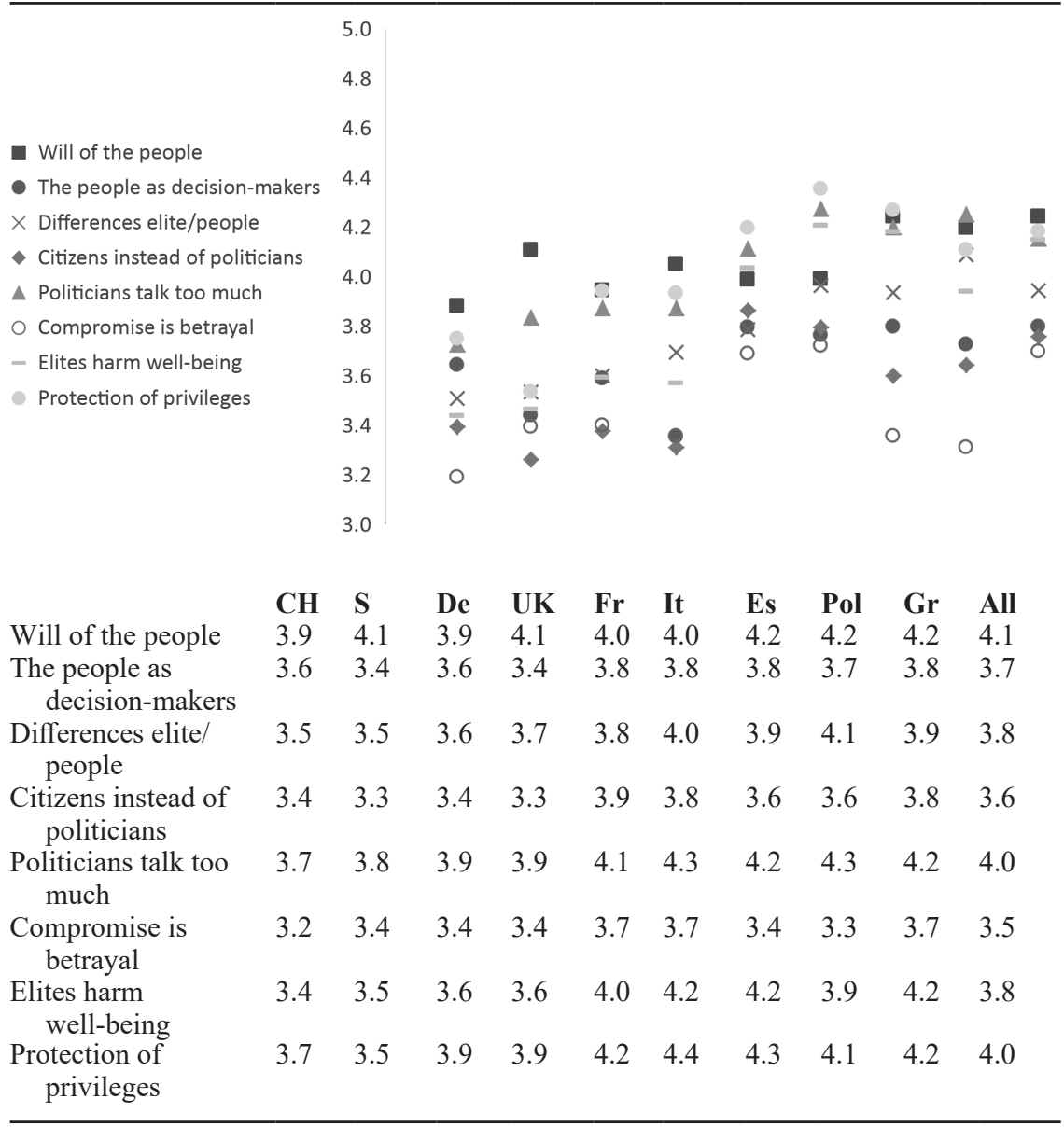

Source: Livewhat WP4 population survey.

Note: Switzerland (CH), Sweden (S), Germany (De), United Kingdom (UK), France (Fr), Italy (It), Spain (Es), Poland (Pol), Greece (Gr) and all countries (All).

approval values. The Swedish respondents, in particular, differ significantly from the overall picture. Apart from the sentiment that parliament should do what the people want and that politicians talk too much, Swedes are the least critical of the political class.

These individual statements themselves do not yet measure populist orientations; some of them are even part of democratic self-perception. This applies, for example, to the opinion that parliament should represent the will of the people. And the statement that the people should make important political decisions also corresponds to the convictions of plebiscitary democracy and its procedures (e.g., 
referendums or citizens' petitions). However, in combination with the other statements, these statements also contain a populist reckoning with the political establishment. In political science research, these attitudes are therefore not treated individually but are only associated with populist beliefs as a package (Akkerman et al. 2014; Stanley 2011; Elchardus and Spruyt 2016; Rico and Anduiza 2016). This practice is also to be followed here.

For the following evaluations, these eight statements have therefore been summarised into an indicator that is intended to capture basic populist beliefs in the population. A factor analysis pointed to two dimensions, but all statements were loaded very clearly with the first dimension, while the second could hardly be interpreted meaningfully. An overall indicator has, therefore, been maintained. The internal consistency of the indicator with all eight statements is good, as the reliability test showed an alpha value of 0.87 for the total sample, and values for the individual countries, which were between 0.82 (Greece) and 0.90 (France). Table 5.6 summarises the descriptive results of this indicator. It is confirmed that the populist orientation is highest on average in Italy. But in Greece, France, Spain and Poland, too, the needle tends to swing in the direction of higher approval. The scatter around the mean value is rather small because, with less than one point, the respondents are oriented more or less populistically than the average of the country.

This indicator has been divided into three equally large groups in order to identify those respondents who stood out for their high approval levels of the populism index (i.e., on average between 4.2 and 5 of the 5 -point scale). As can be seen in Table 5.6, about a third of all respondents can be assigned to this group. In Switzerland, the group is quite manageable, with only one in seven respondents. There are also fewer people who share populist beliefs in the UK, Sweden and Germany. The largest group is in Italy, with almost one in two respondents, but Spain and France are just behind Italy with just under $40 \%$, followed by Greece and Poland.

It would now make sense to attribute the unequal distribution of populist beliefs to the consequences of the economic and financial crisis because this crisis led to a significant drop in living standards in southern European countries. For many people, it meant the precarisation of their personal situation, social decline and impoverishment. But even households from more secure backgrounds could not avoid such worries; one only needs to think back to the majority of Greek, Italian or Spanish respondents who said in this survey that their country was in a serious crisis. Therefore, the question arises in which circumstances the respondents with populist convictions live, and in what situation they see themselves. At the same time, it must be clarified whether this group of people consistently rate their own living standards as worse than those in other countries when comparing living conditions. They would then be expressing the feeling of being neglected or left behind within Europe.

To answer these questions, it is important to validate the explanatory power of a number of factors analysed in previous chapters, because they have confirmed their relevance by earlier studies on populist beliefs. First, it must be clarified 


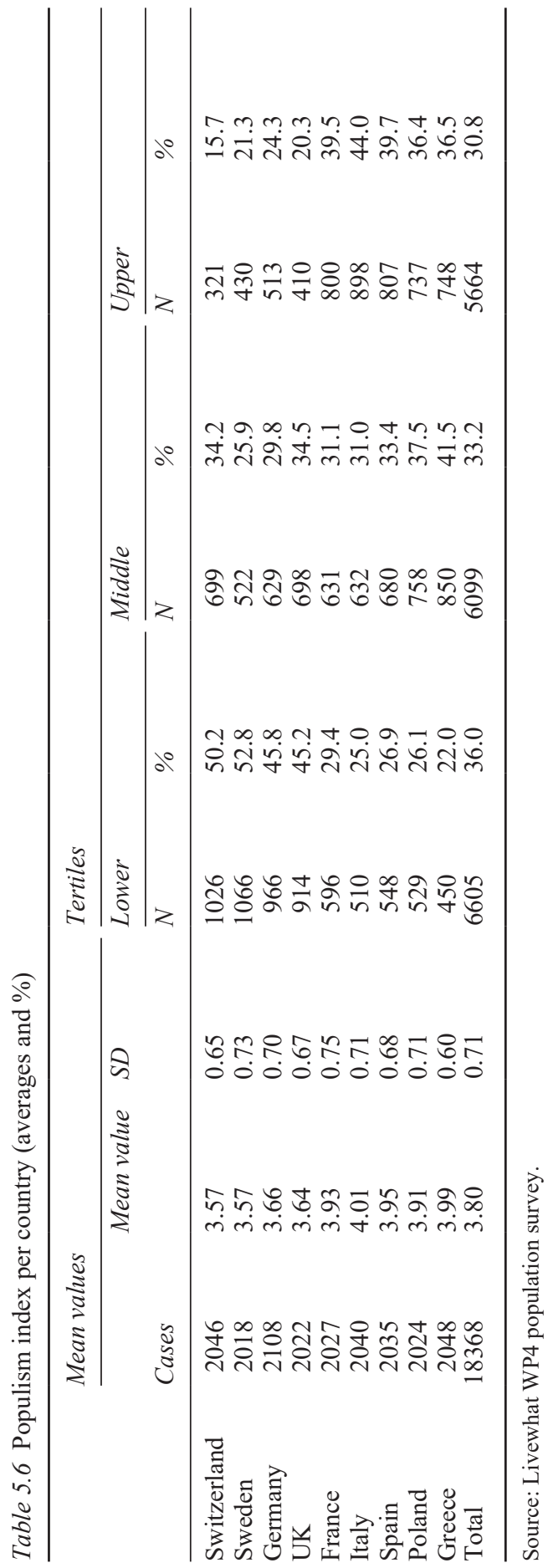


whether people with high levels of approval are characterised by greater social disadvantage when they are compared with those without affinity with populist orientations. Populism research assumes this, although one would have to differentiate between different assumptions here. Initially, the expectation is that modernisation and globalisation processes create new structures of division and lines of conflict that essentially generate winners and losers (Kriesi et al. 2006; Kriesi and Pappas 2015). The losers are likely to be people with fewer societally relevant resources such as education, income and professional status.

However, populist beliefs do not necessarily have to be a consequence of objective social disadvantage, but may just as well correspond to subjective perceptions of social decline, unfair treatment and being the victims of an increasingly divided society (Elchardus and Spruyt 2016; Rico and Anduiza 2016). This expands the circle of people who are open to populist beliefs because even people in more secure circumstances can fear a deterioration in the economic situation of their household or perceive a deterioration in the economic situation in their country, which could sooner or later have a negative impact on them personally. The aim is, therefore, to clarify whether the perception of such macroeconomic or personal threats is more important for the expression of populist convictions than the objective, socio-structural position of the respondents.

In addition to these socio-economic factors, political determinants must also be considered, above all because the described economic crisis phenomena can also lead to a political acceptance crisis. Indeed, it is assumed that populist attitudes are not primarily a reaction to social changes and economic crises but rather a response to the perceived inability of politicians to find solutions (Laclau 2005; Pappas 2014). It appears more likely that the differences between people with and without populist beliefs can be explained by their relationship with political institutions. If the observation is correct that populist beliefs can be found in all political camps, they should not vary along the political left-right spectrum, but along satisfaction with government work and trust in politics, in other words, with the general acceptance of political conditions.

These factor bundles are part of a basic model to which a number of control variables are then added. It is important to exclude that populist beliefs are linked to specific population groups that share socio-demographic characteristics (age, gender, place of residence or migration background). It must also be checked whether these factors lose their explanatory power as soon as the countries are introduced as variables, as in this case, it is also possible that the populist approval rates are not due to the social-structural variables and political attitudes of the respondents, but can be attributed solely to the differences between the countries. As in the previous analyses, the assumptions are to be checked using a regression analysis (ordered logit model).

Table 5.7 confirms most of the assumptions of the basic model; only the sociostructural location of the respondents has little influence on populist beliefs. Although respondents with low educational attainment are more likely to agree with the populist world view rather than those with a university degree, there is no clear correlation with regard to household income. More important is the 
Table 5.7 Populist beliefs, basic model (ordered logistic regression, average marginal effects)

\begin{tabular}{|c|c|c|c|}
\hline & Rejection & Neither & Agreement \\
\hline \multicolumn{4}{|l|}{ Educational attainment (university) } \\
\hline Secondary education & $-0.026 * * *$ & $0.002 * * *$ & $0.024 * * *$ \\
\hline Less than secondary education & $-0.031 * * *$ & $0.002 * * *$ & $0.029 * * *$ \\
\hline \multicolumn{4}{|l|}{ Monthly household income (top third) } \\
\hline Middle third & -0.007 & 0.000 & 0.007 \\
\hline Lower third & -0.004 & 0.000 & 0.004 \\
\hline No details & 0.014 & -0.001 & -0.013 \\
\hline \multicolumn{4}{|l|}{$\begin{array}{l}\text { Subjective class affiliation (upper class, } \\
\text { upper-middle class) }\end{array}$} \\
\hline Middle class & $-0.039 * * *$ & $0.006^{* *}$ & $0.033 * * *$ \\
\hline Lower middle class & $-0.066^{* * *}$ & $0.008 * * *$ & $0.058 * * *$ \\
\hline Lower class & $-0.096 * * *$ & $0.009 * * *$ & $0.087 * * *$ \\
\hline Other, don't know & -0.025 & 0.004 & 0.021 \\
\hline \multicolumn{4}{|l|}{$\begin{array}{l}\text { Economic situation of the household over } \\
\text { the past five years (better) }\end{array}$} \\
\hline Similar & $0.021 * * *$ & $-0.002 * * *$ & $-0.019 * * *$ \\
\hline Worse & $-0.042 * * *$ & $0.001 * *$ & $0.041 * * *$ \\
\hline Don't know & -0.019 & 0.001 & 0.018 \\
\hline \multicolumn{4}{|l|}{ Crisis perception (no crisis) } \\
\hline Non-serious crisis & $-0.055^{* * *}$ & $0.010 * * *$ & $0.045^{* * *}$ \\
\hline Serious crisis & $-0.131 * * *$ & $0.012 * * *$ & $0.119 * * *$ \\
\hline No details & $0.074 * * *$ & $-0.022 * * *$ & $-0.052 * * *$ \\
\hline \multicolumn{4}{|l|}{$\begin{array}{l}\text { Satisfaction with government work } \\
\text { (mostly satisfied) }\end{array}$} \\
\hline Neither & $-0.081 * * *$ & $0.017 * * *$ & $0.064 * * *$ \\
\hline Mostly dissatisfied & $-0.208^{* * *}$ & $0.010 * * *$ & $0.198 * * *$ \\
\hline Don't know & $-0.066^{* * *}$ & $0.015 * * *$ & $0.050 * * *$ \\
\hline \multicolumn{4}{|l|}{ Trust in institutions (high) } \\
\hline Medium & $-0.156^{* * *}$ & $0.047 * * *$ & $0.109 * * *$ \\
\hline Low & $-0.325 * * *$ & $0.020 * * *$ & $0.305^{* * *}$ \\
\hline Don't know & $-0.087 * * *$ & $0.032 * * *$ & $0.055^{* * *}$ \\
\hline Political interest (mostly disinterested) & $-0.027 * * *$ & $0.002 * * *$ & $0.025 * * *$ \\
\hline \multicolumn{4}{|l|}{ Political orientation (centre) } \\
\hline Right wing & -0.009 & 0.001 & 0.009 \\
\hline Left wing & $-0.022 * * *$ & $0.001 * * *$ & $0.021 * * *$ \\
\hline Don't know & $-0.019 * *$ & $0.001 * *$ & $0.018 * *$ \\
\hline Life satisfaction (mostly dissatisfied) & 0.008 & -0.001 & -0.008 \\
\hline Gender (male) & $0.037 * * *$ & $-0.002 * * *$ & $-0.035 * * *$ \\
\hline \multicolumn{4}{|l|}{ Age } \\
\hline $25-44$ & $-0.049 * * *$ & $0.007 * * *$ & $0.042 * * *$ \\
\hline $45-64$ & $-0.081 * * *$ & $0.008 * * *$ & $0.073 * * *$ \\
\hline $65+$ & $-0.071 * * *$ & $0.008 * * *$ & $0.063 * * *$ \\
\hline Migration background ( $n o$ ) & -0.002 & 0.000 & 0.002 \\
\hline \multicolumn{4}{|l|}{ Place of residence (city) } \\
\hline Town (small) & -0.003 & 0.000 & 0.002 \\
\hline Village and countryside & $-0.013 *$ & $0.001 *$ & $0.012 *$ \\
\hline
\end{tabular}

(Continued) 
Table 5.7 Continued

\begin{tabular}{llcc}
\hline & Rejection & Neither & Agreement \\
\hline Country (Switzerland) & $0.022^{*}$ & $-0.003^{*}$ & $-0.019^{*}$ \\
Sweden & $-0.038^{* * *}$ & $0.002^{* *}$ & $0.036^{* * *}$ \\
Germany & $0.047^{* * *}$ & $-0.007^{* * *}$ & $-0.040^{* * *}$ \\
United Kingdom & $-0.072^{* * *}$ & 0.001 & $0.071^{* * *}$ \\
France & $-0.034^{* * *}$ & $0.002^{* *}$ & $0.032^{* * *}$ \\
Italy & -0.009 & 0.001 & 0.008 \\
Spain & $-0.102^{* * *}$ & -0.002 & $0.104^{* * *}$ \\
Poland & $0.043^{* * *}$ & $-0.006^{* * *}$ & $-0.036^{* * *}$ \\
$\quad$ Greece & 17333 & & \\
Cases & 0.146 & & \\
Pseudo R & & & \\
\hline
\end{tabular}

Note: Significance levels: $* P<0.1, * * P<0.05, * * * P<0.01$.

Data: Livewhat WP4 population survey.

subjective assessment of one's situation. People who feel that they belong to the lower classes and assume that the economic situation of their household has deteriorated in the last five years are remarkably more susceptible to populist beliefs when they are compared with respondents in a subjectively better situation. Above all, it is confirmed that populist views have a conspicuous affinity with crisis perception, as respondents who believe their country is in a serious crisis share populist opinions more often (i.e., 11.9\%) than those who do not perceive a crisis; in terms of predictive probabilities, the difference is between $24.2 \%$ and $36.2 \%$. This finding is highlighted by the fact that respondents who have no opinion on the crisis issue are much less likely to agree with the populist world view.

The strongest correlations result from political attitudes. Those who are dissatisfied with government work express populist beliefs over $20 \%$ more often when compared to satisfied people. And with regard to confidence in the political institutions, the probability of populist beliefs is $31 \%$ higher, although it should be noted here that the content of this question is very close to the populist question items, which is why this finding is hardly surprising. It is remarkable that populist attitudes are by no means a sign of lack of political interest; on the contrary, these respondents are more interested in politics. In terms of political orientation, there is only a slight tendency for people on the left of political ideologies to more frequently share a populist view. However, the weak association is an indication that populist beliefs are at home in all political camps. Finally, the results show that the various control variables hardly challenge the explanatory power of the basic model; populist attitudes are more common among men and older age groups; migration experiences and place of residence have no discernible influence. In terms of countries, the differences outlined in Tables 5.5 to 5.6 are confirmed, given that the British population is less populist compared with Switzerland, and the Polish population is more populist. All in all, it can be confirmed that populist beliefs are not a sign of sheer disinterest in politics, but more fundamentally an expression of disenchantment with politics and alienation from the established 
political system. This disenchantment with politics seems to be most widespread among those sections of the population who feel pushed to the margins of society and feel that there is a serious crisis in the current situation.

The basic model thus confirms much of what previous research already addressed (Pappas 2014; Elchardus and Spruyt 2016; Rico and Anduiza 2016). However, this study is interested in the question of whether populist beliefs are also linked to the comparative assessment of living conditions in other countries, in addition to the explanations already provided by the basic model. The results of the extended regression analyses (see Figure 5.6) underpin the relevance of the intra-European comparisons, since the likelihood that respondents share basic populist beliefs also depends on how they assess their living conditions in comparison with those of other Europeans. This figure summarises the effects of the nine regression analyses graphically. People are more likely to hold populist beliefs once they feel that people in other countries are better off than they are. And conversely, those whose situation seems to be better than in other countries are less likely to agree with populist statements. The effect is greatest in relation to Switzerland as a top-ranked country. People who rate their personal living conditions to be better than those in Switzerland are unlikely to share populist beliefs. This probability decreases steadily when moving from the top-ranked countries to the crisis countries, and the effect is reversed when looking at Greece. This is understandable because, in our overall sample, there are many respondents who believe that the living conditions in their country are better than in Greece. The

approval

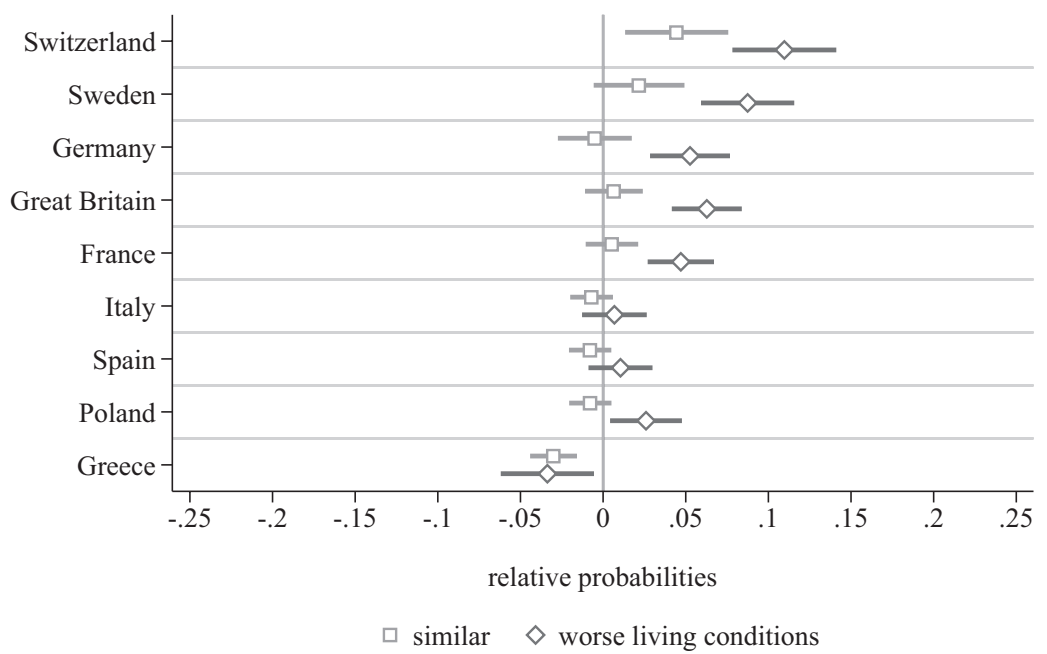

Figure 5.6 Populist beliefs - extended model detail (ordered logistic regression, average marginal effects). Source: Livewhat WP4 population survey. 
group is therefore very large and inevitably includes people with and without populist attitudes.

Cross-border comparisons thus inspire populist beliefs, especially when one's situation declines in relation to others. In this case too, however, it must be clarified whether this correlation applies to each of the nine country samples because so far, only the effects across all countries have been calculated. As in the previous chapters, predictive margins have been calculated for this purpose that allow us to indicate the probability of basic populist beliefs for each country and each reference group. Figure 5.7 compiles these coefficients for two countries at the top of the list, Switzerland and Sweden. The results show first of all that some countries, especially France and Italy, have a larger following of populist beliefs among the population, which is why the average probabilities here are also higher. However, the differences between the different comparison groups within the national samples are more meaningful. Populist beliefs are much more likely among those who see their personal living conditions below the Swiss and Swedish living standards. And this association exists in all countries. The difference is particularly marked in countries with a higher overall distribution of populist beliefs, such as France and Italy. The differences between the three groups are not so marked when comparisons are made with Swedish living conditions. It is striking that those who see their personal situation to be equal to the Swedish level share populist views only marginally more often than those who are better off than the Swedish population. And this picture continues with the other reference countries, which have not been taken into account here for space reasons. Better and similar living conditions are accompanied by populist opinions less often. It is only the perceived worst position compared to people in other countries that significantly increases the proximity to populist convictions.

In this case, too, it is a matter of correlations, and it can only be noted that populist attitudes and a feeling of being in a worse position than can be found elsewhere probably belong together. However, the question of a clear causality is less important for our purposes, as both sides are obviously part of a common pattern of perception and interpretation. The fact that people brand the political elites of their countries as detached, selfish and harmful fits into a world view that sees their own country in a bad situation, trailing behind other states. The establishment of the EU has given these populist beliefs a recipient for their political dissatisfaction. And especially in the course of the 2010s, populist parties and groups throughout Europe have significantly tightened their anti-European programme. However, in Chapter 6 it will be shown that people localise the problem much more clearly in their own country, as the feeling of not being heard politically is much more pronounced and momentous in the national context than the feeling of not being heard within the EU. The dissatisfaction is therefore also directed at national politics.

The EU thus contributes (unintentionally) to the spread of populist beliefs. It provides people with a yardstick for measuring the European social space, and according to the survey data, this social space is perceived as eminently unequal. These subjectively perceived divisional structures seem to fuel concerns about 
approval
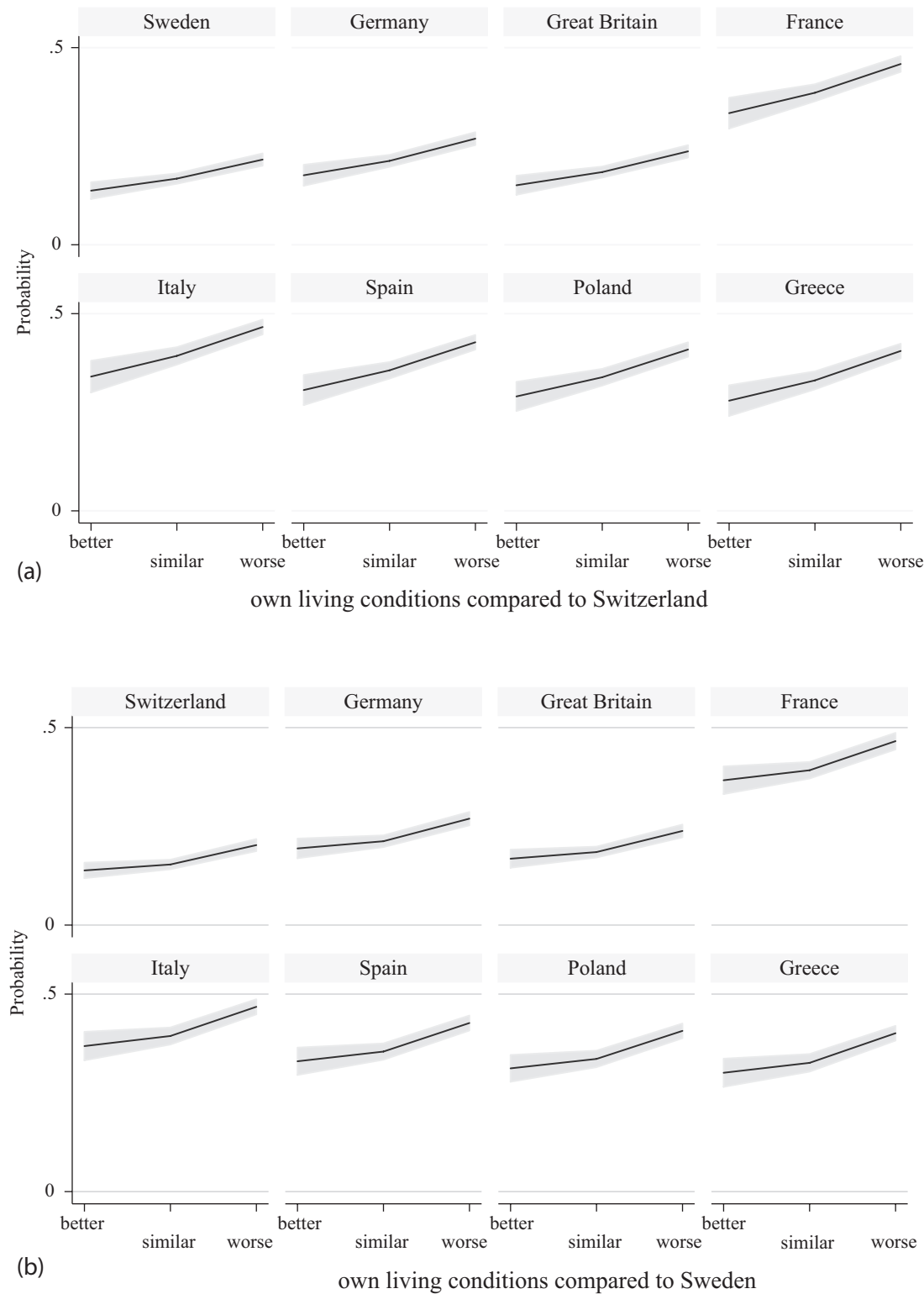

Figure 5.7 Populist convictions and country comparisons (predictive margins). Source: Livewhat WP4 population survey. 
social decline, which are shared in particular by people in insecure or precarious living conditions. When these people report that they and their households have been threatened or affected by a social decline in recent years, and when they feel that their country is in a serious crisis, these assessments take on a particularly negative value when compared with other countries. Following this perception, the European social space is interspersed with differences, inequalities or lines of division. This view can fuel the belief in a fundamental distribution conflict, according to which conditions in one's own country are curtailed by those of other countries. This view is not shared by all Europeans, because as will be shown in Chapter 6, the majority of people perceive there to be more common elements than divisive elements between the populations of Europe. However, it was also shown that $18 \%$ of those questioned are of the opposite opinion and thus emphasise the divisive elements. This belief in a distribution conflict here could develop considerable political volatility for the EU. After all, it must be considered that populist beliefs have become a pan-European phenomenon, paving the way for the respective parties and groups to enter parliaments in all member states (Taggart 1995; 2004; Mudde 2004; Kriesi et al. 2006; Kriesi and Pappas 2015).

\section{Political protest in times of European crises}

This raises the question of whether the attitudes identified so far - the crisis affinity of the population, dissatisfaction with governments, populist beliefs and the perception of a relatively bad position compared with others - also shape the political actions of European citizens. After all, the European economic and financial crisis has triggered political controversy in many countries and has also provoked street protests against the governments' austerity policies (della Porta and Mattoni 2014). The people also use elections to express their dissatisfaction because, in many places, the ruling parties lose votes in favour of the parliamentary opposition and smaller, sometimes new protest parties (Kouki and Fernandez 2018). In many countries (Greece, Portugal, Spain, Italy and also Germany), this has significantly changed the political landscape, in some cases even turned it upside down.

In Greece, for example, the traditional two-party system - with the conservative "New Democracy" (ND) and the social-democratic "Panhellenic Socialist Movement" (PASOK) - was dismantled by the 2009 and 2012 elections in favour of smaller parties on the margins of the political spectrum. In particular, the socialist Syriza party benefited most from this upheaval, since it succeeded in forming a government in 2015, alongside the right-wing populist Independent Greeks. However, since then Syriza has had to meet the reform requirements of international lenders, which led to a dramatic drop in approval levels in the election polls and the reappearance of street protests.

Other European countries have witnessed the emergence of protest parties that are critical of the political establishment (Kriesi and Pappas 2015; Hernández and Kriesi 2016). In Italy, for example, the Five Star Movement led by TV entertainer Beppe Grillo in the 2013 national parliamentary elections ousted Silvio 
Berlusconi's right-wing conservative Il Popolo della Libertà and former Prime Minister Matteo Renzi's centre-left alliance Partito Democratico (Democratic Party) with an astonishing election victory of more than $25 \%$. In the parliamentary elections of 2018, the movement was even able to increase its share of the vote to over $32 \%$, which is why it became part of the ruling coalition with the Lega Nord in early summer 2018. Similar upheavals have taken place in Spain with the two popular parties, the Partido Popular and the PSOE (Spanish socialist workers' party), suffering severe defeats in the December 2015 general elections, while the new Unidos Podemos, led by lateral entrant Pablo Iglesias, received over $20 \%$ of the vote in those elections. The party sees itself as the left-wing populist mouthpiece of an extra-parliamentary protest movement (especially the Indignados and the so-called 15-M Movement). These demonstrations were directed not only against the austerity policies of the Spanish government but also against the established parties and representation system, which they perceived to be in a serious crisis and wanted to transform into a more direct democracy (Kouki and Fernandez 2018).

In many European countries, right-wing populist protest parties also experienced a brisk influx of supporters. Parties such as the French Rassemblement National, the Dutch Partij voor de Vrijheid, the Austrian Freiheitliche Partei Österreichs, the Belgian Vlaams Belang, the German Alternative für Deutschland or the British UK Independence Party should be mentioned here. This success was not necessarily supported by broader, extra-parliamentary protest movements. Nevertheless, street protests for this right-wing populism are not completely unknown, such as the German PEGIDA (patriotic Europeans against the Islamisation of the Occident) movement, which has organised regular demonstrations against immigration, alienation and asylum policy since 2014 (Vorländer, Herold and Schäller 2018). This right-wing populism is driven by the demand to seal off one's own country in times of crises, which is why, in comparison with the countries in crisis in southern Europe, one should rather speak of wealthprotectionist, right-wing national populism.

The attention given to these anti-establishment parties, however, paints a onesided picture, given that the stronger mobilisation of the population in times of economic crisis has also led to the emergence of new civil society organisations and groups. Particularly in Greece, numerous citizens' initiatives, associations and aid projects have emerged in response to the economic and financial crisis (Clarke and Huliaras 2015). Most of their activities are aimed at alleviating the immediate needs of the population, which have been exacerbated by years of recession, high mass unemployment, falling wages and the reduction of welfare state benefits (Sotiropoulos and Bourikos 2014; Kousis, Kalogeraki, Papdaki, Loukakis and Velonaki 2018; Papadaki and Kalogeraki 2017). Essentially, however, this commitment is also a political one, since a large number of these initiatives see their task in mobilising protests for the purpose of a political transformation of Greece (Diani and Kousis 2014; Kousis 2014). Similar findings are also available for the other crisis countries because in Spain, Portugal or Italy, too, civic involvement in informal networks, initiatives or civil society organisations is of greater 
importance. Their goals include not only alleviating the immediate plight of the population but also the political mobilisation of the public (Pérez de Armiño 2014; Baumgarten 2017). Despite the widespread dissatisfaction with the political parties, one should therefore not necessarily speak of a rampant disenchantment with politics. Rather, this commitment seems to be a sign of a persistently high politicisation of the population.

This overview suggests that the consequences of the economic and financial crisis have increased people's tendency to protest in many member states at the same time (della Porta and Mattoni 2014; Kriesi 2016a). Street protests were directed against the consequences of the recession and national debt, especially in the crisis countries, against the consolidation and austerity measures of national governments but also against the reform dictates of the EU and the leading member states. Since late summer 2015, there have also been public disputes about European asylum and immigration policy, which have intensified as a result of the increasing number of refugees. As the survey data used here originate from the summer of 2015 , it is, however, possible to rule out any influence of these conflicts on the protest behaviour of the people identified. But even for this period, it can be assumed that people were dissatisfied with the political conditions in Europe in the face of the economic, financial and sovereign debt crises that grew into a crisis of governance and acceptance of the EU. They may have been prepared to protest because they perceived the plights and inequalities in their own environment also to be a consequence of a pan-European crisis. And they were probably also prepared to protest because they compared the situation in their country with the reality of life in other European countries and felt that the perceived inequalities were unfair.

It can, therefore, be assumed that the protest behaviour of the people in the individual countries did not have local or national causes alone. Rather, it is assumed that the participation in the protest was also marked by common problems and evaluation standards. This assumption can be verified when the explanatory models introduced in the previous chapters are taken up and developed further. In this sense, it should be assumed that protest behaviour becomes more and more likely as soon as people perceive the current situation as critical and assess the living conditions in their country as worse than those in the other European countries. The effect of these two factors must be balanced against other influences (here, in particular, socio-structural situations and political attitudes), which have been repeatedly confirmed in previous research as determinants of political protests.

The survey data used here provides important insights into people's propensity to participate politically because the respondents were asked whether they had campaigned for matters in the public interest. "There are different ways of trying to improve things or help prevent things from going wrong" (Livewhat 2015, p. 5). Respondents were able to choose from a list of 16 activities, and these included contacts with politicians, variants of political consumption, various forms of street protests and political communication in the social media. Respondents were asked to indicate whether they had previously performed the listed actions (last year, last five years, at some point in their lives), whether they could imagine performing these actions or whether they would never perform any of them. 
The following analyses will focus on the three listed forms of political street protests: participation in demonstrations, marches or rallies, participation in occupations, sit-ins or blockades and participation in protests where the property was damaged. Participation in demonstrations is particularly useful for our purposes because it is now a rather widespread form of political participation that is chosen by many groups to give their demands a voice in public.

Table 5.8 summarises how many people reported having participated in these protest events. One in ten respondents said they had demonstrated in the last 12

Table 5.8 Participation in protest events (in \%)

\begin{tabular}{|c|c|c|c|c|c|c|}
\hline & $\begin{array}{l}\text { Last } \\
12 \text { months }\end{array}$ & $\begin{array}{l}\text { Last } \\
5 \text { years }\end{array}$ & $\begin{array}{l}\text { Earlier } \\
\text { in life }\end{array}$ & $\begin{array}{l}\text { Never, but } \\
\text { conceivable }\end{array}$ & $\begin{array}{l}\text { Would } \\
\text { never } \\
\text { do it }\end{array}$ & $N$ \\
\hline \multicolumn{7}{|c|}{ Demonstrations, marches or rallies } \\
\hline Switzerland & 5.8 & 8.9 & 15.9 & 23.3 & 46.0 & 2046 \\
\hline Sweden & 7.3 & 6.0 & 16.1 & 21.4 & 49.3 & 2018 \\
\hline Germany & 8.1 & 9.5 & 21.7 & 21.6 & 39.0 & 2108 \\
\hline UK & 4.3 & 6.5 & 15.6 & 21.2 & 52.5 & 2022 \\
\hline France & 13.8 & 11.0 & 14.0 & 21.1 & 40.2 & 2027 \\
\hline Italy & 11.8 & 13.2 & 19.9 & 21.0 & 34.1 & 2040 \\
\hline Spain & 17.5 & 18.4 & 20.6 & 17.4 & 26.1 & 2035 \\
\hline Poland & 6.2 & 7.2 & 14.2 & 23.5 & 48.9 & 2024 \\
\hline Greece & 23.1 & 19.2 & 18.6 & 21.8 & 17.3 & 2048 \\
\hline All respondents & 10.9 & 11.1 & 17.4 & 21.4 & 39.2 & 18368 \\
\hline \multicolumn{7}{|c|}{ Occupations, sit-ins or blockades } \\
\hline Switzerland & 1.3 & 3.1 & 7.1 & 17.7 & 70.8 & 2046 \\
\hline Sweden & 0.6 & 1.7 & 5.9 & 17.0 & 74.9 & 2018 \\
\hline Germany & 1.8 & 3.6 & 6.8 & 19.5 & 68.3 & 2108 \\
\hline UK & 0.6 & 1.4 & 6.8 & 17.9 & 73.3 & 2022 \\
\hline France & 1.7 & 4.5 & 7.9 & 18.6 & 67.2 & 2027 \\
\hline Italy & 4.3 & 6.3 & 14.0 & 17.5 & 57.9 & 2040 \\
\hline Spain & 3.1 & 6.1 & 9.2 & 28.7 & 52.9 & 2035 \\
\hline Poland & 2.1 & 4.6 & 7.4 & 19.5 & 66.3 & 2024 \\
\hline Greece & 5.4 & 11.1 & 19.3 & 26.5 & 37.7 & 2048 \\
\hline All respondents & 2.3 & 4.7 & 9.4 & 20.3 & 63.3 & 18368 \\
\hline \multicolumn{7}{|c|}{ Protests involving property damage } \\
\hline Switzerland & 1.42 & 1.96 & 5.57 & 3.76 & 87.3 & 2046 \\
\hline Sweden & 0.30 & 0.94 & 4.71 & 2.63 & 91.4 & 2018 \\
\hline Germany & 1.14 & 2.13 & 4.65 & 5.55 & 86.5 & 2108 \\
\hline UK & 0.30 & 0.45 & 3.17 & 3.02 & 93.1 & 2022 \\
\hline France & 0.99 & 2.37 & 2.96 & 4.83 & 88.9 & 2027 \\
\hline Italy & 1.81 & 3.53 & 3.82 & 3.58 & 87.3 & 2040 \\
\hline Spain & 1.18 & 1.62 & 3.00 & 4.62 & 89.6 & 2035 \\
\hline Poland & 1.78 & 3.51 & 4.10 & 5.43 & 85.2 & 2024 \\
\hline Greece & 1.03 & 1.32 & 2.00 & 4.44 & 91.2 & 2048 \\
\hline All respondents & 1.1 & 2.0 & 3.8 & 4.2 & 88.9 & 18368 \\
\hline
\end{tabular}

Source: Livewhat WP4 population survey. 
months; another $11 \%$ are added as soon as the period is extended to the last five years, and another $17 \%$ can be added as soon as the respondents look further back into their lives. More than one in three had therefore participated in street protests. Another $21 \%$ could imagine doing so, which is why only $40 \%$ remain who categorically excluded demonstration participation. Percentages fall sharply when moving to confrontational and even violent forms of political protest. Almost twothirds categorically ruled out participation in blockades, and almost $90 \%$ oppose violent protests. Only 7\% and 3\% said they had participated in blockades or violent protests in the last year or the last five years, respectively.

The differences between countries are minimal for violent forms of protest, as at least $85 \%$ of respondents categorically excluded participation. Thus, the vast majority of people in Europe agreed that violence is not a legitimate means of political expression. The non-violent but confrontational forms of protest show greater differences. Only one-third of Greek respondents could not, in principle, imagine participating, and the same applies to one in two in Italy and Spain. Compared with other countries, more people considered taking part in these forms of protest. In other countries, two-thirds of those surveyed were fundamentally opposed to participation. The greater affinity with confrontational forms of protest in the southern European countries is also evident in the fact that the proportion of those who have participated in occupations or blockades in the last 12 months or 5 years was significantly higher in Greece, Italy and Spain $(16.5 \%, 10.6 \%$ and $9.2 \%$, respectively) than in the other countries.

The greater degree of mobilisation in Greece, Italy and Spain applies above all to demonstrations and rallies; France also joins this group. In these countries, the proportion of those who cannot imagine participating in principle is the lowest. In Greece, only a small minority of just $17 \%$ is not prepared to go to a demonstration. It is also remarkable that demonstration participation in these countries is also relatively recent. Almost one in four respondents from Greece has attended a demonstration in the last 12 months, and the same applies to $17 \%$ of the Spanish and $14 \%$ and $12 \%$ of the French and Italian population, respectively. The circle of respondents who have participated in a demonstration in the last five years is similar.

The greater protest affinity of the people of southern Europe can be attributed to the continuing consequences of the economic and financial crisis and the political reforms of governments (della Porta and Mattoni 2014; della Porta 2015; Kriesi 2016a). Since the survey was conducted in mid-2015, it can be ruled out that this has anything to do with the conflicts surrounding the European immigration and asylum policy since the summer of 2015. However, it may also be an expression of the political culture of these countries. For Greece, it has been shown that the recurring street protests with their confrontational, partly violent forms of action are an expression of its history because the memories of the military dictatorship (1967-1974) and the transition to democracy have established a "culture of sympathy" for resistance against the state (Andronikidou and Kovras 2012). But a more confrontational political culture has also been diagnosed for France and the other southern European countries. This is attributed, among other things, to 
the greater mistrust towards political elites and political parties (Torcal, Gunther and Montero 2002). However, the reduced enthusiasm for conventional forms of political participation such as elections or membership in parties and associations also plays a role (Fernandes, Cancela, Coppedge, Lindberg and Hicken 2015). Reference is also made to the greater politicisation and ideological divisions of the association system, for example, among the trade unions (Schmalz and Weinmann 2016).

For our empirical analyses, these national protest rates are less important because this book is interested in individual protest participation and the possible factors that could explain such political behaviour. It is known from previous research that socio-structural circumstances and political attitudes are of central importance. On the one hand, the socio-economic standard model assumes that social inequalities contribute to unequal participation in political life, since people with fewer resources (income, education, contacts or civic competences) are more often politically inactive (Verba, Nie and Kim 1978; Brady, Verba and Schlozman 1995; Schur, 2003). Concern about securing one's lifestyle may be at the forefront, or there may be a lack of means, skills and experience to actively participate politically in protests. Research has also shown that there are class-specific forms of political participation (Cainzos and Voces 2010), e.g., a middle-class bias among participants of street protests (Parkin 1968; Kriesi 1989; Eder 1993).

In addition to the socio-structural factors, research to date has also shown that participation in protest activities is influenced by basic political orientations. It can be assumed that people are more likely to take part in protests if they are politically interested. Political self-positioning on the left side of the ideological spectrum should also promote an affinity for protests because the "new social movements" dominated street protests for a long time and thus clearly shaped the protest culture (Kriesi, Koopmans, Duyvendak and Giugni 1995; Meyer and Tarrow 1998). However, it must be clarified whether this still applies in the present day because right-wing conservatives and national-populist groups are also claiming the streets for themselves and are now mobilising a different faction (Hutter 2014; Aslanidis 2016; Vorländer et al. 2018). It may, therefore, be that the political orientations along the left-right spectrum no longer help to distinguish between demonstrators and non-participants.

It will be determined below, on the basis of the findings and assumptions presented, which of these factors encourage or inhibit protest in the countries examined. In a second step, it will then be clarified whether the European comparative horizon also plays a significant role. These questions are to be analysed using one of the forms of protest already described: participation in demonstrations and rallies. It would be helpful to determine whether there are differences between the respondents who declared such participation and those who categorically exclude participation. In particular, it is important to identify the characteristics that can be used to distinguish these two groups most reliably. For this purpose, the factors that were introduced gradually in the previous chapters will be used. These factors can be condensed into four assumptions, which are based on explanations that 
have already proven themselves in protest research. Firstly, three variables that may be able to measure a protest-inhibiting effect of socio-structural disadvantage are included (income, education and subjective class affiliation). Secondly, it must be examined whether the perception of a serious crisis and the deterioration of the economic situation of one's household is encouraging participation in demonstrations. Thirdly, variables that increase the protest-encouraging influence of political orientations are inserted (interest in politics and left-right locations). Fourthly, it is assumed that protest in recent times is also an expression of political alienation from the political system, which is why the model includes variables that measure trust or distrust in political institutions, dissatisfaction with government work and populist beliefs.

As in the previous calculations, control variables are also to be introduced here. It must be clarified whether the factors introduced above retain their explanatory power when socio-demographic characteristics and the different countries are taken into account. On the one hand, people's affinity to protest is likely to be shaped by age, gender, place of residence and migration background. On the other hand, it must be checked whether protest participation depends above all on the (more or less protest affine) country in which the people live. The higher protest rate in the southern European countries seems to suggest such a country effect.

The regression analysis centres on the three active groups of people: those who participated in a demonstration only recently (i.e., in the last 12 months), those who took to the streets at an earlier point in their lives and those who can at least imagine doing so. These groups are contrasted with the notorious nondemonstrators. Table 5.9 shows that some of the findings of previous research can be confirmed. Many of the effects are negative. Overall, a clear profile of supporters emerges: demonstrators are more likely to be male, are under 25 years of age and live in large cities; they are more likely to have higher educational attainment and count themselves among the middle and lower classes; and they trust political institutions, are interested in politics and are more politically leftist. With these factors, it makes little difference whether people started to participate in street protest only recently or earlier years because this profile remains largely unchanged. Political disenchantment and political alienation from the state and politics are therefore not applicable to these demonstrators. Rather, these are people who assume that protesting is worthwhile, in part because the institutions can be trusted. For some factors, this profile is even more pronounced among the recently active (especially institutional confidence, political interest, left-wing orientations) than among people who were protesting a long time ago.

The countries also play a role because protest participation is much more likely amongst the Greek population; on average, the probability of protest participation in the last year is $10.6 \%$ for Greek respondents when compared to the Swiss. Italy, the UK and France also show higher values. It seems that the people of Greece have more reason to protest, and the same could be said for Spain, Italy and France; perhaps the people there also have a greater affinity for protest as a whole. For our purposes, however, this finding is less important. Much more remarkable 
Table 5.9 Participation in demonstrations -basic model (ordered logistic regression, average marginal effects)

Never Conceivable At an earlier In the last time in the past 12 months

Educational attainment

(university)

Secondary education

Less than secondary

$0.049 * * * \quad 0.002 * * * \quad-0.027 * * * \quad-0.023 * * *$

education

$0.100 * * *-0.000 \quad-0.056 * * * \quad-0.043 * * *$

Monthly household income

(top third)

Middle third

Lower third

No details

$\begin{array}{rr}-0.006 & -0.000 \\ 0.006 & -0.000\end{array}$

0.004

0.003

$-0.000$

$-0.000$

$-0.003$

$-0.003$

0.000

0.000

Subjective class affiliation

(upper class, upper-middle class)

Middle class

Lower middle class

Lower class

Other, don't know

Economic situation of the

household over the past

5 years (better)

Similar

Worse

Don't know

Crisis perception (no crisis)

Non-serious crisis

Serious crisis

No details

Satisfaction with government work (mostly satisfied)

Neither

Mostly dissatisfied

Don't know

Trust in institutions (high)

Medium

Low

Don't know

Political interest (not very interested)

Political orientation (centre)

Right wing

Left wing

Don't know

Populist beliefs (low)

Medium

0.001

0.012

0.008

$-0.047 * * * \quad 0.001$

$0.026^{* * *}$

$0.020 * * *$

$-0.045^{* * *} \quad 0.001$

$0.025^{* * *}$

$0.019 * * *$

$-0.023$

0.001

0.013

0.009

$\begin{array}{lccc}-0.001 & 0.000 & 0.001 & 0.000 \\ -0.018^{*} & -0.000 & 0.010^{*} & 0.008^{* *} \\ 0.042 & -0.002 & -0.024 & -0.017 \\ & & & \\ 0.006 & -0.000 & -0.003 & -0.003 \\ -0.023^{* *} & -0.000 & 0.013^{* *} & 0.010^{* *} \\ 0.034^{* *} & -0.001 & -0.019^{* *} & -0.013^{* *} \\ & & & \\ & & & \\ 0.021^{* *} & 0.000 & -0.011^{* *} & -0.009^{* *} \\ 0.009 & 0.000 & -0.005 & -0.004 \\ 0.043^{* * *} & -0.000 & -0.024^{* * *} & -0.019^{* * *} \\ & & & \\ 0.036^{* * *} & 0.001^{* *} & -0.020^{* * *} & -0.018^{* * *} \\ 0.053^{* * *} & 0.001^{* *} & -0.029^{* * *} & -0.025^{* * *} \\ 0.082^{* * *} & -0.000 & -0.045^{* * *} & -0.036^{* * *} \\ -0.164^{* * *} & 0.006^{* * *} & 0.094^{* * *} & 0.064^{* * *}\end{array}$

High

$\begin{array}{rrrr}0.066^{* * *} & -0.005^{* * *} & -0.039^{* * *} & -0.022^{* * *} \\ -0.146^{* * *} & -0.018^{* * *} & 0.085^{* * *} & 0.079^{* * *} \\ 0.085^{* * *} & -0.007^{* * *} & -0.050^{* * *} & -0.027^{* * *} \\ & & & \\ -0.002 & 0.000 & 0.001 & 0.001 \\ -0.012 & -0.000 & 0.007 & 0.006 \\ -0.009 & 0.000 & 0.005 & 0.004\end{array}$

Life satisfaction (mostly dissatisfied) 
Table 5.9 Continued

\begin{tabular}{lrllr}
\hline & Never & Conceivable & $\begin{array}{l}\text { At an earlier } \\
\text { time in the past }\end{array}$ & $\begin{array}{c}\text { In the last } \\
12 \text { months }\end{array}$ \\
\hline Gender (male) & $0.023^{* * *}$ & 0.000 & $-0.013^{* * *}$ & $-0.010^{* * *}$ \\
Age & & & & \\
$\quad$ 25-44 & $0.062^{* * *}$ & $0.005^{* * *}$ & $-0.034^{* * *}$ & $-0.033^{* * *}$ \\
$\quad 45-64$ & $0.076^{* * *}$ & $0.005^{* * *}$ & $-0.041^{* * *}$ & $-0.039^{* * *}$ \\
$\quad 65+$ & $0.158^{* * *}$ & -0.001 & $-0.088^{* * *}$ & $-0.069^{* * *}$ \\
Migration background (no) & -0.007 & -0.000 & 0.004 & 0.003 \\
Place of residence (city) & & & & \\
$\quad$ Town (small) & $0.032^{* * *}$ & $0.000^{* *}$ & $-0.018^{* * *}$ & $-0.014^{* * *}$ \\
$\quad$ Village and countryside & $0.051^{* * *}$ & -0.000 & $-0.029^{* * *}$ & $-0.022^{* * *}$ \\
Country (Switzerland) & & & & \\
$\quad$ Sweden & 0.011 & -0.001 & -0.007 & -0.004 \\
$\quad$ Germany & $-0.037^{* * *}$ & $0.002^{* *}$ & $0.022^{* * *}$ & $0.013^{* * *}$ \\
$\quad$ Great Britain & $0.083^{* * *}$ & $-0.011^{* * *}$ & $-0.048^{* * *}$ & $-0.023^{* * *}$ \\
$\quad$ France & $-0.096^{* * *}$ & -0.000 & $0.058^{* * *}$ & $0.039^{* * *}$ \\
$\quad$ Italy & $-0.099^{* * *}$ & -0.001 & $0.060^{* * *}$ & $0.040^{* * *}$ \\
$\quad$ Spain & $-0.169^{* * *}$ & $-0.013^{* * *}$ & $0.099^{* * *}$ & $0.083^{* * *}$ \\
$\quad$ Poland & $0.062^{* * *}$ & $-0.008^{* * *}$ & $-0.037^{* * *}$ & $-0.018^{* * *}$ \\
$\quad$ Greece & $-0.199^{* * *}$ & $-0.022^{* * *}$ & $0.114^{* * *}$ & $0.106^{* * *}$ \\
Cases & 17.333 & & & \\
Pseudo R & 0.08344 & & & \\
\hline
\end{tabular}

Source: Livewhat WP4 population survey.

Note: Significance levels: ${ }^{*} P<0.1, * * P<0.05$, *** $P<0.01$.

is that the social and political profile of typical protest supporters across countries is very similar.

Overall, it can, therefore, be said that the people taking part in street protests are similar in all countries. It is surprising in this context that crisis perception plays only a secondary, in some cases, even a marginal role. As shown in Table 5.9, crisis sensitivity is important when it comes to participating in recent protests. Compared with those who categorically reject participation, people who participated in demonstrations in the last 12 months are somewhat more often of the opinion that their country is going through times of serious crisis, but the association is not very significant.

This finding puts the insights of protest and movement research into perspective, as the latter assumes that the protests in the crisis countries were clearly related to the crisis. People took to the streets to protest against the consequences of the economic and financial crisis and the political austerity measures and consolidation reforms of national governments (Schmalz and Weinmann 2018; Kousis 2014; della Porta and Mattoni 2014; Kouki and Fernandez 2018; Kriesi 2016a). Our findings paint a somewhat different picture, which does not have to contradict the described insights. Protest and movement research looked at very specific mobilisation episodes, while our data measure general participation in 
street protests. The association with the crisis is there, but it appears this association is not a unique feature of the people demonstrating. The findings are understandable because people protest for many reasons, and the rallies or marches in which the respondents took part can be responses to a variety of grievances.

This finding has implications for our question because if the assessment of the overall economic situation is not directly reflected in people's tendency to protest, it is unclear to what extent the perception of unequal living conditions within Europe is also important. Are protests driven by the fact that people rate their own living conditions as worse than those in other European countries? Do protests therefore also have to do with a feeling of relative deprivation? The answer to these questions is not obvious due to inconclusive findings from previous research. On the one hand, it is not very likely that people have explicitly and exclusively taken to the streets to protest unequal living conditions in Europe. On the other hand, however, it is not far-fetched that a sense of relative deprivation could encourage protest. Protest research was able to provide some evidence of this (e.g., Dubé and Guimond 1986; Grasso and Giugni 2016). However, there are sceptical voices arguing that feelings of relative deprivation only increase the general motivation to protest, but need not necessarily result in actual protest action (McCarthy and Zald 1977; Rucht 1994). However, it is not excluded that this translation from dispositions into actions is more likely in times of crisis, because under such circumstances, feelings of relative deprivation may receive the necessary (political) salience to trigger protest participation. It, therefore, appears necessary to review this assumption empirically. This validation has to struggle with one limitation because the survey asked people about their current assessment of their living conditions, while the reported protest participation was in the past. However, it is to be expected that these comparative assessments are likely to have been internalised by respondents before the time of the survey, which is why they may at least have been relevant to recent protest behaviour.

In order to determine the effect of the mental map of European living conditions on protest behaviour, a second regression analysis (ordered logistic model) was conducted. As in the previous section, this analysis is based on the basic model (see Table 5.9) but is supplemented by comparative assessments of living conditions. In this case, too, the model had to be calculated separately for each reference country. As before, the correlation measures are compiled only for the nine country comparisons. All other factors of the basic model are not printed here, although they have been taken into account in the calculations.

Figure 5.8 shows that protest participation does not really have to do with a feeling of relative disadvantage. Since the picture is repeated for all answer categories, only the results for last year's protest participation are shown. In fact, the respondents who took part in street protests barely differ from those who categorically refuse to take part when asked about the perception of disadvantage.

The assumption that the protest behaviour of the population is influenced by the comparative assessment of living conditions in Europe can, therefore, be rejected, which makes it possible to confirm the assumption that the feelings of relative deprivation may affect the motivation to protest, but not the actual 
participation in the last 12 months

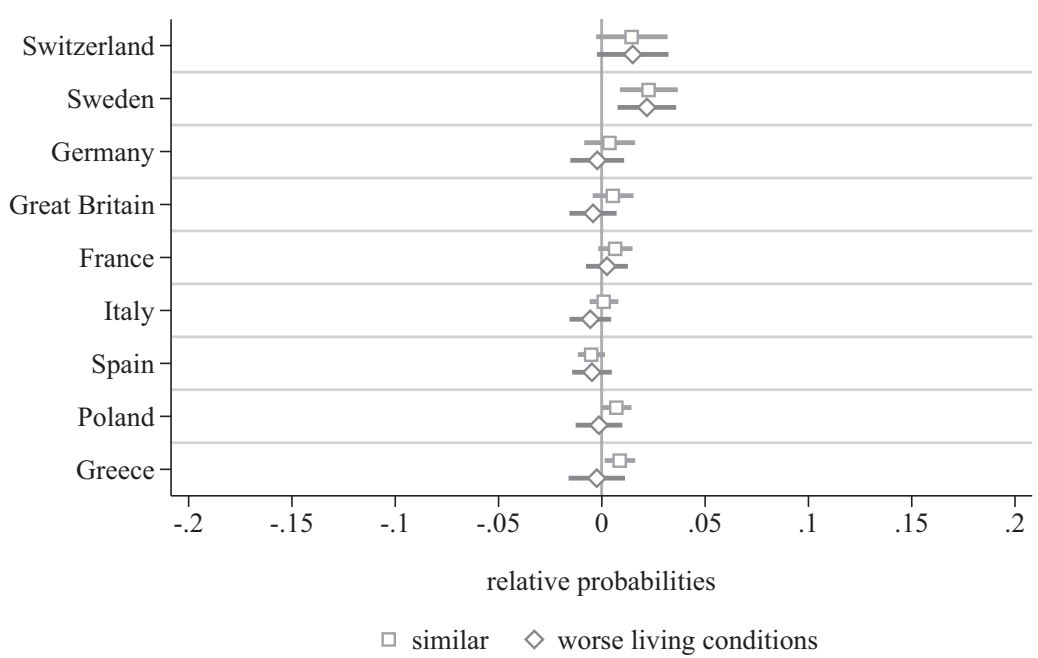

Figure 5.8 Demonstration participation and European living conditions - extended model (ordered logistic regression, average marginal effects). Source: Livewhat WP4 population survey.

protest behaviour (McCarthy and Zald 1977; Rucht 1994). Rather, reported protest behaviour is related to the social and political profile of the people as well as country-specific factors. The perception and evaluation of unequal living conditions in Europe is thus merely a latent motivation, which is dwarfed by a multitude of other, more important factors.

\section{The European social space and the political thinking and action of citizens}

In general, one must paint a differentiated picture of the political attitudes and actions of European citizens. Firstly, it has become clear that people still think and act within a national frame of reference. This national reference horizon is certainly set out in the wording of most of the questions of our investigation, as well as all the usual surveys because people are asked to take a stand on national matters (e.g., the severity of the crisis, satisfaction with government work, trust in institutions). Even the assessment of living conditions in Europe follows this pattern because as has been shown, people always assess living conditions in other European countries from the perspective of their own country. Respondents agree that the standard of living in Sweden and Switzerland is better than in Poland or Greece. But the assessment of each individual country always varies depending on where people live because the Swiss situation is portrayed better in Greece than it is in Sweden or Germany. 
Furthermore, people's political thinking and actions vary considerably between countries. Satisfaction with government work, the extent of populist alienation from the political system or the degree of protest participation all depend very much on the country in which the respondents live. This is not surprising, as people live in societies with very different levels of prosperity and social welfare standards, and, after all, the nation state is still the primary point of reference for political decision-making and democratic participation.

However, our analyses have also shown that people's political thinking no longer stops at national borders. This can be seen above all in the fact that they have internalised a mental map of the European social space in which they locate and assess themselves and others accordingly. When people are asked about living conditions in other European countries, hardly any respondents refuse this task. Almost all of them have formed their own judgement. Their answers create a tableau of European living conditions that reveals a surprising consensus. Their assessments - within a certain range - are remarkably consistent. People have in mind a mental map of the European social space in which they can locate the individual countries. The unanimity of the evaluations is an indication that the respondents have internalised similar, possibly even common, evaluation criteria of what can be considered good or bad living conditions. How else would respondents be able to make such similar assessments?

It was also surprising that this mental map of the European social space had a noticeable influence on the political perceptions and judgements of the respondents. Such influences have been demonstrated on three issues: crisis perception, satisfaction with the work of the government and agreement with populist beliefs. In order to avoid jumping to premature conclusions, these influences have been examined using the usual explanatory models. It is known from research to date that people living in socially disadvantaged circumstances and/or are concerned about social decline are more likely to display an affinity for crises, dissatisfaction with government work, agreement with a populist worldview and critique of the political establishment. While it was possible to confirm the validity of these explanation models, at the same time, however, it was shown that political thinking in each of these aspects has also been shaped by the mental map of Europe. People who rated living conditions in their own country to be worse than in other countries were more crisis sensitive, more dissatisfied and more distanced from the political establishment.

This mental map does not override national thinking because the questions and assessments examined here practically encouraged the respondents to put countries in a relationship with each other. However, according to the respondents' answers, these countries are part of a pan-European social space. This has consequences for people's political thinking because this social space is apparently also perceived as a political field of political forces in which governments, parties or populations struggle to shape societal and political conditions. This European slant proves that people are dissatisfied with their respective governments as soon as they get the impression that their country is worse off than others and that they question the political establishment for the same reasons. The fact that 
people's satisfaction with their own government increases as soon as they have the impression that living conditions in their country are comparable to those of other European countries also highlights that people's horizon of judgement is currently more European. The equivalence of living conditions seems to be the compass that guides people's political thinking.

However, these observations must be specified and narrowed down in two places. On the one hand, it was shown that the respondents naturally incorporate Switzerland into the mental map of the European social space. This shows us that people are primarily looking at Europe and not at the EU in the narrow sense when they perceive and judge living conditions. This is because this mental map mainly concerns the living conditions and thus the social space of Europe. The question of how respondents position countries in the political field of the EU and how they relate these countries to each other cannot be determined on the basis of this survey because corresponding questions have not been taken into account. It was only possible to determine that people believe that national governments must also be held responsible for how their own country fares in comparison with others. Peoples' concerns that their country could lose ground to others in times of crisis are tangible in our results and show that people recognise Europe, and possibly the European Union in particular, as a political force field. It appears that this political field is about something specific, namely the equivalence, subordination or superiority of living conditions between European populations, and there may also be lines of conflict between countries when it comes to political distribution issues or cut-throat economic competition.

It must, however, be emphasised that the European reference horizon and the described mental map mainly influence people's political attitudes but not their political actions. As shown from the example of political protest and the participation of people in these forms of protest, people's political action is not a direct reflection of their political attitudes - and thus also not a tangible reflection of the conveyed European map of social living conditions. It would have been conceivable that the perception of unequal living conditions in Europe - and the feeling of relative deprivations - would have increased the general willingness of people to take part in political street protests. But the results of our analyses have shown that the European reference horizon has found little resonance in protest behaviour. It is concrete population groups and countries that have a greater affinity for protest, and participation continues to be seemingly driven by concrete grievances and demands, which is why the large-format map of the European social space does not really develop any formative force. 


\title{
6 Social divisions and perceptions of the European Union
}

\author{
Local and European landmarks
}

For many years, people's approval of the European integration project was seen as a given. In their efforts to expand economic and political cooperation, governments and European institutions saw themselves supported by a "permissive consensus" that the populations of the member states seemed to share (Lindberg and Scheingold 1970; Hix 1999: 135; Hooghe and Marks 2009). This tacit approval, however, was deceptive because citizens did not always prove to be supportive of the European project once they were asked to vote in referendums about their country's accession to the EC/EU, the introduction of the euro as currency, the newly negotiated treaties or the draft proposal for a European constitution. European integration was a potentially contentious issue that was able to inspire criticism and political resistance under specific circumstances depending on the issue at stake and the constellation of political interests and powers in the various countries.

Today, however, the EU has become a continuously politicised topic. EU-critical parties are present in all European member states (Hernández and Kriesi 2016; Treib 2020) and a considerable share of the population supports Eurosceptic opinions (Lubbers and Scheepers 2005; Hooghe and Marks 2007; Boomgaarden et al. 2011; de Vries 2018). The EU is being criticised by groups to the left and right side of the ideological spectrum (Otjes and Katsanidou 2017), even though right-wing populist parties have been the most successful and loudest political entrepreneurs in mobilising and organising Euroscepticism (e.g., Hutter and Grande 2014; Hong 2015; Stockemer and Barisione 2016; Kneuer 2019). Public opinion about the European Union is thus highly divided.

Research has recurrently pointed to the fact that this political division is being fed by growing cleavages within European societies. In general terms, the division of pro-European and Eurosceptic citizens is one that corresponds to the cleavage between the winners and losers of societal modernisation, Europeanisation and globalisation (Kriesi 2016a). These divisions have increased during the last decades due to continuous European crises and austerity-driven public policies (Kriesi and Pappas 2015; Barbieri and Cutuli 2016; Hermann 2014). According to these observations, Euroscepticism is nurtured by social, political and cultural cleavages and is thus supported by social groups and strata of the population that wish to confront social degradation, the decay of national sovereignty and the 
loss of cultural identity. In more specific terms, the division between pro-Europeans and Eurosceptics is co-determined by social inequalities and vulnerabilities (Kuhn et al. 2016; Dotti Sani and Magistro 2016; Ritzen et al. 2016). Access to valued resources (e.g., income, education, social capital) and unequal exposure to deprivations and vulnerabilities (e.g., unemployment, poverty, social exclusion or cultural marginalisation) seem to impact strongly on political support for the EU.

In this chapter, I wish to engage in a systematic analysis of this potential driver of political opinions about the EU. Building on previous research, I will draw a picture that takes into consideration the various dimensions of social inequalities and their potential impact on pro-European or Eurosceptic attitudes. In the first instance, it is necessary to take a look at the effect of objective inequalities, both in terms of social stratifications between citizens and in regard to spatial disparities between countries and regions. Additionally, the analysis has to consider the subjective dimension of social inequalities, here, in particular, the way citizens assess their position within society. Previous studies have corroborated that these dimensions have an impact on the political support of the EU (Lubbers and Scheepers 2005; Schraff 2019; Kuhn et al. 2016; Ritzen et al. 2016) but here the attempt is to develop an integrated account of social and spatial cleavages. Conforming to the field-theoretical approach introduced in Chapter 2, I wish, finally, to ponder on the potential effect the perceptions of different living conditions in other European countries can have on the support or criticism of the European Union in order to substantiate the assumption that the social position of European citizens (both in stratificational and spatial terms) conditions the degree to which they support or oppose the EU. The aim is to validate whether Europe as a social space is patterned by discernible structures of inequalities that translate into political dissent in the EU and across the European continent.

For this purpose, this chapter will draw on two separate datasets. First, it will take a closer look at the situation in eight European countries by means of an online survey conducted in the context of an EU-funded research project (TransSOL), given that this survey asked respondents their opinions about the EU and included the battery of questions mapping the perception of different living conditions in Europe, already used in Chapter 5 to assess their impact on national politics. Second, the scope of analysis will be enlarged to embrace all EU member states in order to check whether findings of the more restrained sample of countries apply to the EU at large. Additionally, the aim is to differentiate the general picture by disaggregating the national datasets along regional differentiations in order to check whether the relations between social divisions and political cleavages are structured along national or regional lines. For this purpose, Eurobarometer data will be used.

\section{Public support for the European Union: the role of perceptions of inequality}

Research within the social sciences has devoted considerable attention to the spread of Euro-critical attitudes among the European population. Since the late 
1990s, numerous publications, especially in the English-speaking world, have dedicated themselves to so-called Euroscepticism (Hooghe and Marks 2007; Krouwel and Abts 2007; McLaren 2007; Lubbers and Scheepers 2010; de Vries 2018). This concept is interested in the growing unease about the European Union, which can be seen in doubts, criticism or even rejection of the EU and the European integration process. The results to date confirm that Euroscepticism has become a powerful force in the European political landscape, although there are quite distinct types and degrees of Eurosceptic attitudes (Weßels 2007; Rooduijn 2014).

Numerous studies have mapped public support of the EU in its various dimensions, for instance, by focusing on cognition and emotions or diffuse and specific attitudes (Easton 1965; 1975; Dalton 1999; 2004). On the one hand, studies have been interested in the general and diffuse attitudes towards the EU as an overall system or community, and on the other hand, in concrete forms of unease relating to individual European institutions, policy areas or politicians (McLaren 2004; Krouwel and Abts 2007). With regard to the types of attitudes, research has mainly focused on the cognitive dimension. In this regard, studies have focused on whether Europeans evaluate the membership of their own country in the EU as a good or bad thing and whether they see any benefit of membership (McLaren 2007; Garry and Tilley 2009). The emotional dimension has also been studied in relation to identification with the EU or feelings of belonging to Europe (Green 2000; Díez-Medrano 2003; Bruter 2004). Questions of trust or mistrust in the EU or other countries have been treated the same way (Delhey 2007), as have citizens' fears and concerns about the EU and its expansion (McLaren 2004; Grauel, Heine and Lahusen 2014).

The following analyses will be devoted to EU-related attitudes in their cognitive dimension, making use of a standard question that was adopted by the TransSOL survey that asked respondents to give a general assessment of their country's membership of the EU. The analysis will not only depict levels of support for the EU but also identify social and political determinants of EU-friendly and EU-sceptical responses. In line with the general objective of this study, it will be particularly interested in highlighting the effect of social inequalities on EU-related attitudes. The first step will show the levels of public support for the eight countries under study and engage in an analysis of the correlates of Euroscepticism. The net effect of social inequalities will be validated by controlling for the relevance of other standard predictors used to explain Eurosceptic opinions. In the second step, the analysis will move to perceptions of divergent living standards between member countries, thus taking up the argument introduced in Chapter 5. As the TransSOL survey was conducted in late 2016, and thus 18 months after the Livewhat study, it will be necessary to confirm whether the perceptions of living conditions in other European countries follow the same patterns as in 2015 and whether they continue to have the same effects on the assessment of national politics. In the third step, the analysis will move back to the European level in order to corroborate whether the perception of social disparities between countries affects support for the EU. 


\section{Determining levels and correlates of Euroscepticism}

Respondents were asked to indicate whether they thought that, generally speaking, their country's membership of the European Union is a good thing, a bad thing or neither good nor bad. The data show that public opinion is rather split in regard to this question, as shown in Figure 6.1. In all countries, the share of supporters is bigger than the group of Eurosceptics, but the proportion of undecided citizens is substantial, one in four respondents, on average. Moreover, in some countries, the distance between supporters and critics is moderately small (e.g., Italy, Greece, particularly the UK). There is a clear majority in favour of EU membership in Poland and Germany only, followed by Denmark with a substantial share of the population. In regard to Switzerland, we see that the option to join the EU is insignificant. As will be shown later on, these findings paint a gloomier picture of EU-related support than the Eurobarometer data, due most probably to methodological differences and the volatility of public opinions on this issue. These variations, however, are of less concern for the analytic purposes of this chapter, given that the aim is to identify those factors that make pro-European or Eurosceptic attitudes more likely. In this regard, the comparison of the two data sets will be most instructive, given that they paint a very similar picture of the social and political profiles of both groups.

The identification of these profiles can build on a very well-developed research field. In particular, relevant factors corroborated by previous studies can be used to validate the net influence of those two factors at the centre of

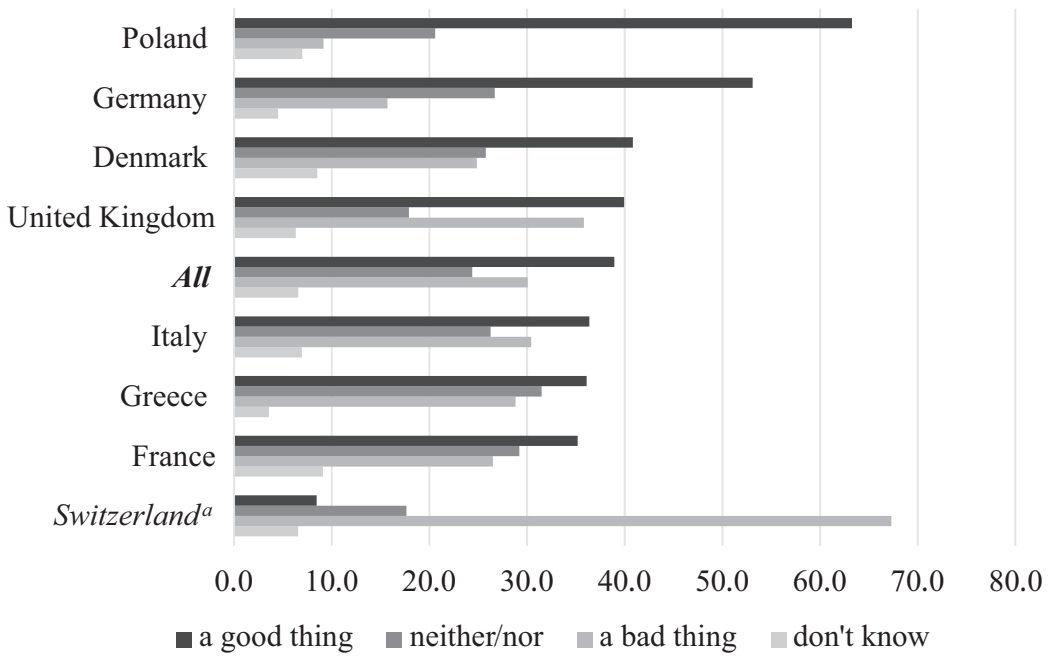

Figure 6.1 Opinion about the country's membership of the EU (in \%) a Swiss respondents were asked whether "joining the EU would be a ...". Source: TransSOL WP3 population survey. 
attention: the role of social inequalities and divisions and the effect of the subjective perception of relative differences in living conditions across European countries. In this sense, it is advisable to make use of available knowledge in order to compile standard predictors of Euroscepticism into a basic explanatory model. Among these standard predictors, scholars of Euroscepticism have highlighted a number of political attitudes, identifications and preferences (Hooghe and Marks 2005). People with more traditional views of life and ethnocentric worldviews are more sceptical about the EU (Green 2000; Nelsen, Guth and Fraser 2001: 204f; Boomgaarden and Freire, 2009: 1242f.; van Elsas, Hakhverdian and van der Brug 2016). Additionally, populist attitudes fuel Euroscepticism because populism has become an expression of unease with the political system based on the belief that the political classes are no longer committed to the needs of people and conduct politics over which ordinary people no longer have any influence (Treib 2014; Hong 2015). Collective identities play a role, as well, given that EU-related attitudes largely depend on the extent to which citizens have developed a feeling of belonging to Europe, while the attachment to the nation state might be conducive to opposition to the EU (de Vries and van Kersbergen 2007; Hooghe and Marks 2005; 2007; Fligstein et al. 2012). Finally, media consumption has a significant impact on critical attitudes because the mass media are actively engaged in shaping public opinions and tend to lean towards critical news coverage that nurtures Eurosceptic attitudes among their users (de Vreese and Boomgaarden 2006; Maier and Rittberger 2008; Conti and Memoli 2017; Galpin and Trenz 2019; Adam et al. 2019).

These standard predictors have thus been proven to convincingly explain the likelihood of Eurosceptic attitudes among respondents. My own ambition, however, is to test the relevance of social-structural factors - in particular, social vulnerability - against these standard predictors. For this reason, it is necessary to compile an extended model that adds a number of socio-structural factors in order to test their net explanatory power. In general terms, we can expect, on the basis of previous studies, that population groups in precarious living situations, experiencing socio-structural disadvantages are more likely to be critical of the EU, while the socially privileged tend to support the EU and their country's membership (McLaren 2004: 900; Lubbers and Scheepers 2010: 800; also Fligstein 2008). In regard to individual predictors, it is to be expected that income inequalities and precarious occupational status will boost criticism. In particular, educational inequalities seem to increase the likelihood of scepticism (Kuhn et al. 2016). Moreover, we need to validate the role of subjective perceptions of inequality when contrasted with objective indicators. The relevance of subjective perceptions would be the first indication that the cross-national assessment of inequality might be an important, additional factor to take into consideration.

The empirical analysis shows that both political and social-structural predictors play an important role in explaining EU-related attitudes - as summarised in Table 6.1. The calculation is based on a regression analysis (ordered logistic model), which determines response probabilities. To this end, the procedure compares the groups of Eurosceptics (membership is a bad thing) and those of the 
Table 6.1 Assessment of EU membership (ordered logistic regression, marginal effects)

\begin{tabular}{|c|c|c|c|}
\hline & A bad thing & Neither/nor & A good thing \\
\hline \multicolumn{4}{|l|}{ Political factors } \\
\hline \multicolumn{4}{|l|}{ Left-right orientation (left) } \\
\hline Centre & $0.041 * * *$ & $0.007 * * *$ & $-0.049 * * *$ \\
\hline Right & $0.069 * * *$ & $0.011 * * *$ & $-0.080 * * *$ \\
\hline Don't know & $0.055 * * *$ & $0.009 * * *$ & $-0.065 * * *$ \\
\hline \multicolumn{4}{|l|}{ Populist orientation (disagree) } \\
\hline Neither/nor & $0.046 * * *$ & $0.009 * * *$ & $-0.055^{* * *}$ \\
\hline Agreement & $0.096 * * *$ & $0.014 * * *$ & $-0.109 * * *$ \\
\hline Don’t know & 0.013 & 0.003 & -0.017 \\
\hline Level of political participation (std.) & $0.006^{*}$ & $0.001 *$ & $-0.006^{*}$ \\
\hline Political interest (low) & $0.010^{*}$ & $0.001 *$ & $-0.012 *$ \\
\hline \multicolumn{4}{|l|}{ Media usage } \\
\hline Tabloid & $0.040 * * *$ & $0.006^{* * *}$ & $-0.046^{* * *}$ \\
\hline TV & $-0.047 * * *$ & $-0.007 * * *$ & $0.054 * * *$ \\
\hline \multicolumn{4}{|l|}{ Attachment to } \\
\hline Own country & $0.021 * * *$ & $0.003 * *$ & $-0.024 * * *$ \\
\hline European Union & $-0.314 * * *$ & $-0.123 * * *$ & $0.438^{* * *}$ \\
\hline \multicolumn{4}{|l|}{ Intra-European help } \\
\hline Help is moral duty & $-0.060 * * *$ & $-0.009 * * *$ & $0.069 * * *$ \\
\hline Help is in mutual interest & $-0.095 * * *$ & $-0.014 * * *$ & $0.109 * * *$ \\
\hline No help if countries handle money badly & $0.048^{* * *}$ & $0.007 * * *$ & $-0.055^{* * *}$ \\
\hline \multicolumn{4}{|l|}{ Social-structural factors } \\
\hline \multicolumn{4}{|l|}{$\begin{array}{l}\text { Educational attainment (lower secondary } \\
\text { and below) }\end{array}$} \\
\hline Upper secondary & $-0.024 * * *$ & $-0.003 * * *$ & $0.027 * * *$ \\
\hline Tertiary & $-0.057 * * *$ & $-0.008 * * *$ & $0.065 * * *$ \\
\hline \multicolumn{4}{|l|}{ Household income (lowest tercile) } \\
\hline Intermediate tercile & 0.001 & 0.000 & -0.001 \\
\hline Highest tercile & -0.010 & -0.001 & 0.011 \\
\hline Prefer not to say & 0.011 & 0.001 & -0.013 \\
\hline Financial strain & $0.043 * * *$ & $0.006 * * *$ & $-0.049 * * *$ \\
\hline \multicolumn{4}{|l|}{$\begin{array}{l}\text { Occupational status (full-time } \\
\text { employment) }\end{array}$} \\
\hline Part-time & $0.023 * * *$ & $0.003 * * *$ & $-0.026^{* * *}$ \\
\hline In education or service & $-0.028 * *$ & $-0.005^{*}$ & $0.034 * *$ \\
\hline Unemployed, sickness & $0.031 * * *$ & $0.004 * * *$ & $-0.034 * * *$ \\
\hline Retired & -0.009 & -0.002 & 0.011 \\
\hline Housework, care & 0.004 & 0.001 & -0.005 \\
\hline \multicolumn{4}{|l|}{ Subjective class affiliation (upper class) } \\
\hline Middle class & $0.029 * * *$ & $0.006 * *$ & $-0.035^{* * *}$ \\
\hline Lower middle class & $0.034 * * *$ & $0.006 * * *$ & $-0.040 * * *$ \\
\hline Lower class & $0.058 * * *$ & $0.009 * * *$ & $-0.067 * * *$ \\
\hline Other/don't know & $0.041 *$ & $0.007 * * *$ & $-0.049 * * *$ \\
\hline \multicolumn{4}{|l|}{ Socio-demographic features } \\
\hline Gender (male) & -0.001 & -0.000 & 0.001 \\
\hline Age (std.) & 0.003 & 0.000 & -0.004 \\
\hline Born outside country (no) & -0.010 & -0.001 & $\begin{array}{l}0.012 \\
\quad(\text { Conti }\end{array}$ \\
\hline
\end{tabular}


Table 6.1 Continued

\begin{tabular}{lrrr}
\hline & A bad thing & Neither/nor & A good thing \\
\hline Country (Denmark) & & & \\
Germany & $-0.028^{* * *}$ & $-0.006^{* * *}$ & $0.035^{* * * *}$ \\
UK & $0.049^{* * *}$ & $0.007^{* * *}$ & $-0.056^{* * *}$ \\
France & $0.059^{* * *}$ & $0.008^{* * *}$ & $-0.066^{* * *}$ \\
Poland & $-0.088^{* * *}$ & $-0.028^{* * *}$ & $0.116^{* * *}$ \\
Italy & $0.082^{* * *}$ & $0.009^{* * *}$ & $-0.091^{* * *}$ \\
Greece & $0.033^{* * *}$ & $0.005^{* * *}$ & $-0.038^{* * *}$ \\
Observations & 13181 & 13181 & 13181 \\
Pseudo R & 0.23 & 0.23 & 0.23 \\
\hline
\end{tabular}

Source: TransSOL WP3 population survey.

Note: Significance levels: ${ }^{*} P<0.1 .,{ }^{* *} P<0.05, * * * P<0.01$.

undecided (membership is neither good nor bad) with the group of supporters (membership is a good thing) for each of the explanatory factors listed in order to determine whether the Eurosceptics differ significantly from Euro-supporters in the characteristics studied. The average marginal effects summarised in the table indicate the average probability for each of the groups of people with the listed characteristics to voice Eurosceptic or pro-European opinions. The model includes four sets of factors: political characteristics, socio-demographic factors, the country of residence and social-structural traits. The first three sets of variables were included to corroborate the accuracy of previous research findings, but primarily as a means to identify the net effect of those factors that are the focus of this study, namely social vulnerability. The regression analysis was conducted without respondents answering "don't know" to the question about EU membership and also excluding Swiss respondents, as they received a rather hypothetical question about potential membership within the EU.

The group of political factors includes items measuring political orientations, levels and forms of political involvement and EU-related attitudes. The guiding assumption behind these factors is that respondents who lean towards populism and orientations to the right of the political spectrum, are less politically involved, strongly attached to a national community and do not see merit in inner-European cooperation will be more sceptical of the membership of their country within the EU, while the inverse should be valid for the supporters of EU membership. In regard to political orientations, the assumption is validated, given that right-wing respondents are more critical of the $\mathrm{EU}$, while leftists support the membership of their country. Those not sure where to locate themselves on the ideological axis tend to be Eurosceptic. More pronounced is the effect when considering populist attitudes - a simplified index that consists of the four items of the composite measure introduced in Chapter 5. In regard to political involvement, the effects are very small, even though there is evidence that self-reported political interest and the scope of political activities increase 
the likelihood of being more critical about the EU. ${ }^{1}$ The choice of mass media outlets to "keep informed about current events" also correlates with EU-related attitudes, as EU-friendly respondents tend to watch television, while tabloid readers lean towards Euroscepticism. In regard to EU-related attitudes, it was to be expected that attachment to the EU drastically increases the likelihood of supporting EU membership, while national identities have the inverse effect. Respondents in favour of EU membership, finally, are convinced of the value in international cooperation and solidarity, ${ }^{2}$ while Eurosceptic respondents insist on the conditionality of intra-European aid, excluding those countries assumed to have misused financial help.

These findings corroborate that opponents and supporters of EU membership can be distinguished by their political convictions and preferences. Eurosceptics are more conservative in their political orientations, share a populist mistrust of the political establishment, are more attached to their nation state and more critical of intra-European solidarity. They might be more alienated from the political institutions, but are not politically disengaged, as they report to be active politically and interested in politics. More distant from mainstream media, they tend to inform themselves more often via the tabloid press that is more critical of the EU itself.

The relevance of these political factors is quite pronounced but does not neutralise the effect of socio-structural traits. In fact, findings show that vulnerability is a factor to take into account when explaining EU-related attitudes. Respondents with lower educational credentials, being either unemployed, permanently sick or only partially employed subscribe more often to the statement that EU membership is a bad thing, while those with full-time work and higher education credentials are in favour of membership. The household income itself does not correlate with the assessment of EU membership, while the feeling of financial strain does. This observation shows that vulnerability has not only an objective dimension, mirrored in educational attainment and occupational status but implies a feeling of being socially excluded or deprived, as the self-reported class affiliation shows. In fact, respondents placing themselves at the lower end of the social ladder are more often critical of the EU when compared to those describing themselves as members of the upper class. This means that a weaker position within the social

1 Respondents could name up to 14 different activities they had done during the last 5 years: contacting politicians, donating money, displaying badges, signing a petition, boycotting or buying products, attending meetings, demonstrations, strikes or occupations, discussing via social networks, joining a political group, visiting the website of a political party or searching for information about politics online. The composite variable measures the number of items indicated.

2 The survey asked respondents to tick whether they agreed with a set of statements about intraEuropean help. "There are many reasons to state for or against financial help for EU countries in trouble. Which one of the following best reflects how you feel? (1) It is our moral duty to help other member states that are in need. (2) The European Union member states should help each other, as somewhere along the way every country may require help. (3) Financial help should not be given to countries that have proven to handle money badly" TransSOL (2016: 39). 
structure goes hand in hand with a feeling of social vulnerability when focusing on those strata of the population that subscribe more openly to the EU being a bad thing.

The net effect of social vulnerability is a consistent factor of Euroscepticism when breaking down the results by country. Figure 6.2 presents the predicted probability of respondents affiliated with different social classes to be critical of the EU for each of the eight countries. The likelihood diverges between countries, given that the support of the EU is much more diffused in Poland and Germany, while it is least developed in Greece, Italy and the United Kingdom. However, social class affiliation makes a difference everywhere. In Poland, upper class respondents approve EU membership by $73 \%$, while support decreases to $67 \%$ among the lowest strata. The differences among British respondents span between $42 \%$ and $36 \%$ and in Greece, between $43 \%$ and $36 \%$.

These findings reveal that support of EU membership not only correlates with political orientations and practices but with stratificational divisions as well. Objective inequalities are an important predictor of EU-related attitudes, particularly in regard to education credentials. More important is the subjective perception of vulnerabilities and deprivations. This observation, however, leaves unanswered the question of the frame of reference, to which these subjective perceptions are tied. Eurosceptics tend to place themselves lower down the ladder of the stratificational hierarchy of classes, but this seems to indicate that the perception of stratificational inequalities within a country is the driving force increasing

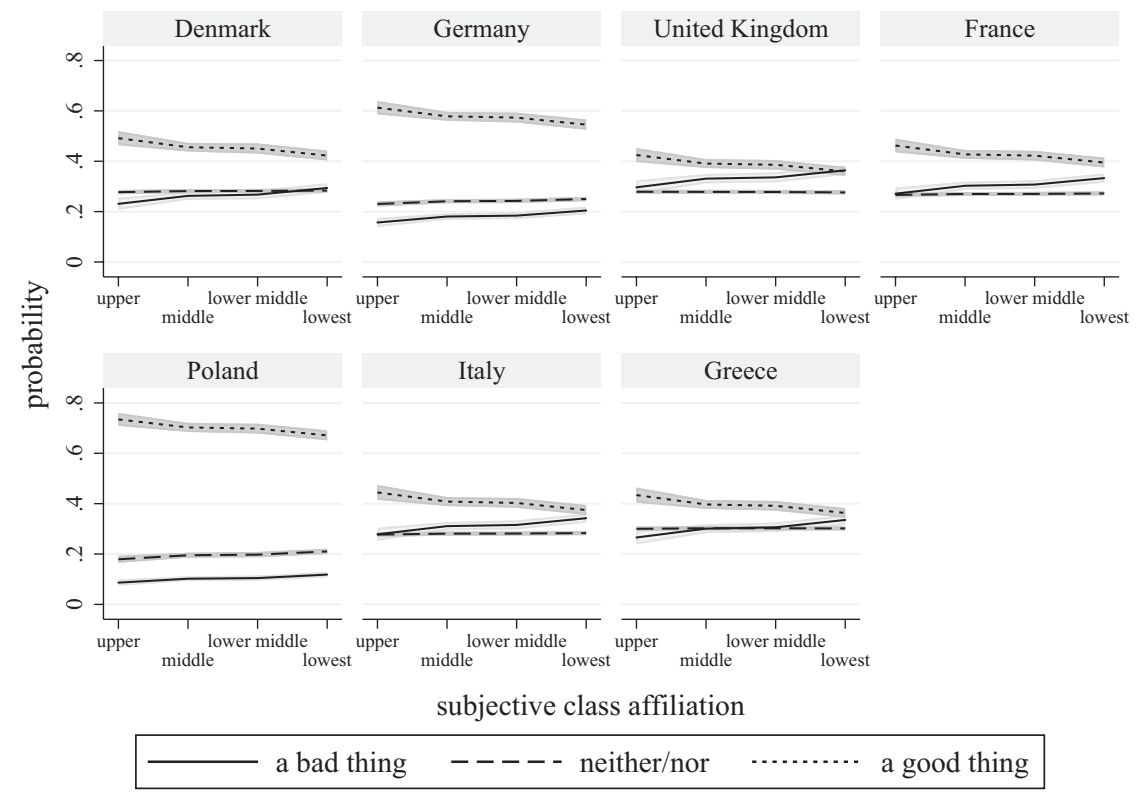

Figure 6.2 Assessment of EU membership and social class affiliation (predictive margins). Source: TransSOL WP3 population survey. 
the likelihood of Euroscepticism. In fact, the perception of personal deprivations and vulnerabilities might be nurtured by the fact that respondents compare their living conditions with better-off fellow citizens. However, we cannot exclude that the perception of inequalities is also fuelled by comparisons with living standards in other European countries. As has been shown in Chapter 5, European citizens do not hesitate to assess living conditions in other countries, and these assessments have a significant impact on the way they perceive and evaluate the social and political conditions in their own country. Respondents who see other Europeans as much better off are more critical about national politics, which means that the perception of inequality within Europe provides a benchmark for developing a judgement about the state of national politics in one's own immediate environment.

\section{The continuing relevance of different living conditions in Europe}

European citizens continued to assess living conditions in other European countries when the TransSOL survey confronted them with the same battery of questions 1.5 years later. The degree of agreement is not only remarkably high and stable, but respondents also used these perceptions as a European benchmark to assess politics in their country, as their fellow citizens did many months earlier. This enduring relevance merits attention before we move to the impact of this European benchmark for EU-related attitudes.

Table 6.2 shows that the perception of living conditions in other European countries has remained unchanged since the winter of 2016/17, compared to the results of the Livewhat survey 1.5 years earlier (see Chapter 4). The percentage of respondents that was unable or unwilling to assess the living conditions abroad remains stable, with less than $10 \%$ choosing this option. The average assessment is very similar to the 2015 survey, and the ranking is the same: the northern European countries lead the list, while Greece is relegated to the lowest position. The distance between the best and worst-off countries has decreased in the second survey, when compared to 2015, given that Greece improved slightly, while most other countries are evaluated marginally less favourably (in particular, the northern countries at 0.8 on an 11-point scale). These slight changes might be due to the first signs of economic recovery in Greece in 2016, which were widely discussed in the media that year. The prospect of moving beyond the fiscal and economic crisis apparently led respondents to put less emphasis on the gap between strong and weak economies. However, in relative terms, the distances are still remarkable and stable across time, which shows that the cognitive map of living conditions in Europe is still a part of European citizens' perceptions and evaluations.

It is also noteworthy that the cognitive map of European living conditions has not lost its relevance for the political opinions of Europeans and the way they assess the performance of their national governments. Before moving to the EU-related attitudes, it is worth validating whether the observation made with regard to the Livewhat survey for the year 2015 remains stable when considering respondents' views 1.5 years later. What the second survey shows is that the 


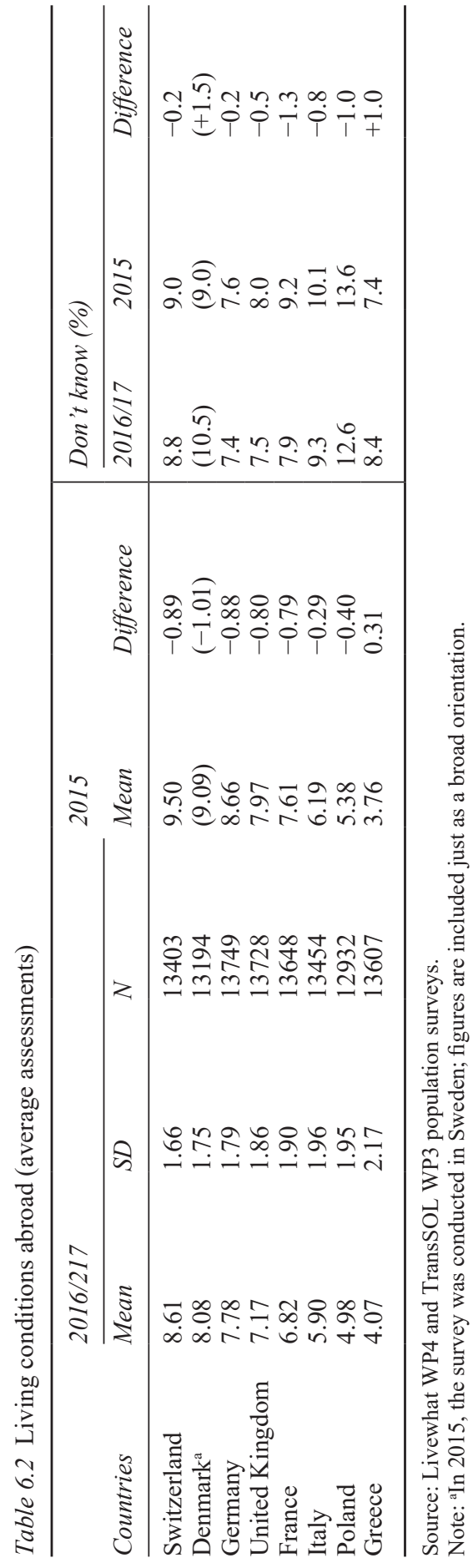




\section{dissatisfied}

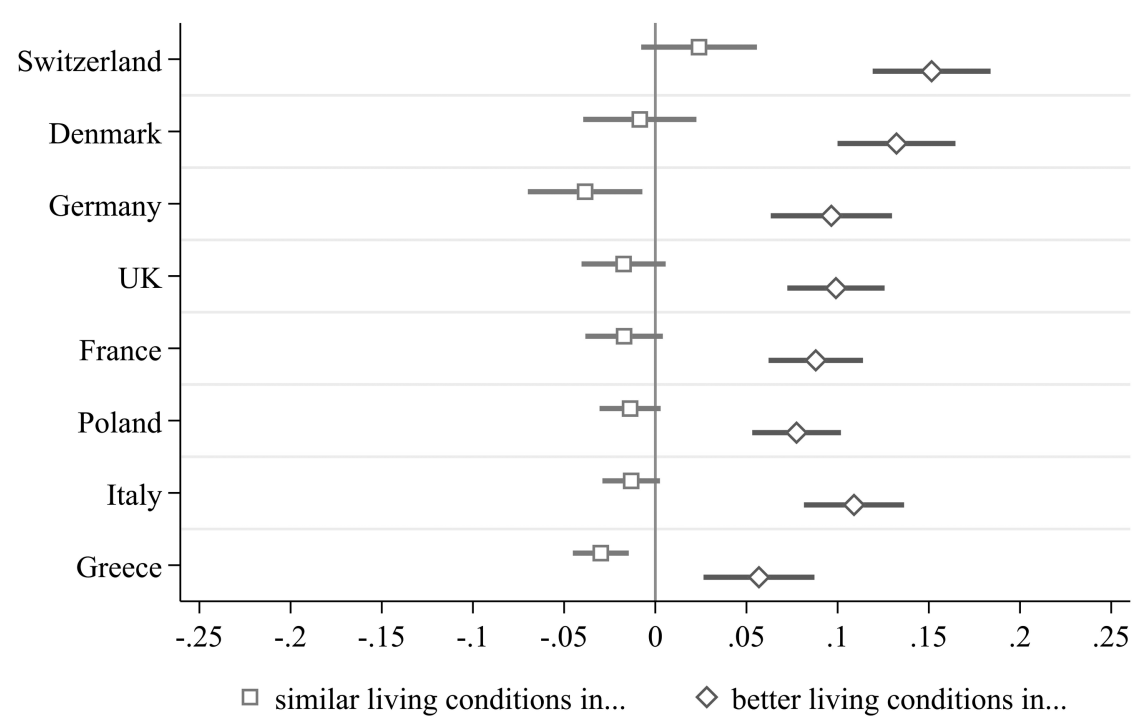

Figure 6.3 Satisfaction with government policies and living conditions abroad (predictive probabilities). Source: TransSOL WP3 population survey.

perceptions of unequal living standards in Europe continued to affect the assessment of national politics also in the winter of 2016/2017. Figure 6.3 presents the findings in regard to the composite variable measuring dissatisfaction with government policies - an item that was introduced and discussed already in Chapter $5 .^{3}$ The results are based on the explanatory model tested in the regression analysis, presented in Table 6.1, and thus presents the net effect of country comparisons when controlling for all other social and political factors. Swiss respondents were excluded from the analysis because they will also be disregarded when analysing support of EU membership.

These data corroborate the findings based on the Livewhat data from 2015. Respondents reporting that living conditions in other countries are better than their own are significantly more often dissatisfied with government policies when compared to those who see themselves in a better situation than people in other countries. Similar living conditions seem to reduce the likelihood of being

3 The index comprises variables measuring satisfaction "with the way in which the government is dealing with": the economy, poverty, education, unemployment, employment, healthcare, immigration and the refugee crisis. A factor analysis and reliability test demonstrated that the various items basically measure the same item: levels of general satisfaction with government performance (alpha 0.93). 
dissatisfied with one's government, thus suggesting that citizens tend to expect national politics to guarantee comparable living standards in Europe (Simpson 2019). The effect is significant in regard to all countries; however, nation states placed higher on the ranking of living conditions are a more relevant benchmark when assessing the performance of national governments. This conforms with the findings of previous research, as it testifies that upward comparisons are socially more consequential than downward comparisons (see, e.g., Delhey and Kohler 2006; Boyce et al. 2010). Hence, the overall picture painted by the earlier survey from 2015 (see Figure 5.4 above) has not changed, thus suggesting that perceptions of unequal living conditions are a pervasive factor patterning opinion about national politics.

\section{The perceptions of spatial disparities and Euroscepticism}

These findings raise the question of whether the cognitive map of European living conditions has a similar effect on EU-related attitudes, in particular, on the likelihood of seeing the EU membership of one's country as a good or bad thing. Given the lack of previous studies and findings, it is necessary to avoid overhasty inferences because the relationship between the perception of spatial disparities and Euroscepticism is far from being self-evident. On the contrary, three scenarios are equally plausible. First, we might expect that the perception of strong inequalities between living conditions in European countries might encourage criticism of the $\mathrm{EU}$, given that the $\mathrm{EU}$ is committed to the aim of ensuring similar living conditions across Europe. Member state citizens might make the EU accountable for not complying with this mission and thus not being effective in eliminating or reducing existing inequalities in national living standards. Second, it is also plausible to assume that the perception of unequal living conditions in Europe might - on the contrary - boost public support for membership in the EU. Citizens affirming that living conditions are much better in other European countries might think that their own country's membership is a good thing, exactly because the EU proclaims to be engaged in developing more equal living standards across Europe. Sharing membership with wealthier countries (e.g., Sweden, Germany, the UK) might nurture the conviction that the EU is beneficial for all the other countries, including one's own. In this case, Euroscepticism would be linked to the inverse comparison: citizens seeing themselves as worse off than Europeans from weaker countries (e.g., Greece, Italy or Spain) might believe that membership of the EU is beneficial for others, at the expense of their own country's prospects, thus nurturing the preference of leaving a union that benefits others. Finally, a null hypothesis can also be formulated when considering that the perception of unequal living conditions in Europe might be fully unrelated to EU-specific attitudes. This is highly probable because European citizens might perceive significant differences between countries without relating these inequalities to their own situation. Moreover, the European Union might not be held accountable for these differences. As the previous analysis has shown (Chapter 5), respondents attribute responsibility to their own government, which means that the perceptions of 
European inequalities might only impact how national politics is evaluated, not European.

In order to examine these propositions, I conducted an extended regression analysis that added the comparative assessments of living conditions in the nine reference countries onto the baseline model that was discussed earlier (see Table 6.1). Also, in this case, various observations were excluded from the analysis: respondents not answering the question about EU membership (about 1,100 respondents preferring a "don't know") and participants of the Swiss survey were excluded, given that they were only asked to report whether "joining the EU" would be a good or bad thing. However, the comparisons with living standards in Switzerland were included in the model as an explanatory factor because the option to consider Switzerland as part of the cognitive map of European living conditions could not be excluded. Switzerland is not a member of the EU, but part of various treaties (e.g., the Schengen Treaty, the European Free Trade Association and the European Economic Area), which means that citizens might consider Switzerland as a relevant reference point for the formation of political opinions about the EU.

The findings highlight that upward comparisons increase the likelihood of supporting the EU membership of one's country (Figure 6.4). Comparing living conditions in Germany seems to be the most consequential because it accounts for an estimated difference of $21 \%$. Respondents that rank German living standards higher than their own are 13\% more likely to see membership as a good thing and $9 \%$ less likely to rank it as a bad thing. Also, the perception of similar living standards ensures support for the EU because these respondents are more often in support $(+10 \%)$ and less often against $(-8 \%)$. It is noteworthy that those respondents that place their own living standards above the German standards do not report significant differences in their support of EU membership, although the supportive attitude outweighs the critical one by $9 \%$.

The effect is significant for the three leading countries on our list (Switzerland, Denmark and Germany), while the assessment of the living conditions in the intermediate group (UK, France and Poland) has no significant impact on support of the EU. Comparisons with the countries at the lower end of European living conditions are rather associated with Euroscepticism. Citizens that believe that the Greeks are living better than themselves are 7\% more likely to see EU membership as a bad thing and $12 \%$ less likely to be among those that cherish it as a good thing. A comparison with inferior living conditions does not seem to encourage enthusiasm for the EU, as it might lead to resentment or bitterness about others benefitting at the expense of oneself.

The relevance of European living conditions is corroborated when breaking down the findings for each of the six countries that compare their own living standards with those in Germany. As shown in Figure 6.5, we see that the level of approval or disagreement depends largely on the provenience of respondents. Polish respondents are, in general, the most supportive of their country's membership, thus relegating Eurosceptics to the margins. A similar observation is true for the Danish respondents. In the other countries, supporters and critics are more evenly distributed, thus 


\section{a bad thing}

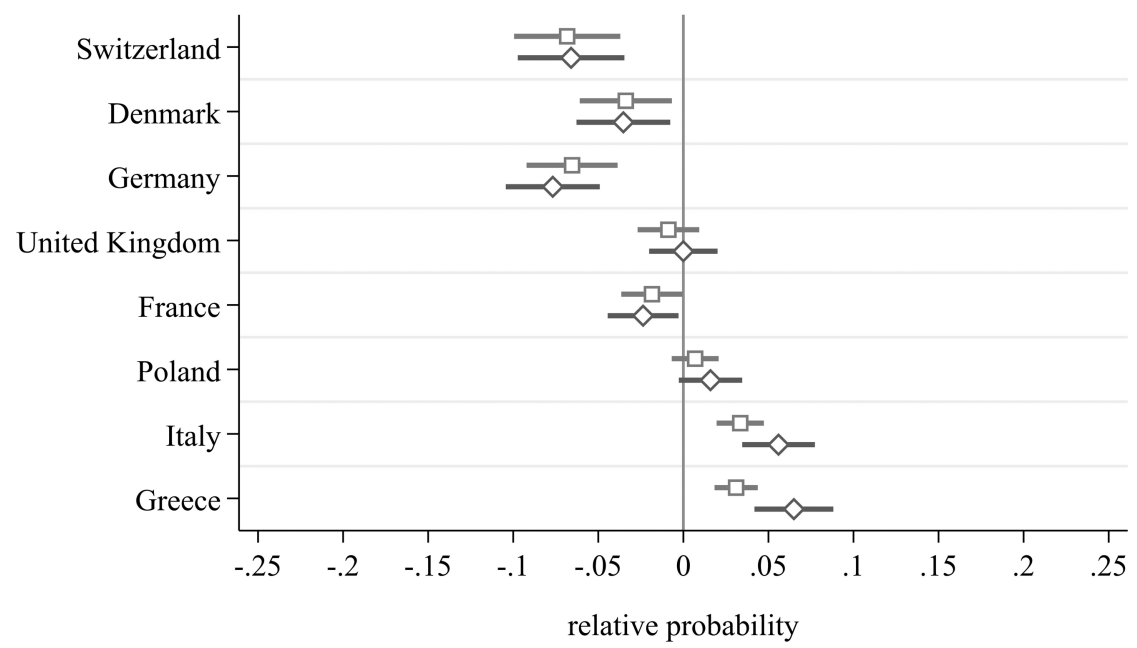

(a) $\square$ similar living conditions in... $\quad \diamond$ better living conditions in...

\section{a good thing}

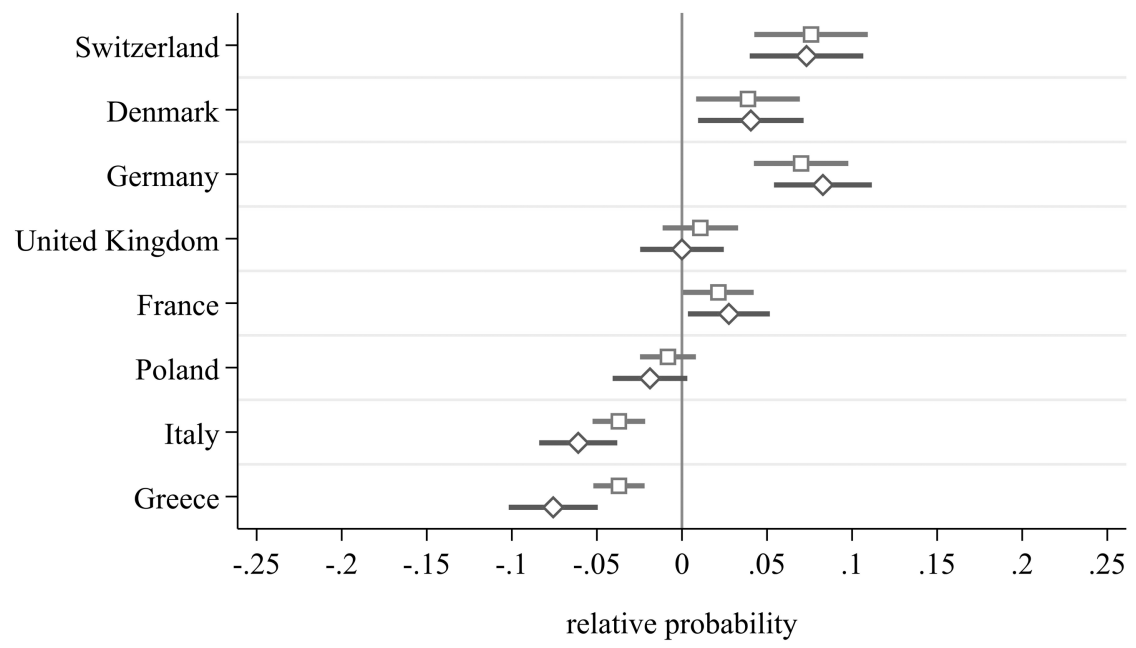

(b) $\quad \square$ similar living conditions in... $\quad \diamond$ better living conditions in...

Figure 6.4 Membership in the EU and living conditions in Europe (predictive margins). Source: TransSOL WP3 population survey. 


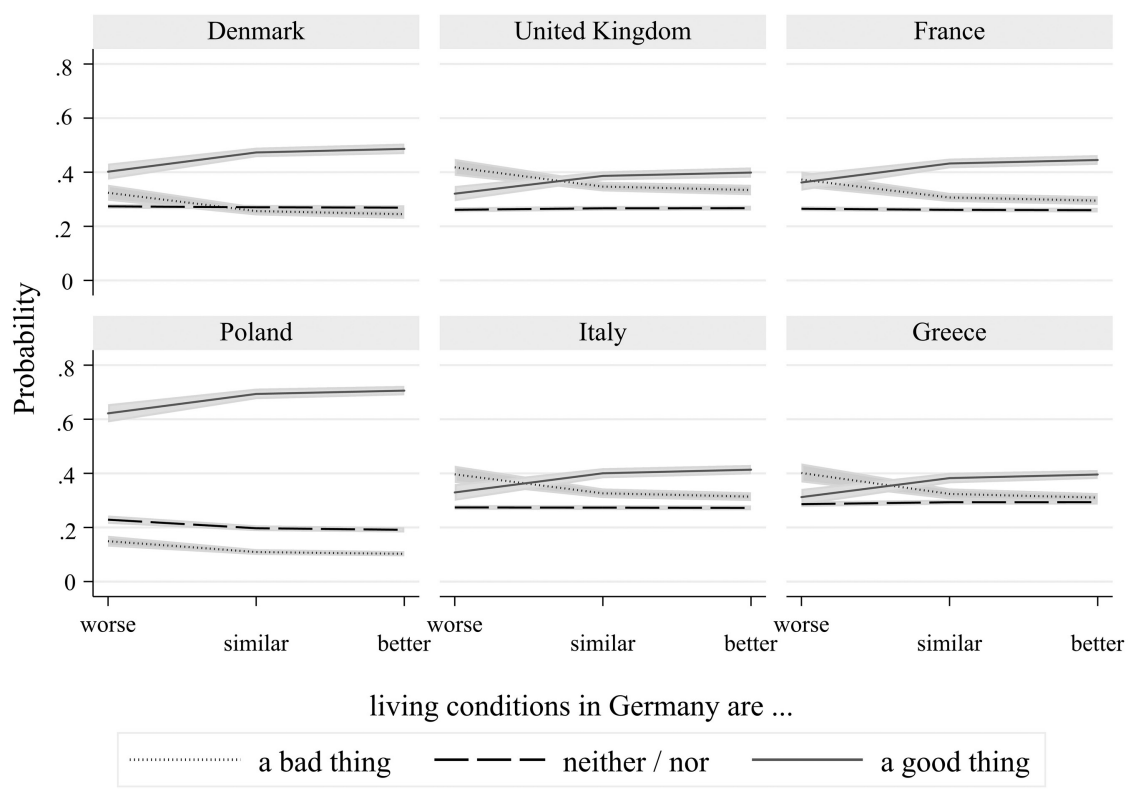

Figure 6.5 EU membership and living conditions in Germany (predictive probabilities). Source: TransSOL WP3 population survey.

representing $30 \%$ to $40 \%$ of the sample, along with approximately $25 \%$ of undecided respondents. The relative strength of supporters and critics changes, however, when taking the assessment of living conditions in Germany into account. Respondents arguing that German living conditions are below their own situation are more likely to have a negative view of EU membership (e.g., particularly among the British, Italian and Greek respondents), while those seeing Germans in a similar or better position are clearly more often supportive of their country's EU membership. In estimated percentages, the better-off British respondents are more often critical of EU membership (42\%), while those citizens seeing Germans in a better position are supportive of the EU (40\%). Similar indications are true for all the other respondents, even though majorities are more clearly defined in Denmark and Poland. In most countries, however, the assessment of European living standards seems to make a difference whether the majority decides for or against the EU.

The evidence thus confirms that the comparative perception of living conditions in other European countries affects the support of the EU among EU citizens. ${ }^{4}$ The

4 This general observation is corroborated when looking at the assessments among Swiss respondents, which can be considered a control group given that they are not formally members of the EU. Swiss respondents were asked to give their opinion about the idea of "joining the EU". Only a minority thinks that this is a good thing $(8.5 \%)$, while two-thirds are convinced that this would be a bad idea (67.3\%). A further $17.7 \%$ are undecided. Separate calculations based on the regres- 
latter seem to presuppose that the added value of membership of the EU resides in the strength of the other members belonging to the union. Countries with higher living conditions operate as a benchmark or role model of what European living standards could or should be for all members of the community. In this sense, European citizens tend to reaffirm the belief and mission of the EU in aiming for comparable living standards everywhere in Europe. This perception is one that might make a difference when Europeans are asked to assess whether membership in the EU is a good or bad thing and whether they might favour remaining or exiting the union in the event of a referendum. In fact, respondents evaluating the EU membership of their country as a bad thing are more often inclined to leave the EU, while the supportive respondents are for a remain - as indicated in Figure 6.6. As the wording of the various answers is not identical to the assessment of the EU membership (see Figure 6.1), more citizens have opted against a clear answer for or against membership. Given the share of undecided citizens, who opted for "don't know" or "would not vote", it would be difficult to foresee whether a referendum would favour exiting or remaining. Only Germany and Poland show a substantial majority. In other countries, a "remain" is most probable, given the size of this group when compared to supporters of exiting (e.g., Denmark, France, and Italy). A stable split is still true for the United Kingdom, but also in Greece, public opinion is divided equally.

The dividing line between "remainers" and "leavers" is strongly patterned by the social and political factors already identified in the previous analysis. This is shown by a logistic regression that used the predictors included in the previous

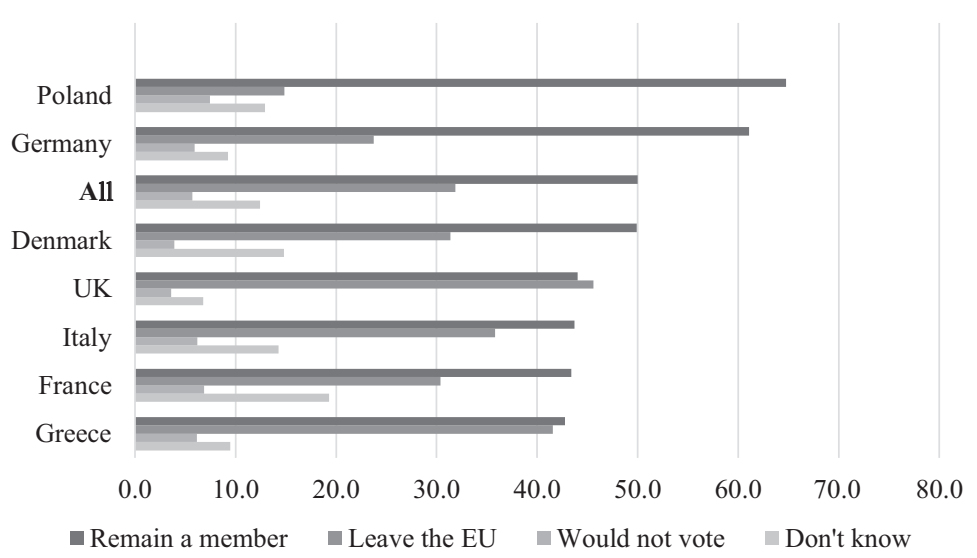

Figure 6.6 Voting in a referendum on EU membership (in \%).

sion analysis and its model specifications of Table 6.1 and Figure 6.5 indicate that the likelihood of evaluating an accession to the EU as a good thing is not affected by the perception of higher living conditions in Germany. The probability of agreeing to a membership is only $2 \%$ higher among those respondents who see Germany in a better position when compared to the others - and the effect is statistically not significant. 


\section{Social divisions and perceptions of the $E U$}

analysis (see Table 6.1). Figure 6.7 presents the findings by concentrating on a number of social and political factors that are particularly indicative. A number of variables were suppressed because they were of minor importance (e.g., political activities and interest, income, citizenship) or highly interrelated (e.g., attachment to the EU, country). The figure presents the regression model with the effect of the perceived German living conditions.

The findings confirm the picture painted by the previous analysis, given that the dividing line between those viewing the membership of their country as a good or bad thing is also the one marking the difference when identifying remainers and leavers. Leavers tend to lean towards the political right and share populist orientations, while remainers are more oriented towards the left. The former make more use of tabloids, while the latter watch mainstream TV. "Exiteers" are more often exposed to vulnerabilities in terms of education and labour market inclusion; they feel aggrieved by financial difficulties and see themselves at the lower end of the social stratification, while those who wish to stay in the EU are socially better off. For leavers, inner-European help should be conditional on the behaviour of receiving governments, while remainers highlight that governments are bound by shared duties and common interests.

The perception that other member states - in this case, Germany - have better living standards than oneself seems to encourage respondents to pledge for a remain. Superior living conditions are thus an incentive to stay within the EU, and

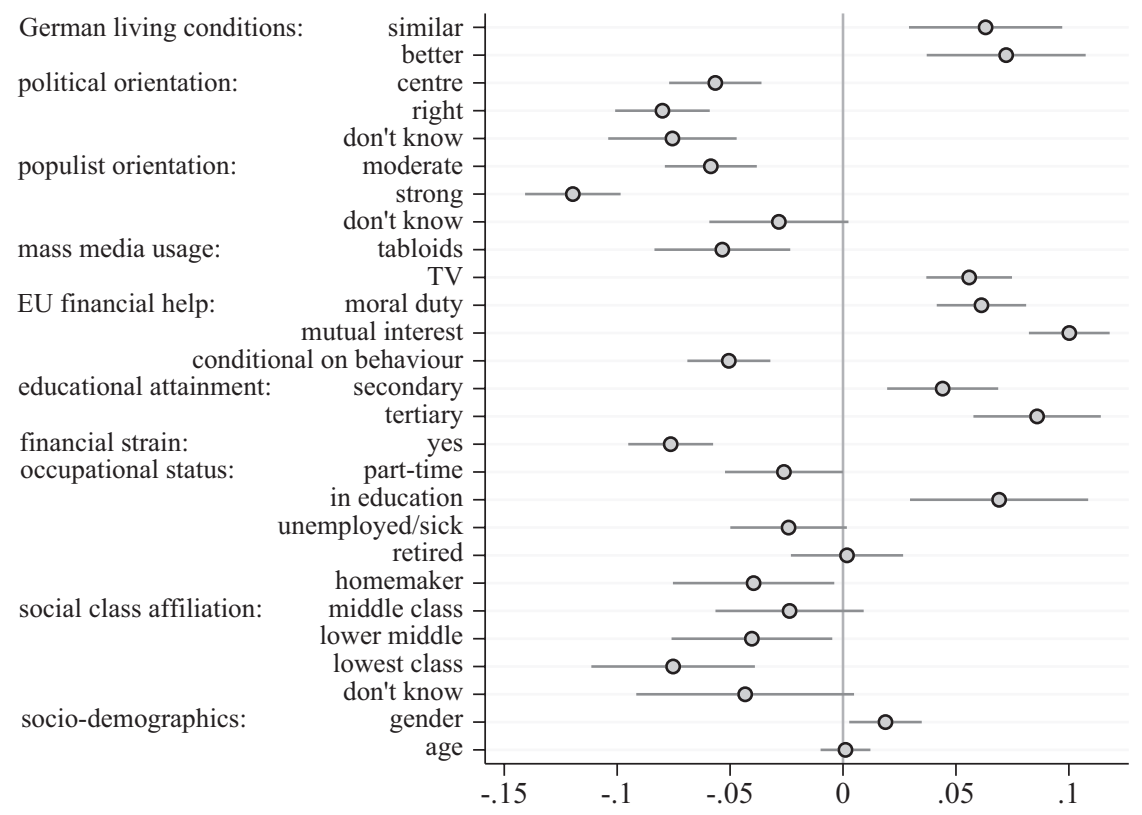

Figure 6.7 EU referendum: leave versus remain in the EU (logistic regression, average marginal effects). Source: TransSOL WP3 population survey. 
the perception of sharing the EU with stronger countries is an attenuating factor that reduces Euroscepticism across all social strata. The calculation of predictive probabilities shows that among the respondents affiliating themselves with the lower class, the likelihood of opting for a remain is $18 \%$ higher when German living conditions are lauded to be better, and among those associating themselves with the upper classes, the probability is $17 \%$. Respondents affiliating themselves with different social classes might thus be divided in their inclination to reaffirm EU membership, but everybody seems to draw the same lessons from the European map of living conditions.

This shows that respondents do not seem to blame the EU for unequal living conditions in Europe. On the contrary, the EU still seems to be a community that is associated with the promises of ensuring equal living conditions for everybody. Apparently, the pressure lies on the shoulders of national governments, which are held accountable for their low performance in attaining this goal. The cognitive map of European living conditions thus has a nuanced effect on political attitudes. The perception of inequalities tends to support the idea of a European Union and its common mission, while it encourages public demands stipulating that governments must live up to expectations by contributing to the reduction of cross-national divisions.

\section{Stratification and spatial inequalities across the EU 28}

Social divisions impact the perception and assessment of the European Union, given that social vulnerability increases the likelihood of critical attitudes towards the membership of one's country within the community and encourages preferences for leaving the EU, even though the perspective of sharing membership with stronger countries with higher living standards attenuates Euroscepticism. The previous analysis, however, has been restricted to a limited number of European countries, albeit covering a diversity of socio-economic, political and cultural contexts. Additionally, attention was directed at countries, assuming that living conditions - with their stratificational differentiations - are similar across national territories. In this chapter, I wish to move beyond these limitations by expanding on and differentiating the analysis. On the one hand, it is necessary to validate whether the main finding of the previous analyses, namely that social divisions influence political cleavages to a significant degree, also applies to the European Union with all its member states in 2016, and thus to all European citizenry as such. On the other hand, it is advisable to look inside the various countries to disaggregate the picture along regional divisions in order to examine whether EU-friendly and EU-sceptical attitudes are patterned by spatial differences in living conditions at national and regional levels. Both aims are interrelated because it is necessary to test what the role of horizontal divisions along spatial inequalities is in shaping EU-related attitudes, and whether these horizontal divisions are as significant as the vertical divisions along the stratification of social class. 


\section{Social divisions and political dissent: Euroscepticism as a social fault line}

These analyses will make use of Eurobarometer survey data from late 2016 to match the previously used TransSOL survey results. As discussed earlier (see Chapter 1), this dataset is not without limitations and needs to be used with care, particularly in regard to the support of EU membership as findings from the Eurobarometer survey deviate from the TransSOL data presented before, given that the former paints a picture of a more supportive public opinion when compared to the TransSOL findings. In both cases, we should abstain from taking the data at face value, given that the level of support or criticism of EU membership is volatile, reacts to contextual circumstances at the time of fieldwork and is influenced by sampling and data collection methodology. For the purposes of this study, however, it is less relevant to identify the exact level of support or criticism. The main objective differs because the intention is to detect determinants of EU-related attitudes. In this regard, both surveys provide instructive data, given that they identify the individual correlates of supportive or critical opinions. As will be shown in this chapter, findings between both datasets are very similar. The rates of support for the EU might diverge, but correlates and determinants of support or criticism do not, thus suggesting that the evidence generated by the statistical analyses is robust.

Figure 6.8 summarises the answers of respondents from all member states to the question about EU membership of their country. The share of supporters and critics diverges considerably between the countries, with the Benelux and Scandinavian countries indicating greater sympathy toward the EU than the British, Italians or the Greeks. According to this data, 15 countries, a clear majority, support EU membership, and in a further 12 countries, the supporters outnumber the outspoken critics. Only in Greece is disapproval slightly more diffused than approval for the EU. Additionally, it is important to highlight that less supportive countries not only share a more outspoken criticism of the EU membership but tend to have more citizens indicating that EU membership is a good and bad thing at the same time.

This map of EU-related attitudes is to be taken with care, as already mentioned, given the volatility of public opinion on this matter. Since the beginning of the Eurobarometer survey, the share of supporters of EU membership across all countries has seen times of generalised support (e.g., the late 1980s with up to $66 \%$ of all respondents in the EU 12) as well as dwindling enthusiasm (e.g., the early 2010s with less than 47\% supporters in the EU 27). Additionally, low rates of outspoken EU critics (a bad thing) seem to convey a seductive confidence because it distracts from those respondents opting for "neither a good nor a bad thing", that indicate clear reservations towards EU membership and might opt against it in the event of a referendum. In fact, the experience of a referendum on the membership of the United Kingdom teaches us that citizens with reservations against the EU might easily opt for leave. For instance, the share of British supporters of EU membership in the Eurobarometer survey of 2016 (i.e., 47\%, 


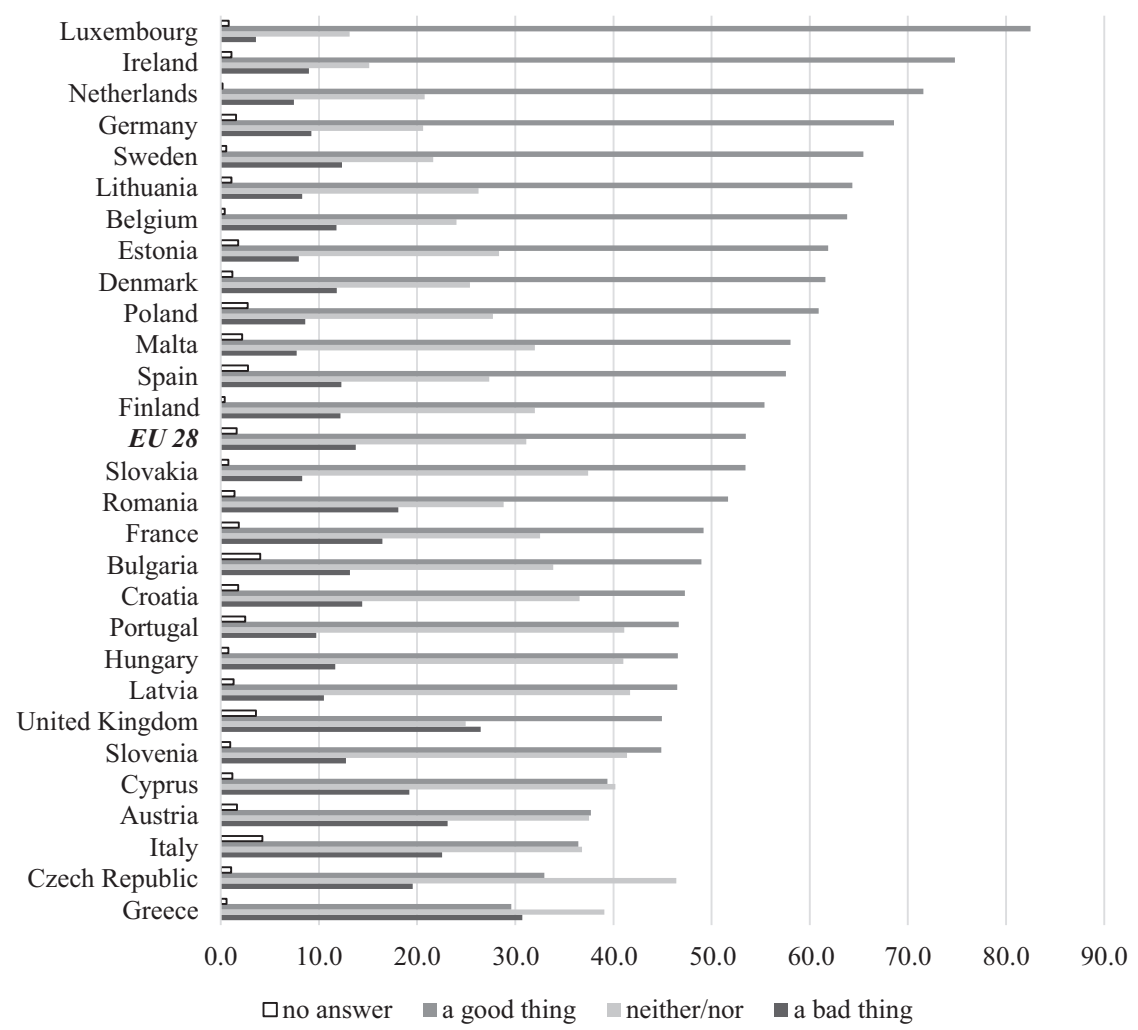

Figure 6.8 Membership of the EU: a good or bad thing (\%). Source: Eurobarometer 86.1 (ZA6697).

if "don't knows" are not counted) largely conforms to the number of "remain" votes in the Brexit referendum from July of the same year, and this figure has been confirmed by opinion polls (e.g., YouGov 2016). This means that citizens opting for leave are recruited not only from among those respondents evaluating EU membership as a "bad thing", but also from those having reservations (neither good nor bad), making up 51.5\% of all British respondents to the Eurobarometer survey. Both questions are not strictly interrelated, given that the assessment of EU membership does not necessarily predetermine voting in a referendum. What the comparison shows is that the intermediate category is used by respondents to stress that the EU has its good and bad sides, and thus seems to mirror a position of tentative Euroscepticism.

The data on EU membership can thus be used to identify those groups that lean towards tentative and/or outspoken Euroscepticism. The fact that the Eurobarometer data identifies a smaller share of outspoken EU critics (a bad thing), when compared to the TransSOL survey presented above, is an asset for 
the explanatory purposes of this chapter because it helps to paint a more focused picture of those social and political characteristics that seem to be associated with an outspoken EU-critical posture. Additionally, the Eurobarometer data highlights even more forcefully than the TransSOL survey that EU-related attitudes diverge considerably between countries. The findings thus help to highlight spatial divisions between countries and thus to analyse the extent to which EU-related attitudes are determined by place of residence and thus by the social and political context in which respondents live.

The following analysis wishes to validate whether EU-related attitudes are conditioned by horizontal stratifications within society and by spatial divisions along countries and regions. First, I wish to identify the relevance of stratificational traits (objective features and subjective assessments), when controlled for political perceptions and orientations. For this purpose, two regression analyses were calculated: the first calculations focus on political attitudes and orientations that have testified to explain the likelihood of Eurosceptic views, the second reduces the number of political factors to the main predictors, while at the same time introducing the social-structural characteristics of interest in this study in order to check their net explanatory power.

Table 6.3 summarises the findings of the first regression analysis, focusing exclusively on political predictors. It introduces three sets of factors identified in previous studies as highly relevant determinants: self-reported levels of political efficacy, ideological orientations and EU-specific attitudes. The first set of factors assumes that scepticism, determined by the citizen's perceptions of their own political efficacy (Pollock 1983; Madsen 1987), is high among those people who are not convinced about their own political competences in terms of knowledge or skills (internal efficacy) and who believe that the political institutions (in particular, the EU) ignore or disregard their own interests (external efficacy). The results confirm these assumptions. The decisive factor is the assessment of external efficacy, i.e., the opinion that political institutions do not listen to respondents. Those who feel that they are not being heard in their own country or the EU are $7 \%$ more likely to be against their own country's membership of the EU, while the probability of believing it to be a good thing is $13 \%$ lower. Interestingly, the feeling of lack of influence at home is more crucial for Eurosceptics than a lack of voice in the EU (Hooghe and Marks 2005; Ares et al. 2017). Eurosceptics seem to believe that their own government does not take their concerns sufficiently into account, particularly when negotiations at EU level are about representing national interests and wishes. The finding that Eurosceptics are not politically disinterested is also in keeping with this because they talk more often about European politics than those in favour of the EU. Those who talk less often about European politics tend to opt for a more diplomatic "both" when it comes to assessing their country's EU membership.

The second set of factors relates to political orientations. Previous studies have shown that Euroscepticism is closely linked to populist criticism of the ruling politics and the established parties, highly relevant for voting behaviour at European elections (Hix and Marsh 2007; Hong 2015; Stockemer and Barisione 2016). 
Table 6.3 Country's membership of the EU, political factors (ordered logistic regression, average marginal effects), 2016

A bad thing Neither/nor Good thing

\section{Political efficacy}

Discuss national political matters with friends or relatives (ref. frequently)

Occasionally

Never

Discuss European political matters with friends or relatives (ref. frequently)

Occasionally

Never

Can convince others of my opinion

(ref. rarely to never)

My voice counts in my country (ref. agree)

My voice counts in the EU (ref. agree)

Political orientations

Political self-positioning (ref. left)

Centre

Right

Don't know/not specified

Refused

Rise of anti-elite parties (ref. cause for concern)

National media trustworthy (ref. yes)

National media free from political or commercial pressure pressure (ref. yes)

Attitudes towards the EU

Similarities larger than differences (ref. agree)

Disagree

Don't know/not specified

European identity: characteristics (Ref: no answer)

Democratic values

Common currency

Economic success

Culture

Greatest challenges of the EU (ref. no answer)

Immigration, security

Social inequalities, unemployment

Socio-demographic characteristics

Age (ref. 15-24 years)

25-39 years

40-54 years

55 years and older

$\begin{array}{lll}0.009 * & 0.008^{*} & -0.017 * \\ 0.013 * * & 0.012 * * & -0.024 * *\end{array}$

$\begin{array}{lll}-0.007 & -0.007 & 0.014 \\ 0.015^{* *} & 0.013^{* *} & -0.028^{* *} \\ -0.001 & -0.001 & 0.002 \\ & & \\ 0.070^{* * *} & 0.063^{* * *} & -0.134^{* * *} \\ 0.026^{* * *} & 0.024^{* * *} & -0.050^{* * *} \\ & & \\ & & \\ 0.006^{*} & 0.006^{*} & -0.012^{*} \\ -0.003 & -0.003 & 0.006 \\ 0.013^{* *} & 0.012^{* *} & -0.025^{* *} \\ 0.036^{* * *} & 0.029^{* * *} & -0.066^{* * *} \\ 0.013^{* * *} & 0.012^{* * *} & -0.025^{* * *} \\ & & \\ 0.050^{* * *} & 0.045^{* * *} & -0.095^{* * *} \\ 0.005 & 0.005 & -0.010\end{array}$

$0.144 * * *$

$0.095 * * * \quad-0.240 * * *$

$0.060 * * * \quad 0.060 * * * \quad-0.120 * * *$

$\begin{array}{lll}-0.040^{* * *} & -0.036 * * * & 0.075^{* * *} \\ -0.038^{* * *} & -0.034^{* * *} & 0.072 * * * \\ -0.031^{* * *} & -0.028^{* * *} & 0.060^{* * *} \\ -0.019^{* * *} & -0.017^{* * *} & 0.037^{* * *}\end{array}$

$0.003 \quad 0.002 \quad-0.005$

$0.013 * * * \quad 0.011 * * * \quad-0.024 * * *$

$\begin{array}{lll}0.021 * * * & 0.024 * * * & -0.045 * * * \\ 0.037 * * * & 0.038 * * * & -0.075 * * * \\ 0.041 * * * & 0.042 * * * & -0.082 * * *\end{array}$

(Continued) 
Table 6.3 Continued

\begin{tabular}{lccl}
\hline & A bad thing & Neither/nor & Good thing \\
\hline Gender (ref. male) & 0.002 & 0.002 & -0.005 \\
Place of residence (ref. country or village) & & & \\
$\quad$ Small, medium-sized town & $-0.008^{* *}$ & $-0.007^{* *}$ & $0.015^{* *}$ \\
$\quad$ Large city & $-0.032^{* * *}$ & $-0.030^{* * *}$ & $0.061^{* * *}$ \\
Cases & 24.319 & & \\
Pseudo R & 0.127 & & \\
\hline
\end{tabular}

Source: Eurobarometer 86.1 (ZA6697).

Note: Significance levels: ${ }^{*} P<0.1$., ${ }^{* *} P<0.05, * * * P<0.01$.

The results show that Euroscepticism cannot be clearly placed on the ideological spectrum. It is particularly interesting that those respondents who do not know or even refuse to provide a political self-positioning, lean most clearly towards Euroscepticism, which may be an indication that Eurosceptics cannot or do not want to be clearly positioned on the traditional party spectrum. This insight is supported by research findings because populist parties and electorates come from all parts of the political spectrum (Mudde 2004; Rooduijn 2014). Rebellion against the political establishment is the hallmark here.

The third set of political predictors is more tightly linked to the EU, reflecting previous studies that link Eurosceptic attitudes with the perception of the EU and its policies (e.g., Eichenberg and Dalton 2007) and with cognitive and affective evaluations of the EU (Hooge and Marks 2005; Boomgaarden et al. 2011). In our model, we assume that a negative assessment of EU membership is stronger among those who stress challenges and problems with which the EU is confronted (e.g., inequalities and unemployment), see more divisions than commonalities between European people and are less convinced that there are identifiable characteristics that give rise to a European identity. The findings corroborate these assumptions by highlighting that Eurosceptic respondents refer much more frequently to unresolved social problems (inequality and unemployment) than EU supporters. Complementary to this, it is striking that respondents who find more divisive than unifying elements are $14 \%$ more likely to be of the opinion that EU membership is a bad thing and $24 \%$ less likely to acknowledge that this membership is good. The fact that such an opinion leads to more scepticism or opposition is an indication that the EU is perceived as a battlefield of competing (national) interests rather than a union of different countries. In the face of this, Eurosceptics tend to omit the fact that a community is built on a shared identity. Finally, in addition to these results, regression analysis has also identified sociodemographic characteristics of the respondents as relevant explanatory factors. For the following analyses, it is interesting to highlight that EU opposition is less pronounced in metropolitan areas than in rural areas, thus exhibiting spatial differences within countries.

Findings so far show that Euroscepticism is accompanied by a feeling of political marginalisation. Critics of the EU insist on having little influence on 
political life and feelings of greater detachment. This sentiment seems to motivate Euroscepticism because these respondents see the EU as a battlefield of competing national interests. Not being heard politically by one's government must thus be quite a serious issue for EU citizens. Considering that these people attribute more disadvantages than benefits to the EU and perceive the union as more divisive than unifying, makes it possible to understand why the lack of political influence is motive enough for being opposed to EU membership. Distribution conflicts within the EU are lost to people if their respective governments do not take their interests into account. Criticism of political conditions at national and European levels is interrelated and, therefore, has the potential to contribute to the fundamental alienation of people from the political status quo.

These findings thus corroborate that opponents and supporters of EU membership can be distinguished by their political convictions and preferences. However, they do not clarify the question of whether these groups also have special characteristics with regard to their socio-structural position in society. Here one can refer to numerous findings of previous research. Studies have been able to show that population groups in precarious situations and experiencing socio-structural disadvantages are more likely to be critical of the EU, while the socially privileged tend to support the EU and their country's membership (McLaren 2004: 900; Lubbers and Scheepers 2010: 800; Fligstein 2008; Kuhn et al. 2016). These precarious living conditions are linked to certain socio-cultural attitudes because people with more traditional views of life, materialistic orientations and ethnocentric worldviews also tend to regard the EU with more scepticism (Green 2000; Nelsen et al. 2001: 204f.; Boomgaarden and Freire 2009: 1242f.; de Vries and van Kersbergen 2007; Hooghe et al. 2007: 329).

To test the relevance of social-structural characteristics in general, and the role of social vulnerabilities in particular, a second regression analysis was computed, which lists a number of related factors, while controlling for those political attitudes that have proven to be important predictors. The Eurobarometer survey of 2016 sets some limits to such an analysis since the basic socio-structural data are collected in a simplified form. However, it provides sufficient information for the analyses. It includes data on the level of education, as respondents were asked to indicate their age when they completed their full-time education. Additionally, it gathered evidence on the respondents' occupations, ${ }^{5}$ thus offering an approxi-

5 The Eurobarometer survey can only provide clues, since questions on the occupation focus solely on the type of employment. The group of employees is especially heterogenous. However, according to the classification by Oesch (2006), I have allocated them as follows: the groups of housewives/ househusbands, students, the unemployed and pensioners remain unaffected; the self-employed have been divided into lower middle class (farmers, fishermen and shopkeepers/craftsmen) and middle class (liberal professions and entrepreneurs); the employees have been divided into liberal professionals in an employment relationship, the upper management and middle management employees into the management group; the qualified office and administration employees and civil servants also include employees in the service sector (including social and health); the low-qualified workers consist of master craftsmen and foremen, skilled workers and other workers. 
mate insight into occupation-specific income situations and status groups. Finally, the data also provide us with information on self-reported social disadvantage: a measure of financial strain (self-reported difficulties in paying bills) and subjective class affiliation.

The correlation measures listed in Table 6.4 indicate the (percentage) likelihood that the persons with a negative or deliberating opinion will occupy a less privileged social position with regard to the characteristics mentioned. The reference group consists of people who have had a long education, are employed as managers, never have difficulties paying their bills and feel they belong to the upper middle class or upper class. In this model, too, the effect of the respondents' country of origin has been included as a control variable but is not listed in the table for space reasons.

The findings paint a very clear picture, as they confirm the link between Euroscepticism and social disadvantage. It is surprising that this finding can be proven for the European population virtually across all member states. This is an indication that EU citizens are exposed to similar social influences with regard to their opinion of the EU. In particular, the findings show that the likelihood of seeing EU membership as a bad thing is 8\% higher among people without a completed education than among those who left school or university at the age of 20 or later. The likelihood of a positive assessment of EU membership is reduced by $15 \%$ on average. The effect of the other socio-structural features repeats this picture. There is a slight tendency towards Euroscepticism among non-employed persons (housewives and househusbands, as well as the unemployed) and among qualified office and administrative employees. Opposition is much more pronounced among the low-skilled workers and the self-employed in the lower middle class segment, who are noticeably more sceptical than the senior managers. After all, Eurosceptics are more often people with financial difficulties, who are more likely to locate themselves in the lower middle or working class.

When adding the other attitude-specific characteristics, the effects of which are also confirmed in this extended calculation, it is possible to describe the opponents and supporters of EU membership as two opposing groups. On the side of the sceptics, one frequently encounters socially disadvantaged people who do not feel politically heard and who feel that there is more that divides than unites people in the EU. Conversely, it can be seen that among the supporters of EU membership, there are far more well-off people who feel they are taken seriously politically and emphasise what is common in the EU and also include several characteristics suggestive of a European identity. These results show that in the support or rejection of the EU, a distinction must be made between privileged and nonprivileged groups of people, between winners and losers in the social and political environment. This finding corresponds to the picture drawn to date (Hooghe and Marks 2005; Tucker, Pacek and Berinsky 2002; Koopmans 2007; Fligstein 2008), although its clarity is surprising. Moreover, assessment criteria seem to deviate as well because supporters and opponents seem to introduce ideational values or material benefit into the deliberations. Eurosceptics link their rejection 
Table 6.4 Country's membership of the EU, social factors (ordered logistic regression, average marginal effects), 2016

\begin{tabular}{|c|c|c|c|}
\hline & A bad thing & Neither/nor & A good thing \\
\hline \multicolumn{4}{|l|}{ Socio-structural characteristics } \\
\hline \multicolumn{4}{|l|}{ Education, age of completion ( $r e f .>20)$} \\
\hline $16-19$ years & $0.035 * * *$ & $0.035 * * *$ & $-0.070 * * *$ \\
\hline Less than 15 years & $0.059 * * *$ & $0.052 * * *$ & $-0.111 * * *$ \\
\hline No full-time education & $0.082 * * *$ & $0.066 * * *$ & $-0.147 * * *$ \\
\hline \multicolumn{4}{|l|}{ Occupation (ref. manager) } \\
\hline Housewife/househusband & $0.033 * * *$ & $0.029 * * *$ & $-0.062 * * *$ \\
\hline Unemployed & $0.028 * * *$ & $0.026 * * *$ & $-0.054 * * *$ \\
\hline Pensioner & $0.012 * *$ & $0.012 * *$ & $-0.025 * *$ \\
\hline Self-employed, lower middle class & $0.029 * * *$ & $0.026^{* * *}$ & $-0.056^{* * *}$ \\
\hline Self-employed, middle class & 0.004 & 0.005 & -0.009 \\
\hline Office/administrative employees & $0.019 * * *$ & $0.018 * * *$ & $-0.037 * * *$ \\
\hline Low-qualified workers & $0.030 * * *$ & $0.027 * * *$ & $-0.057 * * *$ \\
\hline \multicolumn{4}{|l|}{$\begin{array}{l}\text { Difficulties paying bills (ref. almost never) } \\
\text { never) }\end{array}$} \\
\hline Occasionally & $0.021 * * *$ & $0.019 * * *$ & $-0.040 * * *$ \\
\hline Most of the time & $0.043 * * *$ & $0.034 * * *$ & $-0.077 * * *$ \\
\hline \multicolumn{4}{|l|}{$\begin{array}{l}\text { Subjective class assignment (ref. upper } \\
\text { class/upper middle class) }\end{array}$} \\
\hline Middle class & $0.027 * * *$ & $0.029 * * *$ & $-0.056^{* * *}$ \\
\hline Lower middle class & $0.040 * * *$ & $0.040 * * *$ & -0.080 \\
\hline Working class & $0.044 * * *$ & $0.044 * * *$ & $-0.088 * * *$ \\
\hline \multicolumn{4}{|l|}{ Political attitudes and orientations } \\
\hline My voice counts in my country (ref. agree) & $0.070 * * *$ & $0.061 * * *$ & $-0.130 * * *$ \\
\hline My voice counts in the EU (ref. agree) & $0.023 * * *$ & $0.020 * * *$ & $-0.042 * * *$ \\
\hline \multicolumn{4}{|l|}{ Political self-positioning (ref. left) } \\
\hline Centre & 0.004 & 0.004 & -0.008 \\
\hline Right & -0.005 & -0.005 & 0.009 \\
\hline Don't know/not specified & $0.014 * *$ & $0.012 * *$ & $-0.027 * *$ \\
\hline Refused & $0.035 * * *$ & $0.027 * * *$ & $-0.062 * * *$ \\
\hline $\begin{array}{l}\text { Rise of anti-elite parties (ref. cause for } \\
\text { concern) }\end{array}$ & $0.014 * * *$ & $0.012 * * *$ & $-0.025 * * *$ \\
\hline National media trustworthy (ref. yes) & $0.055 * * *$ & $0.048 * * *$ & $-0.102 * * *$ \\
\hline \multirow{2}{*}{\multicolumn{4}{|c|}{$\begin{array}{l}\text { Attitudes towards the EU } \\
\text { Similarities larger than differences } \\
\text { (ref. agree) }\end{array}$}} \\
\hline & & & \\
\hline Disagree & $0.142 * * *$ & $0.090 * * *$ & $-0.232 * * *$ \\
\hline Don’t know/not specified & $0.053 * * *$ & $0.052 * * *$ & $-0.105 * * *$ \\
\hline \multicolumn{4}{|l|}{$\begin{array}{l}\text { European identity: characteristics } \\
\quad \text { (ref. no answer) }\end{array}$} \\
\hline Democratic values & $-0.036^{* * *}$ & $-0.031 * * *$ & $0.067 * * *$ \\
\hline Common currency & $-0.037 * * *$ & $-0.032 * * *$ & $0.069 * * *$ \\
\hline Economic success & $-0.032 * * *$ & $-0.028 * * *$ & $0.060 * * *$ \\
\hline Culture & $-0.018^{* * *}$ & $-0.016^{* * *}$ & $0.034 * * *$ \\
\hline
\end{tabular}

(Continued) 
Table 6.4 Continued

\begin{tabular}{llll}
\hline & A bad thing & Neither/nor & A good thing \\
\hline Socio-demographic characteristics & & & \\
Age (ref. 15-24 years) & & & \\
$\quad$ 25-39 years & $0.020^{* * *}$ & $0.020^{* * *}$ & $-0.041^{* * *}$ \\
$\quad$ 40-54 years & $0.028^{* * *}$ & $0.028^{* * *}$ & $-0.056^{* * *}$ \\
$\quad 55$ years and older & $0.028^{* * *}$ & $0.027^{* * *}$ & $-0.056^{* * *}$ \\
Gender (ref. male) & 0.005 & 0.004 & -0.009 \\
Place of residence (ref. country or village) & & & \\
$\quad$ Small, medium-sized town & -0.006 & $-0.005^{\mathrm{c}}$ & $0.011^{\mathrm{c}}$ \\
$\quad$ Large city & $-0.024^{* * *}$ & $-0.022^{* * *}$ & $0.045^{* * *}$ \\
Cases & 22.612 & & \\
Pseudo $\mathrm{R}^{2}$ & 0.139 & & \\
\hline
\end{tabular}

Source: Eurobarometer 86.1 (ZA6697).

Note: Significance levels: ${ }^{*} P<0.1, * * P<0.05$, *** $P<0.01$.

to considerations of usefulness. Membership should pay off but fails to do so. For those in favour of Europe, usefulness is certainly also an issue. However, ideational factors, in particular belonging to a Europe based on commonalities, play a much greater role for them. In this regard, we can follow Bourdieu's thinking (1988; 1990: 122-34; 1998: 75-91). The socially privileged pursue a strategy of "disinterested interest" - in our case, in the EU - since their interest is primarily in the matter itself, as opposed to considerations of usefulness. The socially disadvantaged, however, display their personal sensitivities and interests openly, where they risk losing political legitimacy if Europe is about larger contexts and a common good spanning particular interests. The strategy of indifference promises advantages in terms of reputation and legitimacy, precisely due to the fact that the socially privileged already benefit much more from this very union than their socially disadvantaged - counterparts.

From a sociological perspective, we thus see that the political cleavage about EU membership is closely related to a social divide between privileged and less privileged social groups. This raises the question of whether the political dissent of the population is to be understood ultimately as an implicit class conflict across the member states. In this sense, we would speak of a transnational cleavage between supporters and opponents that in itself conforms to a transnational division between well-off and vulnerable groups of the population. This provocative thesis must be critically verified. In fact, our findings have been able to show that social divisions between privileged and non-privileged groups are relevant across all countries. However, the analyses have been unable to show that divisions between social strata or classes have an identical impact on EU-related attitudes and that it is possible to speak about transnational divisions with identical positions towards the EU. It is advisable to be cautious because country differences are substantial, which means that stratificational positions are not strictly comparable when considering the material situation of 
privileged or non-privileged strata in western or eastern, northern or southern European countries. Additionally, we have seen that the likelihood of supporting or criticising the EU varies strongly between countries, thus implying that privileged citizens and vulnerable groups are not exclusively supportive or critical, respectively.

The relationship between stratificational and spatial divisions and their effect on EU-related attitudes should thus be more complex than the simple hypothesis of transnational class division implies. This assumption can be tentatively validated when breaking up the results of our regression analysis (see Table 6.4) for one of the determinants measuring social inequalities: educational careers. In this regard, it is useful to statistically determine the probability of a Eurosceptic attitude among educationally disadvantaged persons for each country (so-called predictive margins). Figure 6.9 summarises the results in graphic form. The $\mathrm{x}$-axis lines up the four educational groups (from older than 20 years, 16-19 years and 15 years or younger to no full-time education), the y-axis indicates the level of the respective probabilities. It is first of all striking that the national climate of opinion makes a significant difference for all four education groups because, in Europefriendly countries, people with a low level of education are also highly likely to be in favour of EU membership, while the opposite is the case in countries with a generally Eurosceptic climate of opinion. For example, in countries such as Luxembourg or Ireland, which are characterised by an overall pro-European public opinion, it can be seen that all educational groups are highly likely to join the chorus of supporters. The likelihood of people with long and short educational biographies seeing membership as a good thing is $85 \%$ and $76 \%$, respectively, for Luxembourg, and 79\% and 67\%, respectively, for Ireland. In Eurosceptic countries, it is the other way around, because in Austria, the predictive probability of a positive assessment is considerably lower for all Austrians. Among the social classes with higher and lower levels of education, the proportion of people in favour is only $40 \%$ and $29 \%$, respectively. In Greece, the figures are as low as $32 \%$ and $22 \%$, respectively.

Although the climate of opinion rubs off on respondents' attitudes, it is remarkable that education makes a certain difference in all countries. Everywhere, it is less likely that people from less educated backgrounds see their country's EU membership as a good thing, and everywhere it is more likely that they see membership as something bad. The differences between educationally disadvantaged and advantaged groups are similarly large everywhere; the probability of a positive assessment is $9 \%$ to $16 \%$ lower among the respondents with lower levels of education, and the probability of negative evaluations is $4 \%$ to $9 \%$ higher when compared to the respondents with longer educational careers. A similar picture emerges for other socio-structural characteristics, such as subjective class affiliation, or for difficulties in making ends meet with disposable household income. Social disadvantage always reduces the likelihood of seeing EU membership as a good thing. However, the probability varies only slightly, while the differences between countries are much greater. As these individual results do not provide any new information, they are not presented here. 


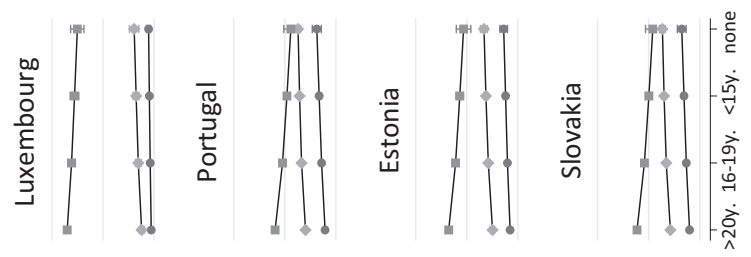

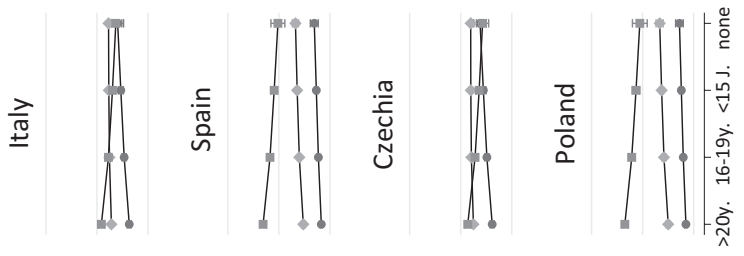

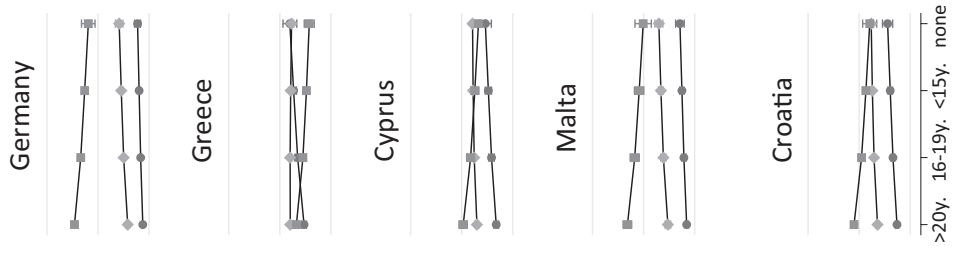
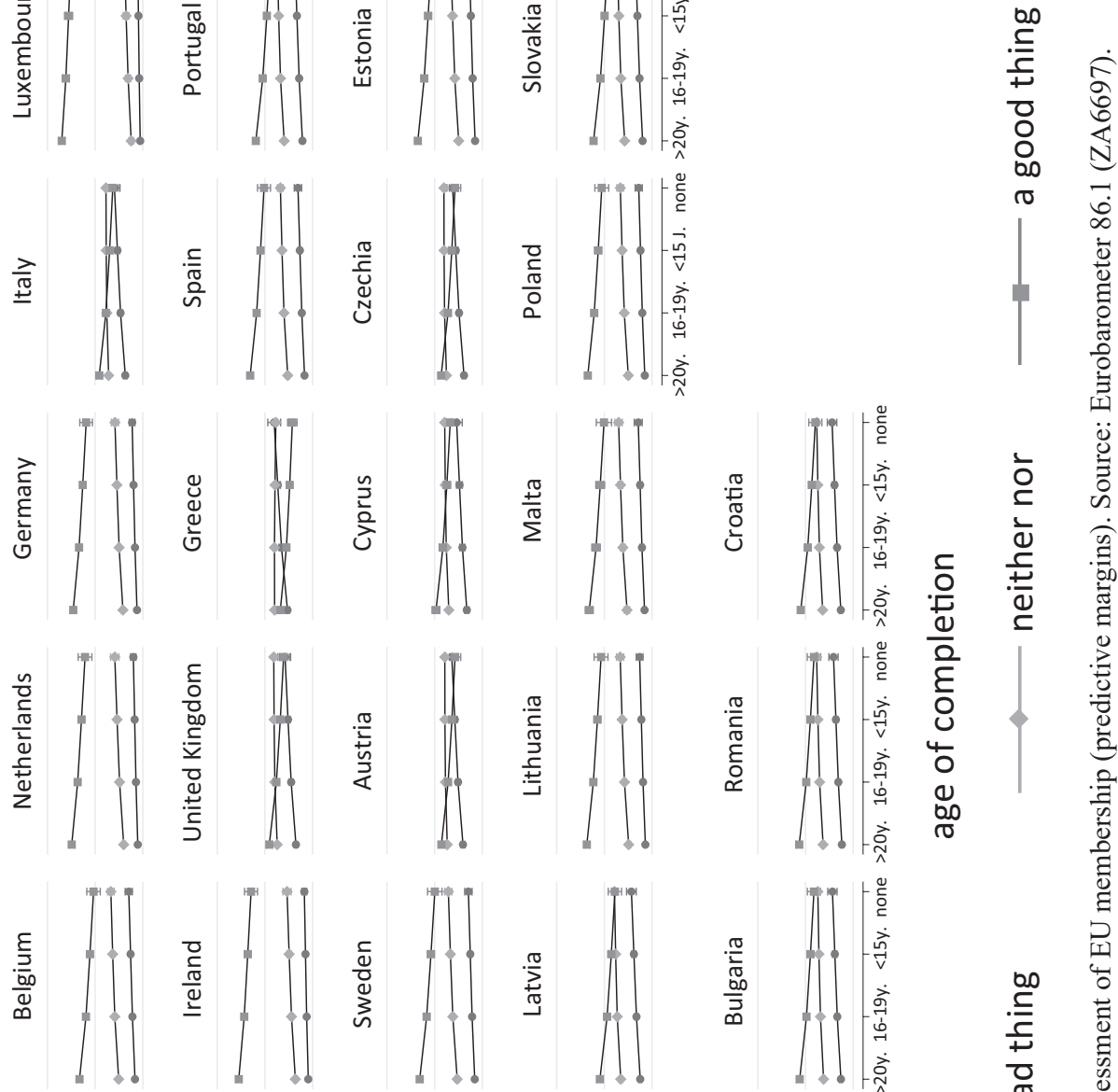

$\sum_{\pi}^{\frac{\pi}{3}}$
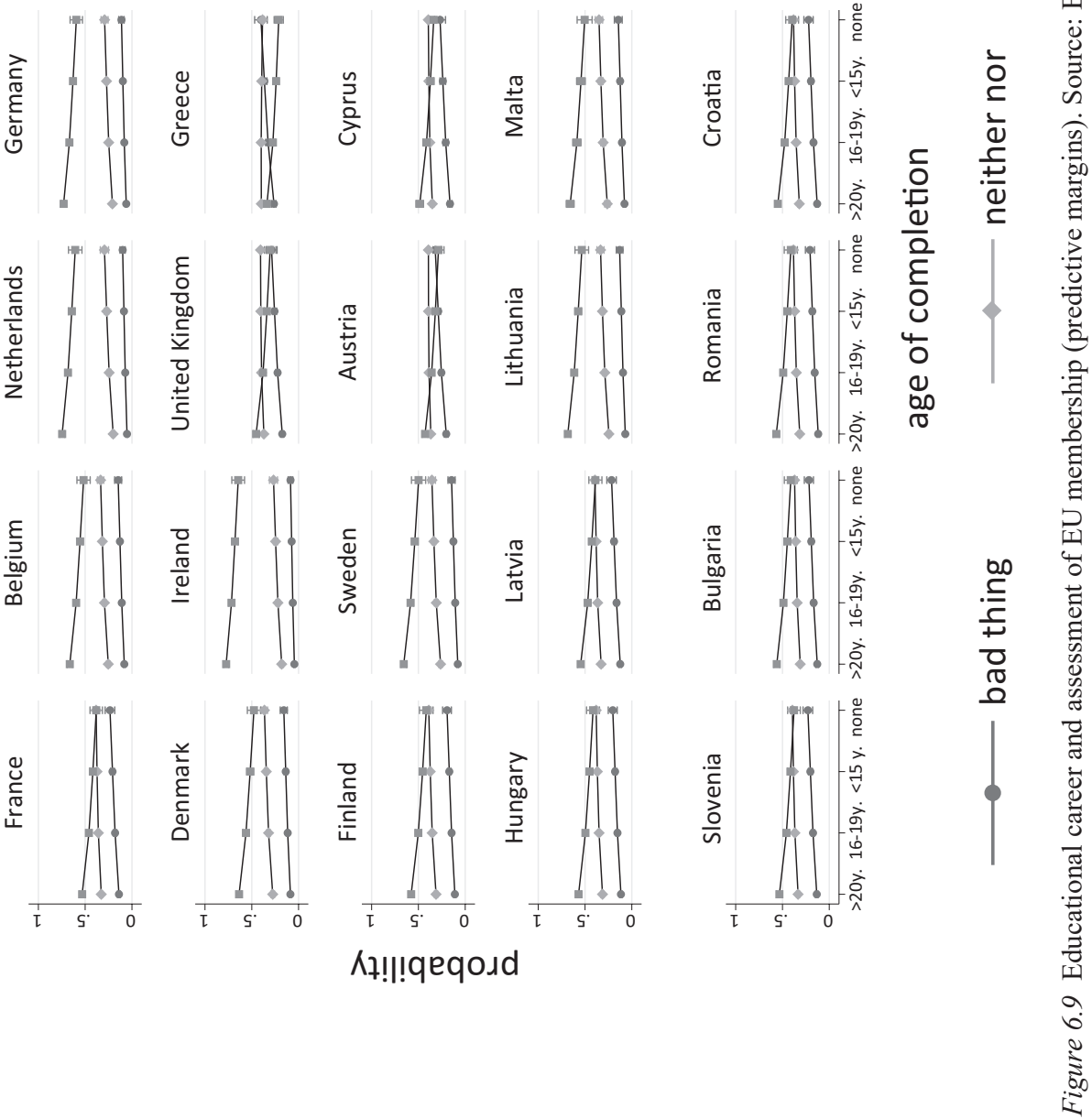


\section{Spatial disparities: multilevel causation along the regional and national levels}

Overall, our evaluations show that the thesis of a pan-European line of conflict between supporters and opponents of EU membership and a class-specific line of division between privileged and non-privileged people is not true in its simplicity. While it is true that social position tangibly influences the respondents' attitude towards the EU, the differences between the respondents were even more pronounced in terms of residence, as the likelihood of Eurosceptic attitudes and the distribution between supporters and opponents of EU membership seem to reflect country-specific conditions. These observations, however, raise a number of unanswered questions. If spatial differences are a highly relevant factor in explaining rates of Euroscepticism among respondents, then what are the driving forces behind these differences? In part, national differences might just mirror different socio-economic contexts and living standards. If the availability of education, employment and income seems to influence the assessment of the EU, as the analysis of vertical divisions along the stratificational inequalities has shown, then we might assume that national differences in public opinion reflect socioeconomic performance. Following the sociological perspective, countries should display different social conditions (e.g., prosperity levels, income levels) that shape the living conditions of individuals and their political views. This would mean that the social positioning of the individual has a double effect on the support of EU membership. It could be assumed that the socially disadvantaged from structurally weak countries are more likely to be among the opponents of the EU when compared with the socially disadvantaged from the economically wealthier and more stable countries. Conversely, socially privileged respondents from the socio-economically better-off countries would most frequently be among the proponents.

Diverging rates of Euroscepticism in different countries might, however, not be conditioned exclusively by socio-economic conditions. Previous studies have highlighted that these differences in public opinion are strongly conditioned by political factors specific to each of the European member states. Political conditions, such as, for instance, those established by national party systems, play an important intervening role. These include anti-European parties, some of them populist, that are mobilising against their country's membership of the EU and are thus also shaping public opinion (Hutter and Grande 2014; Hong 2015; Stockemer and Barisione 2016; Treib 2020). Furthermore, reference is made to the role of the mass media, which in many countries report critically on the EU and can often also spread Eurosceptic opinions among the population and thus also reinforce them (Hooghe et al. 2007: 341; Lubbers and Scheepers 2010; Fligstein et al. 2012; Conti and Memoli 2017). Finally, it is pointed out that approval of the EU also depends on identities, as countries with a dominating sense of national belonging and identification with their own country have less room for European identities and a lower willingness to support the EU, even in times of public criticism (Hooghe and Marks 2005; Fligstein et al. 2012). 
Research, therefore, assumes that European attitudes are not only shaped by the living conditions of individual citizens but also by the socio-economic and political contexts in which they live. An in-depth analysis of explanatory factors must, therefore, look at both dimensions at the same time. This requires a multilevel analysis because this statistical procedure aims to determine the explanatory power of individual and contextual factors, simultaneously. For these reasons, previous research has already used multilevel analysis on several occasions. For example, it has been shown that people who identify exclusively with their country do not necessarily hold Eurosceptic attitudes. This connection exists only in countries where the clash between pro-EU and anti-EU parties politicises collective identities and thus pits national identities against European identities (Hooghe and Marks 2004). The role of party political constellations in a country has been repeatedly confirmed (de Vries and Edwards 2009; Armingeon and Ceka 2014), but also the role of the economic situation and the consequences of the economic and financial crisis, when differentiating between Eurosceptic and friendly respondents (Kuhn and Stoeckel 2014; Braun and Tausendpfund 2014; van Erkel and van der Meer 2016).

The analysis of contextual factors, however, cannot stop at the national level but needs to break down countries into regions. Previous studies have highlighted already that levels of Euroscepticism diverge between regions (Lubbers and Scheepers 2005; Schraff 2019; Schoene 2019). For analytic purposes, the analysis of the regional level is important because social conditions within nation states vary considerably, for example, with regard to economic performance, household income or social inequality structures (Heidenreich and Wunder 2008; Geppert and Stephan 2008; Petrakos, Kallioras and Anagnostou 2011; Heidenreich 2016a). EU-related attitudes should be shaped by these regional differences, insofar as the living conditions and socio-economic realities will impact on the residents' satisfaction or confidence with political institutions (van Erkel and van der Meer 2016).

The relevance of the regional level can be easily evidenced when observing EU-related attitudes and grouping the opinions of respondents about EU membership along the regional place of residence. The Eurobarometer survey allows us to break down national rates into regional units, the so-called NUTS regions (nomenclature of territorial units for statistics). Figure 6.10 compiles the average approval values for each of the 245 NUTS regions in regard to two questions: the assessment of a country's own EU membership (1, good; 2, neither nor; 3, bad) and whether the country had benefitted from membership (1, yes; 2, no). For the sake of clarity, the average values of the regions are presented only as a grey point cloud in the background to highlight two countries as examples. The choice fell on the German federal states and the Greek regions, as these countries tend to be among the most EU-friendly and EU-sceptic member states.

It can be seen from the grey point cloud that people in the majority of regions tend to view EU membership positively. And although approval is weaker in a number of regions, regional differences are rather gradual. Only a few are aligned with the more sceptical averages. The German and Greek regions occupy different 


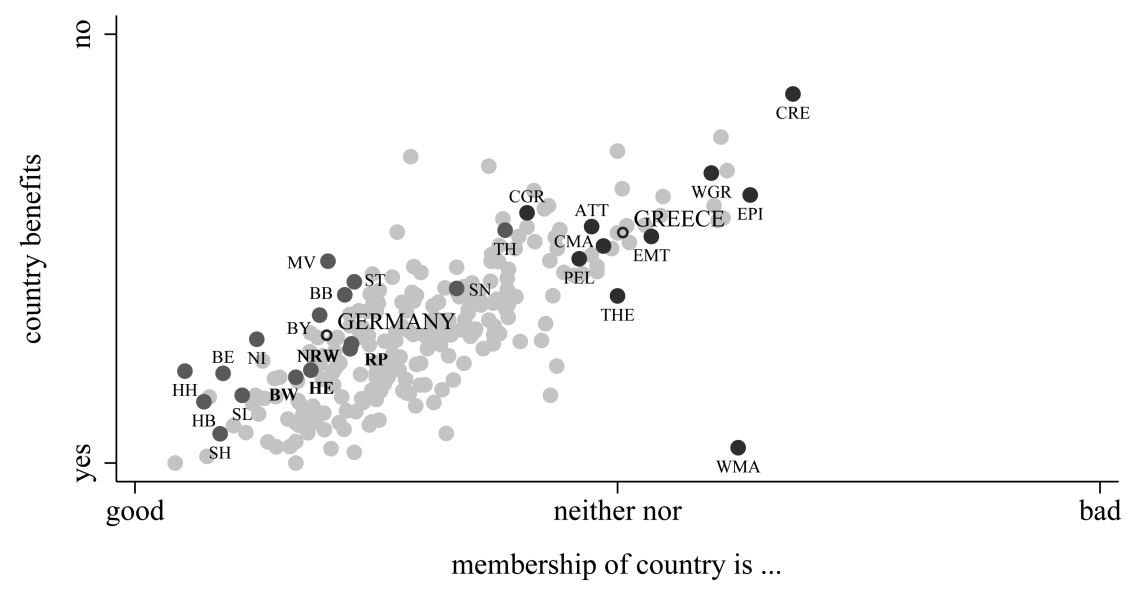

$\begin{array}{ll}\text { - other regions } & \circ \text { country } \\ \text { - German regions } & \bullet \text { Greek regions }\end{array}$

Note: German federal states: BB: Brandenburg, BE: Berlin, BW: Baden-Württemberg, BY: Bavaria, HB: Bremen, HE: Hesse, HH: Hamburg, MV: Mecklenburg-Vorpommern, NI: Lower Saxony, NW: North Rhine-Westphalia, RP: Rhineland-Palatinate, SH: Schleswig-Holstein SL: Saarland, SN: Saxony, ST: Saxony-Anhalt, TH: Thuringia; Greek regions: EMT: Eastern Macedonia and Thrace, CMA: Central Macedonia, WMA: Western Macedonia, THE: Thessaly, EPI: Epirus, WGR: Western Greece, CGR: Central Greece, PEL: Peloponnese,
ATT: Attica/Athens, CRE: Crete.

Figure 6.10 Attitudes to EU membership (mean values, region). Source: Eurobarometer 86.1 (ZA6697).

positions in this point cloud because the German federal states are more approving of the country's membership of the EU, while opinion in the Greek regions is rather ambivalent or even negative. However, the scatter of averages in Germany and Greece is remarkable. On the $\mathrm{x}$-axis, along which people rate membership as good or bad, there are clear differences between most (western) German states and the Greek regions. However, Thuringia and Saxony are two federal states that are more in line with the values in the Greek regions. The scatter is even more pronounced for the question of whether the countries have benefitted from EU membership. Here, only the people from the northern and western German federal states have a positive opinion, while the new federal states of the former German Democratic Republic are just as ambivalent about the situation as the population in Thessaly, the Peloponnese, central Macedonia, Athens and central Greece.

The German and Greek regions thus cover the entire spectrum of opinions. This finding shows that although political attitudes towards the EU vary between countries, this seems to be rather a statistical artefact, given that national averages level out differences within the countries. Hence, political preferences appear to be clearly determined by the regional context. For this reason, it makes sense to carry out a multilevel analysis that takes into account different grouping levels: the individual, the regional and the national levels. This multilevel modelling has two objectives. On the one hand, it is necessary to identify which level of analysis 
is the most relevant in explaining EU-related attitudes and diverging rates of Euroscepticism, in particular. Are regional differences more important in predicting Euroscepticism than national variations? On the other hand, the aim will be to identify the explanatory factors impacting EU-related attitudes. For the individual level, a number of predictors proven to be significant in Table 6.4 were adopted. Social-structural features are included because it is assumed that Euroscepticism is more likely for those with little educational capital, a precarious job and the subjective affiliation to the lower social classes. In addition, political attitudes that have been proven to explain Euroscepticism (i.e., perceptions of political efficacy and European identity) have been added, alongside two control variables, which record age and gender.

For the regional and national levels, several factors have been included in the modelling that measure different societal contexts: socio-economic performance, mass media exposure and collective identities, which all tend to vary strongly between regions. The first set of indicators has been included because it is assumed that the socio-economic conditions in the regions have an impact on political attitudes. As studies to date have shown, the impact of these conditions is rather complex, given that Euroscepticism can flourish in countries that are on the "have" or "have not" side in terms of prosperity, trade integration or financial transfers (Eichenberg and Dalton 1993; McLaren 2004; Braun and Tausendpfund 2014; van Erkel and van der Meer 2016). For our purpose, we will centre on economic performance indicators. Euroscepticism should be more widespread in regions characterised by low gross domestic product and lower economic growth between 2008 and $2015 .{ }^{6}$ Furthermore, this opinion should be more widespread in regions with low household incomes (per capita, purchasing power parity) and higher unemployment. These variables were all standardised to generate coefficients that are directly comparable across factors and levels.

Beyond socio-economic conditions, the importance of the mass media in spreading Eurosceptic attitudes is an important factor to take into consideration, since previous studies have referred to this same mediating actor (de Vreese and Boomgaarden 2006; Maier and Rittberger 2008; Conti and Memoli 2017). Since it is not possible to include any media content in the analyses at this point, this effect is to be determined indirectly via variables measuring the regional patterns of media use. To this end, data from Eurobarometer 86.2 (November 2016) was used to review the importance of different media as a source of information about the EU in the respective regions. Television is the most important medium, as on average, $55.2 \%$ of the local population in all regions use this medium to inform themselves about European affairs. This is followed by the internet (13.6\%), the

6 Both GDP figures are per capita and purchasing power parity. The change over time is measured as a percentage of GDP in 2015 compared to the pre-crisis year, 2008. The figures range from regions with a shrinking GDP (79.3\% of the level in 2008 in eastern Macedonia and Thrace in Greece) to regions with considerable growth $(162.5 \%$ as in the Border Region, the Midlands and Western Ireland). 
press $(9.6 \%)$, radio $(6.8 \%)$ and social media (3.2\%). However, the regions differed considerably in media use, as can be illustrated through the example of the most popular medium, television. In Castilla-La Mancha the share is only $7 \%$, in the Algarve, over $88 \%$. This data should help us to verify whether the different extent of regional media use has an influence on Eurosceptic attitudes.

Finally, a measurement value was determined by the strength of a region's collective identities. To this end, a question from the aforementioned Eurobarometer survey on the degree of perceived attachment to one's country or the European Union was used. Based on this information, it is possible to calculate for each region the average proportion of the population that feels attached to their own country or the EU. The figures give us insight into the regional climate of opinion. On average, all regions have a very strong attachment to their own country, with a 3.51 on a 4-point scale from "not at all" to "very attached". However, the values vary greatly between regions. Regions with a low degree of attachment include the autonomous regions of Spain (Basque Country, Navarra, Catalonia and Valencia, with values of 2.5-2.8), those with a high degree include the Austrian region of Carinthia or the Greek region of Western Macedonia (4.0). By contrast, the average regional population feels much less attached to the EU (2.47). Here too, the figures vary between the French Limousin (1.0) and the Croatian county of Požega-Slavonia (3.25). It can be assumed that Eurosceptic attitudes are more widespread in regions where attachment to one's country is higher, with lower rates of attachment to the EU.

Finally, we also included indicators at the country level. Here, in particular, we aim to measure the effect of the political and institutional context on EU-related attitudes. The general assumption reflects previous research and assumes that the nation state and national politics are used by citizens as proxies, benchmarks or yardsticks to assess European politics (Anderson 1998; Hooghe and Marks 2005; Muñoz et al. 2011; Desmet et al. 2012; Armingeon and Ceka 2014; Guinjoan and Rico 2018; de Vries 2018). For this reason, three indicators of this political context have been included. First, it is highly probable that the contentiousness within the political party systems of European member states has a direct impact on Euroscepticism, given that political parties are active in forming and mobilising public opinion for their demands. In the first instance, we might expect that the heterogeneity and polarisation of national party systems will increase the likelihood of Eurosceptic attitudes among the population, given that citizens in these countries might feel more at ease in expressing outspoken criticism, also against a perceived mainstream. For this purpose, I rely on data from the Manifesto Project that gathered data on election programmes of all parties participating in national elections, here, in particular, composite data on the divergence of issues with emphasis across parties (heterogeneity) and the left-right polarisation of the party system. Given that elections took place at different times, mean coefficients for the period 2010 to 2017 were calculated and included in the modelling. Additionally, it has been highlighted that the existence of Eurosceptic parties must be considered, as these groups express fundamental criticism of their country's membership of the EU in an attempt to influence public opinion (de Vries and Edwards 
2009; Armingeon and Ceka 2014; Kuhn and Stoeckel 2014; Treib 2020). For our purposes, a variable measuring the proportion of votes (in \%) for anti-European political parties in the 2014 European Parliament elections for each country was included. The focus was on the political party that, according to a typology by Hernández and Kriesi (2016), was most anti-European - regardless of whether the positioning was right-wing nationalist or left wing. Finally, we also control for the effect of perceived governance effectiveness, as measured by the World Bank's indicator (World Bank 2020). For countries with higher rates of satisfaction, we might expect less discontent with established political institutions, membership within the EU included.

Table 6.5 shows the results of this multilevel analysis. The question of the assessment of the respondents' country's membership of the EU has been reduced to two manifestations, to simplify the analysis, contrasting only those people who see membership as a "good" or "bad" thing. The exclusion of those who see membership as neither good nor bad reduces the number of cases by about 8,700 respondents. Due to the binary structure of our dependent variable (attitudes on EU membership), a multilevel logistic regression was used, and variables for the individual, regional and national levels were introduced successively. The calculations reside in a nested random-effects model, where regions were nested in countries in order to account for the assumption that the regional economy, media consumption and levels of attachment to the nation and Europe are embedded in a national context.

The results show that all three levels contribute to the explanation of Euroscepticism, albeit to a different degree. The first column presents the basic intercept model estimating the percentage of explained variance for each level (see the variance of regions and countries and the intraclass correlation coefficient, ICC). The proportion of the variance explained by the regions and countries is low with countries accounting for $10 \%$ and regions adding $7 \%$. This means that individual-level factors are decisive in understanding Euroscepticism, as argued by previous studies (e.g., Hooghe and Marks 2004; Braun and Tausendpfund 2014; Schoene 2019). The second model summarises the effect of individuallevel predictors. Findings show that people's personal living conditions influence their political attitudes in the expected way. Also, the perception of low political efficacy and conflicting interests within the EU increases the likelihood of Eurosceptic attitudes, even when controlled by region and country. These indications corroborate that social vulnerability and feelings of political marginalisation are decisive factors across the entire EU.

New insights are provided by the third model, which breaks down the regional level into the contextual variables introduced earlier. The socio-economic factors paint a differentiated picture because the assumption that Euroscepticism is more prevalent in regions from an economically disadvantaged position cannot be maintained. On the one hand, the results show that a higher GDP tends to reduce a region's probability of criticism of EU membership. More decisive, however, is economic development, because countries that are currently characterised by higher economic growth than in 2008 are also those regions in which 
Table 6.5 Euroscepticism and its determinants - multilevel logistic analysis (average marginal effects)

\begin{tabular}{|c|c|c|c|c|}
\hline & Model 1 & Model 2 & Model 3 & Model 4 \\
\hline \multicolumn{5}{|l|}{ Individual attributes } \\
\hline \multicolumn{5}{|l|}{$\begin{array}{l}\text { Education, age of completion } \\
\quad \text { (no full-time education) }\end{array}$} \\
\hline 15 years or younger & & -0.037 & -0.037 & -0.034 \\
\hline $16-19$ years & & $-0.075^{* *}$ & $-0.075^{* *}$ & $-0.071^{* *}$ \\
\hline 20 years and older & & $-0.133^{* * *}$ & $-0.132 * * *$ & $-0.128 * * *$ \\
\hline \multicolumn{5}{|l|}{ Subjective class affiliation (Worker) } \\
\hline Lower middle class & & -0.007 & -0.007 & -0.007 \\
\hline Middle class & & $-0.046^{* * *}$ & $-0.045^{* * *}$ & $-0.045^{* * *}$ \\
\hline Upper middle class & & $-0.064 * * *$ & $-0.064 * * *$ & $-0.064 * * *$ \\
\hline \multicolumn{5}{|l|}{$\begin{array}{l}\text { Employment status (Housewifel } \\
\text { househusband) }\end{array}$} \\
\hline Unemployed & & $0.032 * *$ & $0.032 * * *$ & $0.031 * * *$ \\
\hline Low-qualified worker & & $0.029 * * *$ & $0.028 * * *$ & $0.028 * * *$ \\
\hline Self-employed, lower middle class & & $0.031^{* *}$ & $0.031^{* *}$ & $0.030^{* *}$ \\
\hline Self-employed, middle class & & -0.016 & -0.015 & -0.015 \\
\hline Qualified administrative employee & & -0.009 & -0.009 & -0.009 \\
\hline Manager & & $-0.028 * *$ & $-0.027 * *$ & $-0.027 * *$ \\
\hline My voice counts: Country (yes) & & $0.120 * * *$ & $0.118^{* * *}$ & $0.117 * * *$ \\
\hline My voice counts: EU (yes) & & $0.059 * * *$ & $0.058 * * *$ & $0.058 * * *$ \\
\hline Europe: more divisive elements & & $0.195 * * *$ & $0.192 * * *$ & $0.191 * * *$ \\
\hline European identity attributes (none) & & $0.055^{* * *}$ & $0.054 * * *$ & $0.054 * * *$ \\
\hline Gender (male) & & -0.001 & -0.001 & -0.001 \\
\hline $\mathrm{Age}^{\mathrm{a})}$ & & -0.000 & -0.000 & -0.000 \\
\hline \multicolumn{5}{|l|}{ Regional context ${ }^{\mathrm{a}}$} \\
\hline Gross domestic product per capita & & & -0.015 & -0.015 \\
\hline Economic growth $(2008 / 2015)$ & & & $-0.021 * *$ & $-0.021 * *$ \\
\hline Unemployment rate $(\%)$ & & & -0.004 & -0.008 \\
\hline Per capita income & & & 0.021 & 0.015 \\
\hline \multicolumn{5}{|l|}{ Information about EU via: } \\
\hline TV & & & $0.011 *$ & 0.010 \\
\hline Press & & & 0.009 & 0.008 \\
\hline Internet & & & 0.005 & 0.004 \\
\hline $\begin{array}{l}\text { Attachment to country (none to very } \\
\text { strong) }\end{array}$ & & & 0.001 & -0.003 \\
\hline $\begin{array}{l}\text { Attachment to Europe (none to very } \\
\text { strong) }\end{array}$ & & & $-0.020 * * *$ & $-0.018 * * *$ \\
\hline \multicolumn{5}{|l|}{ National context ${ }^{\mathrm{a})}$} \\
\hline Votes for Eurosceptic parties (in \%) & & & & 0.017 \\
\hline Ideological polarisation & & & & $0.026^{*}$ \\
\hline Party heterogeneity & & & & 0.010 \\
\hline Government effectiveness & & & & -0.005 \\
\hline No. of observations & 16031 & 16031 & 16031 & 16031 \\
\hline No. of groups & 245 & 245 & 245 & 245 \\
\hline \multicolumn{5}{|l|}{ SD_cons } \\
\hline$\overline{\text { Country }}$ & 0.629 & 0.688 & 0.520 & 0.397 \\
\hline Region & 0.515 & 0.545 & 0.522 & 0.523 \\
\hline
\end{tabular}


Table 6.5 Continued

\begin{tabular}{lcccc}
\hline & Model 1 & Model 2 & Model 3 & Model 4 \\
\hline ICC & & & & \\
$\quad$ Country & 0.100 & 0.117 & 0.070 & 0.042 \\
$\quad$ Region/country & 0.167 & 0.190 & 0.142 & 0.116 \\
\hline
\end{tabular}

Source: Eurobarometer 86.1 (ZA6697).

Note: ${ }^{\text {a) }}$ Standardised variables, Significance levels: ${ }^{*} P<0.1$., ** $P<0.05$, *** $P<0.01$.

the likelihood of criticism is lower. The reverse applies to regions with declining economic output: regions that have had lower growth rates since the crisis year 2006 are more strongly against EU membership. It is not the low economic output as such, but the drop in output that seems to make the difference.

It is surprising, however, that high regional unemployment rates have a moderating effect on Euroscepticism and that, conversely, regions with a higher per capita income seem to promote Euroscepticism, even if the effects are not statistically significant. These findings suggest that it is not the absolute structural weakness of the region that inspires Euroscepticism, but a relative weakness. People living in regions with a higher average household income seem to have more reason to criticise membership in times of deteriorating economic performance, as their personal situation could also deteriorate. And a similar effect could be behind the negative effect of regional unemployment rates on Euroscepticism. It tends to be regions with lower unemployment rates that fuel people's concern that EU membership could increase the economic risks for the region and burden the regional labour market in times of economic downturns.

Media consumption contributes only slightly to Euroscepticism. The wider the use of various mass media within the regional population is, the greater the likelihood that respondents see their country's membership of the EU as a bad thing. Television, newspapers and the internet are not only the media most used by the regional population to learn about European affairs; they are also the media that encourage the likelihood of Eurosceptic attitudes. However, the effect is statistically significant only for TV consumption. Feelings of belonging also influence Eurosceptic attitudes at regional levels. However, it is only the feeling of belonging to the EU that matters; regions where this attachment is more prevalent are friendlier towards the EU.

The third model, finally, adds the national level predictors measuring the role of political and institutional contexts. Perceived governance effectiveness tends to reduce the probability of Eurosceptic attitudes, as was to be expected, but the effect is not statistically significant. The structure of the national party systems has a much stronger effect, even though the mere heterogeneity of issues promoted by parties does not necessarily nurture Euroscepticism significantly. It is the stronger polarisation of the party system along the left-right divide and the stronger representation of overtly anti-European parties that fuels criticism of EU membership, even though the latter is not statistically significant. The existence of political 
parties with Eurosceptic programmes and demands is important, but apparently, the ideological polarisation adds an important component to public opinion by fuelling more outspoken criticism of the EU. The introduction of these factors does not diminish the explanatory power of the individual and regional level factors, with the exception of the mass media, indicating that it is not necessarily the mass media itself, but the political parties influencing news coverage and public opinion.

The multilevel analysis suggests that there are cumulative effects of social vulnerabilities on EU-related attitudes. In fact, respondents in a vulnerable situation living in vulnerable regions seem to have a much higher probability of criticising their country's membership of the EU, while residents of economically prosperous regions living in privileged circumstances will more often positively value the membership. This assumption can be validated when comparing rates of Eurosceptics among occupational groups in regions with prospering and shrinking economies (i.e., the variable measuring GDP growth between 2008 and 2015 in the model) when grouped in deciles. Of the low-skilled workers living in the lowest decile - the recessive regions $-24.5 \%$ think that EU membership is a bad thing compared to $13.8 \%$ of those residing in the highest decile - the most prosperous regions with growth rates beyond $30 \%$. The share of critical executive employees in the weakest regions $(12.2 \%)$ is slightly below the latter group of critical workers and decreases further to $5.6 \%$ among those living in the most prosperous regions.

These descriptive findings do not control for the effect of the other variables included in the multilevel regression model (Table 6.5). If the predictive probabilities on the basis of this model are calculated, we still see the same cumulative effects of social vulnerability: low social status and weak economic performance in the regions augment Euroscepticism. Figure 6.11 summarises the findings for a selection of occupational groups.

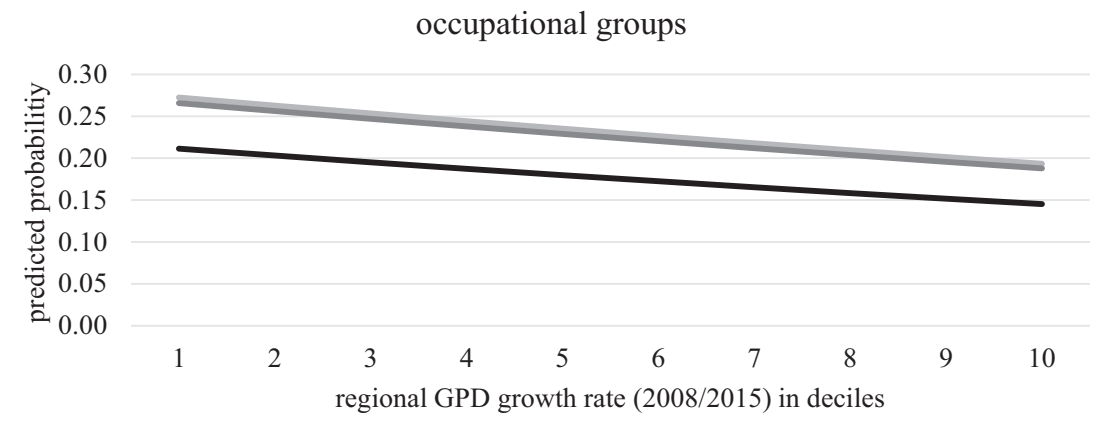

—managers, executive employees —unemployed low skilled workers

Figure 6.11 Cumulative effects of vulnerabilities on Euroscepticism (predictive probabilities). Source: Eurobarometer 86.1 (ZA6697). 
The likelihood of criticising EU membership is estimated to be $27 \%$ and $19 \%$ for low-skilled workers, depending on whether they live in the economically weakest or strongest regions, respectively, while the probability among executive employees in weak regions is only slightly higher (21\%) than the latter group of low-skilled workers, and decreases further to $14 \%$ for managers living in the most prosperous decile. The group of the unemployed respondents follows the same path of the low-skilled workers, as they have a stronger disposition to criticise the EU, even in the most prosperous regions. Among the jobless living in less favourable economic conditions, this EU-sceptic opinion is more widely diffused.

\section{Conclusion: political attitudes and the European social space}

The European Union has become a subject of political debate between supporters and opponents of the EU, right down to the level of the European population. Our analyses have shown that these disputes run along structures of social inequality, as people develop political attitudes towards the EU that reflect their position within the European social space. Low-skilled workers have everywhere a worse opinion about their country's membership of the EU than managers. These differences are even more pronounced when considering spatial disparities between and within countries. Managers living in prosperous regions (e.g., Bavaria, Bratislava or Dublin) have a substantially better opinion about EU membership than lowskilled workers from the worst-off regions (e.g., Greek Macedonia, Andalusia or Cyprus). It is, therefore, possible to speak of a cumulative effect of social divisions on Euroscepticism. The question of EU membership is a source of controversy between supporters and opponents, but this controversy is sparked by social relations between advantaged and disadvantaged population groups and advantaged and disadvantaged regions. The EU thus becomes an arena of political contentions in which social divisions shape political conflict lines and cleavages.

While the findings paint a clear picture, it is necessary to remind ourselves that these are only statistical probabilities. In no way does unemployment necessarily and automatically lead to Euroscepticism, belonging to the upper middle or upper classes does not necessarily imply support and even living in a prosperous region does not automatically go hand in hand with EU-friendly opinions. Political attitudes are individual and thus reflect an array of personal convictions, hopes and fears. However, the social situation of people does seem to define the position from which they look at political issues, events or actors and how they perceive and evaluate them. The EU offers them ample opportunity to do so because it has established a political field embracing different actors, positions and opinions, and this field enables people to locate themselves according to the social and political positions they hold.

In fact, the analyses have shown that people who see their country's membership of the EU as a good thing or a bad thing tend to live in different societal conditions. On the one side, Eurosceptics have been identified as a group of people who more often remain in socially disadvantaged situations and live in regions whose economies are stagnating or shrinking. Unemployment rates are 
not necessarily higher per se; it appears that unemployment seems to be perceived rather as a looming risk in times of economic downturn. The European economic and financial crisis seem to have had a significant impact on the overall mood. EU-friendly people, on the other side, are better placed in society. They live in stable conditions when considering class, income levels and educational capital and live in regions that emerged unscathed from the economic and financial crisis and may even have emerged from this crisis stronger.

However, this line of social division is not the only source of EU criticism. Euroscepticism is also nurtured by political divisions. On the one side, Eurosceptic citizens are those who assume that they are politically voiceless and ineffective and who emphasise what separates them in the EU; they also tend to regard EU membership as a losing deal. On the other side are the EU-friendly people who talk about their own political effectiveness, emphasise what is common within the EU and see advantages in membership. The conclusion that socially disadvantaged people from structurally weak regions regard the EU as a structural fight for distribution, which can only be avoided by terminating membership, is just as logical as the view of socially advantaged people from structurally strong regions who feel that the EU is based on common ground that brings advantages for their own country - and for all others.

The discontent, however, is also nurtured by political entrepreneurs within European member states. This argument has been discussed and empirically proven by political science research on Europe, as it was possible to show that political parties - and thus also the political disputes between rival parties - influence people's political opinions, judgements and demands. Eurosceptic opinions are more widespread in countries where anti-European parties have achieved decisive electoral success and are represented in parliaments (Hooghe and Marks 2005; Hutter and Grande 2014; Armingeon and Ceka 2014; Hong 2015; Stockemer and Barisione 2016; Treib 2020). Mass media contribute to the encouragement and mobilisation of discontent because they offer political actors a public stage on which to publicise their pro- or anti-European opinions and demands and they shape the public opinion about the EU through a certain type of reporting (Boomgaarden et al. 2013; Statham and Trenz 2013; de Vreese and Boomgaarden 2006; Maier and Rittberger 2008; Zschache 2016; Galpin and Trenz 2019; Adam et al. 2019).

Criticism of the EU, however, is attenuated by the fact that European citizens have broadened their viewpoints. They are not only able to assess living conditions in other European countries, their agreement across countries is also considerable and tends to hint at an implicit consensus. Apparently, Europeans have developed a sense of how it is to live in Europe, both in their own country and abroad. And this European map of living conditions provides them with a broader framework to assess the social and political life around them. The comparative analysis of nine countries has shown that this cognitive map of Europe increases the sensitivity to threats to the national economy in terms of crisis perceptions, it decreases the satisfaction with government performance and encourages a populist criticism of the political establishment. European citizens seem to hold 
national institutions accountable for the fact that their own living conditions are significantly below those standards common in other countries. It is remarkable, however, that the perceptions of spatial inequalities in living conditions nurture and, at the same time, support the EU. European citizens seem to believe that it is good to be in a political union with stronger countries, given that this upholds the promises of the common European project to strive towards more equal living conditions between all Europeans. 


\section{The political (dis) integration of Europe}

The European integration process has shaped the living conditions of the European population and has also influenced the way Europeans perceive and assess the social and political reality around them. Evidence presented in this book has shown that the nation state remains an important point of reference for people's political interests, identifications and ideas. However, this does not make Europe in any way irrelevant, as an empirical analysis in nine European countries has evidenced. On the one hand, it has shown that Europeans think in European dimensions. They have not only formed a more or less clear opinion about the EU but more importantly, have become accustomed to locating the social and political conditions in their immediate vicinity - and elsewhere - within a European frame of reference, evaluating them from this perspective. That is, they not only perceive and assess the EU from a national perspective, but they also perceive and assess their national governments from a European perspective. On the other hand, this study was particularly interested in assessing the relevance of social inequalities - both in terms of social stratification and spatial disparities - in nurturing political dissent in public opinion about national governments and the European Union. Also in this regard, the analyses showed that cross-national patterns of social inequalities across European countries affect people's political attitudes. In objective terms, social inequalities along stratification and spatial disparities (e.g., social class and interregional differences) translate into divergent attitudes towards national politics and the EU. In subjective terms, the perception of being worse off than other countries in terms of social living conditions encouraged a more sceptical opinion about the socio-economic situation in one's own country and the performance of national governments.

European integration thus leads to an amalgamation of perspectives. People perceive the European Union through a national lens, as various studies have testified (Anderson 1998; Muñoz et al. 2011; Armingeon and Ceka 2014; Guinjoan and Rico 2018; de Vries 2018). However, they also comprehend national politics through a European lens. This relational perspective can be clearly traced empirically and has implications for the European integration process, given that it sensitises for both integrating and disintegrating energies. In fact, Europe has become a common horizon of perception for the entire European population, meaning that 
social inequalities and divisional structures tend to translate into political lines of conflict within and across European member states.

\section{Horizontal Europeanisation of public opinions}

People's political thinking has indeed opened up and "Europeanised" across borders. The view is not only upwards to the European institutions in Brussels, Strasbourg or Luxembourg, but also sideways to the other member states. This broadening of the political horizon corresponds with what has been described in specialist literature as "horizontal Europeanisation" (Beck and Grande 2007; Mau 2009; Heidenreich 2019). In cognitive terms, this Europeanisation implies two things: it can be assumed that people perceive and evaluate political and social conditions in other countries and that they implicitly or explicitly use these realities as a yardstick or benchmark for assessing political facts, persons or institutions in their own country.

This broadening of the political horizon presupposes a cross-border, mass media communication and information flow because, without this, it would be more difficult for people to assess life in other countries and use appropriate comparisons in the formation of political opinions. The existence of such a cross-border communication space within the EU has been proven by numerous research projects (Pfetsch et al. 2006; Lahusen 2009; Statham and Trenz 2013; Zschache 2016; Eisele 2017; Segesten and Bossetta 2019). The evaluations in the course of this study have also confirmed these findings, although the focus was even more on the question of whether public debates in the mass media are indeed horizontally open and interrelated between the individual member states. The analysis of media coverage of the European financial and economic crisis between 2006 and 2014 has shown that such an opening did indeed occur for the nine countries surveyed (Germany, France, Greece, the UK, Italy, Poland, Sweden, Switzerland and Spain). Not only did EU institutions have their say in the national newspapers and were addressed by national actors, on a horizontal level, it was also possible to see that actors from other countries had their say in the reporting of the member states examined and that domestic actors also referred to the political and social conditions in other countries.

These European elements do not necessarily diminish the role of the nation state. Public debates are tightly linked to a national frame of reference when looking at the topics discussed, the persons quoted and the actors addressed. Although we are dealing with a global or European economic and financial crisis, it has mostly been discussed in its national forms and implications. Discussions focused on company closures and short-time work, unemployment and wage reductions, public debt and savings in public spending and social benefits at home. Only one in ten comments raised the crisis issue in its European dimension, and just as many spoke of its global dimensions. These cases mostly concerned macro-economic, monetary and fiscal issues. European actors were mainly involved in the public debates in Greece and Germany. Such comments were rarer in other countries. Finally, it should be noted that the vertical penetration of public debates was more 
pronounced than the horizontal one, as the EU institutions and their staff appeared three times more frequently than actors from other member states. At just under $2 \%$, this share was very low. These findings show that even international developments, such as the global and European crisis, are processed and communicated along national relevance structures (Kutter and Jessop 2015; Zamponi and Bosi 2016; Sommer et al. 2016; Monza and Anduiza 2016). This pertains to language areas and nationally patterned mass media systems. Additionally, mass media reporting is clearly geared towards social elites because it favours statements by governments, parties or associations (Bennett 1990; Boomgaarden et al. 2013; Skogerbo et al. 2016). This practice creates a dominant national focus, as political elites are also bound to a national electorate or membership base. As a consequence, they primarily address national agendas, action plans or responsibilities.

However, these findings by no means imply that national debates are not interspersed with or open to European aspects. After all, within a sample of 9000 claims covered in national newspaper in the nine countries understudy, every tenth statement contained European references (topics, actors, addressees), which meant that these explicitly European debates kept moving over time. More importantly, the national discourses were interconnected across borders; national actors talked about European issues, and European actors spoke on national issues. In one-third of these cases, national actors addressed European or global issues, just as global and European actors talked about national issues or addressed their European and global dimensions.

The public debates about the crisis thus reveal that one should not speak of an integrated public media but transnationally interwoven discourses. This horizontal element has to do with the importance of political or economic elites within the mass media as well. The latter addressed national audiences and thus were inclined to frame the (global or European) issues in national categories. However, they were also actively involved in cross-national negotiations and debates on the European economic, monetary and financial crisis. This did not leave national debates untouched. It is particularly surprising that the discussions in the national media were dominated by similar topics and groups of actors. There was certainly disagreement between the government and the opposition, business representatives, trade unions, institutes and non-governmental organisations on individual issues and measures. However, the vast majority of public statements supported the opinion that the reforms agreed at the EU level to contain the crisis were right and important. The voices of those who wished for a fundamental departure from the agreed austerity policy and also addressed similar topics and arguments were barely audible in the overall discourse. There was thus a dominant discourse - and a marginalised counter-discourse - that spread across borders and streamlined the debates in the respective countries. For the most part, both discourses were equally timed.

These empirical findings show that the European Union has become a publicly relevant arena for political deliberation and decision-making. National and European actors are part of a common political field, meaning that they observe the positions of other actors and react to them. This relational positioning was 
evident in our newspaper data. The strict austerity policy stance of the German government, which was supported by the majority of representatives of German banks and entrepreneurs, trade associations and research institutes, is difficult to understand unless it is put in relation to Greek demands for greater flexibility in growth policy programmes (e.g., government investment or demand-oriented tariff or social policy), which were also supported in other countries (especially Italy and France).

This evidence raises questions about the integrating and disintegrating consequences of these interlocked public debates. On the one hand, it can be seen that the European Union has, to some extent, interlinked and integrated the debates conducted by the mass media. The EU has established a political field that involves political and economic elites from the member states in common discourses, and these debates reveal a surprising consensus on the correct diagnosis of the problem and the appropriate solutions. Additionally, political contentions are not necessarily a disintegrative force per se, given that political conflicts have been an important incentive and instrument for defining and constructing the European Union throughout its history (Eder 2004; Trenz 2008; Vobruba 2012). The flipside, however, is that public debates are subject to a growing political contentiousness that also has disintegrative tendencies. Even if public debates are horizontally interrelated, (published) public opinion still has a primarily national audience in mind. National actors raising their voice in the media do know about each other and speak to each other, but ultimately, they discuss problems, needs, interests and demands primarily within a national framework. This only partially integrated European public sphere carries risks because national actors talk less to each other than about each other (Mylonas 2012; Papathanassopoulos 2015; Caiani and Guerra 2017; Adam et al. 2019). Even if they agree on the perception and assessment of the economic and financial crises, public debates seem to be guided by the discomfort that the actor's host country is not receiving its fair share.

\section{Public dissent about national politics in an integrated social space}

The perceptions and opinions of European citizens impressively reflect this national segmentation of Europe. Europe remains nationally segmented, not only because its political attitudes are strongly linked to the nation state, but also to social inequalities, which take centre place in this study. Living standards not only diverge between countries when taking macro-economic indicators into account (e.g., the economic performance in GDP, household income, material deprivations). People also recognise that the social conditions in this common Europe diverge very strongly along national borders. However, these perceptions are also possible because Europe has become a mental map that allows people to distinguish between good and bad living conditions. Above all, it offers them a grid for assessing the conditions in their own country in light of this map. 
The previous chapters validate this proposition because they show that European citizens in the nine countries under analysis had no great difficulty in assessing living conditions in other European countries. People seem to be as familiar with living conditions elsewhere as they are with those in their own country. These assessments are undoubtedly abstract, as respondents were asked to assess living conditions in a number of countries on an 11-point scale, from very poor to very good living conditions. It is likely that respondents used approximations of national averages as a basis for their assessment. The willingness with which people answered these questions, however, shows that they do not find such abstractions absurd. It also reveals that people use countries as relevant reference groups to perceive and evaluate themselves and their environment. This had already been confirmed by earlier research studies (Kapteyn et al. 1978; Frey and Stutzer 2000; Böhnke 2008). In this context, it could be shown that the comparison with other countries also has concrete consequences because it influences people's degree of satisfaction with their lives and their environment (Delhey et al. 2002; Delhey and Dragolov 2014; Lahusen and Kiess 2019).

People's political thinking is influenced by these comparisons. Respondents have no difficulty in assessing the living conditions of other member states, but it was particularly surprising that their assessments were largely consistent across national borders. This suggests that the European population shares a mental map of living conditions in Europe, and thus also common ideas about what should be considered good or bad living conditions. It has also been shown that these assessments have political consequences because people often tend to see their country in a serious crisis when they perceive living conditions in other countries to be much better than their own. The same applies to satisfaction with one's government. The proximity to populist attitudes and criticism of the political elite and the political establishment is also similarly related to the comparison of living conditions in Europe. In this respect, our findings confirm the assumption of the theories of relative deprivation (Runciman 1966; Olson, Herman and Zanna 1986; Merton and Kitt 1950), above all with regard to the frequently confirmed influence of a perceived disadvantage on political attitudes such as populism (Elchardus and Spruyt 2016; Decker, Kiess and Brähler 2016). Deprivation also has an effect on the motivation to protest (Dubé and Guimond 1986; Rucht 1994), as our own evaluations with regard to the fundamental willingness to participate in street protests have shown. Only political action itself does not seem to be directly affected by this mental map because people who took part in street protests were not characterised by more pronounced feelings of social disadvantage. This conforms to research findings that testify that feelings of relative deprivation do not translate directly into protest but require resources, opportunities and motivations (Bernburg 2015; Grasso and Giugni 2016).

These findings sensitise us to the integrative and disintegrative tendencies that are inherent to this mental map of Europe. On the one hand, our results show that the European population as a whole has internalised congruent assessments of living conditions in European countries and thus seems to base what can be considered a good or bad life on similar parameters. From a cognitive point of 
view, the EU seems to have come very close to its core objective of unifying and communitising Europe because people have adopted the EU's objective that the European project should achieve equal living conditions throughout Europe. Our evaluations do at least show that political dissatisfaction is reduced when people perceive equality among living conditions, while the perception of social disadvantage increases criticism of political conditions. The associations are logical when taking into account the fact that the integration process is intended to reduce socio-economic differences between people and population groups, countries and regions and expand social cohesion (EU Commission 2008; 2009; Council of Europe 2004; 2010). This objective requires a constant comparison of the living conditions of countries and people, which is why the EU has launched a whole series of measures (e.g., the Open Method of Coordination or the European Semester of the Europe 2020 Strategy) that provide data and procedures (Hodson and Maher 2001; Heidenreich and Zeitlin 2009; Jessoula 2015; Copeland and Daly 2018). In this respect, people seem to have internalised the goals and selfimage of the European integration project and taken them seriously.

It is precisely this common evaluation horizon that also unfolds disintegrating forces, as it sets in motion a programmatic comparison of living conditions and thus necessarily also identifies the winners and losers of the integration process. This already applies to the crisis sensitivity of the European population because it appears that the interpretation of a given situation as a crisis refers back to comparisons; it takes root where people feel left behind compared to other countries. The same applies to political dissatisfaction because it also requires people to regard their government as more incompetent than the political leaders of other countries. Finally, the mental map of Europe also seems to have contributed to the dissemination of populist beliefs because the EU offers people a matrix for locating their personal situation in a European social space that is perceived by people as eminently unequal. The subjective perception of social inequalities and lines of division seems to encourage concerns about social decline, and these concerns are particularly significant for people in insecure or precarious living conditions. The fact that people live in times of crisis and that they are not satisfied with the government and the establishment has to do with the fact that people see themselves and their country as socially and politically left behind. This view can under populist auspices - promote the belief of distributional conflict, according to which the conditions in one's country are curtailed by those of other countries. In this respect, the mental map of the European social space contains dynamite for political life. After all, it must be considered that populist beliefs have become a pan-European phenomenon, paving the way for parties and groups in all member states to enter parliaments (Taggart 1995; 2004; Mudde 2004; Kriesi et al. 2006; Kriesi and Pappas 2015; Kneuer 2019).

\section{Social divisions in Europe - political dissent about Europe}

Opinions on the European Union are divided. In addition to the strong supporters and opponents of the EU, one in three believes that their country's membership 
of the EU is neither good nor bad. Generally, however, political developments seem to drive the population towards a clear position. This politicisation of the EU has been a trend for several years (Hooghe and Marks 2009; de Wilde and Zürn 2012; Kriesi 2016b) but public controversies have increased in scope and severity since 2008 in the wake of the economic and financial crisis and the waves of political mobilisation and protest directed against the austerity policies of the EU and its governments (Schmalz and Weinmann 2016; Kousis 2014; della Porta and Mattoni 2014; Kouki and Fernandez 2018; Kriesi 2016a). Before this backdrop, we seem to witness the emergence of a new political cleavage that runs across all member states (Kriesi et al. 2006; Kriesi 2016b; Hooghe and Marks 2018; Zeitlin et al. 2019; Kneuer 2019; Treib 2020).

Given this growing contentiousness, it is hardly surprising that people differ as to whether the EU is a good or bad thing. These conflicts are not unrelated to social inequalities, as the previous chapters have highlighted (Kuhn et al. 2016; Simpson 2019; Lauterbach and de Vries 2020). The political dissent about the EU runs along the social divide between disadvantaged and privileged population groups, regions and countries. The European Union has given the living space of the European population a common political constitution and outline that provides people with a political reference point for their demands, desires and fears. Social inequalities and divisional structures, which may only be of statistical significance within the European social space, are thus transferred into a European field of politics and translated into political lines of conflict.

The verdict that people have reached about the EU seems to depend on the concrete position of people in the social space of Europe. This realisation is not surprising from a sociological point of view because the social sciences fundamentally assume that people's political thinking and actions are shaped by society. People form their political attitudes and opinions from the position they occupy within the social fabric, and this position is determined by two dimensions of inequality. Firstly, the social situation is defined by the position of the individual within the hierarchically structured social space along the social classes and strata. Secondly, the European social space also has a horizontal territorial component because the place of residence and the affiliation of people to a country and/or a region also determine people's living conditions and opportunities. Both assumptions could be validated in regard to a sample of eight European countries (Denmark, France, Germany, Greece, Italy, Poland, Switzerland, United Kingdom), and were confirmed for the EU's 28 member states on the basis of Eurobarometer data.

With regard to the horizontal axis, in the previous chapters, it was possible to demonstrate that the opinion climate differs considerably between member states, but also between regions, because living conditions diverge considerably within countries, just as rates of Eurosceptic citizens do. In fact, EU-related attitudes are shaped by social and political factors located at the regional and national levels alike. Europe-friendly regions stand opposite regions that are sceptical of Europe. Factors affecting the general climate of opinion include the experience of an economic recession in the wake of the economic and financial crisis in 2008 and beyond. The mass media also have an influence on this polarisation because 
Euroscepticism is more widespread in regions where more people use mass media to inform themselves about European affairs. This may be due to reporting that is fundamentally critical of Europe (Mylonas 2012; Papathanassopoulos 2015; Caiani and Guerra 2017; Adam et al. 2019). However, media reporting may play a role simply because it informs people about social and political conditions in other member states. The media, therefore, offer a matrix for the comparative perception and evaluation of living conditions within Europe and thus also for the development of feelings of social disadvantage or deprivation. At the national level, the ideological polarisation of the party system and the mobilising power of populist parties also play a notable role in shaping EU-related attitudes. In fact, polarised party systems and higher electoral success of anti-European sentiment parties tend to encourage EU-sceptic opinions within the public sphere.

People's political attitudes towards the EU, however, not only vary between countries and regions. From a vertical point of view, hierarchical structures between social strata remain highly relevant for the shaping of Eurosceptic or Eurofriendly attitudes. What is particularly interesting is that these hierarchical structures are relevant across national borders. Similar living conditions lead to similar political preferences throughout Europe, which is why the divisional structures of the social space also feed lines of conflict within the political field. This is a strong indication that, objectively speaking, people live in a common social space because the concrete social position they occupy within this social area also seems to shape political positions in the EU field. Everywhere, the socially privileged are more often of the opinion that membership of the EU benefits the country and that concept unites the people of Europe more than it divides them. And everywhere, it is the socially disadvantaged who are far less often able to recognise these advantages and highlight what divides rather than what unites. People thus hold the EU jointly responsible for the societal conditions in which they live.

The territorial component and social stratification both have an effect on EU-related attitudes; both divisive structures are intertwined. This seems to contribute to a differentiation of the Eurofriendly and Eurosceptic opinion camps. On the one hand, it is possible to show that vertical and horizontal structures seem to have a mediating effect on each other. The socially privileged, who normally turn more towards the EU, tend to be much more Eurosceptic when they live in regions sceptical of Europe. By contrast, in regions with a Eurofriendly climate of opinion, the socially disadvantaged are much more likely to support their country's membership of the EU, even if they tend to be Eurosceptics in general. An intervening context effect can, therefore, be assumed. The socio-economic and political conditions in the region and the country influence people's attitudes towards the EU (Kuhn and Stoeckel 2014; Braun and Tausenpfund 2014; van Erkel and van der Meer 2016) without necessarily changing the relationship between the strata. One can speak of an elevator effect because Euroscepticism fluctuates greatly in the regions but varies everywhere between better-off and worse-off people.

These findings, however, need to be qualified in regard to one factor at the centre of this study: the perception of social inequalities in other European 
countries. European citizens living in vulnerable conditions might be more critical of national governments and the EU. And the perception that other Europeans are more fortunate in their living standards might increase their dissatisfaction with national politics. But the perceptions that living conditions are much better in other EU member states when compared with their own household situation encourages citizens to support their country's membership of the EU. These perceptions even attenuate Euroscepticism among those groups of the population that exhibit higher rates of criticism of the EU and would prefer to leave the union if asked in a referendum. These findings corroborate that European citizens have developed a common understanding and norm of comparable living conditions. This norm of equality seems to guide their political assessments because they judge politics in their ability to conform to it. The perception that social reality deviates from this norm when comparing living standards in Europe seems to feed discontent with national politics. That is, European citizens make their national governments accountable for the fact that their living standards are below this European norm. The same perception, however, seems to reassure Europeans in their conviction to remain within the EU, given that they share membership with stronger countries. Better living conditions abroad seem to uphold the promises of the common European project in its aim to secure equal living conditions among all Europeans.

\section{Europe as a political field}

The political thinking of the European people bears a clear European signature. However, as our empirical analyses have repeatedly shown, this cognitive Europeanisation is not at the expense of the national element. Research to date has impressively documented this fact; because people are much more interested in national politics, they identify more strongly with the nation state, and they also participate much more regularly in national elections. The European Union places second politically in many respects (Reiff and Schmitt 1980; Hix and Marsh 2007; Hobolt and Wittrock 2011; Boomgaarden et al. 2016). Moreover, people assess the EU and their country's membership from the perspective of their immediate reality and national affiliation, using national polities and politics as a proxy, a yardstick or a benchmark to assess the EU, as this relational element has previously been termed (Anderson 1998; Kritzinger 2003; Muñoz et al. 2011; Desmet et al. 2012; Armingeon and Ceka 2014; de Vries 2018). In addition, European citizens might have formed an opinion on living conditions throughout Europe as a second yardstick or benchmark for assessing national and European politics. However, these assessments and comparisons ultimately run along national categories. This is not surprising, as people live in societies with very different levels of prosperity and clearly divergent social welfare standards. After all, the nation state is still the primary point of reference for political deliberation, decisionmaking and democratic participation.

In spite of these observations corroborating the ongoing importance of the nation state, research has moved beyond a purely national framework of analysis. 
Political science studies have taken this fact into account when calling the political entity a vertical multilevel system (Marks et al. 1996; Bache and Flinders 2004) that consists of a variety of political arenas at the same time (municipal, regional-federal, nation state and supranational European arenas). These arenas are assigned different political responsibilities, but as they mutually refer to each other, highly complex and interwoven processes of political deliberation and decision-making develop (Scharpf 1997; Kohler-Koch 2003; 2005; Zürn and Joerges 2005). This reference to the multilevel structure makes sense from the perspective of political systems, as it is a matter of distinguishing institutionalised arenas of politics (bodies, procedures and staff). For a sociological research agenda that is not only interested in the institutional constitution of politics but also takes the social constitution of everyday life into account, a field-theoretical concept is able to contribute additional insights into the horizontal element of the European social space and the Europeanised field of politics. As shown in the conceptual chapter (Chapter 2) of this study, politics is to be understood as a political field of interrelated forces in which actors vie for political opinions and decisions. The EU has extended the political field to a pan-European area (Georgakakis and Weisbein 2010; Cohen 2011; Kauppi and Madsen 2013) insofar as it has acquired competence and thus made political issues the subject of joint decision-making. Political actors in the respective member states have to reckon with other member states and EU bodies (Commission, Council of Ministers or EU courts, for example) in various areas of regulation, and often use the pronouncements or decisions of these bodies to hone their own positions and/or to push forward their own projects - with or against the EU.

In regard to our study, the EU has proved to be a very powerful force in communitising political disputes. This applies to negotiations and conflicts between the governments of the member states but also representatives of social interest groups and associations. This political communitarisation seems to be very effective on a cognitive level, as public policy analyses have impressively shown (Hodson and Maher 2001; Knill and Lehmkuhl 2002; Radaelli 2003; Checkel 2007; Favell and Guiraudon 2011). Such cognitive communitarisation has also been demonstrated in the analysis of mass media debates (Pfetsch et al. 2006; Lahusen 2009; Trenz 2016) because the EU seems to be able to successfully occupy issues and put them on the agenda of the mass media of all member states. But this process also affects people's political opinions. Citizens have internalised Europe and the EU as a common frame of reference and orientation for their thinking, which is why they perceive and evaluate society and politics in a European way. People observe and judge social living conditions on a Europe-wide scale, which also means that they perceive Europe as a social area with different living standards, and thus as a hierarchical order of advantage or disadvantage. They also observe and assess political conditions on a Europe-wide scale. On the one hand, people judge the EU from the specific situation of their country and from the perspective of their personal living conditions, but on the other hand, they also judge politics in their country from the perspective of the European social space with its unequal living conditions. The national and the European elements cannot be considered as 
separate entities (system, institutions), but must be seen as elements of a common political field with European contours and national segmentation.

\section{A fundamental directional decision?}

Following this line of argument, Europeans may not be so concerned about the right balance between the EU and their nation state and shift or relocation of competences to the EU or the member states. The findings presented in this study suggest that Europeans have internalised a normative idea of equal living conditions within Europe, which they use as a yardstick to assess national politics and the EU. If the reality differs from this normative standard of comparable living standards, dissatisfaction with national and European politics is voiced. Both sides seem to be in the same boat. While national governments are more strongly held accountable for a lack of performance, European citizens seem to regard both sides as political actors who share responsibility for the unfulfilled promise of the European integration project (EU Commission 2009; Council of Europe 2010).

The fact that Europeans have internalised these normative ideas of equivalence or equality has been corroborated by many studies. It has been pointed out that the majority of people in European countries believe that all Europeans should have equal rights, for example, with regard to access to the national labour market and associated social rights (Gerhards and Lengfeld 2013; 2015). This belief is closely linked to implicit norms of distributive justice because the European population has repeatedly subscribed related demands when asked in surveys. This applies, for example, to income inequalities, since a large majority of people in European countries argue that it is important to reduce these, not only within European countries but also among them (Kaltenthaler, Ceccoli and Gelleny 2008; Lahusen and Grasso 2018; Gerhards et al. 2019). Recent survey data also show that the majority of the population in a number of countries are convinced that the member states should be committed to mutual assistance in times of crisis. This concerns financial transfers or aid measures (fiscal solidarity) between governments, but respondents would also welcome European social protection and redistribution programmes (Gerhards, Lengfeld and Häuberer 2016; Baute, Meulemann and Abts 2018; Gerhards et al. 2019). In this sense, normative ideas of equality translate into demands for solidarity among Europeans. This solidarity is not categorical because redistribution is often conditional on the target group, the specific needs and the target group's perceived behaviour or attitude. Moreover, the support of solidarity is unevenly distributed among the European population, as in this respect, too, approval depends on the social situation, collective identities and political allegiances (Mau 2005; Baute et al. 2019; Kuhn, Nicoli and Vandenbroucke 2020; Lahusen 2020). But the general orientation is quite clear, given that equality and solidarity are widely shared norms.

The European population thus seems to agree that more equality is a political goal to work towards. The problem, however, is that they have different views on how to deal with existing disparities and inequalities. It is precisely this common cognitive frame of reference, which encourages people to think and evaluate 
social situations and political conditions in pan-European categories, that seems to nurture a pan-European line of conflict that is tightly interrelated with social divisions. The empirical evidence presented in this study shows, for example, that socially better-off people assume that their voices will be heard, that they are satisfied with the national government and that they express less criticism of their country's political establishment and membership of the EU. Evidently, these people do not worry that they or their country could be socially left behind and that they or their country are being politically ignored within the EU. From their perspective, they perceive the positive effects of the European integration process for themselves and their country. The feeling that there are no fundamental distribution conflicts in the EU then also prevails. When there are disputes over political goals and the distribution of scarce resources, these people assume that these disputes can be resolved because they are firmly convinced that the dividing factor within the EU is far less decisive than the uniting factor.

The social disadvantage seems to nurture the opposite view, and this view is driven by the conviction that social and political life is shaped above all by antagonistic struggles for distribution. As the findings have shown, Euroscepticism, dissatisfaction with one's government and criticism of the political establishment come together to form an opinion that assumes that politics does not listen to the interests of the disadvantaged. This complaint is thus directed not only at the EU but primarily at national policymakers who are held politically responsible for these issues. This overall assessment reflects a social situation characterised by multiple disadvantages and thus produces a view of social reality based on a consistently unequal distribution of goods, resources and opportunities. As far as Europe is concerned, this disenchanted view resides in feelings of social vulnerability and political marginalisation and assumes that there are no gifts to be had from the EU. In accordance with this viewpoint, there is a fundamental conflict over the distribution of scarce resources, which is why the profits of individual countries and regions mean losses for other member states. From this perspective, belief in a European Union seems to be farcical because what is common between people, regions and countries is clearly eclipsed by what divides them. Against this background, cancelling the country's membership seems to be the only option.

These conflicting views place the social question on the EU and its member states' agenda. After all, the future of the European project seems to depend very much on the resolution of social divisions and complementary political lines of conflict. The social issue has also become an urgent problem because the EU itself has promised to work for the improvement and harmonisation of social prosperity and thus to achieve comparable living conditions between people and countries. People evidently take this promise seriously and have accepted it as a yardstick for assessing social and political conditions in Europe.

In principle, this conflict between ambition and reality could be resolved by the EU withdrawing from this promise. Following the results of our analysis, Eurosceptics assume that this promise is not the best in times of economic, political and social crises, tough interest policy and interstate conflicts and that this 
claim has degenerated into mere lip service. However, it will not be so easy to banish the expectations and requirements of a fair and just Europe from people's minds. For this reason, the EU seems to have no choice but to find an answer to the social question. Member states and EU institutions must make a more concerted effort to meet the public desire for equal opportunities and comparable living conditions for all Europeans. The way to achieve this goal is not mapped out and requires political decision-making. In principle, however, two alternatives seem conceivable. First, the established responsibilities could be maintained, which is why the national welfare state would remain responsible for combating social divisions and ensuring social redistribution, social cohesion and justice. The homework to be done would thus be primarily national. Supplementary measures at the EU, however, would be necessary in order to assist and/or encourage member states in harmonising the employment situation and the social security standards in their countries. Second, a stronger communitarisation of inequalityrelevant policy areas could be a possible option, albeit not very likely politically. Agreement on more ambitious instruments of a European social union would have to be reached between the member states. They could include minimum requirements for national employment and social policies, the promotion of collective bargaining and social partnership agreements and solidarity-based redistribution measures between countries and European social security programmes. All in all, the EU institutions and the governments of the member states must recognise that the future of the European integration process depends on the responses they provide to the existing social inequalities and divisions within Europe. Ultimately, people will judge the policies of the EU and its member states based on the relevance of the fruit of their labour. 



\section{References}

Adam, Silke, Beatrice Eugster, Eva Antl-Wittenberg, Rachid Azrout, Judith Möller, Claes de Vreese, Michaela Maier and Sylvia Kritzinger (2019). "News Media's PositionTaking Regarding the European Union: The Synchronization of Mass Media's Reporting and Commentating in the 2014 European Parliament Elections." Journal of European Public Policy, 26(1): 44-62.

Akkerman, Agnes, Cas Mudde and Andrej Zaslove (2014). "How Populist Are the People? Measuring Populist Attitudes in Voters." Comparative Political Studies, 47(9): 1324-1353.

Amnå, Erik and Joakim Ekman (2014). "Standby Citizens: Diverse Faces of Political Passivity." European Political Science Review, 6(2): 261-281.

Anderson, Benedict (1991). Imagined Communities: Reflections on the Origin and Spread of Nationalism, rev. and ext. edition. London: Verso.

Anderson, Christopher J. (1998). "When in Doubt, Use Proxies: Attitudes Toward Domestic Politics and Support for European Integration." Comparative political studies, 31(5): 569-601.

Andronikidou, Aikaterini and Iosif Kovras (2012). "Cultures of Rioting and Anti-Systemic Politics in Southern Europe.” West European Politics, 35(4): 707-725.

Archer, Margaret (1996). "Social Integration and System Integration: Developing the Distinction.” Sociology, 30(4): 679-699.

Ares, Macarena, Besir Ceka and Hanspeter Kriesi (2017). "Diffuse Support for the European Union: Spillover Effects of the Politicization of the European Integration Process at the Domestic Level." Journal of European Public Policy, 24(8): 1091-1115.

Armingeon, Klaus and Besir Ceka (2014). "The Loss of Trust in the European Union during the Great Recession Since 2007: The Role of Heuristics from the National Political System." European Union Politics, 15(1): 82-107.

Armingeon, Klaus and Kai Guthmann (2014). "Democracy in Crisis? The Declining Support for National Democracy in European Countries, 2007-2011." European Journal of Political Research, 53(3): 423-442.

Aslanidis, Paris (2016). "Populist Social Movements of the Great Recession.” Mobilization, 21(3): 301-321.

Atkinson, Anthony B. and Andrea Brandolini (2013). "On the Identification of the 'Middle Class'.” In: Janet C. Gornick and Markus Jantti (eds.), Income Inequality: Economic Disparities and the Middle Class in Affluent Countries (pp. 77-100). Stanford, CA: Stanford University Press.

Augenstein, Daniel (ed.) (2012). 'Integration through Law' Revisited: The Making of the European Polity. Farnham: Ashgate. 
Bach, Maurizio (2006). "The Enlargement Crisis of the European Union: From Political Integration to Social Disintegration?" In: Maurizio Bach, Christian Lahusen and Georg Vobruba (eds.), Europe in Motion. Social Dynamics and Political Institutions in an Enlarging Europe (pp. 11-28). Berlin: Edition Sigma.

Bache, Ian and Matthew Flinders (eds.) (2004). Multi-Level Governance. Oxford: Oxford University Press.

Balme, Richard and Didier Chabanet (2008). European Governance and Democracy. Power and Protest in the EU. Lanham, MD: Rowman \& Littlefield.

Barbieri, Paolo and Giorgio Cutuli (2016). "Employment Protection Legislation, Labour Market Dualism, and Inequality in Europe." European Sociological Review, 32: 501-516.

Baumgarten, Britta (2017). "Back to Solidarity-Based Living? The Economic Crisis and the Development of Alternative Projects in Portugal." Partecipazione e Conflitto, 10(1): 169-192.

Baute, Sharon, Koen Abts and Bart Meuleman (2019). "Public Support for European Solidarity: Between Euroscepticism and EU Agenda Preferences?" Journal of Common Market Studies, 57(3): 533-550.

Baute, Sharon, Bart Meuleman and Koen Abts (2018). "Welfare State Attitudes and Support for Social Europe: Spillover or Obstacle?” Journal of Social Policy, 48(1): 1-19.

Beck, Ulrich (2000). "The Cosmopolitan Perspective: Sociology of the Second Age of Modernity." British Journal of Sociology, 51(1): 79-105.

Beck, Ulrich (2003). "Understanding the Real Europe.” Dissent, 50(3): 32-38.

Beck, Ulrich and Elisabeth Beck-Gernsheim (2002). Individualizaton. Institutionalized Individualism and its Social and Political Consequences. London: Sage.

Beck, Ulrich, Anthony Giddens and Scott Lash (1994). Reflexive Modernization. Politics, Tradition and Aesthetics in the Modern Social Order. Stanford, CA: Stanford University Press.

Beck, Ulrich and Edgar Grande (2007). Cosmopolitan Europe. Cambridge, MA: Polity.

Beckfield, Jason (2006). "European Integration and Income Inequality." American Sociological Review, 71: 964-985.

Bennett, Lance W. (1990). "Toward a Theory of Press-State Relations in the United States." Journal of Communication, 40(2): 103-125.

Berezin, Mabel and Juan Díez-Medrano (2008). "Distance Matters: Place, Political Legitimacy and Popular Support for European Integration." Comparative European Politics, 6(1): 1-32.

Berezin, Mabel and Martin Schain (eds.) (2003). Europe without Borders: Remapping Territory, Citizenship, and Identity in a Transnational Age. Baltimore, MD: Johns Hopkins University Press.

Bernburg, Jón Gunnar (2015). "Economic Crisis and Popular Protest in Iceland, January 2009: The Role of Perceived Economic Loss and Political Attitudes in Protest Participation and Support." Mobilization, 20(2): 231-252.

Bertelson, Judy (1974). "Political Interest, Influence, and Efficacy: Differences Between the Sexes, and Among Marital Status Groups." American Politics Research, 2(4): 412-426.

Bijsmans, Patrick and Christina Altides (2007). “'Bridging the Gap' between EU Politics and Citizens? The European Commission, National Media and EU Affairs in the Public Sphere." Journal of European Integration, 29(3): 323-340.

Bislev, Sven, Dorte Salskov-Iversen and Hans Krause Hansen (2002). "The Global Diffusion of Managerialism: Transnational Discourse Communities at Work." Global Society, 16(2): 199-212. 
Böhnke, Petra (2008). "Does Society Matter? Life Satisfaction in the Enlarged Europe." Social Indicators Research, 87(2): 189-210.

Bohmann, Gerda and Georg Vobruba (1992). "Crisis and their Interpretations. The World Economic Crises of 1929ff. and 1974ff. in Austria." Crime, Law and Social Change, 17(2): 145-163.

Boomgarden, Hajo G. and André Freire (2009). "Religion and Euroscepticism: Direct, indirect or no effects?" West European Politics, 32(6): 1240-1265.

Boomgaarden, Hajo G., David Johann and Sylvia Kritzinger (2016). "Voting at National versus European Elections: An Individual Level Test of the Second Order Paradigm for the 2014 European Parliament Elections." Politics and Governance, 4(1): 130-144.

Boomgaarden, Hajo G., Andreas R. T. Schuck, Matthijs Elenbaas and Claes H. de Vreese (2011). "Mapping EU Attitudes: Conceptual and Empirical Dimensions of Euroscepticism and EU Support." European Union Politics, 12(2): 241-266.

Boomgaarden, Hajo G., Claes H. De Vreese, Andreas R. T. Schuck, Rachid Azrout, Matthijs Elenbaas, Joost H. P. Van Spanje and Rens Vliegenthart (2013). “Across Time and Space: Explaining Variation in News Coverage of the European Union." European Journal of Political Research, 52(5): 608-629.

Börzel, Tanja A. (1999). "Towards Convergence in Europe? Institutional Adaptation to Europeanization in Germany and Spain." Journal of Common Market Studies, 37: 573-596.

Bourdieu, Pierre (1979). "Public Opinion Does Not Exist." In: A. Mattelart and S. Siegelaub (eds.), Communication and Class Struggle (pp. 124-130). New York, NY: International General.

Bourdieu, Pierre (1985). "The Social Space and the Genesis of Groups." Theory and Society, 14(6): 723-744.

Bourdieu, Pierre (1987). "The Force of Law: Toward a Sociology of the Juridical Field." Hastings Law Journal, 38(5): 814-853.

Bourdieu, Pierre (1988). Intérêt et désintéressement. Cours du Collège de France à la Faculté d'Anthropologie et de Sociologie de l'Université Lumière Lyon 2, les ler et 8 décembre 1988. Lyon: Cahiers de Recherche $n^{\circ} 7$.

Bourdieu, Pierre (1990). The Logic of Practice. Stanford, CA: Stanford University Press.

Bourdieu, Pierre (1991). Language and Symbolic Power. Cambridge, MA: Harvard University Press.

Bourdieu, Pierre (1996). The State Nobility: Elite Schools in the Field of Power. Stanford, CA: Stanford University Press.

Bourdieu, Pierre (1998). Practical Reason. On the Theory of Action. Stanford, CA: Stanford University Press.

Boyce, Christopher, Gordon D. A. Brown and Simon C. Moore (2010). "Money and Happiness Rank of Income, Not Income, Affects Life Satisfaction." Psychological Science, 21(4): 471-475.

Brady, Henry E., Sidney Verba and Kay L. Schlozman (1995). "Beyond SES: A Resource Model of Political Participation." The America Political Science Review, 89(2): 271-294.

Braun, Daniela and Markus Tausendpfund (2014). "The Impact of the Euro Crisis on Citizens' Support for the European Union." Journal of European Integration, 36(3): 231-245.

Brenke, Karl, Ulf Rinne and Klaus F. Zimmermann (2011). Short-Time Work: The German Answer to the Great Recession. IZA Discussion Paper No. 5780. Bonn: Insitut zur Zukunft der Arbeit. 
Brüggemann, Michael and Hagen Schulz-Forberg (2009). "Becoming Pan-European? Transnational Media and the European Public Sphere." International Communication Gazette, 71(8): 693-712.

Bruter, Michael (2004). “On What Citizens Mean by Feeling 'European': Perceptions of News, Symbols and Borderlessness." Journal of Ethnic and Migration Studies, 30(1): 21-39.

Bude, Heinz and Jessica Spengler (2018). Society of Fear. Cambridge, MA: Polity Press.

Burley, Anne-Marie and Walter Mattli (1993). "Europe Before the Court: A Political Theory of Legal Integration." International Organization, 47(1): 41-76.

Burns, Williams J., Ellen Peters and Paul Slovic (2011). "Risk Perception and the Economic Crisis: A Longitudinal Study of the Trajectory of Perceived Risk." Risk Analysis, 32(4): 659-677.

Caiani, Manuela and Simona Guerra (eds.) (2017). Euroscepticism, Democracy and the Media. Communicating Europe, Contesting Europe. London: Palgrave/Macmillan.

Cainzos, Miguel and Carmen Voces (2010). "Class Inequalities in Political Participation and the 'Death of Class' Debate.” International Sociology, 25(3): 383-418.

Chanley, Virginia A., Thomas J. Rudolph and Wendy M. Rahn (2000). "The Origins and Consequences of Public Trust in Government: A Time Series Analysis." Public Opinion Quarterly, 64(1): 239-256.

Castles, Francis G. and Deborah Mitchell (1992). "Identifying Welfare State Regimes: The Links Between Politics, Instruments and Outcomes." Governance, 5(1): 1-26.

Checkel, Jeffrey T. (2007). International Institutions and Socialization in Europe. Cambridge: Cambridge University Press.

Christiansen, Thomas, Knud Erik Jorgensen and Antje Wiener (eds.) (2001). The Social Construction of Europe. London: Sage.

Cinalli, Manlio and Marco Giugni (2016). "Citizens' Responses to the European Economic Crisis in the Public Domain." Politics and Policy, 44: 388-399.

Clark, Nick and Robert Rohrschneider (2009). "Second-Order Elections versus First-Order Thinking: How Voters Perceive the Representation Process in a Multi-Layered System of Governance." Journal of European Integration, 31(5): 645-664.

Clarke, Jennifer and Asteris Huliaras (2015). Austerity and the Third Sector in Greece. Civil Society at the European Frontline. London: Routledge.

Cohen, Antonin (2011). "Bourdieu Hits Brussels: The Genesis and Structure of the European Field of Power." International Political Sociology, 5(3): 335-339.

Coleman, Stephen (2013). "How to Make a Drama Out of a Crisis." Political Studies Review, 11(3): 328-335.

Conti, Nicolò and Vincenzo Memoli (2017). "How the Media Make European Citizens More Eurosceptical." In: Manuela Caiani and Simona Guerra (eds.), Euroscepticism, Democracy and the Media. Communicating Europe, Contesting Europe (pp. 121-140). London: Palgrave/Macmillan.

Copeland, Paul and Mary Daly (2018). "The European Semester and EU Social Policy." Journal of Common Market Studies, 56(5): 1001-1018.

Cordero, Guillermo and Pablo Simón (2016). "Economic Crisis and Support for Democracy in Europe." West European Politics, 39(2): 305-325.

Council of Europe (2000). Strategy for Social Cohesion. Strasbourg: European Committee for Social Cohesion (CDCS).

Council of Europe (2004). A New Strategy for Social Cohesion. Revised Strategy for Social Cohesion. Adopted by the Committee of Ministers of the Council of Europe on 31 March 2004. 
Council of Europe (2010). A New Strategy and Council of Europe Action Plan for Social Cohesion. Adopted by the Committee of Ministers of the Council of Europe on 7 July 2010.

Countouris, Nicola (2007). The Changing Law of the Employment Relationship. Comparative Analysis in the European Context. Aldershot: Ashgate.

Crouch, Colin (1999). Social Change in Western Europe. Oxford: Oxford University Press.

Crouch, Colin (2016). Society and Social Change in 21st Century Europe. London: Macmillan/Palgrave.

Dalton, Russell J. (1999). "Political Support in Advanced Industrial Democracies." In: Pippa Norris (ed.), Critical Citizens. Global Support for Democratic Governance (pp. 57-77). New York, NY: Oxford University Press.

Dalton, Russell J. (2004). Democratic Challenges, Democratic Choices: The Erosion of Political Support in Advanced Industrial Democracies. Oxford: Oxford University Press.

Dalton, Russell J. (2005). "The Social Transformation of Trust in Government." International Review of Sociology, 15(1): 133-154.

Dalton, Russell J. (2008). "Citizenship Norms and the Expansion of Political Participation." Political Studies, 56(1): 76-98.

de Vreese, Claes H. (2007). "The EU as a Public Sphere." Living Reviews in European Governance, 2(3): 3-16.

de Vreese, Claes H. and Hajo G. Boomgaarden (2006). "Media Effects on Public Opinion about the Enlargement of the European Union." Journal of Common Market Studies, 44(2): 419-436.

de Wilde, Pieter, Asimina Michailidou and Hans-Jörg Trenz (2013). Contesting Europe. Exploring Euroscepticism in Online Media Coverage. Coulchester: ECPR Press.

de Wilde, Pieter and Michael Zürn (2012). "Can the Politicization of European Integration be Reversed?” Journal of Common Market Studies, 50(1): 137-153.

de Vries, Catherine E. (2018). Euroscepticism and the Future of European Integration. Oxford: Oxford University Press.

de Vries, Catherine E. and Erica E. Edwards (2009). "Taking Europe to its Extremes. Extremist Parties and Public Euroscepticism." Party Politics, 15(1): 5-28.

de Vries, Catherine and Kees van Kersbergen (2007). "Interests, Identity and Political Allegiance in the European Union." Acta Politica, 42(2): 307-328.

Decker, Oliver, Johannes Kiess and Elmar Brähler (2016). "Fertile Soil for Ideological Confusion? The Extremism of the Centre." In: Oliver Decker, Johannes Kiess and Elmar Brähler (eds.), German Perspectives on Right-Wing Extremism (pp. 93-113). London: Routledge.

Delanty, Gerard (1998). "Social Theory and European Transformation: Is there a European Society?" Sociological Research Online, 3(1): 1-15.

Delhey, Jan (2007). "Do Enlargements Make the European Union Less Cohesive? An Analysis of Trust Between EU Nationalities." Journal of Common Market Studies, 45(2): 253-279.

Delhey, Jan, Petra Böhnke, Roland Habich and Wolfgang Zapf (2002). "Quality of Life in a European Perspective. The Euromodule as a New Instrument for Comparative Welfare Research." Social Indicators Research, 58: 161-76.

Delhey, Jan, Emanuel Deutschmann, Timo Graf and Katharina Richter (2014). "Measuring the Europeanization of Everyday Life: Three New Indices and an Empirical Application.” European Societies, 6(3): 355-377. 
Delhey, Jan and Georgi Dragolov (2014). "Why Inequality Makes Europeans Less Happy: The Role of Distrust, Status Anxiety, and Perceived Conflict.” European Sociological Review, 30(2): 151-165.

Delhey, Jan and Ulrich Kohler (2006). "From Nationally Bounded to Pan-European Inequalities? On the Importance of Foreign Countries as Reference Groups." European Sociological Review, 22(2): 125-140.

della Porta, Donatella (2015). Social Movements in Times of Austerity: Bringing Capitalism Back into Protest Analysis. Cambridge, MA: Polity Press.

della Porta, Donatella and Manuela Caiani (2009). Social Movements and Europeanization. Oxford: Oxford University Press.

della Porta, Donatella and Alice Mattoni (eds.) (2014). Spreading Protests: Social Movements in Times of Crisis. Colchester: ECPR Press.

Desmet, Pieterjan, Joost van Spanje and Claes de Vreese (2012). “'Second-Order' Institutions: National Institutional Quality as a Yardstick for EU Evaluation.” Journal of European Public Policy, 19(7): 1071-1088.

Deutschmann, Emanuel and Jan Delhey (2015). "People Matter: Recent Sociological Contributions to Understanding. European Integration from Below." Perspectives on Europe, 45(2): 25-32.

D'haen, Theo and Iannis Goerlandt (ed.) (2009). A Literature for Europe? Amsterdam and New York, NY: Brill/Rodopi.

Díez-Medrano, Juan (2003). Framing Europe: Attitudes to European Integration in Germany, Spain and the United Kingdom. Princeton, NJ: Princeton University Press.

Dotti Sani, Giulia M. and Beatrice Magistro (2016). "Increasingly Unequal? The Economic Crisis, Social Inequalities and Trust in the European Parliament in 20 European Countries." European Journal of Political Research, 55(2): 246-264.

Dubé, Lise and Serge Guimond (1986). "Relative Deprivation and Social Protest: The Personal-Group Issue.” In: James M. Olson, C. Peter Herman and Mark P. Zanna (eds.), Relative Deprivation and Social Comparison (pp. 201-2016). Hillsdale, NJ: Lawrence Aerlbaum.

Easton, David (1965). A Framework for Political Analysis. Englewood Cliffs, NY: Prentice Hall.

Easton, David (1975). "A Re-Assessment of the Concept of Political Support." British Journal of Political Science, 5(4): 435-457.

Eichenberg, Richard C. and Russell J. Dalton (1993). "Europeans and the European Community: The Dynamics of Public Support for European Integration." International Organization, 47(4): 507-534.

Eichenberg, Richard C. and Russell J. Dalton (2007). "Post-Maastricht Blues: The Transformation of Citizen Support for European Integration, 1973-2004." Acta Politica, 42(2-3): 128-152.

Eder, Klaus (1993). The New Politics of Class: Social Movements and Cultural Dynamics in Advanced Societies. London and Newbury Park, CA: Sage Publications.

Eder, Klaus (2004). "The Two Faces of Europeanization: Synchronizing a Europe Moving at Varying Speeds.” Time \& Society, 13(1): 89-107.

Eder, Klaus (2014). "The EU in Search of Its People: The Birth of a Society Out of the Crisis of Europe." European Journal of Social Theory, 17(3): 219-237.

Eder, Klaus and Bernd Giesen (2001). "Conclusion: Citizenship and the Making of European Society: From the Political to the Social Integration of Europe." In: Klaus Eder and Bernd Giesen (eds.), European Citizenship Between National Legacies and Postnational Projects (pp. 245-269). Oxford: Oxford University Press. 
Ehrenreich, Barbara (1989). Fear of Falling: The Inner Life of the Middle Class. New York, NY: Pantheon.

Eisele, Olga (2017). "Complementing, Competing, or Co-Operating? Exploring Newspapers' Portrayals of the European Parliament and National Parliaments in EU Affairs." Journal of European Integration, 39(4): 435-451.

Eisenstadt, Shmuel N. (1964). "Social Change, Differentiation and Evolution." American Sociological Review, 29(3): 375-386.

Elchardus, Mark and Bram Spruyt (2016). "Populism, Persistent Republicanism and Declinism: An Empirical Analysis of Populism as a Thin Ideology." Government and Opposition, 51(1): 111-153.

Eriksen, Erik Oddvar (2005). “An Emerging European Public Sphere.” European Journal of Social Theory, 8(3): 341-363.

Esping-Andersen, Gøsta (1990). The Three Worlds of Welfare Capitalism. Princeton, NJ: Princeton University Press.

EU-Commission (2008). Green Paper on Territorial Cohesion. Turning Territorial Diversity into Strength. Brussels: Communication from the Commission to the Council, the European Parliament, the Committee of the Regions and the European Economic and Social Committee. COM 2008616 Final.

EU-Commission (2009). Sixth Progress Report on Economic and Social Cohesion. Brussels: Report from the Commission to the European Parliament and the Council. COM (2009) 295, SEC(2009) 828 Final.

Faas, Daniel (2007). "Youth, Europe and the Nation: The Political Knowledge, Interests and Identities of the New Generation of European Youth." Journal of Youth Studies, 10(2): 161-181.

Fairclough, Norman (1993). Discourse and Social Change. Cambridge, MA: Polity Press.

Favell, Adrian (2008). Eurostars and Eurocities: Free Movement and Mobility in an Integrating Europe. Oxford: Blackwell and Wiley-Blackwell.

Favell, Adrian and Virginie Guiraudon (2009). "The Sociology of the European Union. An Agenda.” European Union Politics, 10(4): 550-576.

Favell, Adrian and Virginie Guiraudon (2011). Sociology of the European Union. Houndmills, Basingstoke: Palgrave/Macmillan.

Featherstone, Kevin and Claudio Radaelli (eds.) (2003). The Politics of Europeanization. Oxford: Oxford University Press.

Fernandes, Tiago, João Cancela, Michael Coppedge, Staffan I. Lindberg and Allen Hicken (2015). "Measuring Political Participation in Southern Europe: The Varieties of Democracy Approach." V-Dem Working Paper 2015:15. Available from: https://ssrn .com/abstract=2692553.

Fieschi, Catherine and Paul Heywood (2004). "Trust, Cynicism and Populist Anti-Politics." Journal of Political Ideologies, 9(3): 289-309.

Finifter, Ada W. (1970). "Dimensions of Political Alienation." American Political Science Review, 64(2): 389-410.

Fligstein, Neil (2008). Euroclash: The EU, European Identity, and the Future of Europe. Oxford: Oxford University Press.

Fligstein, Neil and Dough McAdam (2012). A Theory of Fields. Oxford: Oxford University Press.

Fligstein, Neil, Alina Polyakova and Wayne Sandholtz (2012). "European Integration, Nationalism and European Identity." Journal of Common Market Studies, 50(1): $106-122$. 
Fossum, John Erik and Philip Schlesinger (2007). "The European Union and the Public Sphere: A Communicative Space in the Making?" In: John Erik Fossum and Philip Schlesinger (eds.), The European Union and the Public Sphere: A Communicative Space in the Making? (pp. 1-20). Milton Park: Routledge.

Franzosi, Roberto (1987). "The Press as a Source of Socio-Historical Data: Issues in the Methodology of Data Collection from Newspapers." Historical Methods, 20: 5-16.

Frey, Bruno S. and Alois Stutzer (2000). "Happiness, Economy and Institutions." Economic Journal, 110(446): 918-938.

Fuchs, Dieter and Hans-Dieter Klingemann (eds.) (2011). Cultural Diversity, European Identity and the Legitimacy of the EU. Studies in EU Reform and Enlargement. Cheltenham: Edward Elgar.

Fuchs, Dieter and Christian Schneider (2011). "Support of the EU and European Identity." In: Dieter Fuchs and Hans-Dieter Klingemann (eds.), Cultural Diversity, European Identity and the Legitimacy of the EU (pp. 61-85). Cheltenham: Edward Elgar.

Fusco, Alessio, Anne-Catherine Guio and Eric Marlier (2010). "Characterizing the Income Poor and the Materially Deprived in European Countries." In: Anthony B. Atkinson and Eric Marlier (eds.), Income and Living Conditions in Europe (pp. 133-153). Luxembourg: Office for Official Publications of the European Communities.

Galpin, Charlotte and Hans-Jörg Trenz (2019). "Converging Towards Euroscepticism? Negativity in News Coverage during the 2014 European Parliament Elections in Germany and the UK." European Politics and Society, 20(3): 260-276.

Garry, John and James Tilley (2009). "The Marcoeconomic Factors Conditioning the Impact of Identity on Attitudes towards the EU." European Union Politics, 10(3): 361-379.

Georgakakis, Didier and Jay Rowell (eds.) (2013). The Field of Eurocracy. Mapping EU Actors and Professionals. Houndmills, Basingstoke: Palgrave/Macmillan.

Georgakakis, Didier and Julien Weisbein (2010). "From Above and from Below: A Political Sociology of European Actors." Comparative European Politics, 8(1): 93-109.

Geppert, Kurt and Andreas Stephan (2008). "Regional Disparities in the European Union: Convergence and Agglomeration.” Regional Science, 87(2): 193-217.

Gerhards, Jürgen (2001). "Missing a European Public Sphere.” In: Martin Kohli and Mojca Novak (eds.), Will Europe Work?: Integration, Employment and the Social Order 5 (pp. 145-158). London: Routledge.

Gerhards, Jürgen and Silke Hans (2013). "Transnational Human Capital, Education, and Social Inequality. Analyses of International Student Exchange. " Zeitschrift Für Soziologie, 42(2): 99-117.

Gerhards, Jürgen, Silke Hans and Sören Carlson (2017). Social Class and Transnational Human Capital. How Upper and Middle Class Parents Prepare Their Children for Globalization. London/New York, NY: Routledge.

Gerhards, Jürgen and Holger Lengfeld (2013). "European Integration, Equality Rights and People's Beliefs: Evidence from Germany." European Sociological Review, 29(1): 19-31.

Gerhards, Jürgen and Holger Lengfeld (2015). European Citizenship and Social Integration in the European Union. London/New York, NY: Routledge.

Gerhards, Jürgen, Holger Lengfeld and Julia Häuberer (2016). "Do European Citizens Support the Idea of a European Welfare State? Evidence from a Comparative Survey Conducted in Three EU Member States.” International Sociology, 31(6): 677-700. 
Gerhards, Jürgen, Holger Lengfeld, Zsófia S. Ignácz, Florian K. Kley and Maximilian Priem (2019). European Solidarity in Times of Crisis: Insights from a Thirteen-Country Survey. London: Routledge.

Giugni, Marco and Paul Statham (2002). "The Contentious Politics of Unemployment in Europe. Political Claim-Making, Policy Deliberation and Exclusion from the Labor Market. Codebook Work-Package 1: Political Claim-Making in the Public Domain." European Political Communication Working Paper Series, 2: 2.

Goerke, Laszlo and Markus Pannenberg (2015). "Direct Evidence for Income Comparisons and Subjective Well-Being Across Reference Groups." Economics Letters, 137: 95-101.

Grasso, Maria T. and Marco Giugni (2016). "Protest Participation and Economic Crisis: The Conditioning Role of Political Opportunities." European Journal of Political Research, 55: 663-680.

Grauel, Jonas, Jana Heine and Christian Lahusen (2014). "Who is Afraid of the (Big Bad) European Union? European Integration and Fears About Job Losses.” In: Wil Arts and Loek Halman (eds.), Value Contrasts and Consensus in Present-Day Europe. Painting Europe's Moral Landscapes (pp. 19-43). Boston, MA: Brill.

Green, David Michael (2000). "On being European: The character and consequences of European identity." In: Maria G. Cowles and Michael Smith (eds.), The State of the European Union: Risks, Reform, Resistance, and Revival (pp. 292-322). Oxford: Oxford University Press.

Guinjoan, Marc and Guillem Rico (2018). "How Perceptions of Inequality Between Countries Diminish Trust in the European Union: Experimental and Observational Evidence." Political Psychology, 39(6): 1289-1303.

Guio, Anne-Catherine (2018). "Multidimensional Poverty and Material Deprivation: Empirical Findings." In: Conchita D'Ambrosio (ed.), Handbook of Research on Economic and Social Well-Being (pp. 171-192). Cheltenham: Edward Elgar.

Hajer, M. (1993). "Discourse Coalitions and the Institutionalization of Practice: The Case of Acid Rain in Great Britain.” In: Frank Fischer and John Forester (eds.), The Argumentative Turn in Policy Analysis and Planning (pp. 43-67). London: UCL Press.

Haller, Max (2008). European Integration as an Elite Process: The Failure of a Dream? New York, NY: Routledge.

Hay, Colin (1996). "Narrating Crisis: The Discursive Construction of the 'Winter of Discontent'." Sociology, 30(2): 253-277.

Hay, Colin (2002). Political Analysis. A Critical Introduction. Political Analysis. Houndmills, Basingstoke: Palgrave.

Heath, Anthony, Iain McLean, Bridget Taylor and John Curtice (1999). "Between First and Second Order: A Comparison of Voting Behaviour in European and Local Elections in Britain.” European Journal of Political Research, 35(3): 389-414.

Heidenreich, Martin (2016a). Exploring Inequality in Europe. Diverging Income and Employment Opportunities in the Crisis. Cheltenham, UK: Edward Elgar.

Heidenreich, Martin (2016b). "Introduction: The Double Dualization of Inequality in Europe." In: Martin Heidenreich (ed.), Exploring Inequality in Europe. Diverging Income and Employment Opportunities in the Crisis (pp. 1-21). Cheltenham, UK: Edward Elgar.

Heidenreich, Martin (2016c). "The Europeanization of Income Inequality Before and During the Eurozone Crisis: Inter-, Supra- and Transnational Perspectives." In: Martin Heidenreich (ed.), Exploring Inequality in Europe. Diverging Income and Employment Opportunities in the Crisis (pp. 22-47). Cheltenham, UK: Edward Elgar. 
Heidenreich, Martin (ed.) (2019). Horizontal Europeanisation. The Transnationalisation of Daily Life and Social Fields in Europe. Milton Park: Routledge.

Heidenreich, Martin, Deborah Rice and Katharina Zimmermann (2015). "The Europeanisation of Social Integration in the Eurozone Crisis: A Conceptual Framework." Oldenburger Studien zur Europäisierung und zur transnationalen Regulierung, 24: $1-21$.

Heidenreich, Martin and Christoph Wunder (2008). "Patterns of Regional Inequality in the Enlarged Europe.” European Sociological Review, 24(1): 19-36.

Heidenreich, Martin and Jonathan Zeitlin (eds.) (2009). Changing European Employment and Welfare Regimes. The Influence of the Open Method of Coordination on National Reforms. London: Routledge.

Héritier, Adrienne, Dieter Kerwer, Christoph Knill, Dirk Lehmkuhl, Michael Teutsch and Anne-Cécile Douillet (2001). Differential Europe. The European Union Impact on National Policymaking. Lanham, MD: Rowman \& Littlefield.

Hermann, Christoph (2014). "Structural Adjustment and Neoliberal Convergence in Labour Markets and Welfare: The Impact of the Crisis and Austerity Measures on European Economic and Social Models." Competition \& Change, 18(2): 111-130.

Hernández, Enrique and Hanspeter Kriesi (2016). "Turning your Back on the EU. The Role of Eurosceptic Parties in the 2014 European Parliament Elections." Electoral Studies, 44: 515-524.

Hetherington, Marc J. (1998). "The Political Relevance of Political Trust." American Political Science Review, 92(4): 791-808.

Hix, Simon (1999). The Political System of the European Union. Houndsmill: Palgrave.

Hix, Simon and Michael Marsh (2007). "Punishment or Protest? Understanding European Parliament Elections.” Journal of Politics, 69(2): 495-510.

Hobbins, Jennifer and Christian Lahusen (2015). "Between Evasion and Activism. A Qualitative Inquiry into the Political Behavior of German and Swedish Long-Term Unemployed." Partecipazione e Conflitto, 8(3): 788-813.

Hobolt, Sara B. and Catherine E. de Vries (2016). "Public Support for European Integration." Annual Review of Political Science, 19: 413-432.

Hobolt, Sara B. and James Tilley (2014). Blaming Europe? Responsibility Without Accountability in the European Union. Oxford: Oxford University Press.

Hobolt, Sara B. and Jill Wittrock (2011). "The Second-Order Election Model Revisited: An Experimental Test of Vote Choices in European Parliament Elections." Electoral Studies, 30: 29-40.

Hodson, Dermot and Imelda Maher (2001). "The Open Method as a New Mode of Governance.” Journal of Common Market Studies, 39(4): 719-746.

Hofmann, Herwig C. H. (2008). "Mapping the European Administrative Space." West European Politics, 31: 662-676.

Hong, Geeyoung (2015). "Explaining Vote Switching to Niche Parties in the 2009 European Parliament Elections." European Union Politics, 16(4): 514-535.

Hooghe, Liesbet (2003). "Europe Divided? Elites vs. Public Opinion on European Integration." European Union Politics, 4(3): 281-304.

Hooghe, Lisbet, Jing Jing Huo and Gary Marks (2007). "Does Occupation Shape Attitudes on Europe? Benchmarking Validity and Parsimony." Acta Politica, 42(2): 329-351.

Hooghe, Liesbet and Gary Marks (2004). "Does Identity or Economic Rationality Drive Public Opinion on European Integration?” Political Science \& Politics, 37(3): 415-420.

Hooghe, Liesbet and Gary Marks (2005). "Calculation, Community and Cues. Public Opinion on European Integration.” European Union Politics, 6(4): 419-443. 
Hooghe, Lisbet and Gary Marks (2007). "Sources of Euroscepticism." Acta Politica, 42(2): 119-127.

Hooghe, Liesbet and Gary Mark (2008). "The Neo-Functionalists were (Almost) Right: Politicization and European Integration.” In: Colin Crouch and Wolfgang Streeck (eds.), The Diversity of Democracy. Corporatism, Social Order and Political Conflict (pp. 205-222). Cheltenham: Edward Elgar.

Hooghe, Liesbet and Gary Marks (2009). "A Postfunctionalist Theory of European Integration: From Permissive Consensus to Constraining Dissensus." British Journal of Political Science, 39(1): 1-23.

Hooghe, Liesbet and Gary Marks (2018). "Cleavage Theory Meets Europe's Crises: Lipset, Rokkan, and the Transnational Cleavage." Journal of European Public Policy, 25(1): 109-135.

Höpner, Martin and Bojan Jurczyk (2015). "How the Eurobarometer Blurs the Line between Research and Propaganda." MPIfG Discussion Paper, 15(6): 1-26.

Hudson, John (2006). "Institutional Trust and Subjective Well-Being across the EU." Kyrlos. International Review for Social Sciences, 59(1): 43-62.

Hutter, Swen (2014). Protesting Culture and Economics in Western Europe. New Cleavages in Left and Right Politics. Minneapolis, MN: University of Minnesota Press.

Hutter, Swen and Edgar Grande (2014). "Politicizing Europe in the National Electoral Arena: A Comparative Analysis of Five West European Countries, 1970-2010." Journal of Common Market Studies, 52(5): 1002-1018.

Imig, Doug and Sidney Tarrow (1999). "The Europeanization of Movements? A New Approach to Transnational Contention." In: Donatella della Porta, Hanspeter Kriesi and Dieter Rucht (eds.), Social Movements in a Globalizing World (pp. 112-133). Basingstoke: Palgrave Macmillan.

Imig, Doug and Sidney G. Tarrow (2001). Contentious Europeans. Protest and Politics in an Emerging Polity. Lanham, MD: Rowman \& Littlefield.

Jessoula, Matteo (2015). "Europe 2020 and the Fight against Poverty-Beyond Competence Clash, Towards 'Hybrid' Governance Solutions?" Social Policy \& Administration, 49(4): 490-511.

Kaltenthaler, Karl, Stephen Ceccoli and Ronald Gelleny (2008). "Attitudes toward Eliminating Income Inequality in Europe." European Union Politics, 9(2): 217-241.

Kangas, Olli and Veli-Matti Ritakallio (2007). "Relative to What? Cross National Pictures of European Poverty Measured by Regional, National and European Standards." European Societies, 9(2): 119-145.

Kapteyn, Aire, Bernard M. S. van Praag and Floor G. van Herwaarden (1978). "Individual Welfare Functions and Social Reference Spaces.” Economics Letters, 1(2): 173-77.

Karaca, Banu (2010). "The Art of Integration: Probing the Role of Cultural Policy in the Making of Europe.” International Journal of Cultural Policy, 16(2): 121-137.

Karp, Jeffrey A., Susan A. Banducci and Shaun Bowler (2003). "To Know it is to Love it? Satisfaction with Democracy in the European Union." Comparative Political Studies, 36(3): 271-292.

Katz, Richard S. (1985). "Measuring Party Identification with Eurobarometer Data: A Warning Note." West European Politics, 8(1): 104-108.

Kauppi, Niilo and Mikael Rask Madsen (2013). Transnational Power Elites. The New Professionals of Governance, Law and Security. London: Routledge.

Kneuer, Marianne (2019). "The tandem of populism and Euroscepticism: a comparative perspective in the light of the European crises". Contemporary Social Science, 14(1): $26-42$. 
Kiess, Johannes (2019). "Contention in Times of Crisis: British and German Social Actors and the Quest of Framing Capitalism.” In: Johannes Kiess and Martin Seeliger (eds.), Trade Unions under the Pressure of European Integration. A Question of Optimism and Pessimism? (pp. 208-226). London: Routledge.

Kleinhenz, Thomas (1998). "A New Type of Nonvoter? Turnout Decline in German Elections, 1980-94.” In: Christoper J. Anderson and Carsten Zelle (eds.), Stability and Change in German Elections. How Electorates Merge, Converge, or Collide (pp. 173198). Westport, CT: Praegere.

Knill, Christoph and Dirk Lehmkuhl (2002). "The National Impact of European Union Regulatory Policy: Three Europeanization Mechanisms.” European Journal of Political Research, 41(2): 255-280.

Kohler-Koch, Beate (ed.) (2003). Linking EU and National Governance. Oxford: Oxford University Press.

Kohler-Koch, Beate (2005). "Network Governance Within and Beyond an Enlarged European Union.” In: Amy Verdun (ed.), The European Union in the wake of Eastern enlargement (pp. S. 35-43). Manchester: Manchester University Press.

Kohler-Koch, Beate and Christine Quittkat (2013). De-Mystification of Participatory Democracy: EU-Governance and Civil Society. Oxford: Oxford University Press.

Koopmans, Ruud (2007). "Who Inhabits the European Public Sphere? Winners and Losers, Supporters and Opponents in Europeanised Political Debates." European Journal of Political Research, 46(2): 183-210.

Koopmans, Ruud and Paul Statham (1999). "Political Claims Analysis: Integrating Protest Event and Political Discourse Approaches." Mobilization, 4(2): 203-221.

Kouki, Hara and Joseba Fernandez González (2018). "Syriza, Podemos and Mobilizations Against Austerity: Movements, Parties or Movement-Parties?” In: Jochen Roose, Moritz Sommer and Franziska Scholl (eds.), Europas Zivilgesellschaft in der Wirtschafts- und Finanzkrise. Bürgergesellschaft und Demokratie (pp. 123-140). Wiesbaden: Springer VS.

Kousis, Maria (2014). “The Transnational Dimension of the Greek Protest Campaign against Troika Memoranda and Austerity Policies, 2010-12." In: Donatella della Porta and Alice Mattoni (eds.), Spreading Protests in Social Movements of the Crisis (pp. 137-170). Colchester: ECPR Press.

Kousis Maria, Stefania Kalogeraki, Marina Papadaki, Angelos Loukakis and Maria Velonaki (2018). "Confronting Austerity in Greece: Alternative Forms of Resilience and Solidarity Initiatives by Citizen Groups." In: Jochen Roose, Moritz Sommer and Franziska Scholl (eds.), Europas Zivilgesellschaft in der Wirtschafts- und Finanzkrise. Bürgergesellschaft und Demokratie (pp. 77-99). Wiesbaden: Springer VS.

Kriesi, Hanspeter (1989). "New Social Movements and the New Class in the Netherlands." American Journal of Sociology, 94(5): 1078-1116.

Kriesi, Hanspeter (2016a). "Mobilization and Protest in the Age of Austerity." In: Marcos Ancelovici, Pascale Dufour and Héloïse Nez (eds.), Street Politics in the Age of Austerity: From the Indignados to Occupy (pp. 67-90). Amsterdam: Amsterdam University Press.

Kriesi, Hanspeter (2016b). "The Politicization of European Integration." Journal of Common Market Studies, 54(1): 32-47.

Kriesi, Hanspeter, Edgar Grande, Romain Lachat, Martin Dolezal, Simon Bornschier and Timotheos Frey (2006). "Globalization and the Transformation of the National Political Space: Six European Countries Compared." European Journal of Political Research, 45(6): 921-956. 
Kriesi, Hanspeter, Ruud Koopmans, Jan Willem Duyvendak and Marco G. Giugni (1995). New Social Movements in Western Europe. A Comparative Analysis. London: Routledge.

Kriesi, Hanspeter and Takis S. Pappas (eds.) (2015). European Populism in the Shadow of the Great Recession. Colchester: ECPR Press.

Kritzinger, Sylvia (2003). "The Influence of the Nation-State on Individual Support for the European Union.” European Union Politics, 4(2): 219-241.

Krouwel, André and Koen Abts (2007). "Varieties of Euroscepticism and Populist Mobilization: Transforming Attitudes from Mild Euroscepticism to Harsh Eurocynicism." Acta Politica, 42(2): 252-270.

Kuhn, Theresa (2011). "Individual Transnationalism, Globalisation and Euroscepticism: An Empirical Test of Deutsch's Transactionalist Theory." European Journal of Political Research, 50: 811-837.

Kuhn, Theresa (2012). "Why Educational Exchange Programmes Miss Their Mark: Cross-Border Mobility, Education and European Identity." Journal of Common Market Studies, 50(6): 994-1010.

Kuhn, Theresa, Francesco Nicoli and Frank Vandenbroucke (2020). "Preferences for European Unemployment Insurance: A Question of Economic Ideology or EU Support?" Journal of European Public Policy, 27(2): 208-226.

Kuhn, Theresa, Erika van Elsas, Armen Hakhverdian and Wouter van der Brug (2016). “An Ever Wider Gap in an Ever Closer Union: Rising Inequalities and Euroscepticism in 12 West European Democracies, 1975-2009.” Socio-Economic Review, 14(1): 27-45.

Kuhn, Theresa and Florian Stoeckel (2014). "When European Integration Becomes Costly: The Euro Crisis and Public Support for European Economic Governance.” Journal of European Public Policy, 21(4): 624-641.

Kutter, Amelie and Bob Jessop (2015). "Culture as Discursive Practice: Combining Cultural Political Economy and Discursive Political Studies in Investigations of the Financial Crisis." In: Bob Jessop, Brigitte Young and Christoph Scherrer (eds.), Financial Cultures and Crisis Dynamics (pp. 64-82). London: Routledge.

Laclau, Ernesto (2005). "Populism: What's in a Name?" In: Francisco Panizza (ed.), Populism and the Mirror of Democracy (pp. 32-50). London: Verso.

Lahusen, Christian (2009). "The Hidden Hand of the European Union and the Silent Europeanization of Public Debates on Unemployment: The Case of the European Employment Strategy." In: Marco Giugni (ed.), The Politics of Unemployment in Europe: Policy Responses and Collective Action (pp. 151-171). Aldershot: Ashgate.

Lahusen, Christian (2013). "European Integration, Social Cohesion and Political Contentiousness.” In: Bernadette Andreosso-O'Callaghan and Frédéric Royall (eds.), Economic and Political Change in Asia and Europe (pp. S. 31-52). Dordrecht: Springer.

Lahusen, Christian (eds.) (2020). Citizens' Solidarity in Europe. Civic Engagement and Public Discourse in Times of Crises. Cheltenham: Edward Elgar.

Lahusen, Christian and Maria Grasso (2018). "Solidarity in Europe: A Comparative Assessment and Discussion." In: Christian Lahusen and Maria Grasso (eds.), Solidarity in Europe. Citizens' Responses in Times of Crisis (pp. 253-281). Cham: Palgrave/ Macmillan.

Lahusen, Christian and Johannes Kiess (2019). “'Subjective Europeanization’: Do InnerEuropean Comparisons Affect Life Satisfaction?” European Societies, 21(2): 214-236.

Lahusen, Christian, Maria Kousis, Johannes Kiess and Maria Paschou (2016). "Political Claims and Discourse Formations: A Comparative Account on Germany and Greece in the Eurozone Crisis." Politics \& Policy, 44(3): 525-552. 
Lahusen, Christian, Maria Kousis, Ulrike Zschache and Angelos Loukakis (2018). "European Solidarity in Times of Crisis: Comparing Transnational Activism of Civic Organisations in Germany and Greece." Osterreichische Zeitschrift für Soziologie, 43(Suppl 1): 173-197.

Lauterbach, Fabian and Catherine E. de Vries (2020). "Europe Belongs to the Young? Generational Differences in Public Opinion Towards the European Union During the Eurozone Crisis.” Journal of European Public Policy, 27(2): 168-187.

Lepsius, M. Rainer (2017). Max Weber and Institutional Theory. Cham: Springer.

Leruth, Benjamin and Christopher Lord (eds.) (2016). Differentiated Integration in the European Union. Milton Park: Routledge.

Lindberg, Leon N. and Stuart A. Scheingold (1970). Europe's Would-Be Polity: patterns of Change in the European Community. Englewood Cliffs, NY: Prentice Hall.

Livewhat (2015). Questionnaire for the analysis of individual responses to crises (Deliverable: 4.1). Geneva: University of Geneva [accessible through: https://www .unige.ch/livewhat/wp-content/uploads/2014/07/Deliverable-4.11.pdf, downloaded 14.05.2020].

Livewhat (2016). Integrated Report on Individual Responses to Crises (Deliverable: 4.2). Geneva: University of Geneva. Available from: https:/www.unige.ch/livewhat/wp-co ntent/uploads/2014/02/Integrated-Report.pdf, downloaded 14 May 2020.

Lockwood, David (1964). "Social Integration and System Integration." In: Geroge K. Zollschan and H. Walter Hirsch (eds.), Explorations in Social Change (pp. 244-256). Boston, MA: Houghton Mifflin.

Lubbers, Marcel and Peer Scheepers (2005). "Political Versus Instrumental Euroscepticism: Mapping Scepticism in European Countries and Regions." European Union Politics, 6(2): 223-242.

Lubbers, Marcel and Peer Scheepers (2010). "Divergent Trends of Euroscepticism in Countries and Regions of the European Union." European Journal of Political Research, 49(6): 787-817.

Luhmann, Niklas (1977). "Differentiation of Society." Canadian Journal of Sociology, 2(1): 29-53.

Luhmann, Niklas (1996). The Reality of the Mass Media. Stanford, CA: Stanford University Press.

Luttmer, Erzo F. P. (2005). "Neighbors as Negatives. Relative Earnings and Well-being." The Quarterly Journal of Economics, 120(3): 963-1002.

Machill, Marcel, Markus Beiler and Corinna Fischer (2006). "Europe-Topics in Europe's Media: The Debate about the European Public Sphere: A Meta-Analysis of Media Content Analyses." European Journal of Communication, 21(1): 57-88.

Madsen, Douglas (1987). "Political Self-Efficacy Tested." The American Political Science Review, 81(2): 571-581.

Maier, Jürgen and Berthold Rittberger (2008). "Shifting Europe's Boundaries: Mass Media, Public Opinion and the Enlargement of the EU." European Union Politics, 9(2): 243-267.

Markantonatou, Maria (2013). Diagnosis, Treatment, and Effects of the Crisis in Greece: A 'Special Case' or a 'Test Case? ' Köln: Max Planck Institute für Gesellschaftsforschung, Working Paper No. 13/3.

Marks, Gary, Lisbet Hooghe and Kermit Blank (1996). "European Integration from the 1980s: State-Centric v. Multi-level Governance.” Journal of Common Market Studies, 34(3): 341-378.

Mau, Steffen (2005). "Democratic Demand for a Social Europe? Preferences of the European Citizenry." International Journal of Social Welfare, 14(2): 76-85. 
Mau, Steffen (2009). Social Transnationalism. Lifeworlds beyond the Nation State. London: Routledge.

Mau, Steffen (2015). Inequality, Marketization and the Majority Class: Why Did the European Middle Classes Accept Neo-Liberalism?. Houndmills, Basingstoke: Palgrave/Macmillan.

Mause, Karsten and Bernd Schlipphak (2016). "Increasing Winners-Losers Gap? Increasing Euroscepticism? Exploring the Economic Crisis' Conflict Potential.” In: Tim Krieger, Bernhard Neumärker and Diana Panke (eds.), Europe's Crisis. The Conflict-Theoretical Perspective (pp. 111-132). Baden-Baden: Nomos.

McCarthy, John D. and Mayer N. Zald (1977). "Resource Mobilization and Social Movements: A Partial Theory." American Journal of Sociology, 82(6): 1212-1241.

McLaren, Lauren M. (2004). "Opposition to European Integration and Fear of Loss of National Identity: Debunking a Basic Assumption Regarding Hostility to the Integration Project.” European Journal of Political Research, 43(6): 895-911.

McLaren, Lauren M. (2007). "Explaining Mass-Level Euroscepticism: Identity, Interests, and Institutional Distrust." Acta Politica, 42(2): 233-251.

Merton, R. K. and Alice S. Kitt (1950). "Contributions to the Theory of Reference Group Behaviour." In: Robert K. Merton and Paul F. Lazarsfeld (eds.), Studies in the Scope and Method of The American Soldier (pp. 40-106). Glencoe: The Free Press.

Meyer, David S. and Sidney Tarrow (1998). The Social Movement Society. Contentious Politics for a New Century. London: Rowman \& Littlefield.

Monastiriotis, Vassilis (2013). "Austerity Measures in Crisis Countries-Results and Impact on Mid-Term Development.” Forum Intereconomics, 48(1): 4-32.

Monforte, Pierre (2014). Europeanizing Contention: The Protest Against 'Fortress Europe' in France and Germany. New York, NY: Berghahn Books.

Monza, Sabina and Eva Anduiza (2016). "The Visibility of the EU in the National Public Spheres in Times of Crisis and Austerity." Politics \& Policy, 44(3): 499-524.

Moravcsik, Andrew (1998). The Choice for Europe. Social Purpose and State Power from Messina to Maastricht. Ithaca, NY: Cornell University Press.

Mosher, James S. and David M. Trubek (2003). "Alternative Approaches to Governance in the EU: EU Social Policy and the European Employment Strategy." Journal of Common Market Studies, 41(1): 63-88.

Mudde, Cas (2004). "The Populist Zeitgeist." Government and Opposition, 39(4): 542-563.

Münch, Richard (1996). "Between Nation-State, Regionalism and World Society: The European Integration Process.” Journal of Common Market Studies, 34(3): 379-401.

Münch, Richard (2006). "Solidarity and Justice in the Extended European Union." In: Maurizio Bach, Christian Lahusen and Georg Vobruba (eds.), Europe in Motion. Social Dynamics and Political Institutions in an Enlarging Europe (pp. 79-96). Berlin: Edition Sigma.

Münch, Richard (2008). "Constructing a European Society by Jurisdiction." Union European Law Journal, 14(5): 519-541.

Münch, Richard (2012). Inclusion and Exclusion in the Liberal Competition State. The Cult of the Individual. London: Routledge.

Muñoz, Jordi, Mariano Torcal and Eduard Bonet (2011). "Institutional Trust and Multilevel Government in the European Union." European Union Politics, 12(4): 551-574.

Mylonas, Yiannis (2012). "Media and the Economic Crisis of the EU: The 'Culturalization' of a Systemic Crisis and Bild-Zeitung's Framing of Greece." tripleC, 10(2): 646-671. 
Nelsen, Brent F., James L. Guth and Cleveland R. Fraser (2001). "Does Religion Matter? Christianity and Public Support for the European Union." European Union Politics, 2(2): 191-217.

Newton, Kenneth (2006). "Political Support: Social Capital, Civil Society and Political and Economic Performance.” Political Studies, 54(4): 846-864.

Nissen, Sylke (2014). "The Eurobarometer and the Process of European Integration. Methodological Foundations and Weaknesses of the Largest European Survey." Quality \& Quantity, 48(2): 713-727.

OECD (2014). How's Life? 2015: Measuring Well-Being. Paris: OECD Publishing.

Oesch, Daniel (2006). "Coming to Grips with a Changing Class Structure: An Analysis of Employment Stratification in Britain, Germany, Sweden and Switzerland." International Sociology, 21(2): 263-288.

Olson, James M., C. Peter Herman and Mark P. Zanna (eds.) (1986). Relative Deprivation and Social Comparison. Hillsdale, NJ: Lawrence Aerlbaum.

Otjes, Simon and Alexia Katsanidou (2017). "Beyond Kriesiland: EU Integration as a Super Issue after the Eurocrisis." European Journal of Political Research, 56: 301-319.

Outhwaite, William (2008). European Society. Cambridge, MA: Polity Press.

Papathanassopoulos, Sytlianos (2015). "European Media Views of the Greek Crisis." In: Steve Schifferes and Richard Roberts (eds.), The Media and the Financial Crises. Comparative and Historical Perspectives (pp. 103-118). New York, NY: Routledge.

Pappas, Takis S. (2014). Populism and Crisis Politics in Greece. Houndmills, Basingstoke: Palgrave/Macmillan.

Parkin, Frank (1968). Middle Class Radicalism: The Social Bases of the British Campaign for Nuclear Disarmament. New York, NY: F.A. Praeger.

Parsons, Talcott (1964). "Evolutionary Universals in Society." American Sociological Review, 29(3): 339-357.

Pérez de Armiño, Carlos (2014). "Erosion of rights, Uncritical Solidarity and Food Banks in Spain." In: Graham Riches and Tiina Silvasti (eds.), First World Hunger Revisited: Food Charity or the Right to Food?, 2nd edition (pp. 131-145). Houndmills, Basingstoke: Palgrave/Macmillan.

Petmesidou, Maria and Ana M. Guillén (eds.) (2015). Economic Crisis and Austerity in Southern Europe. Threat of Opportunity for a Sustainable Welfare State. London: Routledge.

Petrakos, George, Dimitris Kallioras and Ageliki Anagnostou (2011). "Regional Convergence and Growth in Europe: Understanding Patterns and Determinants." European Urban and Regional Studies, 18(4): 375-391.

Pew Research Center (2012). Pew Global Attitudes Project 2012, Spring Survey Topline Results. Washington, DC. Available from: https://www.pewresearch.org/global/wp-co ntent/uploads/sites/2/2012/05/Pew-Global-Attitudes-Project-European-Crisis-Topline -May-29-2012.pdf, downloaded 24 April 2020.

Pfetsch, Barbara, Silke Adam and Barbara Berkel (2006). "The Voice of the Media in European Public Sphere. Agenda Setters, Shapers of Conflicts and Bridges of Cross Border Communication." Paper Presented at the IPSA World Congress 2006, Fukuoka (Japan) Panel, Communication, Mobilization and the Media in European Integration, pp. 1-34.

Pierson, Paul (2000). "Increasing Returns, Path Dependence, and the Study of Politics." American Political Science Review, 94(2): 251-267.

Pollack, Mark A. (2001). "International Relations Theory and European Integration." Journal of Common Market Studies, 39(2): 221-244. 
Pollock, Philip H. (1983). "The Participatory Consequences of Internal and External Political Efficacy: A Research Note.” Political Research Quarterly, 36(3): 400-409.

Polyakova, Alina and Neil Fligstein (2016). "Is European Integration Causing Europe to Become More Nationalist? Evidence from the 2007-9 Financial Crisis." Journal of European Public Policy, 23(1): 60-83.

Pressman, Steven (2007). "The Decline of the Middle Class: An International Perspective." Journal of Economic Issues, 41(1): 181-200.

Radaelli, Claudio (2003). "The Europeanization of Public Policy.” In: Keith Featherstone and Claudio Radaelli (eds.), The Politics of Europeanization (pp. 27-56). Oxford: Oxford University Press.

Reichert, Frank (2016). "How Internal Political Efficacy Translates Political Knowledge into Political Participation.” Europe's Journal of Psychology, 12(2): 221-241.

Reiff, Karlheinz and Hermann Schmitt (1980). "Nine Second-Order National Elections A Conceptual Framework for the Analysis of European Election Results." European Journal of Political Research, 8(1): 3-44.

Rico, Guillem and Eva Anduiza (2016). Economic Correlates of Populist Attitudes: An Analysis of Nine European: Countries in the Wake of the Great Recession. Universitad Autonoma de Barcelona. Available from: https:/www.ceu.edu/sites/default/files/attac hment/event/14668/economic-correlates-populist-attitudes-eva-anduiza.pdf, accessed: 23 May 2017.

Risse, Thomas (2010). A Community of Europeans? Transnational Identities and Public Sphere. Ithaca, NY: Cornell University Press.

Risse, Thomas (2001). "A European Identity? Europeanization and the Evolution of Nation-State Identities." In Maria Green Cowles, James Caporaso and Thomas Risse (eds.), Transforming Europe. Europeanization and Domestic Change (pp. 198-215). Ithaca, NY: Cornell University Press.

Risse, Thomas, Richard Herrmann and Marilynn Brewer (eds.) (2004). Transnational Identities. Becoming European in the European Union. Lanham, MD: Rowman \& Littlefield.

Ritzen, Jo, Caroline Wehner and Klaus F. Zimmermann (2016). "Euroscepticism, Income Inequality and Financial Expectations." BE Journal of Economic Analysis \& Policy, 16(2): 539-576.

Rohrschneider, Robert and Matthew Loveless (2010). "Macro Salience: How Economic and Political Contexts Mediate Popular Evaluations of the Democracy Deficit in the European Union.” Journal of Politics, 72(4): 1029-1045.

Rooduijn, Matthijs (2014). "The Nucleus of Populism: In Search of the Lowest Common Denominator." Government and Opposition, 49(4): 573-599.

Roose, Jochen, Kostas Kanellopoulos and Moritz Sommer (2017). "National Anti-Austerity Protests in a European Crisis. Comparing the Europeanizing Impact of Protest in Greece and Germany during the Eurozone Crisis." Journal of Civil Society, 13(3): 284-306.

Rucht, Dieter (1994). "Öffentlichkeit als Mobilisierungsfaktor für soziale Bewegungen." In: Friedhelm Neidhardt (ed.), Öffentlichkeit, öffentliche Meinung, soziale Bewegungen (pp. 337-358). Opladen: Westdeutscher Verlag.

Rumford, Chris (2006). "Introduction: Theorizing Borders." European Journal of Social Theory, 9(2): 155-169.

Runciman, Walter Garrison (1966). Relative Deprivation and Social Justice. London: Routledge.

Ruxton, Megan M. and Kyle L. Saunders (2016). "Declining Trust and Efficacy and its Role in Political Participation." In: Bridgett A. Kind and Kathleen Hale (eds.), Why 


\section{References}

Don't Americans Vote? Causes and Consequences (pp. 1-10). Santa Barbara, CA: ACC-CLIO.

Ruzza, Carlo and Emanuela Bozzini (2008). "Organised Civil Society and European Governance: Routes of Contestation.” European Political Science, 7(3): 296-303.

Saltkjel, Therese (2018). "Welfare Resources and Social Risks in Times of Social and Economic Change: A Multilevel Study of Material Deprivation in European Countries." European Journal of Social Work, 21(5): 639-652.

Sánchez-Cuenca, Ignacio (2000). "The Political Basis of Support for European Integration." European Union Politics, 1(2): 147-171.

Sanchez Salgado, Rosa (2017). "Europeanization of Civil Society Organizations in Times of Crisis? Exploring the Evolution Grant-Seeking Strategies in the EU Multi-Level System." European Politics and Society, 18(4): 511-528.

Scharpf, Fritz W. (1997). "Introduction: The Problem-Solving Capacity of Multi-Level Governance." Journal of European Public Policy, 4(4): 520-538.

Schmalz, Stefan and Nico Weinmann (2016). "Between Power and Powerlessness: Labor Unrest in Western Europe in Times of Crisis." Perspectives on Global Development and Technology, 15(5): 543-566.

Schmitt, Hermann (2003). "The Eurobarometers: Their Evolution, Obvious Merits, and Ways to Add Value to them." European Union Politics, 4(2): 243-251.

Schmitter, Philippe C. (1969). "Three Neo-Functional Hypotheses about International Integration.” International Organization, 23(1): 161-166.

Schmitter, Philippe C. (2009). "On the Way to a Post-Functionalist Theory of European Integration.” British Journal of Political Science, 39(1): 211-215.

Schoene, Matthew (2019). "European Disintegration? Euroscepticism and Europe's Rural/ Urban Divide." European Politics and Society, 20(3): 348-364.

Schraff, Dominik (2019). "Regional Redistribution and Eurosceptic Voting." Journal of European Public Policy, 26(1): 83-105.

Schulz-Forberg, Hagen and Bo Stråth (2010). "Soft and Strong European Public Spheres." In: Robert Frank, Hartmut Kaelble, Marie-Françoise Lévy and Luisa Passerini (eds.), Building a European Public Sphere. From the 1950s to the Present (pp. 55-76). Brüssel: Multiple Europes.

Schur, Lisa (2003). "Employment and the Creation of an Active Citizenry." British Journal of Industrial Relations, 41: 751-771.

Segesten, Anamaria Dutceac and Michael Bossetta (2019). "Can Euroscepticism Contribute to a European Public Sphere? The Europeanization of Media Discourses on Euroscepticism across Six Countries.” Journal of Common Market Studies, 57(5): 1051-1070.

Siedentopf, Heinrich and Benedikt Speer (2003). "The European Administrative Space from a German Administrative Science Perspective." International Review of Administrative Sciences, 69(1): 9-28.

Simpson, Kathryn (2019). "What to do About Inequality? Public Opinion Support for the European Union and further European Integration in the Republic of Ireland." Irish Political Studies, 34(1): 69-91.

Singer, Otto (1990). "Policy Communities and Discourse Coalitions: The Role of Policy Analysis in Economic Policy Making." Knowledge, 11(4): 428-458.

Sissenich, Beate (2007). Building States Without Society. European Union Enlargement and the Transfer of EU Social Policy to Poland and Hungary. Lanham, MD: Lexington Books.

Skogerbo, Eli, Axel Bruns, Andrew Quodling and Thomas Ingebretsen (2016). “AgendaSetting Revisited: Social Media in Mainstream Journalism.” In: Axel Bruns, Gunn Enli, 
Anders Olof Larsson, Eli Skogerbo and Christian Christensen (eds.), The Routledge Companion to Social Media and Politics (pp. 104-120). London: Routledge.

Smith, Christian (2011). "Civic and Political Disengagement." In: Christian Smith, Kari Christoffersen, Hilary Davidson, and Patricia Snell Herzog (eds.), Lost in Transition: The Dark Side of Emerging Adulthood (pp. 195-225). New York, NY: Oxford University Press.

Sommer, Moritz, Jochen Roose, Franziska Scholl and Dimitris Papanikopoulos (2016). "The Eurozone Crisis and Party Conflicts in Greece and Germany. Discursive Struggles about Responsibility." In: Tim Krieger, Bernhard Neumärker and Diana Panke (eds.), Europe's Crisis: The Conflict Theoretic Perspective (pp. 87-110). Baden-Baden: Nomos.

Sotiropoulos, Dimitri A. and Dimitris Bourikos (2014). "Economic Crisis, Social Solidarity and the Voluntary Sector in Greece." Journal of Power, Politics \& Governance, 2(2): 33-53.

Stanley, B. (2011). "Populism, Nationalism, or National Populism? An Analysis of Slovak Voting Behaviour at the 2010 Parliamentary Election." Communist and PostCommunist Studies, 44(4): 257-270.

Statham, Paul (2007). "Forging Divergent and 'Path Dependent' Ways to Europe? Political Communication over European Integration in the British and French Public Spheres." In: Claes de Vreese and Hermann Schmitt (eds.), A European Public Sphere. How Much of It Do We Have and How Much Do We Need? (pp. 79-142). Mannheim: CONNEXs.

Statham, Paul and Hans-Jörg Trenz (2013). The Politicization of Europe. Contesting the Constitution in the Mass Media. New York, NY: Routledge.

Stråth, Bo and Ruth Wodak (2009). "Europe - Discourse - Politics - Media - History: Constructing 'Crises'?" In: Anna Triandafyllidou, Ruth Wodak and Michał Kryżanowski (eds.), The European Public Sphere and the Media. Europe in Crisis (pp. 15-33). Houndmills, Basingstoke: Palgrave/Macmillan.

Streeck, Wolfgang (2012). "Markets and Peoples: Democratic Capitalism and European Integration.” New Left Review, 73(January/February 2012): 63-71.

Streeck, Wolfgang (2017). Buying Time: The Delayed Crisis of Democratic Capitalism, 2nd edition. London: Verso.

Stockemer, Daniel and Mauro Barisione (2016). "The 'New' Discourse of the Front National under Marine Le Pen: A Slight Change with a Big Impact.” European Journal of Communication, 32(2): 100-115.

Taggart, Paul (1995). "New Populist Parties in Western Europe." West European Politics, 18(1): 34-51.

Taggart, Paul (2004). "Populism and Representative Politics in Contemporary Europe." Journal of Political Ideologies, 9(3): 269-288.

Therborn, Göran (1995). European Modernity and Beyond: The Trajectory of European Societies, 1945-2000. London: Sage.

Torcal, Mariano, Richard Gunther and José Ramón Montero (2002). “Anti-Party Sentiments in Southern Europe.” In: Richard Gunther, José Ramón Montero and Juan J. Linz (eds.), Political Parties. Old Concepts and New Challenges (pp. 257-290). Oxford: Oxford University Press.

TransSOL (2016). Population Survey Questionnaire (WP3). Horizon2020-Project Reports and Documents [accessible through: https://ranssol.eu/files/, downloaded 14.05.2020]

TransSOL (2018). Integrated Report on Transnational Solidarity in the Public Domain (WP5). Paris: Science Po. Available from: https://transsol.eu/files/2018/05/deliverable -5-1.pdf, accessed 14 May 2020. 


\section{References}

Treib, Oliver (2014). "The Voter Says No, But Nobody Listens: Causes and Consequences of the Eurosceptic Vote in the 2014 European Elections." Journal of European Public Policy, 21(10): 1541-1554.

Treib, Oliver (2020). "Euroscepticism is Here to Stay: What Cleavage Theory Can Teach Us About the 2019 European Parliament Elections." Journal of European Public Policy. Online First. doi:10.1080/13501763.2020.1737881.

Trenz, Hans-Jörg (2004). "Media Coverage on European Governance: Exploring the European Public Sphere in National Quality Newspapers." European Journal of Communication, 19(3): 291-319.

Trenz, Hans-Jörg (2008). "Elements of a Sociology of European Integration.” In: ARENA Working Papers 11. Oslo: ARENA.

Trenz, Hans-Jörg (2016). Narrating European Society: Toward a Sociology of European Integration. London: Lexington Books.

Trenz, Hans-Jörg and Klaus Eder (2004). "The Democratizing Dynamics of a European Public Sphere: Towards a Theory of Democratic Functionalism." European Journal of Social Theory, 7(1): 5-25.

Tucker, Joshua A., Alexander C. Pacek and Adam J. Berinsky (2002). "Transitional Winners and Losers: Attitudes toward EU Membership in Post-Communist Countries." American Journal of Political Science, 46(3): 557-571.

van der Eijk, Cees, Mark Franklin and Michael Marsh (1996). "What Voters Teach Us About Europe-Wide Elections: What Europe-Wide Elections Teach Us About Voters." Electoral Studies, 15(2): 149-166.

van Elsas, Erika J., Armen Hakhverdian and Wouter van der Brug (2016). "United Against

a Common Foe? The Nature and Origins of Euroscepticism among Left-Wing and Right-Wing Citizens.” West European Politics, 39(6): 1181-1204.

van Erkel, Patrick F. A. and Tom W. G. van der Meer (2016). "Macroeconomic Performance, Political Trust and the Great Recession: A Multilevel Analysis of the Effects of Within-Country Fluctuations in Macroeconomic Performance on Political Trust in 15 EU Countries, 1999-2011." European Journal of Political Research, 55(1): 177-197.

van Gerven, Minna and Marinus Ossewaarde (2012). "The Welfare State's Making of Cosmopolitan Europe: Individualization of Social Rights as European integration." European Societies, 14(1): 35-55.

van Oorschot, Wim, Will Arts and John Gelissen (2006). "Social Capital in Europe. Measurement and Social and Regional Distribution of a Multifaceted Phenomenon." Acta Sociologica, 49(2): 149-167.

van Praag, Bernard M. S. (2011). "Well-Being Inequality and Reference Groups: An Agenda for New Research." The Journal of Economic Inequality, 9(1): 111-127.

Verba, Sidney, Nie H. Norman and Jae-On Kim (1978). Participation and Political Equality: A Seven Nation Comparison. London: Cambridge University Press.

Verbunt, Pim and Anne-Catherine Guio (2019). "Explaining Differences Within and Between Countries in the Risk of Income Poverty and Severe Material Deprivation: Comparing Single and Multilevel Analyses." Social Indicators Research, 144: 827-868. Vobruba, Georg (2012). "The Social Construction of the European Society." In: Harry F. Dahms and Lawrence Hazelrigg (eds.), Theorizing Modern Society as a Dynamic Process (pp. 263-279). Bingley: Emerald Group Publishing.

Vobruba, Georg (2014). "The Europeanization of Distributional Conflicts within the Eurocrisis." In: Nicholas P. Petropoulos and George O. Tsobanoglou (eds.), The Debt Crisis in the Eurozone: Social Impacts (pp. 23-31). Cambridge: Cambridge Scholars. 
Vorländer, Hans, Maik Herold and Steven Schäller (2018). PEGIDA and New Right-Wing Populism in Germany. Basingstoke: Palgrave Macmillan.

Walker, Iain and Heather J. Smith (2010). Relative Deprivation: Specification, Development, and Integration. Cambridge: Cambridge University Press.

Warr, Deborah J. (2006). "Gender, Class, and the Art and Chraft of Social Capital." Sociological Quarterly, 47(3): 497-520.

Weßels, Bernhard (2007). "Discontent and European Identity: Three Types of Euroscepticism." Acta Politica, 42(2): 287-306.

World Bank (2020). Government Effectiveness Estimate. Available from: https://datacat alog.worldbank.org/government-effectiveness-estimate-0, accessed 04 May 2020.

YouGov (2016). YouGov Results - European Mega-Survey Topline Findings. London. Available from: https://d25d2506sfb94s.cloudfront.net/cumulus_uploads/docume nt/smow6e2p43/MegaEurotrackerResults_AugustSeptember2016_Toplines.pdf, accessed 20 May 2020.

Zamponi, Lorenzo and Lorenzo Bosi (2016). "Which Crisis? European Crisis and National Contexts in Public Discourse." Politics \& Policy, 44(3): 400-426.

Zeitlin, Jonathan, Francesco Nicoli and Brigid Laffan (2019). "Introduction: The European Union beyond the Polycrisis? Integration and Politicization in an Age of Shifting Cleavages." Journal of European Public Policy, 26(7): 963-976.

Zoll, Rainer and Enno Neumann (1986). "Workers' Reactions to Crisis.” In: Otto Jacobi, Bob Jessop, Hans Kastendiek and Marino Regini (eds.), Technological Change, Rationalisation and Industrial Relations (pp. 261-275). London: Routledge.

Zschache, Ulrike (2016). The Differential Europeanisation of Public Discourse. Media Debates about the Common Agricultural Policy in Germany and Spain. Baden-Baden: Nomos.

Zürn, Michael and Christian Joerges (eds.) (2005). Law and Governance in Postnational Europe. Compliance Beyond the Nation-State. Cambridge: Cambridge University Press. 


\section{Index}

Note: Bold page numbers refer to tables and Italic page numbers refer to figures; Page numbers followed by ' $n$ ' refer to notes.

ailing banks 45,58

alienation $9,17,114,115,122,127$

attitudes 1-3, 7-9, 11, 16-18, 21-23, 27, 28, 92-93, 96, 115-122, 138, 141, 187-191

austerity policies $43,44,57,95,126$, 127,187

benchmarks $3-5,28,73,148,155,173$, 182, 189

Better Life Index 78

better-off countries or Europeans 91, 102, $148,169,188,192$

budgetary situation 75,109

childcare 106

claims-making and claims-making data 33,46

cognitive Europeanisation 189

cognitive map 3, 20, 28, 63, 89-91, 93, 148, 151, 152, 157, 179; of European social space $89-91$

collective identities 19, 23, 143, 170, 172-173, 191

common currency 44,61

conflicts $4,11,12,20,23,25,128,130$, $182,187,188,190,192$

contentiousness $4,7,173$

control variables 132

Council of Europe 30, 63, 186, 191

crisis, public debates $33-45,52,57-62$

crisis affinity 126

crisis countries 94, 95, 97, 99, 103-105,

$111,112,123,127,128,134$

crisis debates 37,61

crisis perception $60,95-97,99,100,101$, $103,122,134,137$ crisis-sensitising effect 103

crisis sensitivity $9,93,96,97, \mathbf{9 8}-\mathbf{9 9}, 99$, $102,134,186$

Croatia 93, 94

democracy $105,114-130$

Denmark 9, 10, 142, 152, 154, 155, 187

disadvantaged people 164, 179

disadvantaged population groups 4, 178

discourse arenas 45-57

discourse communities 48

discursive Europeanisation 32

disenchantment $114,115,122,123$, 128,132

dissatisfaction 105-109, 111-114

divergent living conditions 65-72

divisive elements $126,162,163$

economic crisis $8,9,33-45,58,59,66,90$, 93-103, 120, 127, 148, 182

economic developments $34,43,44,58$, 66,174

education $8,10,15,75,77,78,96,97$, 103, 106, 107, 131, 132, 146, 167

educational attainment 70, 75, 99, 109, 120,132

elections $114,126,127,131,173$

employment $35,45,60,61,72,78,94$, $107,150,163,169$

EU-related attitudes 10, 11, 141, 143, $145-148,157,158,160,166,167,170$, $172,187-188$

euro 1, 5, 24, 43-45, 55, 139

Eurobarometer data/survey 10-11, 140, $142,158,159,163,170,173,187$

euro countries 44, 45

European Central Bank (ECB) 43, 52, 61 
European comparative horizon 93-103

European compass 63-91

European continent 18, 36, 90, 140

European crises 45, 92, 108, 126, 183

European field of politics 26, 187

European identity 23, 162, 164, 170, 172

European integration project 14, 16, 19, $24,26,31,32,139,182,186,191$

Europeanisation 19, 22, 32, 139, 182

European living conditions 3, 9, 19, 28, 72-77, 90, 135, 137, 148, 151, 152, 157

European political field 11, 26

European politics 2, 6, 7, 14, 19, 20, 23, $25,92,93,160,189,191$

European population 2, 7, 11, 114, 115, $138,140,178,181,185-187,191$

European reference horizon 62, 138

European rescue packages 43,55

European social space 7, 8, 21-24, 28, 29, 89, 100, 136-138, 178, 186, 187, 190; see also social spaces

European Union 1, 3-5, 7, 11, 18, 19, 46, $63,90,92,139,140,157,178-181$, 184, 191-193; perceptions of inequality 140-141; political dissent 186-189; political field 189-191; political (dis) integration of 181-193; political sociology of 13-29; public support for 140-143; (partial) relevance of 4-7; shared space, political experiences 7-12; social divisions in 186-189

euro rescue package 43

Eurosceptic attitudes 1, 3, 140-143, 167, 170, 172-174, 176

Euroscepticism 4, 18, 139, 141-148, 151-164, 172, 174-178, 188, 189; as social fault line $158-168$

Eurosceptics 10, 14, 140, 142, 143, $145-147,160,162,164,177,178,188$ eurozone 43, 44, 57, 59

extra-parliamentary protest movements 127

field theory $8,20-29,62,140$

financial crisis 1, 33-46, 52, 54, 57-59, 61, $62,92,94,107,128,179,183,187$

financial policy $40,42-45$

France 32, 35, 43, 44, 47, 48, 78, 79, 81, $85,107,118$

fundamental directional decision 191-193

GDP growth 34,179

Germany $32-35,59,73,78,88,95,102$, $107,152,171$

global actors $32,48,50,52-54,59$ global economic crisis $36,45,93$

global financial crisis 50, 59

government bonds 43,44

government policies 109,150

Greece 32, 35, 42-44, 54-57, 62, 70-73, $79,80,84,88,95,103,107,123,126$, $130,148,171$

healthcare 106, 107, 150

horizontal Europeanisation 182-184

identities 4, 13, 19, 22, 23, 169

immigration 106, 127, 150

insecure employment 94, 107

integrated social space $184-186$

integration process $1,2,4,11-21,25$, 30-32, 63, 64, 181-183, 185-193

interlocked segmentation 57-62

International Monetary Fund (IMF) 43, 48, $52,55,56,61$

Italy $32,35,44,48,57,61,66,73,78,95$, $107,118,124,126,130$

Livewhat survey $9,10,64,66,73,148$

low educational attainment 97, 109, 120

low-skilled workers 164, 177, 178

macro-economic indicators 67

mass media 8, 26-28, 31-33, 57-60, 62,

$75,146,169,172,177,182-184$

material deprivation $65,66,184$

mental map 85, 100, 103, 135, 137, 138,

184-186

monetary policy 39,41

multilevel causation 169-178

multi-level reciprocity $45-57$

multiple identities 19, 23

national debates $31,32,39,53,58$, 60,183

national discourses $26,36,37,58,62,183$

national economy $5,18,65,66,68,69$, 103,179

national identities 5, 18, 19, 23, 146, 170

national media $31,32,183$

national politics 4-7, 17, 18, 28, 92-138, $148,151,173,181,184-186$, 189 ; assessment of 105 ; political dissatisfaction 105-114; political establishment 114-126; quiet benchmarking 105; satisfaction, respondents' government 105-114 non-governmental organisations 33,48 , 60,183 
occupational groups and status

$70,146,177$

organised civil society $6,48,58$

personal situation $81,83,85,88,90,94$,

$100,102,111,112,118,124$

Poland 33, 42, 48, 73, 75, 78, 81, 88, 107 , 118,147

political acceptance crisis 115,120

political alienation 132

political class $116,117,143$

political conflicts $7,10,11,20,184$

political cleavages $2,8,92,140,157$, 166,187

political disappointment 114-126

political dissatisfaction 9, 104-114,

124, 186

political dissent 158-168

political efficacy 160,172

political elites 27, 28, 60, 124, 131,

183,185

political Europe 20-29

political orientations $10,18,97,122,131$, $132,145-147,160$

political participation $115,126-131$

political perceptions $28,72,92,93$,

137,160

political protest $126-136$

political sociology 13-29

political thinking $12,14,17,77,136-138$,

$182,185,187,189$

politicisation 1, 4, 131, 187

populism index 119

populist attitudes/beliefs $115,116,118$,

$120,122-124,123,126,132,137,143$,

185,186

poverty $66,106,107,140,150$

prosperous regions 177,178

protest behaviour 128, 135, 136, 138

public claims 34

public debt $42-44,55,56,58,182$

public discourses $6,26,27,32-37,45-48$, $57-60$

public dissent 184-186

publicised public opinion 27,28

public opinions $4,5,8,9,17,18,26-28,31$,

$32,58,62,92,142,158,169,173,177$;

horizontal Europeanisation of 182-184

public spheres $27,30-62$

reference groups $64,65,72,73,80,85-87$, $90,91,97,100,185$ regional differences 170-178

right-wing groups and parties 4, 115, 126, $127,139,174$

Schengen Agreement 1

self-perception of personal living

conditions 79-81, 84

social affairs $35,36,45$

social class $2,10,64,70,96,147,167$, $172,181,187$

social disadvantage $64,75,120,164,167$, $185,186,188,192$

social divisions $65-72,92-180,192$; and political dissent $158-168$

social inequalities $1-3,7-9,20,30,63-65$, $140,141,167,178,181,182$

social policies 30, 35, 40, 46, 61, 184, 193

social spaces 2, 3, 8, 20-24, 30, 81, 84, 89-91, 136-138, 186-188

social stratifications $2,3,7,140,156$, 181,188

social vulnerability $143,145,147,157$, 163, 174, 177, 192

socio-demographic factors $73,97,106$, 120,145

Spain $33,35,44,48,58,61,66,78,79,93$, $95,107,118,127,130$

spatial disparities 2, 140, 151-157, 169-178, 181

spatial inequalities 7, 30, 157

state actors $46-48$

subjective perceptions $2,9,22,66,89,90$, $120,143,147,186$

Sweden 33, 35, 42, 44, 48, 57, 59, 66, 70, $78,80,81,84,88,97,107,112$, 117,136

Switzerland 33, 35, 37, 44, 48, 59, 66, 77, $80,84,88,102,107,123,138,152$

top-ranked countries 80,123

trade unions 46, 48, 57, 131, 183

TransSOL survey $10,11,141,148$, $158-160$

United Kingdom (UK) 33, 35, 37, 44, 48, $52,57,59,78,81,85,95,107,116,147$, 155,158

unemployment $36,43,45,46,55,60,94$, $106,107,162,178,179,182$

welfare state $16,65,66$

World Bank 48, 55, 174 